\title{
EFICIÊNCIA EM TECNOLOGIAS DE ILUMINAÇÃO ARTIFICIAL: O LED E A TECNOLOGIA FLUORESCENTE
}

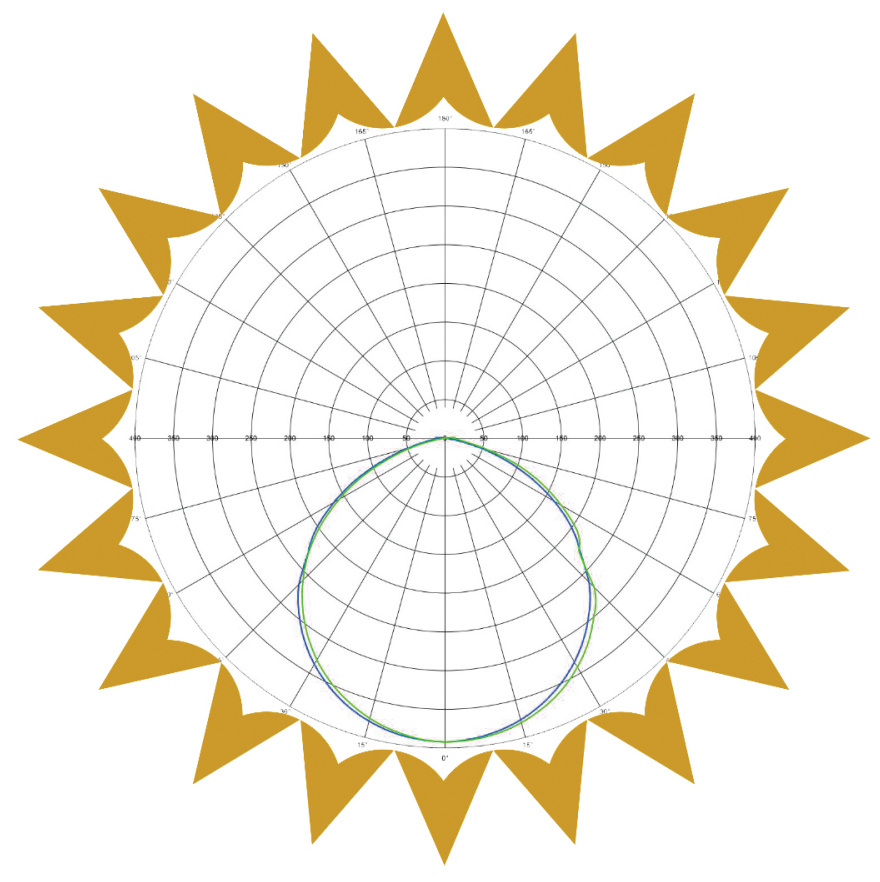

CRISTIANE MITIKO SATO FURUYAMA 


\title{
EFICIÊNCIA EM TECNOLOGIAS DE ILUMINAÇÃO ARTIFICIAL: O LED E A TECNOLOGIA FLUORESCENTE
}

\author{
Tese apresentada à Faculdade de \\ Arquitetura e Urbanismo da Universidade de \\ São Paulo para a obtenção do título de \\ DOUTORA em arquitetura e urbanismo
}

Área de concentração: Tecnologia da Arquitetura

Orientador: Prof. Dr. Marcelo de Andrade Roméro

São Paulo

2019 


\section{AUTORIZO A REPRODUÇÃO E DIVULGAÇÃO TOTAL OU PARCIAL DESTE TRABALHO, POR QUALQUER MEIO CONVENCIONAL OU ELETRÔNICO, PARA FINS DE ESTUDO E PESQUISA, DESDE QUE CITADA A FONTE.}

E-MAIL: crismitiko@yahoo.com.br

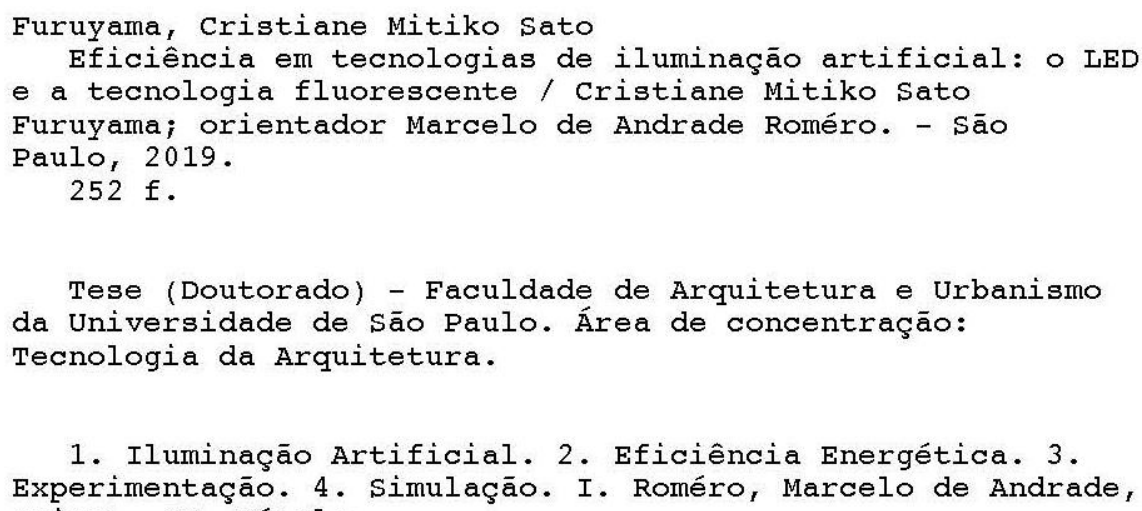

1. Iluminaçāo Artificial. 2. Eficiência Energética. 3 . Experimentaçāo. 4. Simulaçāo. I. Roméro, Marcelo de Andrade, orient. II. Título.

Elaborada eletronic amente đravés do formulário disponivel em: $<$ http://www.fau.usp.br/fichacatalografical $>$ 


\section{DEDICATÓRIA}

Aos meus pais,

Ao Gustavo e ao Guilherme, que são a razão da minha vida. 


\section{AGRADECIMENTOS}

Primeiramente e principalmente, ao meu querido orientador Prof. Dr. Marcelo de Andrade Roméro por suas preciosas orientações, ideias, incentivos e amizade desde o trabalho final de graduação.

Aos professores e amigos que conheci ao longo da tese, pelo apoio e amizade, Alessandra Prata Shimomura, Angelo Filardi, Antonio Gil, Isac Roizenblatt, Joana Carla Gonçalves, Leonardo Monteiro, Paulo Scarazzato, Ranny Nascimento Michalski e Roberta Kronka Mülfarth.

Aos amigos "sustentáveis" Corina Bianco, Silvia Bigoni, Altimar Cypriano, Luis Felipe Xavier, e aos novos amigos que fiz nessa etapa e me apoiaram de alguma forma Bruna Luz, Ruy Soares e Eduardo Gasparelo.

Aos funcionários Viviane Delmondes, Eliane Martinez, Fátima de Morais, Andréia Zaik, Silvana Marques, José Santos, Paula Noia, Eunice Bruno, Ranieri Higa e a equipe da portaria Vancarlos e Ivan.

Aos fabricantes de luminárias Lumicenter, em especial ao Kleiton Zembovici, Rafael Assmé e Tamyres Hein; e ao funcionário Philips Luciano Rosito, que gentilmente puderam concretizar a doação do material necessário para a pesquisa.

Aos funcionários do IEE Liliana Pozzo, Marcelo Jesus, Rinaldo Caldeira, Elvo Burini e ao chefe Roberto Zilles, que abriu a porta para que os ensaios pudessem ser realizados.

Ao engenheiro José Luiz Pimenta que cedeu uma licença temporária do programa AGi32 para que eu pudesse finalizar as simulações com o programa.

À minha cunhada Eliane Furuyama que pôde fazer a correção ortográfica e gramatical desta pesquisa.

Aos amigos Ricardo e Olivia Lui, que por diversas vezes receberam os meus meninos para que eu pudesse dar andamento e concluir esta tese.

E finalmente à minha família, aos meus pais que sempre me incentivaram a estudar, à minha irmã que escutou minhas lamentações e minhas descobertas durante a pesquisa, mesmo sem entender nada do eu falava, e principalmente ao meu marido e ao meu filho que estiveram ao meu lado sempre, mesmo quando eu estava ausente, e que são o motivo de eu querer aprender e viver a cada dia. 


\section{RESUMO}

FURUYAMA, C.M.S. Eficiência em Tecnologias de lluminação Artificial: o LED e a Tecnologia Fluorescente. 252p. Tese (Doutorado). Faculdade de Arquitetura e Urbanismo, Universidade de São Paulo. São Paulo, 2019.

Esta pesquisa aborda a depreciação da tecnologia LED comparada à da tecnologia fluorescente nos sistemas de iluminação mais utilizados em ambientes corporativos internos.

O resultado da depreciação dos sistemas de iluminação foi obtido por meio da experimentação em uma célula teste, com dois modelos de luminárias (com aletas e com difusor) e três fontes de luz: a tradicional lâmpada fluorescente tubular T5 de 28W, o tubo LED T8 de 18W e LED aplicado sobre a luminária.

Os conjuntos foram instalados na célula teste e ficaram ligados por aproximadamente 17.000 horas. As medições foram realizadas a cada 3 meses ao longo de 24 meses (2 anos) com um luxímetro em pontos definidos, de acordo com a norma NBR/ISO 8995:2013.

Juntamente com as medições, os sistemas de iluminação foram ensaiados em laboratório acreditado pelo INMETRO em dois momentos. O primeiro ensaio ocorreu com os sistemas de iluminação em zero hora, e o segundo após a depreciação de todos os sistemas de iluminação utilizados na pesquisa.

Adicionalmente, foram realizadas simulações computacionais para posterior comparação dos resultados entre simulação e experimentação. Os programas de simulação utilizados foram o Dialux EVO, o Relux e o AGi32.

Para verificar as hipóteses da pesquisa, os resultados das medições foram comparados com os valores de fator de manutenção resultantes, conforme norma CIE-97:2005.

Palavras chave: Iluminação artificial, depreciação, LED, fluorescente, eficiência energética, fator de manutenção, medição, simulação. 


\section{ABSTRACT}

FURUYAMA, C.M.S. Efficiency in Artificial Lighting Technologies: LED and Fluorescent Tecnologies. 252p. Thesis (Doctorate). Faculty of Architecture and Urbanism, University of São Paulo. São Paulo, 2019.

This research compares the depreciation of LED technology with fluorescent technology, considering the most commonly used lighting systems in internal corporate environments.

The result of the depreciation of these lighting systems was obtained by experimenting inside a testing room, with two models of luminaires - with fins and with diffuser - and three light sources: the traditional T5 tubular fluorescent lamp of $28 W$, the T8 LED tube of $18 W$ and LED applied over the luminaire.

These sets were assembled in the test cell and kept on for approximately 17,000 hours. Measurements were performed every 3 months over 24 months(2 years) using a luximeter. The placement of the testing points were defined according to the NBR/ISO 8995:2013 norm.

At the same time, the lighting systems were tested in a laboratory accredited by INMETRO in two distinct moments. The first experiment was done with all lighting systems at zero hour and the second after the depreciation of all lighting systems used in the research.

In addition, computational simulations were performed for later comparison of the results between simulation and experimentation. The simulation programs used were Dialux EVO, Relux and AGi32.

To verify the hypothesis of this research, the results of the evaluations were compared to the values of the maintenance factor according to the CIE-97:2005 norm.

Keywords: Artificial lighting, depreciation, LED, fluorescent, energy efficiency, maintenance factor, simulation 


\section{SUMÁRIO}

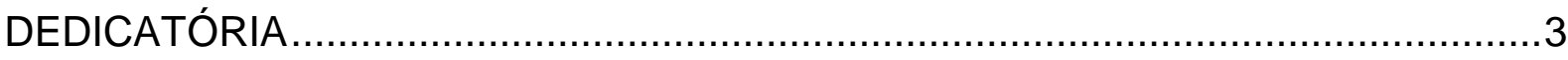

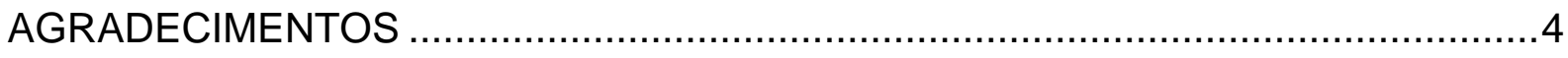

RESUMO

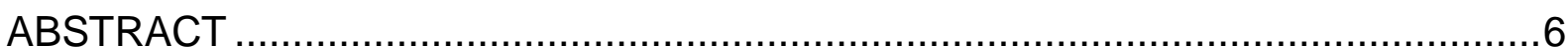

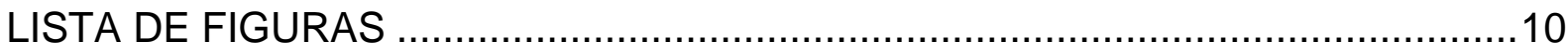

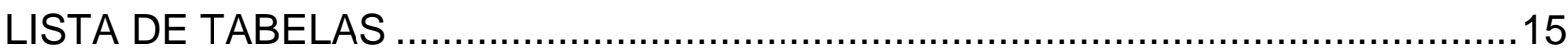

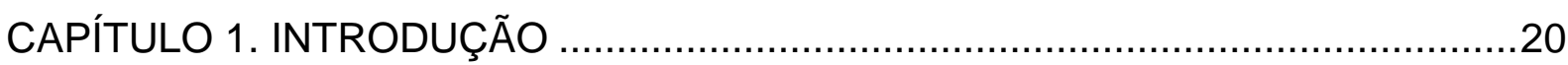

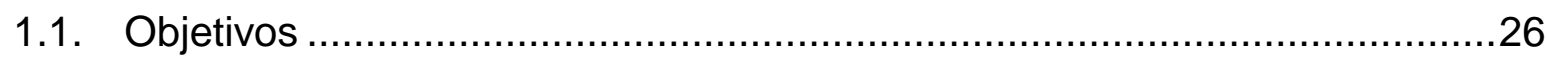

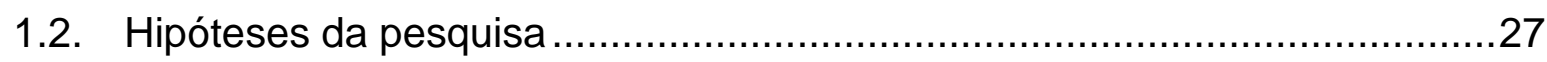

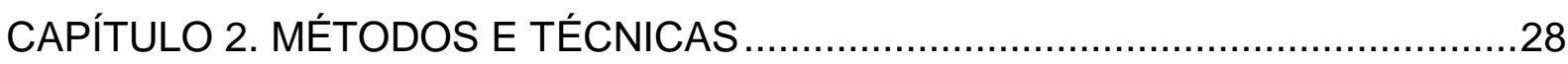

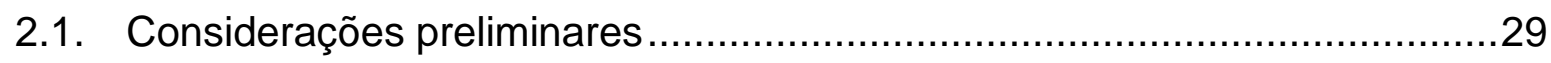

2.2. Levantamento de dados secundários.....................................................30

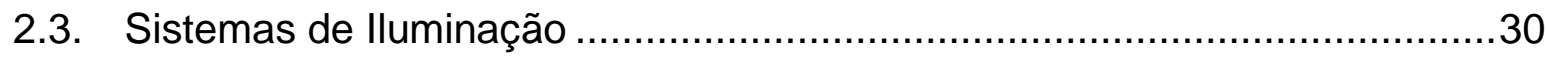

2.4. Busca de apoio para realização da pesquisa .............................................32

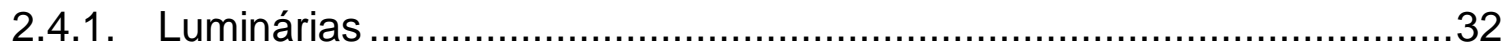

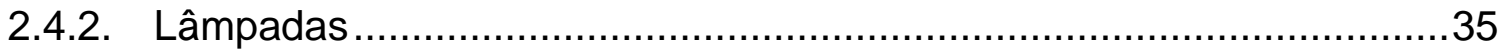

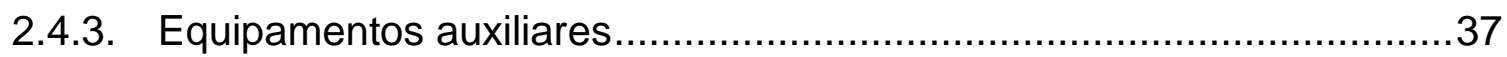

2.5. Determinação do fator de manutenção ……………................................38

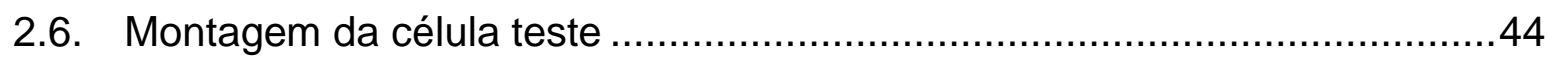

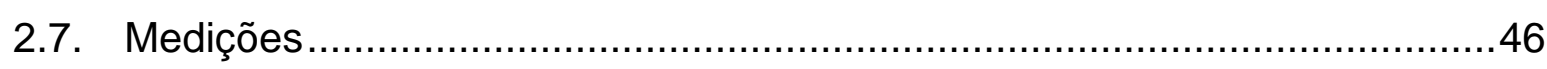

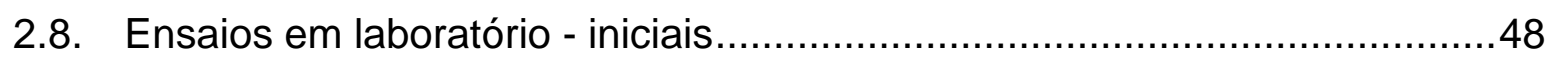

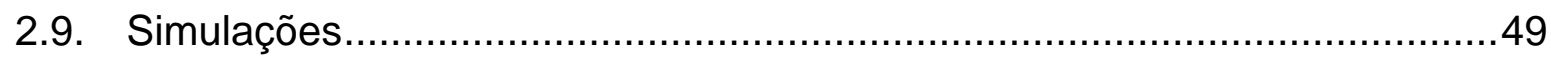

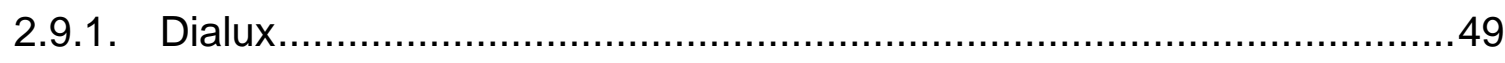

2.9.2. AGi32

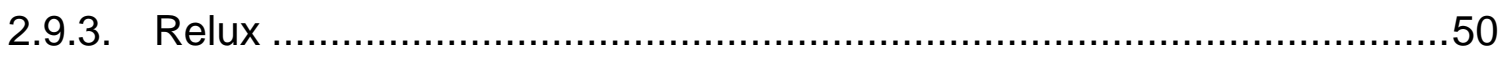


2.10. Comparações simulações $x$ experimentações

2.11. Ensaios em laboratório - depreciados....................................................52

2.12. Comparação Medições $x$ Norma...........................................................53

2.13. Verificação das hipóteses e conclusões .................................................53

CAPÍTULO 3. MEDIÇÕES NA CÉLULA TESTE .................................................54

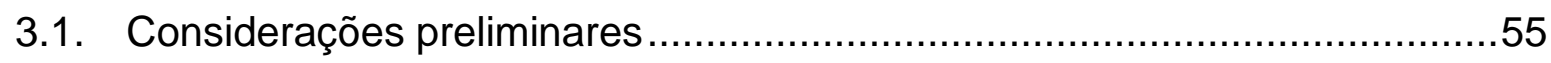

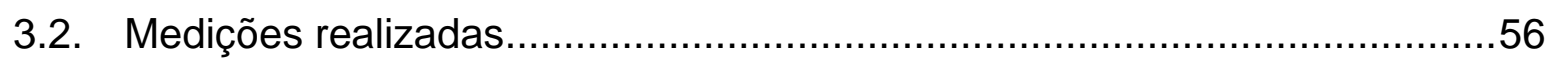

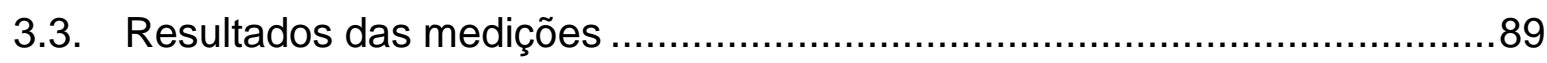

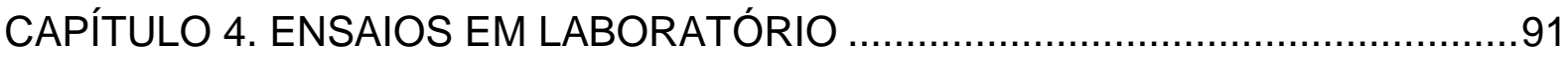

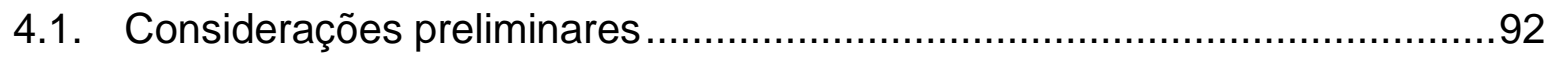

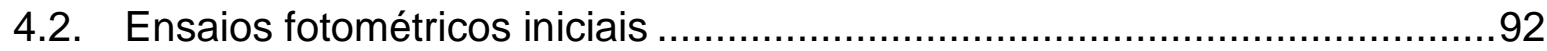

4.3. Ensaios fotométricos finais depreciados ….............................................

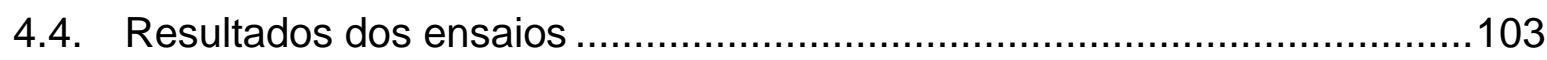

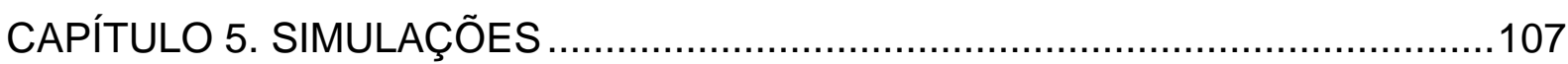

5.1. Considerações preliminares .............................................................108

5.2. Simulações com ambiente vazio ……………….................................108

5.3. Simulações com mobiliário.....................................................................112

5.4. Simulação com mobiliário e cromaticidade ………….............................115

5.5. Comparação dos resultados das simulações ...........................................120

CAPÍTULO 6. COMPARAÇÕES: SIMULAÇÃO x EXPERIMENTAÇÃO ................122

CAPÍTULO 7. COMPARAÇÕES: MEDIÇÕES x NORMA ..................................126

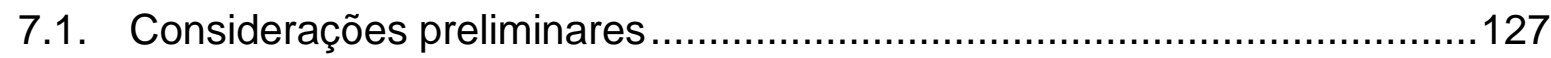

7.2. Resultados da comparação..............................................................129

CAPÍTULO 8. VERIFICAÇÃO DAS HIPÓTESES …..............................................133

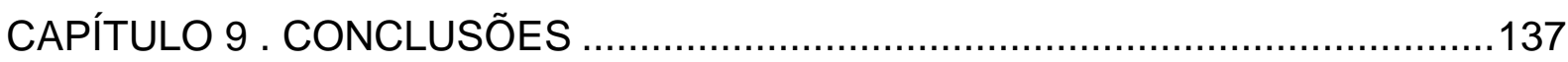

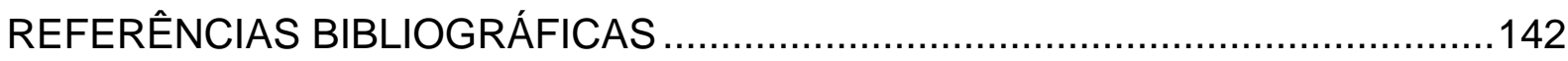

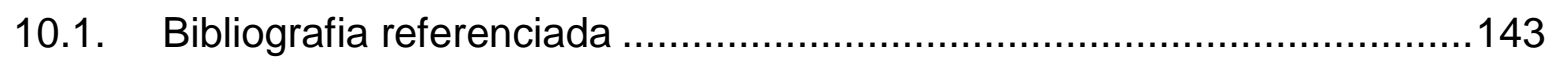




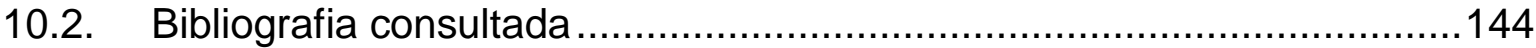

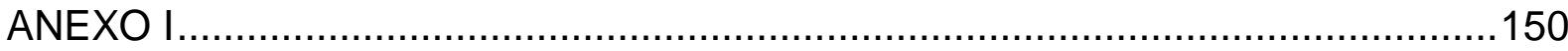

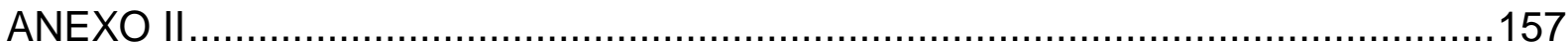

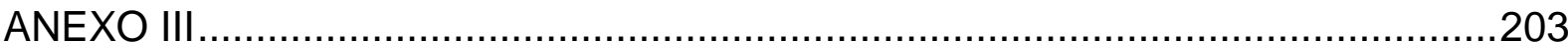

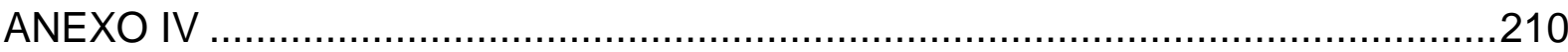




\section{LISTA DE FIGURAS}

Figura 1: Gráfico da evolução do acesso à energia elétrica da população em alguns países. 21

Figura 2: Consumo anual de energia elétrica por classe (nacional) - ano de $2017 . .24$

Figura 3: Fluxograma da pesquisa 29

Figura 4: Resultado do cálculo - curvas isolux do programa Dialux 4.12 31

Figura 5: Foto e curva fotométrica da luminária FAA04-S. .33

Figura 6: Foto e curva fotométrica da luminária CAA02-S .33

Figura 7: Foto e curva fotométrica da luminária EAA02-S .34

Figura 8: Foto e curva fotométrica da luminária FHT07-S 34

Figura 9: Foto e curva fotométrica da luminária CHT10-S ACL .35

Figura 10: Foto e curva fotométrica da luminária LCN13-S .35

Figura 11: Layout da sala teste .44

Figura 12: Vista da sala da porta para janela .45

Figura 13: Vista da sala da janela para porta .45

Figura 14: Sala teste com posição de medição dos sistemas de iluminação..... .45

Figura 15: Planta da sala teste com malha de pontos de medição. .47

Figura 16: Base utilizada na célula teste para medições. .47

Figura 17: Luxímetro da FAU-USP utilizado na medição. .48

Figura 18: Medição do sistema de iluminação tipo 1 - lâmpada fluorescente tubular T5 28W - 0h. .56

Figura 19: Medição do sistema de iluminação tipo 4 - lâmpada fluorescente tubular T5 28W - 0h. .57

Figura 20: Medição do sistema de iluminação tipo 2 - lâmpada fluorescente tubular T8 32W - 0h. .57

Figura 21: Medição do sistema de iluminação tipo 2 - lâmpada tubo LED 18W - 0h .58

Figura 22: Medição do sistema de iluminação tipo 5 - lâmpada fluorescente tubular T8 32W - 0h. .58

Figura 23: Medição do sistema de iluminação tipo 5 - lâmpada tubo LED 18W - 0h .59

Figura 24: Medição do sistema de iluminação tipo 3 - LED aplicado - Oh 60

Figura 25: Medição do sistema de iluminação tipo 6 - LED aplicado - Oh 60 
Figura 26: Medição do sistema de iluminação tipo 1 - 1 mês 61

Figura 27: Medição do sistema de iluminação tipo $4-1$ mês 61

Figura 28: Medição do sistema de iluminação tipo 2 - 1 mês 62

Figura 29: Medição do sistema de iluminação tipo $5-1$ mês 62

Figura 30: Medição do sistema de iluminação tipo 3 - 1 mês .63

Figura 31: Medição do sistema de iluminação tipo 6 - 1 mês 64

Figura 32: Medição do sistema de iluminação tipo 1 - 3 meses .65

Figura 33: Medição do sistema de iluminação tipo 4 - 3 meses 65

Figura 34: Medição do sistema de iluminação tipo 2 - 3 meses .66

Figura 35: Medição do sistema de iluminação tipo 5 - 3 meses .66

Figura 36: Medição do sistema de iluminação tipo 3 - 3 meses .67

Figura 37: Medição do sistema de iluminação tipo 6 - 3 meses .67

Figura 38: Medição do sistema de iluminação tipo $1-6$ meses .68

Figura 39: Medição do sistema de iluminação tipo $4-6$ meses .68

Figura 40: Medição do sistema de iluminação tipo $2-6$ meses 69

Figura 41: Medição do sistema de iluminação tipo $5-6$ meses 69

Figura 42: Medição do sistema de iluminação tipo $3-6$ meses ..............................70

Figura 43: Medição do sistema de iluminação tipo 6 - 6 meses ..............................70

Figura 44: Medição do sistema de iluminação tipo 1 - 9 meses ..............................71

Figura 45: Medição do sistema de iluminação tipo 4 - 9 meses ...............................71

Figura 46: Medição do sistema de iluminação tipo 2 - 9 meses ..............................72

Figura 47: Medição do sistema de iluminação tipo 5 - 9 meses ..............................72

Figura 48: Medição do sistema de iluminação tipo 3 - 9 meses ...............................73

Figura 49: Medição do sistema de iluminação tipo 6 - 9 meses ...............................73

Figura 50: Medição do sistema de iluminação tipo 1 - 1 ano (12 meses) ..................75

Figura 51: Medição do sistema de iluminação tipo $4-1$ ano (12 meses) ..................75

Figura 52: Medição do sistema de iluminação tipo 2 - 1 ano (12 meses) ..................76

Figura 53: Medição do sistema de iluminação tipo 5 - 1 ano (12 meses) ..................76

Figura 54: Medição do sistema de iluminação tipo 3 - 1 ano (12 meses) .................77

Figura 55: Medição do sistema de iluminação tipo 6 - 1 ano (12 meses) ..................77

Figura 56: Medição do sistema de iluminação tipo 1 - 1 ano e 3 meses (15 meses)78

Figura 57: Medição do sistema de iluminação tipo $4-1$ ano e 3 meses (15 meses)78

Figura 58: Medição do sistema de iluminação tipo 2 - 1 ano e 3 meses (15 meses)79 Figura 59: Medição do sistema de iluminação tipo 5 - 1 ano e 3 meses (15 meses)79 
Figura 60: Medição do sistema de iluminação tipo 3 - 1 ano e 3 meses (15 meses)80 Figura 61: Medição do sistema de iluminação tipo 6 - 1 ano e 3 meses (15 meses)80 Figura 62: Medição do sistema de iluminação tipo 1 - 1 ano e 6 meses (18 meses)81 Figura 63: Medição do sistema de iluminação tipo 2 - 1 ano e 6 meses (18 meses)82 Figura 64: Medição do sistema de iluminação tipo 5 - 1 ano e 6 meses (18 meses)82 Figura 65: Medição do sistema de iluminação tipo $3-1$ ano e 6 meses (18 meses)83 Figura 66: Medição do sistema de iluminação tipo 6 - 1 ano e 6 meses (18 meses)83 Figura 67: Medição do sistema de iluminação tipo 2 - 1 ano e 9 meses (21 meses)84 Figura 68: Medição do sistema de iluminação tipo 5 - 1 ano e 9 meses (21 meses)84 Figura 69: Medição do sistema de iluminação tipo 3 - 1 ano e 9 meses (21 meses)85 Figura 70: Medição do sistema de iluminação tipo 6 - 1 ano e 9 meses (21 meses)85 Figura 71: Medição do sistema de iluminação tipo 2 - 2 anos (24 meses) ................86 Figura 72: Medição do sistema de iluminação tipo 5 - 2 anos (24 meses) ................87 Figura 73: Medição do sistema de iluminação tipo 3 - 2 anos (24 meses) ................87 Figura 74: Medição do sistema de iluminação tipo 6 - 2 anos (24 meses) ................88 Figura 75: Gráfico da variação do nível de iluminância das tecnologias utilizadas ...88 Figura 76: Foto e curva fotométrica ensaiada em laboratório - sistema de iluminação tipo 02

Figura 77: Foto e curva fotométrica ensaiada em laboratório - sistema de iluminação tipo 05 (07.dez.2017)

Figura 78: Foto e curva fotométrica ensaiada em laboratório - sistema de iluminação tipo 05 (11.fev.2019)

Figura 79: Foto e curva fotométrica ensaiada em laboratório - sistema de iluminação tipo 03

Figura 80: Foto e curva fotométrica ensaiada em laboratório - sistema de iluminação tipo 06 95

Figura 81: Foto e curva fotométrica ensaiada em laboratório - sistema de iluminação tipo 04 .96

Figura 82: Foto e curva fotométrica ensaiada em laboratório - sistema de iluminação tipo 01 .96

Figura 83: Curvas fotométricas - luminárias modelo tipo 1 98

Figura 84: Curvas fotométricas - luminárias modelo tipo 4 .99

Figura 85: Curvas fotométricas - luminárias modelo tipo 2 100

Figura 86: Curvas fotométricas - luminárias modelo tipo 5 101 
Figura 87: Curvas fotométricas - luminárias modelo tipo 3................................102

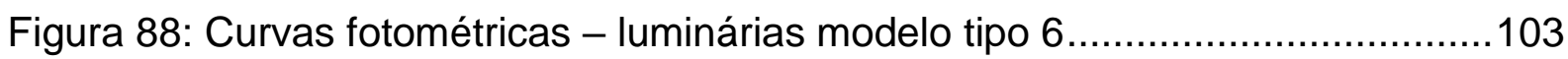

Figura 89: Resultado cálculo ponto a ponto - luminária tipo 1 - sala vazia ............109

Figura 90: Resultado cálculo ponto a ponto - luminária tipo 2 - sala vazia ............109

Figura 91: Resultado cálculo ponto a ponto - luminária tipo 3 - sala vazia ............110

Figura 92: Resultado cálculo ponto a ponto - luminária tipo 4 - sala vazia .............110

Figura 93: Resultado cálculo ponto a ponto - luminária tipo 5 - sala vazia ............111

Figura 94: Resultado cálculo ponto a ponto - luminária tipo 6 - sala vazia ............111

Figura 95: Resultado do cálculo ponto a ponto - luminária 1 - sala mobiliada .......112

Figura 96: Resultado do cálculo ponto a ponto - luminária tipo 2 - sala mobiliada 113

Figura 97: Resultado do cálculo ponto a ponto - luminária tipo 3 - sala mobiliada 113

Figura 98: Resultado do cálculo ponto a ponto - luminária tipo 4 - sala mobiliada 114

Figura 99: Resultado do cálculo ponto a ponto - luminária tipo 5 - sala mobiliada 114

Figura 100: Resultado do cálculo ponto a ponto - luminária tipo 6 - sala mobiliada

Figura 101: Imagem da célula teste no programa Adobe Kuler 116

Figura 102: Resultado do cálculo ponto a ponto luminária tipo 1 - sala mobiliada com cromaticidade.

Figura 103: Resultado do cálculo ponto a ponto luminária tipo 2 - sala mobiliada com cromaticidade

Figura 104: Resultado do cálculo ponto a ponto luminária tipo 3 - sala mobiliada com cromaticidade

Figura 105: Resultado do cálculo ponto a ponto luminária tipo 4 - sala mobiliada com cromaticidade

Figura 106: Resultado do cálculo ponto a ponto luminária tipo 5 - sala mobiliada com cromaticidade

Figura 107: Resultado do cálculo ponto a ponto luminária tipo 6 - sala mobiliada com cromaticidade 119

Figura 108: Gráfico comparativo Experimentação x Simulação - Sistemas de iluminação com aletas

Figura 109: Gráfico comparativo Experimentação x Simulação - Sistema de iluminação com difusor.

Figura 110: Gráfico comparativo dos sistemas de iluminação utilizando tecnologia fluorescente 
Figura 111: Gráfico comparativo dos sistemas de iluminação utilizando tecnologia

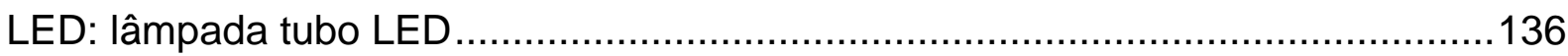

Figura 112: Gráfico comparativo dos sistemas de iluminação utilizando tecnologia LED, aplicado na luminária... 136 


\section{LISTA DE TABELAS}

Tabela 1: Recomendações dos intervalos de inspeção dos sistemas de iluminação dependendo da tarefa realizada.

Tabela 2: Valores aproximados de intervalos de inspeção conforme tipo de luminária

Tabela 3: Tabela de operação anual típica em horas.

Tabela 4: Tabela de depreciação do fluxo luminoso da lâmpada (LLMF) e efeito de falha de envelhecimento da lâmpada (LSF).

Tabela 5: Tabela de fator de manutenção da luminária (LMF).

Tabela 6: Tabela de fator de depreciação do ambiente (RSMF) para luminárias com distribuição direta da luz. 43

Tabela 7: Coeficiente de reflexão de alguns materiais e cores. .51

Tabela 8: lluminância média das medições realizadas 0 h até 2 anos de depreciação.

Tabela 9: Tabela de fluxo luminoso em lumens dos sistemas de iluminação com lâmpadas fluorescentes tubulares

Tabela 10: Tabela de fluxo luminoso em lumens dos sistemas de iluminação com lâmpadas tubo LED 105

Tabela 11: Tabela de fluxo luminoso em lumens dos sistemas de iluminação com LED acoplado. 106

Tabela 12: Tabela comparativa do nível de iluminância média entre os programas de cálculo 120

Tabela 13: Tabela resumo do nível de iluminância medido e simulado 123

Tabela 14: Tabela de fator de manutenção dos sistemas de iluminação do experimento. 128

Tabela 15: Tabela comparativa de fatores de manutenção 130 


\section{LISTA DE ABREVIATURAS E SIGLAS}

CIE Comission Internacionale de L'Eclairage

EPE Empresa de Pesquisa Energética - Brasil

FAU Faculdade de Arquitetura e Urbanismo - USP

HXE Sistema Hexa decimal de cores

IEE Instituto de Energia e Ambiente - USP

IESNA Illuminating Engineering Society of North America

INMETRO Instituto Nacional de Metrologia, Qualidade e Tecnologia

ISO International Organization for Standardization

LED Light Emitting Diode (diodo emissor de luz)

LABAUT Laboratório de Conforto Ambiental e Eficiência Energética - FAUUSP

RGB Modelo de cores Red, Green and Blue 


\section{GLOSSÁRIO}

Aletas

Célula teste

Proteção feita de componentes opacos ou metálicos, posicionados geometricamente para evitar a visão direta das lâmpadas em um determinado ângulo

São edificações ou ambientes construídos unicamente para uso experimental. Podem ser em escala reduzida ou em tamanho real.

Curvas de distribuição de É a curva de uma luminária, geralmente polar, que intensidade luminosa representa a intensidade luminosa em um plano através da fonte, como função do ângulo medido a partir de uma dada direção

Curva de distribuição de É a curva representando a iluminância de uma luminária iluminância num plano vertical, como função do ângulo a partir do nadir.

Curva isolux É o "locus" de pontos em uma superfície onde a iluminância tem o mesmo valor

Difusor

Dispositivo para alterar a distribuição espacial de um fluxo radiante ou luminoso e dependendo essencialmente do fenômeno de difusão

Eficiência luminosa

Fotometria

Iluminância

É a medida que indica a eficiência de uma lâmpada, é o indicador da eficiência do processo de emissão de luz sob o ponto de vista do aproveitamento energético. É a razão entre o fluxo luminoso e a potência da lâmpada, em lúmen/Watt $(\mathrm{Im} / \mathrm{W})$

Medição de quantidades referentes à radiação emitida, de acordo com o efeito visual que produz, como baseado em certas convenções

Quantidade total de luz emitida por uma fonte luminosa em todas as direções. Sua medida é lúmen $(\mathrm{Im})$. É o quociente do fluxo luminoso, incidente em um elemento 


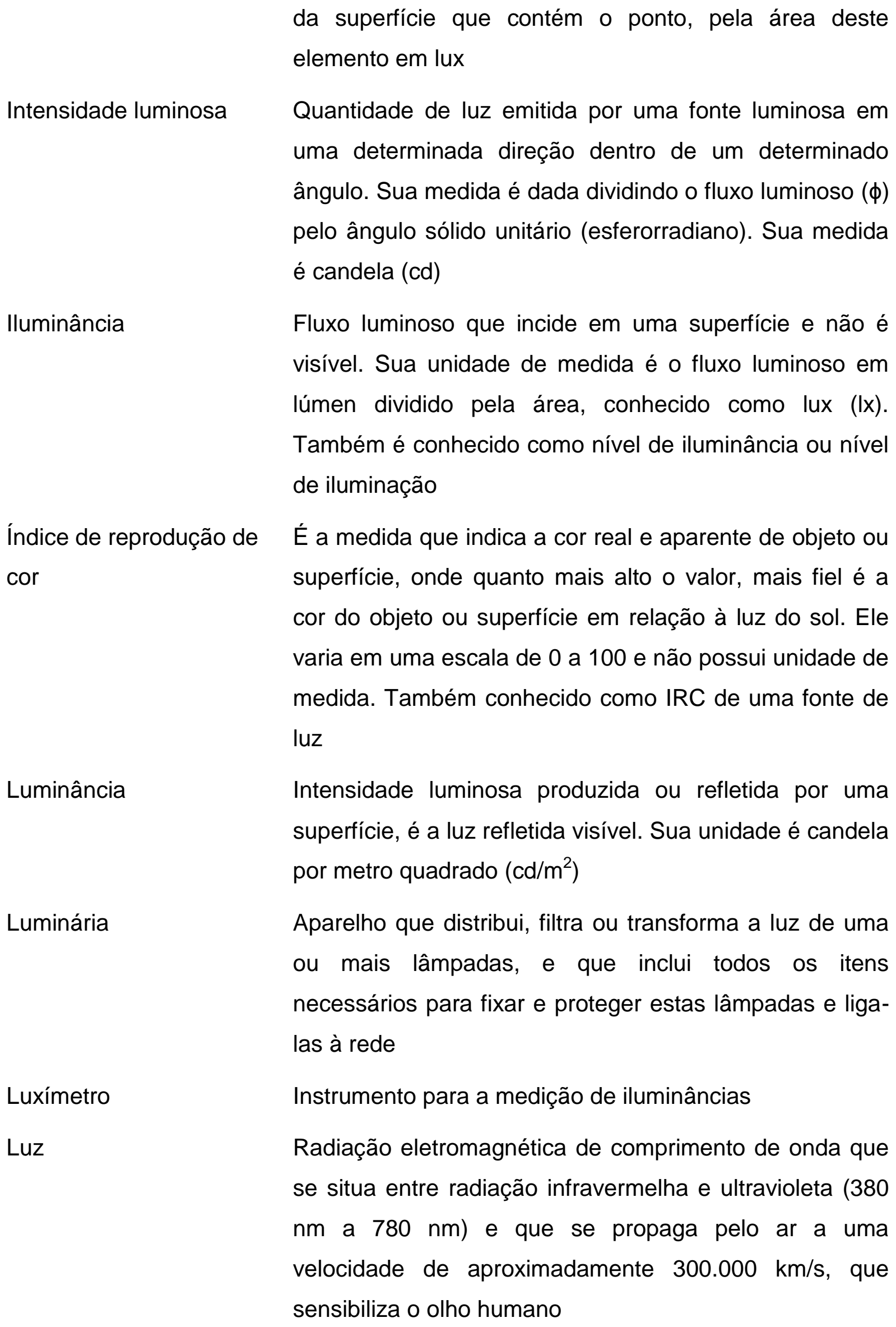


Ofuscamento

Plano de trabalho

Retrofit

Temperatura de cor

Vida útil
Condição de visão em que existe desconforto ou uma redução na capacidade de ver objetos significantes (ou ambos), graças a uma distribuição ou um valor adequado de luminância, ou por contraste extremos em espaços ou tempo

Superfície de referência definida como o plano onde usualmente é feito o trabalho

Termo utilizado principalmente em engenharia para designar o processo de modernização de algum equipamento considerado ultrapassado ou fora da norma É a aparência de cor da luz, onde sua escala apresentada faz referência à cor do aquecimento do radiador de corpo negro ou um radiator absoluto. Sua medida é dada em Kelvin (K)

É o número de horas decorridas até se atingir $70 \%$ da quantidade de luz inicial devido à depreciação do fluxo luminoso de cada lâmpada, somado ao efeito das respectivas queimas ocorridas no período 
CAPÍTULO 1

INTRODUÇÃO 


\section{INTRODUÇÃO}

A iluminação artificial começou a ter importância a partir da descoberta da eletricidade e da invenção da lâmpada no século XIX. Desde então, até os dias de hoje, associada à quantidade, qualidade e eficiência energética, a evolução dos sistemas de iluminação artificial é constante e a substituição das tecnologias por outras mais eficientes vem acontecendo em intervalos menores de tempo.

Com o surgimento da iluminação artificial, o período diurno se estendeu para a realização de mais tarefas cotidianas, além de trazer segurança em vias públicas principalmente para pedestres, para após o pôr do sol.

A eficiência luminosa da fonte de luz cada vez maior contribui para esse avanço, uma vez que é possível iluminar mais gastando menos. (ROSER, 2019).

O World Bank levantou os dados de crescimento do acesso à eletricidade e a iluminação da população desde 1990 até a última atualização realizada em 2016. Na Figura 1 a seguir, podemos observar a evolução desse crescimento em alguns países.

Figura 1: Gráfico da evolução do acesso à energia elétrica da população em alguns países

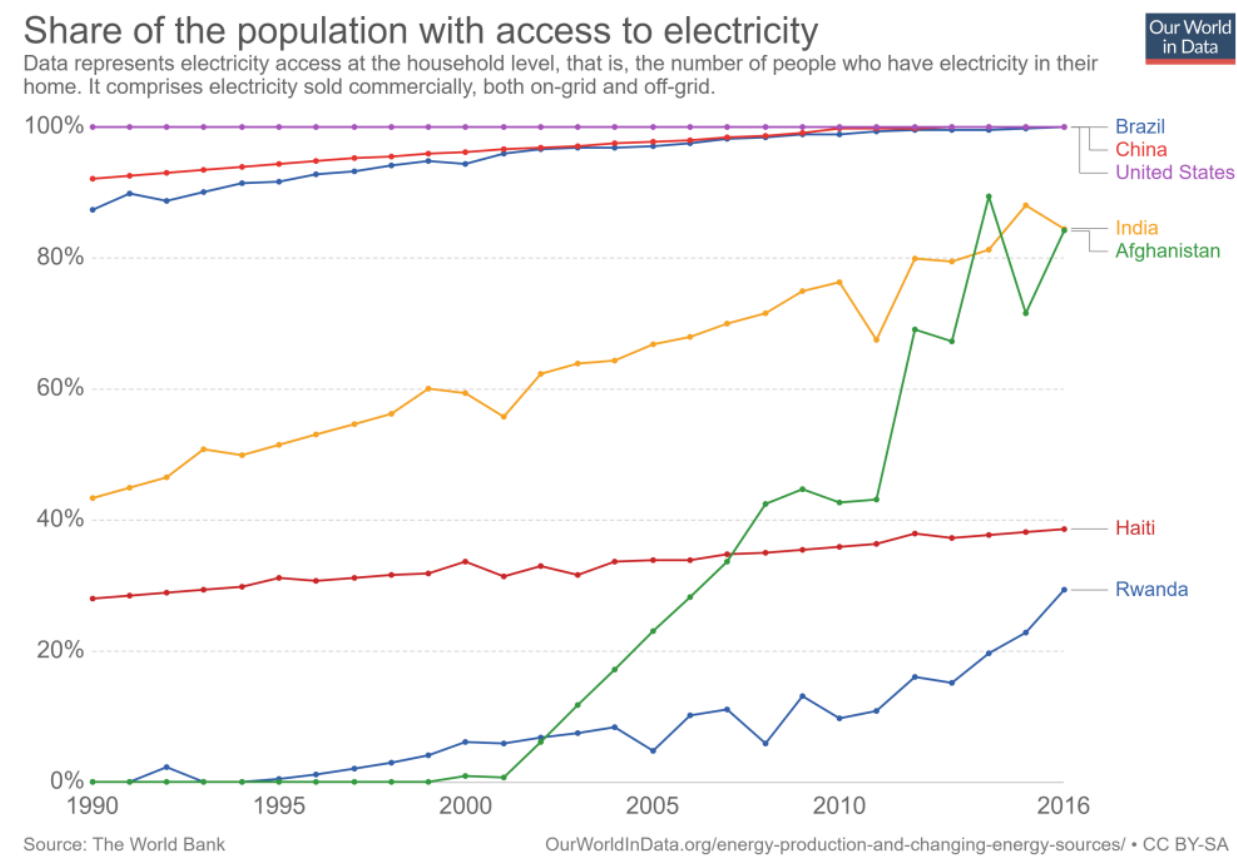

Fonte: World Bank - World Development Indicators 
No Brasil, este crescimento do acesso à eletricidade coincide com os anos que o país vivenciou a crise energética. Segundo GARCIA (2011), no final dos anos 90 e início dos anos 2000 essa crise foi causada, por dois fatores principais relacionados. Houve um aumento de demanda pela energia elétrica, e para atender a essa crescente demanda, as usinas hidrelétricas utilizaram o reservatório de água disponível. No entanto, nesse período, ocorreu também uma grande estiagem devido à redução drástica nas precipitações anuais. Dessa forma, entre os anos de 2000-2001 o nível médio dos reservatórios atingiu as menores marcas, e não havia reserva de água disponível para alimentar as usinas hidrelétricas.

Como decorrência, o governo brasileiro estipulou a redução em $20 \%$ no consumo de energia, e para isso foram definidas metas para os setores residenciais, comerciais e industriais. Foi nessa época que a lâmpada incandescente foi substituída pela lâmpada fluorescente em larga escala, pois a redução chegava a $75 \%$ de economia.

No setor comercial, a solução para economizar energia por meio da iluminação foi a substituição das lâmpadas fluorescentes tubulares T10 de 40W (base G13) pelas lâmpadas fluorescentes tubulares T8 de 32W (base G13), onde apenas com a substituição dessas lâmpadas, economizava-se cerca de $20 \%$.

Após a crise energética, houve uma crescente procura por outras fontes de energia e produtos que trouxessem economia de energia. Nos anos de 2004-2005, referente à iluminação artificial, inicia-se a substituição da lâmpada fluorescente tubular T8 e T10 pela fluorescente tubular T5, que era mais eficiente e tem maior vida útil. Esta tecnologia ainda está sendo utilizada, pois tem uma elevada eficiência energética, grande durabilidade, grande variedade de temperatura de cor e IRC alto. Possui selo de certificação pelo INMETRO desde 1999.

Com a atual preocupação mundial com o meio ambiente e o surgimento dos selos e/ou certificações de sustentabilidade, as lâmpadas fluorescentes começaram a ser substituídas pelos sistemas de iluminação utilizando a tecnologia LED dado o aclamado baixo consumo e alta eficiência energética. Além disso, o descarte do LED tem baixo impacto ambiental se comparado à lâmpada fluorescente tubular.

No momento, a tecnologia LED é considerada o sistema de iluminação mais eficiente do mercado e está cada vez mais sendo utilizada no Brasil e no mundo. No entanto, as normas existentes relativas à fabricação do LED são recentes, de 2012 , e a certificação de lâmpadas LED pelo INMETRO entrou em vigor em fevereiro de 
2016. Até setembro de 2016, ainda não era possível encontrar as lâmpadas tubo LED certificadas em revendedores de grande e médio porte. Era possível encontrar apenas diretamente com os fabricantes.

Apesar da tecnologia LED se mostrar extremamente eficiente na maioria dos casos, estudos como os de SOARES (2018), KYBA (2017) e MERCOLA and WUNSCH (2016) mostram alguns problemas causados devido à exposição prolongada da luz LED, tais com alteração no ciclo circadiano, dores de cabeça, entre outros. Portanto, ainda deve-se ter cautela para a utilização dessa tecnologia.

Em uma entrevista dada à CNN em 2017, o estudioso Christopher Kyba da GFZ German Research Centre for Geosciences, alerta sobre o problema da poluição noturna no mundo, principalmente após a substituição das lâmpadas de vapor de sódio pelas lâmpadas LED na iluminação pública. Não só o ciclo circadiano em humanos sofre alterações, como em muitas espécies de animais, principalmente os noturnos, tem seu ciclo alterado devido à exposição ao LED nesse período.

A American Medical Association fez, em 2016, recomendações relacionadas à iluminação pública referente à temperatura de cor e nível de radiação que seriam menos prejudiciais à saúde. Segundo Christopher Kyba, a tecnologia LED tem trazido benefícios com a grande economia de energia por meio da substituição da tecnologia convencional de vapor de sódio e vapor metálico, porém deve ser utilizada com cautela. Uma das possíveis soluções para as vias públicas seria iluminar apenas o essencial, como o percurso de pedestres e bicicletas, pois os automóveis já possuem luz própria. (GANGULY, 2017).

No setor dos edifícios, dados do EPE mostram que o consumo de energia elétrica no Brasil era de 243.074 GWh em 1995 e foi para 465.130 GWh em 2017. O consumo de energia praticamente dobrou nesses 22 anos. No setor comercial, que engloba edifícios de escritório, instituições de ensino, hospitais, bancos, etc., o aumento foi de $44 \%$ ao longo desses anos. 
Figura 2: Consumo anual de energia elétrica por classe (nacional) - ano de 2017

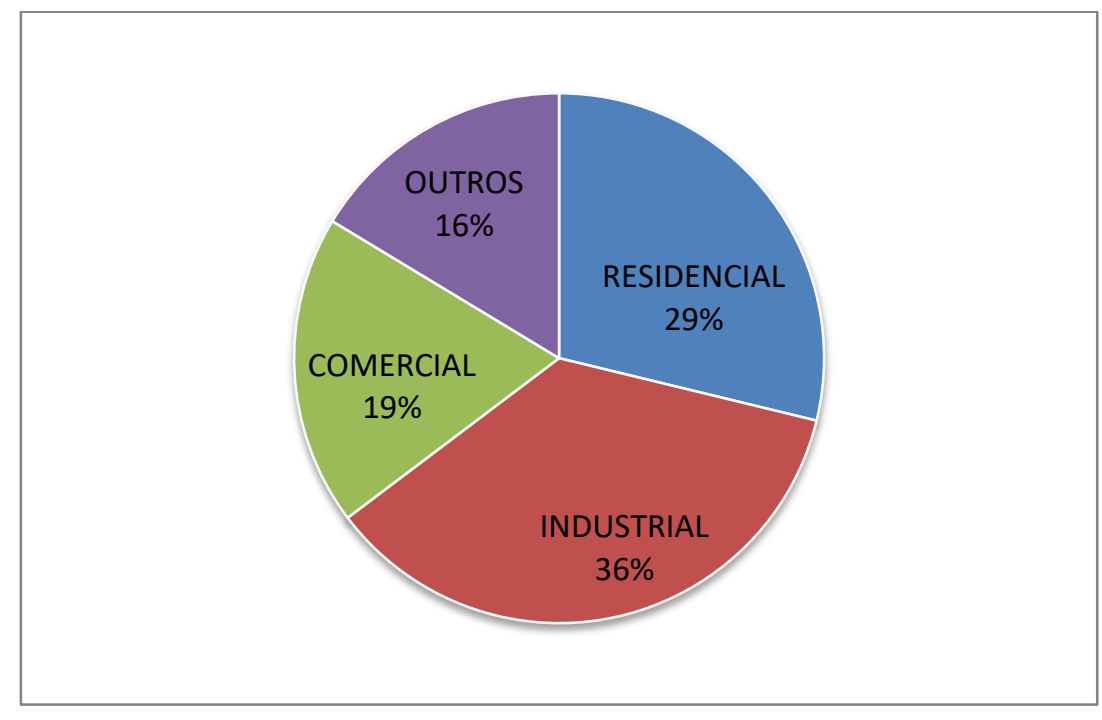

Fonte: EPE

O gráfico apresentado na Figura 2 mostra o consumo por classe ou setor no ano de 2017, o consumo do setor comercial, corresponde a $19 \%$ do total. Ainda em relação ao setor comercial, a pesquisa de posse de equipamentos e hábito de uso, publicada em 2008, mostra com os dados coletados em 2005 que $22 \%$ em média correspondem ao gasto com iluminação (ELETROBRAS, 2009).

Os resultados da nova pesquisa, já realizada pela Eletrobras estarão disponíveis no segundo semestre de 2019. É muito provável que não tenha havido neste período variações significativas nestes percentuais.

Como os gastos com iluminação ainda possuem um percentual elevado, é importante que sejam realizados projetos adequados. Além de manter o conforto luminoso e nível de iluminância apropriado à atividade no plano de trabalho dos usuários, deve proporcionar também, um consumo reduzido de energia. Um estudo cuidadoso para a concretização disso vale tanto para projetos novos como para os de retrofit.

O cuidado deve ser maior no caso de projetos de retrofit pois ainda vende-se a ideia de que substituindo uma lâmpada fluorescente por uma lâmpada LED com formato tubular há economia de energia. No entanto, o nível de iluminação resultante dessa substituição poderá não estar de acordo com a norma.

Infelizmente, no mercado atual, os arquitetos e light designers ainda têm dificuldades em obter os dados básicos que os fabricantes deveriam fornecer junto 
dos seus produtos, tanto em LED como em sistemas de iluminação convencionais. Até o final de 2016, os fabricantes de luminária ainda não disponibilizavam os dados fotométricos utilizando as lâmpadas tubo LED em suas luminárias.

Com o avanço tecnológico dos dias atuais e o acesso das informações por meio da internet, é importante ressaltar que, de forma crescente, os programas de cálculo estão sendo utilizados como ferramenta facilitadora para se pensar em um projeto luminotécnico adequado. A própria IESNA cita, no plano de pesquisas estratégicas de 2016, a importância da utilização dos softwares de cálculo luminotécnico.

Os programas de simulação estão sendo utilizados pelos projetistas no mundo todo e têm suas vantagens pois são facilitadores da operação, têm baixo custo, pois economizam tempo principalmente em projetos mais complexos, e os resultados gráficos são satisfatórios. Porém, não podem ser utilizados sem conhecimento prévio necessário sobre cálculos e projetos luminotécnicos.

No início de um projeto arquitetônico nem sempre estão disponíveis os dados de entrada, por vezes faltam os acabamentos, os mobiliários, o layout e a presença de outras interferências. Os cálculos dos softwares dão uma ideia de quanto haverá de luz e o efeito da mesma no ambiente projetado. Os resultados são produtos de equações programadas, portanto, dependem de dados de entrada confiáveis.

Um dos dados de entrada mais importantes para um projeto de cálculo é o fator de manutenção ou fator de depreciação do sistema de iluminação que será utilizado, pois o ideal é que, após alcançar a depreciação de $30 \%$ do fluxo luminoso do sistema de iluminação, se tomem providências necessárias, por exemplo, que a lâmpada ou o conjunto seja trocado ou seja realizada a limpeza dos mesmos.

Quando a tecnologia fluorescente era dominante no mercado nacional, o projetista recomendava a troca das lâmpadas e limpeza do sistema de iluminação ao atingir tal depreciação. Porém, não era isso que ocorria, as trocas só eram realizadas após a queima de um dos componentes do conjunto. Com a tecnologia LED, os clientes nem pensam em trocar os sistemas e iluminação em LED, pois a promessa é de não haverá queima ou depreciação por muitos anos. Neste caso, já se optaria por uma reforma total no ambiente de trabalho.

A ideia que surgiu ao iniciar a pesquisa é que há depreciação da tecnologia LED, tanto quanto há depreciação da tecnologia fluorescente. Questiona-se, assim, a eficiência dos sistemas de iluminação utilizando a nova tecnologia LED no Brasil e 
a confiabilidade dos dados de entrada nos programas de simulação, assim como a depreciação a ser utilizada e os dados fotométricos fornecidos pelos fabricantes.

A IESNA propõe em seu plano o aumento de pesquisas relacionadas aos sistemas de LED, dado que, provavelmente nos próximos quatro anos, serão as fontes de luz predominantes. Dessa maneira, é importante testar a qualidade e a real eficiência energética desses sistemas de iluminação, pois cada vez mais, pressiona-se para a redução do consumo energético no mundo.

O uso em grande escala de uma tecnologia pode gerar um amplo impacto para um país, por isso, ter o conhecimento profundo do comportamento desta tecnologia é fundamental. Aferir se o resultado esperado condiz com a realidade é mandatório, visto que, em tempos de instabilidade na produção de recursos básicos como a eletricidade, conhecer o consumo real de uma edificação pode significar a viabilidade ou não de uma empresa ou até de um país.

\subsection{Objetivos}

O principal objetivo desta pesquisa é comparar a depreciação da tecnologia LED com a tecnologia fluorescente, prevendo assim, o fator de manutenção adequado em projetos de iluminação.

Para alcançar o objetivo, foi verificada a depreciação do fluxo luminoso em sistemas de iluminação definidos inicialmente, por meio de medições do nível de iluminação no plano de trabalho em uma célula teste. Os mesmos também foram ensaiados em laboratório.

A norma CIE-97:2005 foi utilizada para obter os dados do fator de manutenção que devem ser considerados no projeto luminotécnico. A mesma serviu de base para posterior comparação com as medições realizadas.

Outro objetivo da pesquisa é verificar dentre os sistemas de iluminação que utilizam a tecnologia LED, qual tem maior depreciação. 


\subsection{Hipóteses da pesquisa}

A tese possui três hipóteses:

Hipótese 1: Existe depreciação do fluxo luminoso na tecnologia LED quando comparada com a tecnologia fluorescente

Hipótese 2: A depreciação do fluxo luminoso na tecnologia LED é mais intensa na lâmpada tubo LED quando comparada ao LED aplicado na própria luminária

Hipótese 3: Os dados de depreciação preconizados pela norma CIE-97:2005 não correspondem à realidade, pois as depreciações reais são maiores que a referida norma 


\section{CAPÍTULO 2}

MÉTODOS E TÉCNICAS 


\section{MÉTODOS E TÉCNICAS}

\subsection{Considerações preliminares}

O fluxograma a seguir mostrado na figura 3 apresenta a metodologia adotada nesta pesquisa durante todas as suas etapas.

Figura 3: Fluxograma da pesquisa

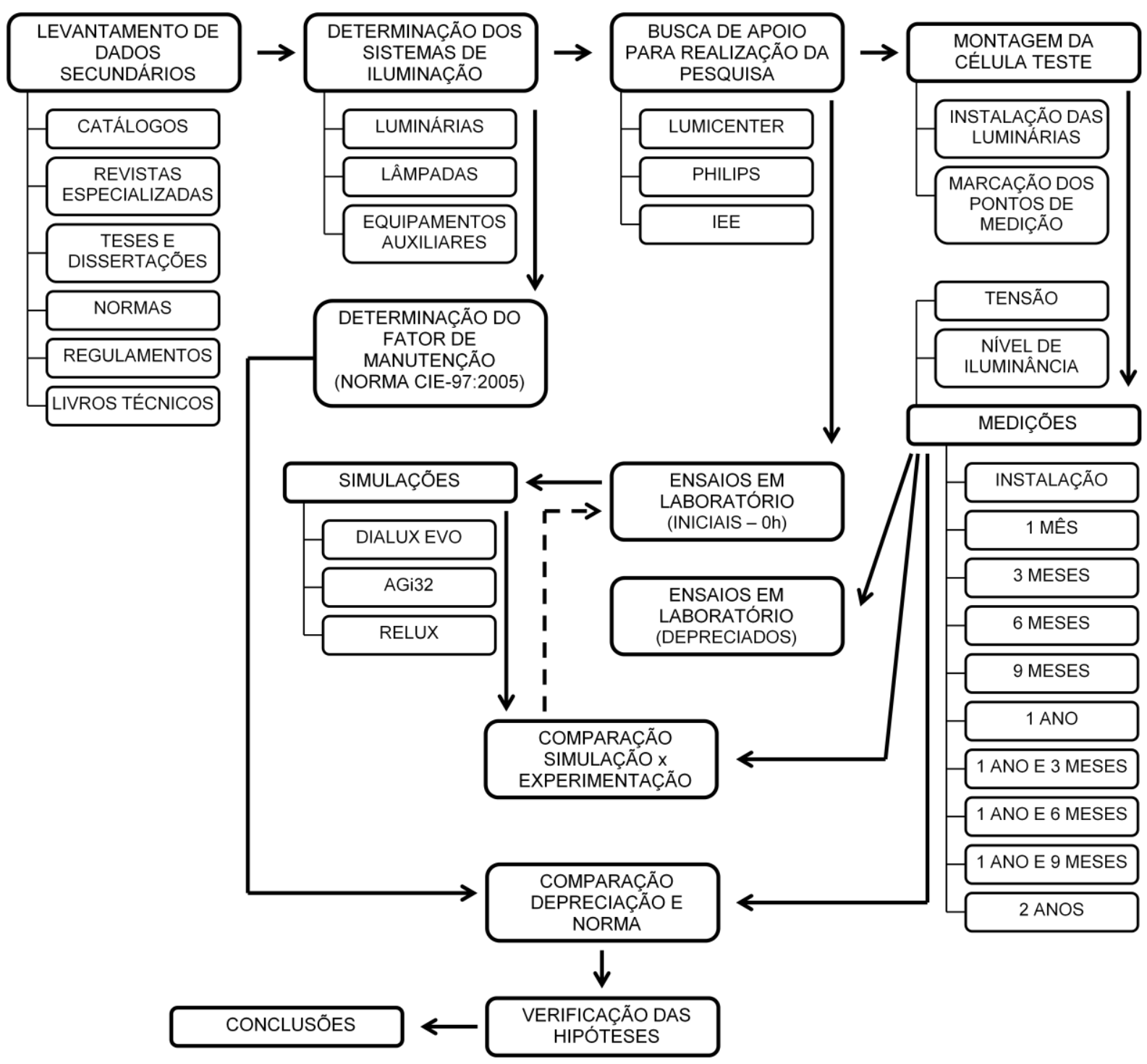

Fonte: Elaborado pela autora 


\subsection{Levantamento de dados secundários}

Inicialmente, foi realizado um levantamento de dados secundários que incluem dissertações e teses sobre iluminação artificial, eficiência energética e LEDs; informações sobre projetos atuais utilizando a tecnologia LED em revistas e sites especializados; e normas e regulamentos sobre o assunto.

Foram levantados dados sobre os sistemas de iluminação utilizando a tecnologia LED que poderiam ser equivalentes aos sistemas de iluminação convencionais utilizando lâmpada fluorescente tubular. Pesquisou-se informações sobre os produtos das empresas nacionais e internacionais mais conhecidas no mercado brasileiro em catálogos e sites de fabricantes.

Determinados os sistemas de iluminação mais utilizados em edifícios comerciais e escolares, iniciou-se o levantamento dos dados primários para a tese.

Decidiu-se que as normas base para realização da pesquisa seriam a NBR ISO/CIE 8995-1 de 2013 - Iluminação de ambientes de trabalho - Parte 1: Interior, adotando o nível de iluminação no plano de trabalho de 500 lux, e a norma CIE 97:2005 para aplicação do fator de manutenção do sistema de iluminação utilizado.

\subsection{Sistemas de lluminação}

Foram adotadas duas tipologias de sistemas de iluminação: modelo de luminária com aletas e luminária com difusor. Deste modo, será estudada a depreciação tanto da tecnologia LED como da tecnologia fluorescente, considerando uma luminária semiaberta e uma fechada. Os sistemas adotados foram:

- Luminária com aletas parabólicas e refletor em alumínio para lâmpada fluorescente tubular 2x28W - Tipo 1;

- Luminária com aletas parabólicas e refletor em alumínio para lâmpada LED tubular equivalente 2x18W - Tipo 2;

- Luminária com aletas parabólicas com LED integrado - Tipo 3;

- Luminária com refletor branco e fechamento translúcido para lâmpada fluorescente tubular 2x28W - Tipo 4;

- Luminária com refletor branco e fechamento translúcido para lâmpada LED tubular equivalente $2 \times 18 \mathrm{~W}-$ Tipo 5 ; 
- Luminária com fechamento translúcido com LED integrado - Tipo 6;

Foi simulado no programa Dialux 4.12 o quantitativo necessário para alcançar o nível de iluminância de 500 lux no plano de trabalho, conforme norma NBR ISO/CIE 8995-1 de 2013 - lluminação de ambientes de trabalho - Parte 1: Interior, considerando que a célula teste será um ambiente de escritório.

Pela norma, a iluminância de 500 lux fica restrita apenas à área onde será realizada a tarefa, no caso, a mesa de trabalho do usuário. A iluminância da área do entorno imediato poderá ser mais baixa que a iluminância de área de tarefa, porém, não poderá ser abaixo de 300 lux conforme norma, para o caso de escritórios.

O resultado dos cálculos realizados utilizando os sistemas de iluminação do fabricante Lumicenter é mostrado na Figura 4 seguinte.

Figura 4: Resultado do cálculo - curvas isolux do programa Dialux 4.12
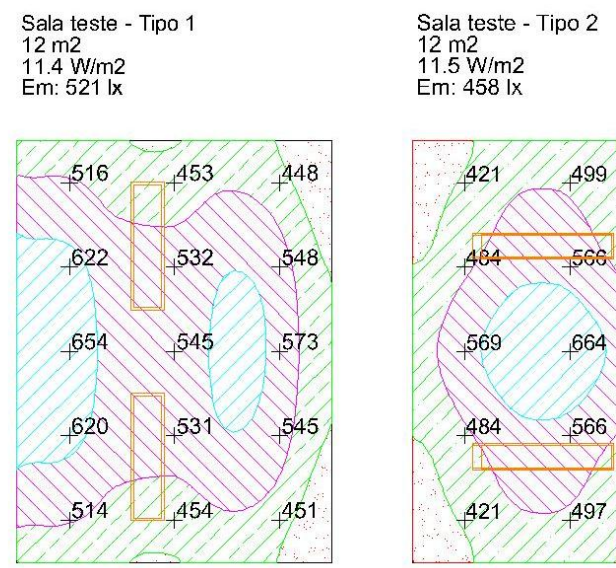

Em: $458 \mathrm{~lx}$
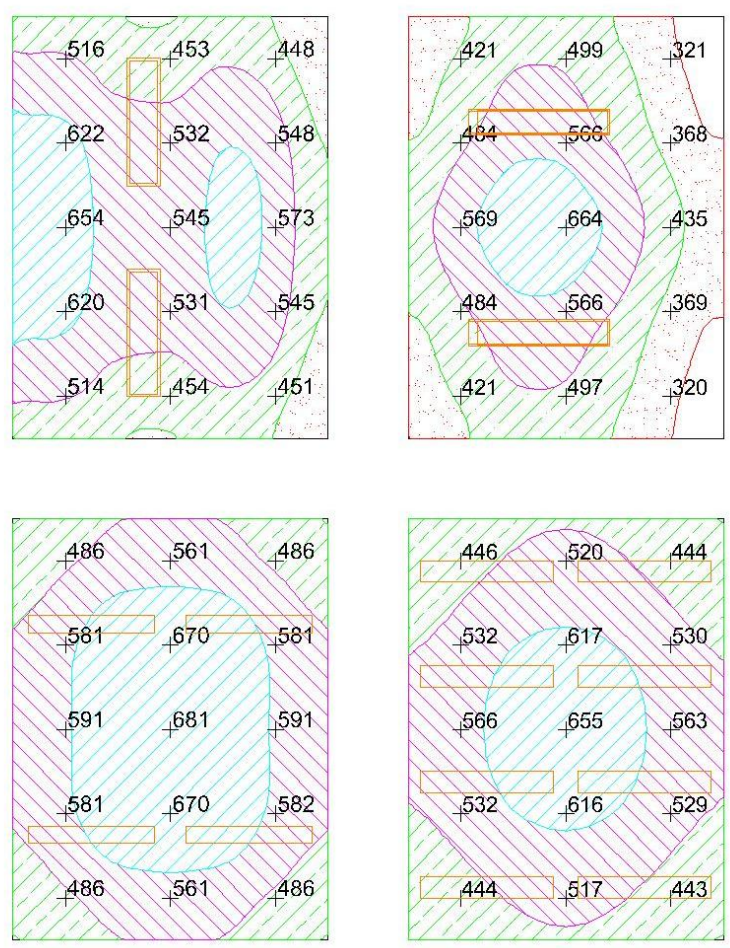

Sala teste - Tipo 4$$
20.6 \mathrm{~W} / \mathrm{m}
$$

Em: $570 \mathrm{~lx}$

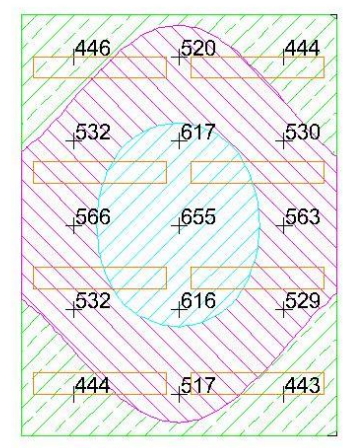

Sala teste - Tipo 5

$12 \mathrm{~m} 2$

Em: $536 \mathrm{Ix}$
Sala teste - Tipo 3

$12 \mathrm{~m} 2$

E.6 W/m2 $611 \mathrm{~lx}$

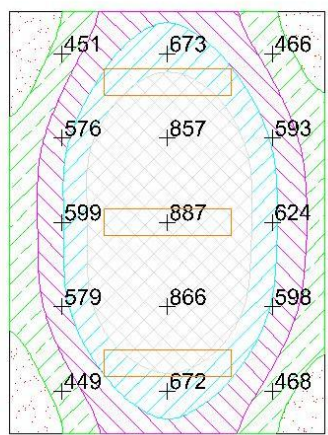

Isolines

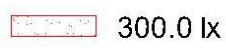

$400.01 x$

$500.0 \mathrm{Ix}$

$600.01 x$

$700.01 x$

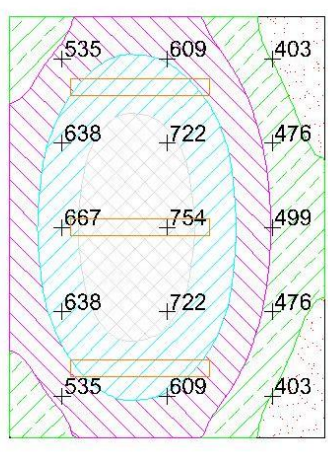

Sala teste - Tipo 6

$12 \mathrm{~m} 2$

E.4 W/m2 568 Ix 
Neste caso, para as tipologias dos sistemas de iluminação 2 e 4, não foi possível realizar o cálculo utilizando as lâmpadas tubo LED, pois os fabricantes ainda não possuíam os ensaios referentes ao mesmo.

Para ter uma ideia dos quantitativos de luminárias necessárias, considerou-se a curva fotométrica utilizando lâmpadas fluorescentes tubulares base T8.

\subsection{Busca de apoio para realização da pesquisa}

O Departamento de Tecnologia da FAU-USP gentilmente cedeu uma das salas do laboratório de pesquisa para ser utilizada como célula teste durante 26 meses.

Buscou-se também o apoio do laboratório de fotometria do IEE para que pudessem ser realizados os ensaios fotométricos necessários para a pesquisa.

Definidos os sistemas, buscou-se, entre diversos fabricantes conhecidos no mercado nacional, aqueles que poderiam doar os materiais para que o experimento pudesse ser realizado.

A empresa Lumicenter doou todos os sistemas de iluminação, no entanto, doou somente duas peças de cada modelo, e a empresa Philips doou todas as lâmpadas utilizadas no experimento.

Devido a esta mudança de cenário, considerou-se somente a utilização de duas luminárias de cada tipologia que seriam instaladas nos mesmos pontos, e seria feita a medição do nível de iluminância em pontos definidos segundo norma NBR ISO/CIE 8995-1.

Assim, foi comparado o nível de iluminância ponto a ponto e o nível de iluminância média que cada sistema de iluminação fornece conforme o conjunto é depreciado em cada situação.

O detalhamento dos sistemas de iluminação utilizados para realização do experimento é listado na sequência.

\subsubsection{Luminárias}

- Tipo 1: Modelo da luminária: FAA04-S228 - Luminária de sobrepor, com corpo em chapa de aço fosfatizada e pintada elestrostaticamente na cor 
branca, refletor e aletas parabólicas em alumínio alto brilho com 2 lâmpadas fluorescente tubular T5 de 28W.

Figura 5: Foto e curva fotométrica da luminária FAA04-S
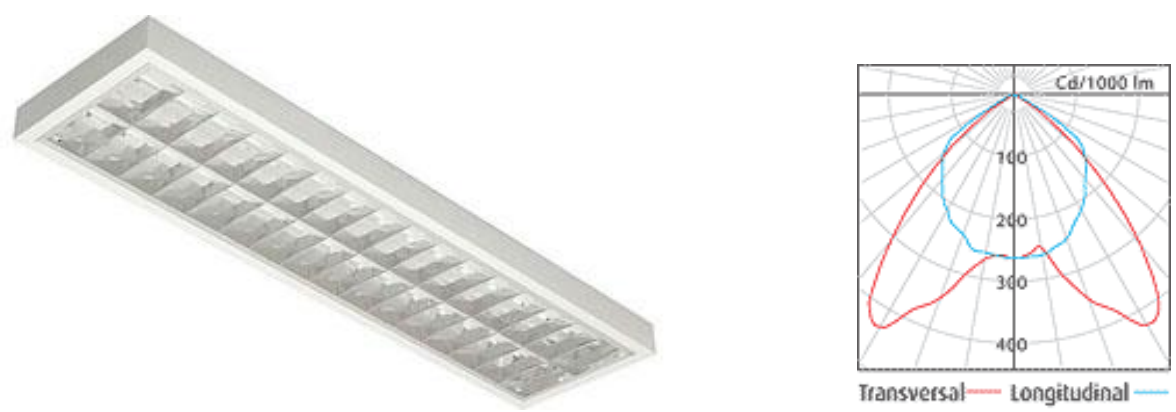

Fonte: Lumicenter

- Tipo 2: Modelo da luminária: CAA02-S232 - Luminária de sobrepor, com corpo em chapa de aço fosfatizada e pintada eletrostaticamente na cor branca, refletor e aletas parabólicas em alumínio alto brilho com 2 lâmpadas tubo LED T8 de 18W.

Figura 6: Foto e curva fotométrica da luminária CAA02-S
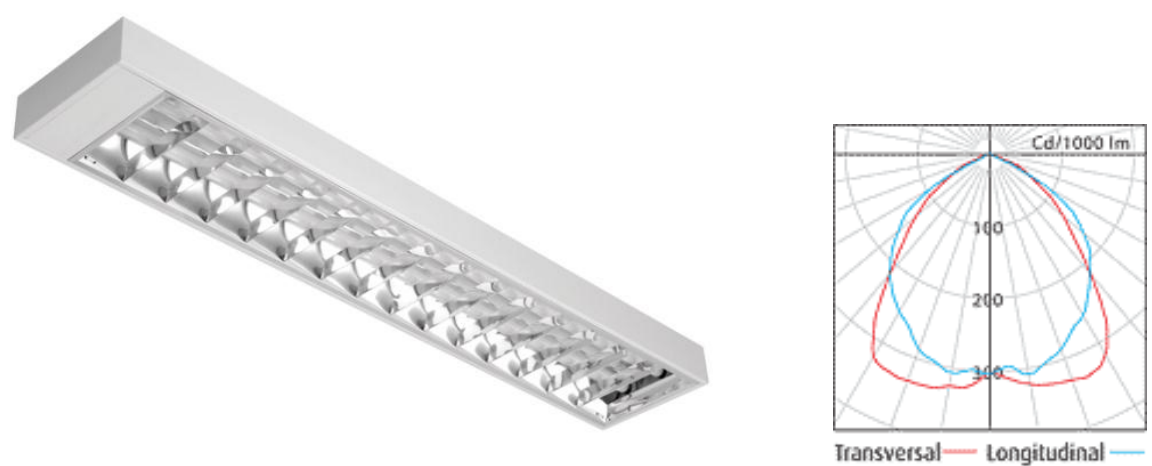

Fonte: Lumicenter

- Tipo 3: Modelo da luminária: EAA02-S3500840 - Luminária de sobrepor à LED, corpo em chapa de aço fosfatizada com pintura microtexturizada. Aletas parabólicas e refletores em alumínio de alto brilho. Difusores recuados em acrílico leitoso. IRC 85 e IP20. Drivers multitensão (100V 250V) integrados à luminária. Consumo total incluindo driver de 37W, 4000K, 3400Im (já consideradas as perdas óticas). Vida útil $30.000 \mathrm{~h}$ de uso em ambientes a $50^{\circ} \mathrm{C}, 3$ anos de garantia. 
Figura 7: Foto e curva fotométrica da luminária EAA02-S
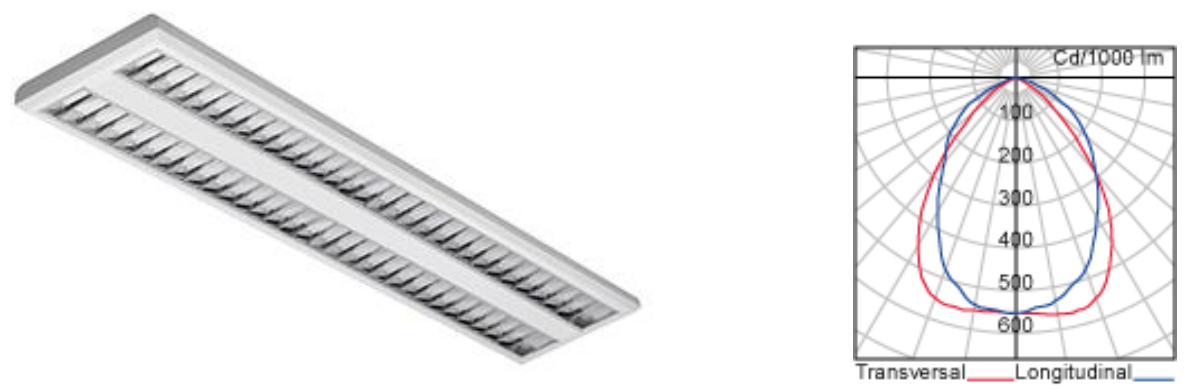

Fonte: Lumicenter

- Tipo 4: Modelo da luminária: FHT07-S28 - Luminária de sobrepor com corpo em chapa de aço fosfatizada e pintada eletrostaticamente na cor branca. Difusor em acrílico leitoso (PMMA - polimetilmetacrilato) com 2 lâmpadas fluorescente tubular T5 de 28W.

Figura 8: Foto e curva fotométrica da luminária FHT07-S
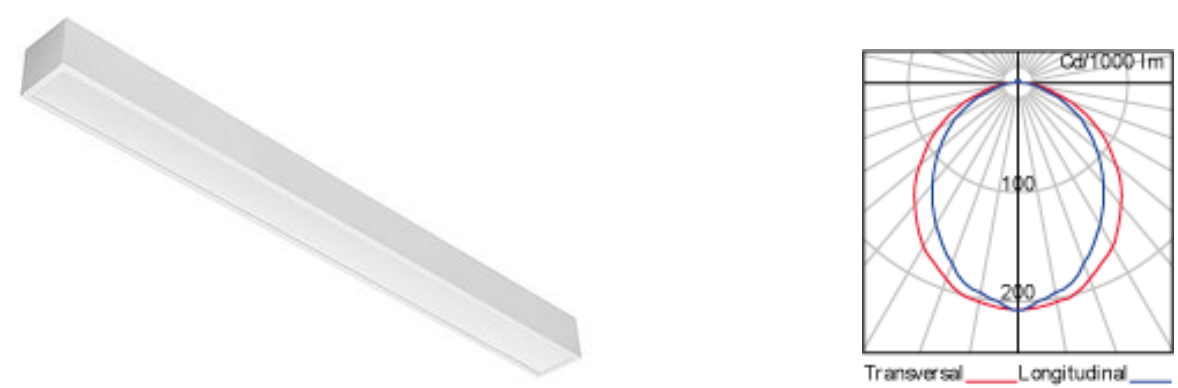

Fonte: Lumicenter

- Tipo 5: Modelo da luminária CHT10-S232ACL - Luminária hermética de sobrepor, com corpo em chapa de aço fosfatizada e pintada eletrostaticamente na cor branca. Difusor em poliestireno leitoso com 2 lâmpadas tubo LED T8 18W. 
Figura 9: Foto e curva fotométrica da luminária CHT10-S ACL

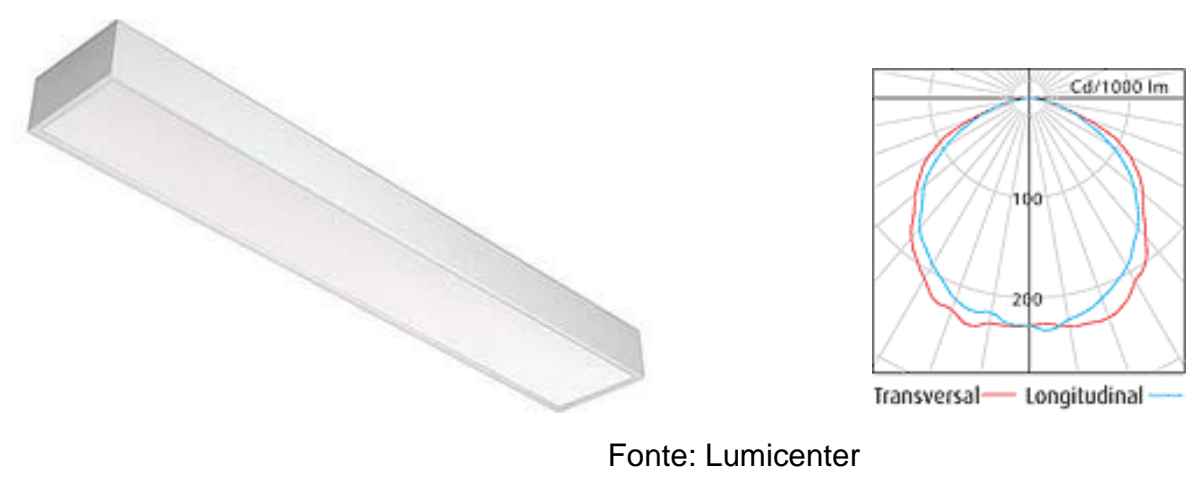

- Tipo 6: Modelo LCN13-S4000840 - Luminária de sobrepor à LED, com corpo em chapa de aço fosfatizada, acabamento em pintura eletrostática pó poliéster na cor branca microtexturizada. Difusor em acrílico leitoso. IRC 80 e IP20. Drivers multitensão (100V 250V) integrados à luminária. Consumo total incluindo driver de $37 \mathrm{~W}, 4000 \mathrm{~K}, 3850 \mathrm{~lm}$ (já consideradas as perdas óticas). Vida útil $50.000 \mathrm{~h}$ de uso.

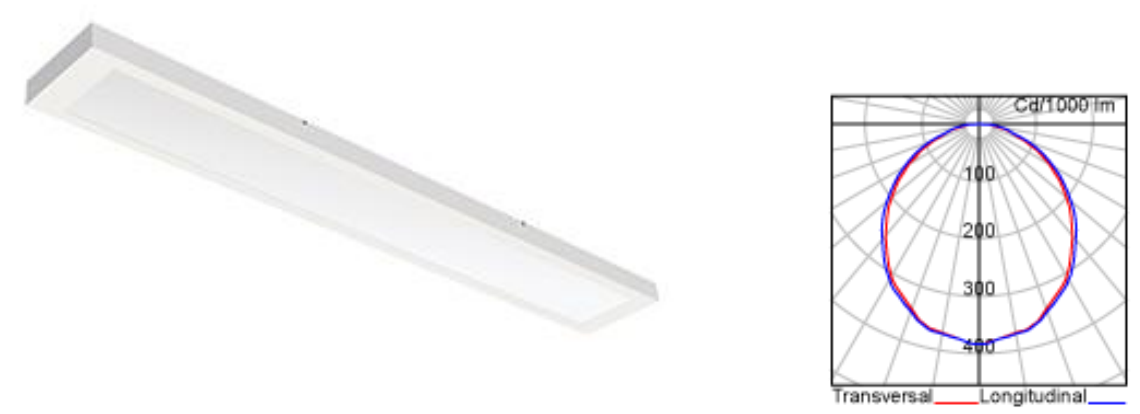

Fonte: Lumicenter

As curvas fotométricas das figuras 6 e 9 são referentes aos sistemas de iluminação utilizando lâmpada fluorescente tubular T8 de 32W.

As fichas técnicas fornecidas pelo fabricante estão no Anexo I deste trabalho.

\subsubsection{Lâmpadas}

As lâmpadas utilizadas nos sistemas de iluminação foram doadas pela empresa Philips do Brasil e têm as seguintes características: 
- Lâmpada fluorescente tubular T5 28W

Marca/Modelo: Philips - TL5 Essential 28W/840 com certificação INMETRO

Potência: $28 \mathrm{~W}$

Base: G5

Temperatura de cor: $4000 \mathrm{~K}$

Fluxo luminoso: $2900 \mathrm{~lm}$

Eficiência: $103 \mathrm{~lm} / \mathrm{W}$

Vida útil: $20.000 \mathrm{~h}$

IRC 80

As lâmpadas estão instaladas nas luminárias de modelo tipo 1 e tipo 4 .

- Lâmpada tubo LED T8 18W

Marca/Modelo: Philips - MASTER LEDTube $18 \mathrm{~W}$ com certificação INMETRO

Potência: $18 \mathrm{~W}$

Base: G13

Temperatura de cor: $6500 \mathrm{~K}$

Fluxo luminoso: $2100 \mathrm{~lm}$

Eficiência luminosa: $117 \mathrm{~lm} / \mathrm{W}$

Vida média: $25.000 \mathrm{~h}$

Tensão: 100 240V - 50/60 Hz

Fator de potência: 0,92

IRC $>82$

As lâmpadas estão instaladas nas luminárias de modelo tipo 2 e tipo 5 .

- Lâmpada fluorescente tubular T8 32W

Marca/Modelo: NSK - Linha Standard FL32T8-6

Potência: 32W

Base: G13

Temperatura de cor: $6500 \mathrm{~K}$

Fluxo luminoso: $2600 \mathrm{~lm}$

Vida média (h): $8000 \mathrm{~h}$

IRC: 70 79 
Esta lâmpada foi utilizada somente na medição inicial das luminárias modelo tipo 2 e tipo 4 para comparação com a lâmpada tubo LED e foi emprestada pela própria FAU-USP apenas para essa finalidade.

\subsubsection{Equipamentos auxiliares}

O equipamento auxiliar empregado nas luminárias utilizando lâmpadas fluorescente tubular T5 de $28 \mathrm{~W}$ foi o reator da marca Philips com as seguintes características:

- Marca/Código do produto: Philips EL1/214-28A26 P 105 250V

Lâmpada: 2x28W

Tensão: $127 \mathrm{~V}$

I. Entrada (A): 0,49A

P. Total: $63 \mathrm{~W}$

F.P.:0,99

THD: $<5 \%$

F.F.L.: 1,00

F. Efic.: 1,59

F.L. $(\mathrm{KHz}): 45$

Para a única medição realizada com lâmpadas fluorescentes tubulares T8 $32 \mathrm{~W}$ foi utilizado o reator, também emprestado pela FAU-USP somente para essa única medição, com as seguintes características:

- Marca/ Código do produto: RCG - RE 232FR Evolution bivolt

Lâmpada: 2x32W

Tensão: 127V

Corrente: $0,51 \mathrm{~A}$

P. Total: $64 \mathrm{~W}$

F.P.:0,99

THD: $10 \%$

F.F.L.: 100\% 
O driver das luminárias com LED integrado tem as seguintes características, que são do próprio fabricante Lumicenter:

- Marca/Código do produto: Lumicenter REREAT00714

Lâmpada: LED 12-17

Tensão: 100 a 250V

I. Entrada (A): 0,32 (127V)

P. Total: $38 \mathrm{~W}$

F.P.: 0,98

THD: $10 \%$

F. Efic.: $90 \%$

F.L. (KHz): 50/60 Hz

\subsection{Determinação do fator de manutenção}

Para encontrar o valor do fator de manutenção a ser considerado em projetos luminotécnicos, foi utilizado a norma CIE-97:2005 - Guia de manutenção dos sistemas elétricos de iluminação internos. Foi selecionada essa norma, pois é importante considerar, ainda na fase projetual, um fator de perdas luminosas pela depreciação da fonte de luz, acúmulo de poeira nos sistemas de iluminação e superfícies do ambiente, e design do próprio sistema de iluminação.

O fator de manutenção a ser considerado é determinado pela seguinte fórmula:

$$
M F=L L M F \times L S F \times L M F \times R S M F
$$

onde: LLMF - depreciação do fluxo luminoso da lâmpada

LSF - efeito de falha por envelhecimento da lâmpada

LMF - fator de manutenção da luminária

RSMF - redução da refletância do ambiente

Seguindo o passo a passo dado na norma CIE 97:2005, temos os seguintes valores de fator de manutenção: 
Tabela 1: Recomendações dos intervalos de inspeção dos sistemas de iluminação dependendo da tarefa realizada.

\begin{tabular}{|c|c|c|}
\hline Intervalo de inspeção & Ambiente & Atividade ou área de tarefa \\
\hline \multirow[t]{2}{*}{3 anos } & Muito limpo (VC) & $\begin{array}{l}\text { Quartos limpos, fábrica de } \\
\text { semicondutores, áreas hospitalares, } \\
\text { centros computacionais }\end{array}$ \\
\hline & Limpo (C) & Escritórios, escolas, enfermarias \\
\hline 2 anos & Normal (N) & $\begin{array}{l}\text { Lojas, laboratórios, restaurantes, } \\
\text { armazéns, oficinas e áreas de montagem }\end{array}$ \\
\hline 1 ano & Sujo (D) & $\begin{array}{l}\text { Fábricas em geral, áreas de carpintaria, } \\
\text { polimento e soldagem. }\end{array}$ \\
\hline
\end{tabular}

Fonte: CIE-97

Conforme Tabela 2, o intervalo de inspeção para escritórios e escolas é de três anos.

Tabela 2: Valores aproximados de intervalos de inspeção conforme tipo de luminária

\begin{tabular}{|c|c|c|c|c|c|c|c|c|c|c|c|c|}
\hline \multirow{4}{*}{\multicolumn{2}{|c|}{$\begin{array}{c}\text { Tipo de } \\
\text { luminária }\end{array}$}} & \multirow{4}{*}{ Classificação } & \multirow{4}{*}{ Descrição } & \multicolumn{9}{|c|}{ Intervalo de limpeza } \\
\hline & & & & \multicolumn{3}{|c|}{3 anos } & \multirow{2}{*}{\multicolumn{3}{|c|}{$\begin{array}{c}2 \text { anos } \\
\text { Ambiente }\end{array}$}} & \multicolumn{3}{|c|}{1 ano } \\
\hline & & & & & & & & & & & & \\
\hline & & & & $\begin{array}{c}\mathrm{VC} \\
\mathrm{C}\end{array}$ & $\mathrm{N}$ & $\mathrm{D}$ & $\begin{array}{c}\mathrm{VC} \\
\mathrm{C}\end{array}$ & $\mathrm{N}$ & $\mathrm{D}$ & $\begin{array}{c}\mathrm{VC} \\
\mathrm{C}\end{array}$ & $\mathrm{N}$ & $\mathrm{D}$ \\
\hline A & & $\begin{array}{l}\text { Fluxo direto e } \\
\text { indireto }\end{array}$ & $\begin{array}{l}\text { Luminárias } \\
\text { abertas }\end{array}$ & $X$ & & & & $X$ & & & & $x$ \\
\hline $\mathrm{B}$ & $\triangleright$ & $\begin{array}{l}\text { Fluxo direto e } \\
\text { indireto }\end{array}$ & Pendentes & $X$ & & & & $\mathrm{X}$ & & & & $\mathrm{X}$ \\
\hline C & & Fluxo direto & $\begin{array}{l}\text { Luminárias } \\
\text { de sobrepor } \\
\text { fechadas. } \\
\text { Luminárias } \\
\text { de embutir } \\
\text { com aletas }\end{array}$ & $X$ & & & $(\mathrm{X})$ & & & & $\mathrm{X}$ & \\
\hline D & ro & Fluxo direto & $\begin{array}{l}\text { Luminárias } \\
\text { fechadas } \\
\text { IP2X }\end{array}$ & $X$ & & & $(\mathrm{X})$ & & & & $\mathrm{X}$ & \\
\hline$E$ & & Fluxo direto & $\begin{array}{l}\text { Luminárias } \\
\text { vedadas a } \\
\text { prova de } \\
\text { poeira IP5X }\end{array}$ & $X$ & $X$ & & & & $X$ & & & \\
\hline $\mathrm{F}$ & & Fluxo indireto & $\begin{array}{l}\text { Luminárias de } \\
\text { fluxo indireto }\end{array}$ & & & & $X$ & & & $(\mathrm{X})$ & $X$ & \\
\hline G & reforar & Fluxo direto & $\begin{array}{l}\text { Luminárias } \\
\text { com abertura } \\
\text { para ar de } \\
\text { retorno (A.C.) }\end{array}$ & $X$ & $X$ & & & & $X$ & & & \\
\hline
\end{tabular}


Analisando a Tabela 3, os sistemas de iluminação utilizados no experimento são do tipo $C$ (modelos tipo 1, 2 e 3 ) e do tipo $D$ (modelos tipo 4, 5 e 6). Ambos os modelos podem ser limpos a cada três anos.

Outro fator importante que deve ser considerado é o tempo que os sistemas de iluminação ficam acesos durante um ano. Em geral, escritórios e escolas funcionam de $8 \mathrm{~h}$ a $12 \mathrm{~h}$ por dia. No entanto, a premissa que será adotada é de que os sistemas de iluminação permanecem acesos $24 \mathrm{~h}$ por dia, sem interrupção, conforme experimento que está sendo realizado. De acordo com a Tabela 4 a seguir, os sistemas de iluminação ficarão acesos durante 8.760 horas por ano. No total, serão aproximadamente 17.000 horas de operação.

Tabela 3: Tabela de operação anual típica em horas.

\begin{tabular}{|c|c|c|c|c|}
\hline \multirow{2}{*}{\begin{tabular}{r|} 
Atividade \\
Incluso turnos \\
\end{tabular}} & \multicolumn{2}{|c|}{ Período de ocupação } & \multirow{2}{*}{$\begin{array}{c}\text { Controle de luz do } \\
\text { dia }\end{array}$} & \multirow{2}{*}{$\begin{array}{c}\begin{array}{c}\text { Operação em } \\
\text { horas }\end{array} \\
\text { horas/ano }\end{array}$} \\
\hline & $N^{\circ}$ de dias & horas/dia & & \\
\hline \multicolumn{5}{|l|}{ Indústria } \\
\hline Contínuo & 365 & 24 & não & 8760 \\
\hline Com controle luz dia & 365 & 24 & $\operatorname{sim}$ & 7300 \\
\hline 2 turnos & 310 & 16 & não & 4960 \\
\hline 6 dias/semana & 310 & 16 & $\operatorname{sim}$ & 3720 \\
\hline 1 turno & 310 & 10 & não & 3100 \\
\hline 6 dias/semana & 310 & 10 & $\operatorname{sim}$ & 1760 \\
\hline 1 turno & 258 & 10 & não & 2580 \\
\hline 5 dias/semana & 258 & 10 & $\operatorname{sim}$ & 1550 \\
\hline \multicolumn{5}{|l|}{ Varejo } \\
\hline $6 \mathrm{dias} / \mathrm{semana}$ & 310 & 10 & não & 3100 \\
\hline \multicolumn{5}{|l|}{ Escritórios } \\
\hline \multirow{2}{*}{5 dias/semana } & 258 & 10 & não & 2580 \\
\hline & 258 & 10 & $\operatorname{sim}$ & 1550 \\
\hline \multicolumn{5}{|l|}{ Escolas } \\
\hline \multirow{2}{*}{5 dias/semana } & 190 & 10 & não & 1900 \\
\hline & 190 & 10 & $\operatorname{sim}$ & 1140 \\
\hline \multicolumn{5}{|l|}{ Hospitais } \\
\hline \multirow{2}{*}{7 dias/semana } & 365 & 16 & não & 5840 \\
\hline & 365 & 16 & $\operatorname{sim}$ & 3504 \\
\hline
\end{tabular}

Tabela 4: Tabela de depreciação do fluxo luminoso da lâmpada (LLMF) e efeito de falha de envelhecimento da lâmpada (LSF).

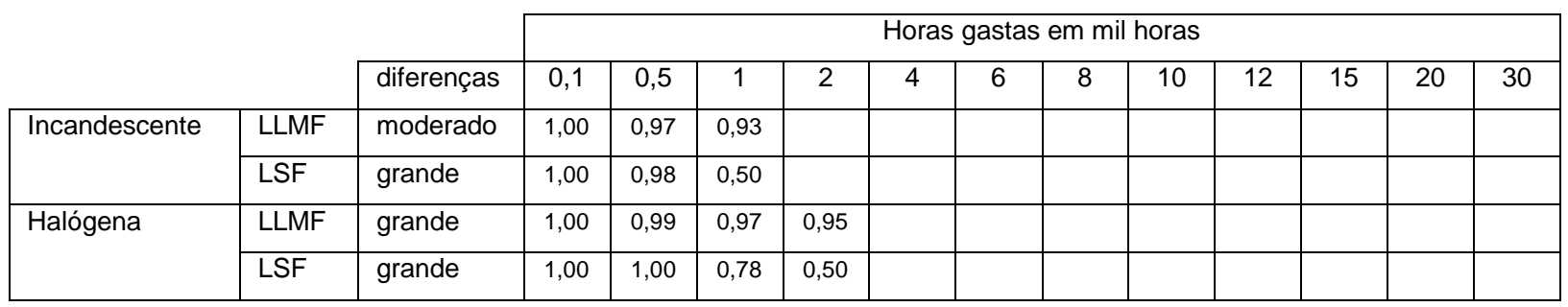




\begin{tabular}{|c|c|c|c|c|c|c|c|c|c|c|c|c|c|c|}
\hline \multirow{2}{*}{$\begin{array}{l}\text { Fluorescente } \\
\text { trifosfato }\end{array}$} & LLMF & moderado & 1,00 & 0,99 & 0,98 & 0,97 & 0,93 & 0,92 & 0,90 & 0,90 & 0,90 & 0,90 & 0,90 & \\
\hline & LSF & moderado & 1,00 & 1,00 & 1,00 & 1,00 & 1,00 & 0,99 & 0,98 & 0,98 & 0,97 & 0,94 & 0,50 & \\
\hline \multirow{2}{*}{$\begin{array}{l}\text { Fluorescente } \\
\text { trifosfato }\end{array}$} & LLMF & moderado & 1,00 & 0,99 & 0,98 & 0,97 & 0,93 & 0,92 & 0,90 & 0.90 & 0.90 & 0,90 & & \\
\hline & LSF & moderado & 1,00 & 1,00 & 1,00 & 1,00 & 1,00 & 0,99 & 0,98 & 0,98 & 0,92 & 0,50 & & \\
\hline \multirow{2}{*}{$\begin{array}{l}\text { Fluorescente } \\
\text { halofosfato }\end{array}$} & LLMF & moderado & 1,00 & 0,98 & 0,96 & 0,95 & 0,87 & 0,84 & 0,81 & 0,79 & 0,77 & 0,75 & & \\
\hline & LSF & moderado & 1,00 & 1,00 & 1,00 & 1,00 & 1,00 & 0,99 & 0,98 & 0,98 & 0,92 & 0,50 & & \\
\hline \multirow{2}{*}{$\begin{array}{l}\text { Fluorescente } \\
\text { compacta }\end{array}$} & LLMF & grande & 1,00 & 0,98 & 0,97 & 0,94 & 0,91 & 0,89 & 0,87 & 0,85 & & & & \\
\hline & LSF & grande & 1,00 & 0,99 & 0,99 & 0,98 & 0,97 & 0,94 & 0,86 & 0,50 & & & & \\
\hline \multirow{2}{*}{$\begin{array}{l}\text { Vapor de } \\
\text { mercúrio }\end{array}$} & LLMF & moderado & 1,00 & 0,99 & 0,97 & 0,93 & 0,85 & 0,82 & 0,80 & 0,79 & 0,78 & 0,77 & 0,76 & \\
\hline & LSF & moderado & 1,00 & 1,00 & 0,99 & 0,98 & 0,97 & 0,94 & 0,90 & 0,86 & 0,79 & 0,69 & 0,50 & \\
\hline \multirow{2}{*}{$\begin{array}{l}\text { Vapor metálico } \\
(250 / 400 W)\end{array}$} & LLMF & grande & 1,00 & 0,98 & 0,95 & 0,90 & 0,87 & 0,83 & 0,79 & 0,65 & 0,63 & 0,58 & 0,50 & \\
\hline & LSF & grande & 1,00 & 0,99 & 0,99 & 0,98 & 0,97 & 0,92 & 0,86 & 0,80 & 0,73 & 0,66 & 0,50 & \\
\hline \multirow{2}{*}{$\begin{array}{l}\text { Vapor metálico } \\
\text { cerâmico } \\
(250 / 400 W)\end{array}$} & LLMF & grande & 1,00 & 0,95 & 0,87 & 0,75 & 0,72 & 0,68 & 0,64 & 0,60 & 0,56 & & & \\
\hline & LSF & grande & 1,00 & 0,99 & 0,99 & 0,98 & 0,98 & 0,98 & 0,95 & 0,80 & 0,50 & & & \\
\hline \multirow{2}{*}{$\begin{array}{l}\text { Vapor de sódio } \\
(250 / 400 \mathrm{~W})\end{array}$} & LLMF & moderado & 1,00 & 1,00 & 0,98 & 0,98 & 0,98 & 0,97 & 0,97 & 0,97 & 0,97 & 0,96 & 0,94 & 0,90 \\
\hline & LSF & moderado & 1,00 & 1,00 & 1,00 & 1,00 & 0,99 & 0,99 & 0,99 & 0,99 & 0,97 & 0,95 & 0,92 & 0,50 \\
\hline \multirow[t]{2}{*}{ LED } & LLMF & grande & \multicolumn{12}{|c|}{ Dados mudam constantemente } \\
\hline & LSF & grande & \multicolumn{12}{|c|}{ Dados mudam constantemente } \\
\hline
\end{tabular}

Fonte: CIE-97

Nos sistemas de iluminação instalados, consideramos as lâmpadas fluorescente trifosfato e o LED, que foram assinalados na Tabela 5 anterior.

Para o valor do fator de manutenção da luminária, cruzamos os dados da Tabela 1 e Tabela 2.

Tabela 5: Tabela de fator de manutenção da luminária (LMF)

\begin{tabular}{|c|c|c|c|c|c|c|c|c|c|}
\hline \multirow{4}{*}{$\begin{array}{l}\text { '. } \\
\text { ल) }\end{array}$} & \multirow{8}{*}{$\begin{array}{l}\stackrel{\Phi}{\frac{D}{d}} \\
\frac{.0}{0} \\
\frac{\varepsilon}{<}\end{array}$} & 口 & $\frac{\Re}{\stackrel{n}{0}}$ & $\begin{array}{l}\infty \\
0 \\
0 \\
0\end{array}$ & $\begin{array}{l}\text { N } \\
\text { مֵ }\end{array}$ & $\begin{array}{l}0 \\
\dddot{0} \\
0\end{array}$ & $\begin{array}{l}\text { R } \\
\text { í }\end{array}$ & 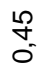 & $\begin{array}{l}\stackrel{1}{\infty} \\
\infty \\
0\end{array}$ \\
\hline & & $z$ & $\begin{array}{l}\text { R } \\
0^{\circ}\end{array}$ & $\begin{array}{l}\text { N } \\
0\end{array}$ & $\overline{0}_{0}^{0}$ & $\frac{\mathscr{N}}{\hat{0}}$ & $\begin{array}{l}+ \\
\infty \\
0\end{array}$ & $\begin{array}{l}\text { L } \\
\text { L } \\
0\end{array}$ & ০০ \\
\hline & & 0 & $\begin{array}{l}\infty \\
\infty \\
0\end{array}$ & $\begin{array}{l}R \\
0^{\circ}\end{array}$ & $\begin{array}{c}\mathbb{N} \\
0^{-}\end{array}$ & $\begin{array}{l}\frac{R}{R} \\
0\end{array}$ & $\begin{array}{l}\text { 8 } \\
0\end{array}$ & $\begin{array}{l}R \\
0 \\
0\end{array}$ & $\begin{array}{l}\stackrel{2}{\circ} \\
\text { ه }\end{array}$ \\
\hline & & $\stackrel{\cup}{>}$ & $\begin{array}{l}\text { ๙ూ } \\
\text { ó }\end{array}$ & $\begin{array}{l}\text { D } \\
0 \\
0\end{array}$ & $\begin{array}{l}\hat{\infty} \\
0 \\
0\end{array}$ & $\begin{array}{l}\text { @ } \\
0 \\
0\end{array}$ & $\begin{array}{l}\widetilde{N} \\
\delta \\
\sigma\end{array}$ & $\begin{array}{l}\infty \\
\infty \\
0 \\
0\end{array}$ & $\begin{array}{l}\text { o } \\
\text { o. } \\
\end{array}$ \\
\hline \multirow{4}{*}{$\stackrel{\sim}{\sim}$} & & 口 & 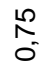 & $\begin{array}{l}\bar{N} \\
0\end{array}$ & 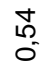 & $\begin{array}{l}\infty \\
0 \\
0 \\
0\end{array}$ & $\begin{array}{l}0 \\
\infty \\
0\end{array}$ & $\begin{array}{l}\bar{n} \\
0 \\
0\end{array}$ & $\begin{array}{l}\mathscr{Q} \\
\infty \\
0^{-}\end{array}$ \\
\hline & & $z$ & $\begin{array}{l}\text { N } \\
\infty \\
0\end{array}$ & $\begin{array}{l}0 \\
0^{\circ}\end{array}$ & $\begin{array}{l}\text { ¿े } \\
0 \\
0\end{array}$ & $\begin{array}{l}\frac{10}{N} \\
0^{\circ}\end{array}$ & $\begin{array}{l}\text { L } \\
\infty \\
0\end{array}$ & \begin{tabular}{l}
8 \\
\hdashline \\
0
\end{tabular} & $\begin{array}{l}\bar{\sigma} \\
\text { б. }\end{array}$ \\
\hline & & 0 & $\begin{array}{l}\hat{\infty} \\
0^{\circ}\end{array}$ & $\begin{array}{l}\widetilde{N} \\
0 \\
0\end{array}$ & $\begin{array}{l}\hat{N} \\
0^{\circ}\end{array}$ & ${ }_{\infty}^{\infty}$ & $\begin{array}{l}\text { ৪ } \\
\text { - }\end{array}$ & 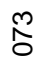 & 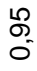 \\
\hline & & $\stackrel{\cup}{>}$ & $\begin{array}{l}\text { M } \\
\text { ó }\end{array}$ & $\begin{array}{l}\bar{\sigma} \\
\sigma\end{array}$ & $\begin{array}{l}\text { D } \\
\infty \\
0\end{array}$ & $\begin{array}{l}\text { ᄋ } \\
\text { Ó }\end{array}$ & $\begin{array}{l}\text { N } \\
\text { ó }\end{array}$ & $\begin{array}{l}0 \\
\infty \\
0\end{array}$ & $\begin{array}{l}\infty \\
\text { o } \\
\text { o. }\end{array}$ \\
\hline
\end{tabular}




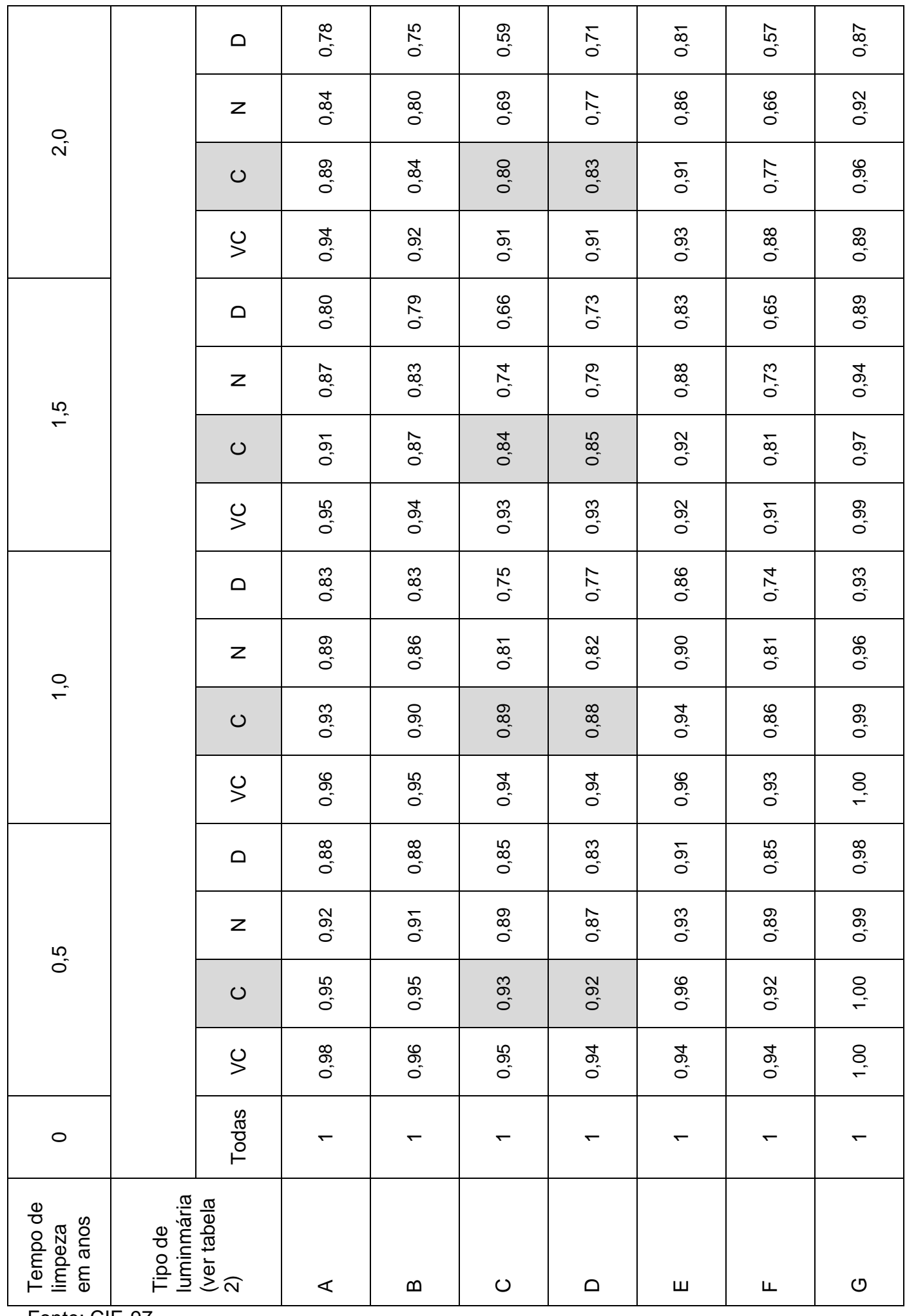

Fonte: CIE-97

Como podemos observar na Tabela 5, o valor máximo de depreciação da luminária seria de 0,74 e 0,79 para os sistemas de iluminação do experimento. No entanto, como o experimento durou aproximadamente 2 anos, utilizamos os valores correspondentes a cada tempo para determinar a depreciação total. 
Por fim, é necessário encontrar o valor da depreciação do ambiente. $O$ acúmulo de sujeira nas superfícies do ambiente reduz a capacidade de reflexão de luz no plano de trabalho com o passar do tempo.

Tabela 6: Tabela de fator de depreciação do ambiente (RSMF) para luminárias com distribuição direta da luz.

\begin{tabular}{|c|c|c|c|c|c|c|c|c|c|c|c|c|c|c|}
\hline \multirow{2}{*}{$\begin{array}{c}\text { Refletância } \\
\text { Teto/parede/piso }\end{array}$} & \multirow{2}{*}{$\begin{array}{c}\text { Tempo/anos } \\
\text { ambiente }\end{array}$} & 0,0 & 0,5 & 1,0 & 1,5 & 2,0 & 2,5 & 3,0 & 3,5 & 4,0 & 4,5 & 5,0 & 5,5 & 6,0 \\
\hline & & \multicolumn{13}{|c|}{ Fator de manutenção da superfície - plano de utilização } \\
\hline \multirow{4}{*}{$0,80 / 0,70 / 0,20$} & Muito limpo & 1,00 & 0,97 & 0,96 & 0,95 & 0,95 & 0,95 & 095 & 0,95 & 0,95 & 0,95 & 0,95 & 0,95 & 0,95 \\
\hline & Limpo & 1,00 & 0,93 & 0,92 & 0,91 & 0,91 & 0,91 & 0,91 & 0,91 & 0,91 & 0,91 & 0,91 & 0,91 & 0,91 \\
\hline & Normal & 1,00 & 0,88 & 0,86 & 0,86 & 0,85 & 0,85 & 0,85 & 0,85 & 0,85 & 0,85 & 0,85 & 0,85 & 0,85 \\
\hline & Sujo & 1,00 & 0,81 & 0,80 & 0,80 & 0,80 & 0,80 & 0,80 & 0,80 & 0,80 & 0,80 & 0,80 & 0,80 & 0,80 \\
\hline \multirow{4}{*}{$0,80 / 0,50 / 0,20$} & Muito limpo & 1,00 & 0,98 & 0,97 & 0,97 & 0,97 & 0,97 & 0,97 & 0,97 & 0,97 & 0,97 & 0,97 & 0,97 & 0,97 \\
\hline & Limpo & 1,00 & 0,95 & 0,94 & 0,94 & 0,94 & 0,94 & 0,94 & 0,94 & 0,94 & 0,94 & 0,94 & 0,94 & 0,94 \\
\hline & Normal & 1,00 & 0,91 & 0,90 & 0,90 & 0,90 & 0,90 & 0,90 & 0,90 & 0,90 & 0,90 & 0,90 & 0,90 & 0,90 \\
\hline & Sujo & 1,00 & 0,86 & 0,85 & 0,85 & 0,85 & 0,85 & 0,85 & 0,85 & 0,85 & 0,85 & 0,85 & 0,85 & 0,85 \\
\hline \multirow{4}{*}{ 0,80/0,30/0,20 } & Muito limpo & 1,00 & 0,99 & 0,98 & 0,98 & 0,98 & 0,98 & 0,98 & 0,98 & 0,98 & 0,98 & 0,98 & 0,98 & 0,98 \\
\hline & Limpo & 1,00 & 0,97 & 0,96 & 0,96 & 0,96 & 0,96 & 0,96 & 0,96 & 0,96 & 0,96 & 0,96 & 0,96 & 0,96 \\
\hline & Normal & 1,00 & 0,94 & 0,93 & 0,93 & 0,93 & 0,93 & 0,93 & 0,93 & 0,93 & 0,93 & 0,93 & 0,93 & 0,93 \\
\hline & Sujo & 1,00 & 0,91 & 0,90 & 0,90 & 0,90 & 0,90 & 0,90 & 0,90 & 0,90 & 0,90 & 0,90 & 0,90 & 0,90 \\
\hline \multirow{4}{*}{ 0,70/0,70/02,0 } & Muito limpo & 1,00 & 0,97 & 0,96 & 0,96 & 0,96 & 0,96 & 0,96 & 0,96 & 0,96 & 0,96 & 0,96 & 0,96 & 0,96 \\
\hline & Limpo & 1,00 & 0,94 & 0,92 & 0,92 & 0,92 & 0,92 & 0,92 & 0,92 & 0,92 & 0,92 & 0,92 & 0,92 & 0,92 \\
\hline & Normal & 1,00 & 0,89 & 0,87 & 0,87 & 0,87 & 0,87 & 0,87 & 0,87 & 0,87 & 0,87 & 0,87 & 0,87 & 0,87 \\
\hline & Sujo & 1,00 & 0,83 & 0,81 & 0,81 & 0,81 & 0,81 & 0,81 & 0,81 & 0,81 & 0,81 & 0,81 & 0,81 & 0,81 \\
\hline \multirow{4}{*}{$0,70 / 0,50 / 0,20$} & Muito limpo & 1,00 & 0,98 & 0,97 & 0,97 & 0,97 & 0,97 & 0,97 & 0,97 & 0,97 & 0,97 & 0,97 & 0,97 & 0,97 \\
\hline & Limpo & 1,00 & 0,96 & 0,95 & 0,94 & 0,94 & 0,94 & 0,94 & 0,94 & 0,94 & 0,94 & 0,94 & 0,94 & 0,94 \\
\hline & Normal & 1,00 & 0,92 & 0,91 & 0,90 & 0,90 & 0,90 & 0,90 & 0,90 & 0,90 & 0,90 & 0,90 & 0,90 & 0,90 \\
\hline & Sujo & 1,00 & 0,87 & 0,86 & 0,86 & 0,86 & 0,86 & 0,86 & 0,86 & 0,86 & 0,86 & 0,86 & 0,86 & 0,86 \\
\hline \multirow{4}{*}{ 0,70/0,30/0,20 } & Muito limpo & 1,00 & 0,99 & 0,98 & 0,98 & 0,98 & 0,98 & 0,98 & 0,98 & 0,98 & 0,98 & 0,98 & 0,98 & 0,98 \\
\hline & Limpo & 1,00 & 0,97 & 0,96 & 0,96 & 0,96 & 0,96 & 0,96 & 0,96 & 0,96 & 0,96 & 0,96 & 0,96 & 0,96 \\
\hline & Normal & 1,00 & 0,95 & 0,94 & 0,94 & 0,94 & 0,93 & 0,93 & 0,93 & 0,93 & 0,93 & 0,93 & 0,93 & 0,93 \\
\hline & Sujo & 1,00 & 0,92 & 0,91 & 0,91 & 0,91 & 0,91 & 0,91 & 0,91 & 0,91 & 0,91 & 0,91 & 0,91 & 0,91 \\
\hline \multirow{4}{*}{ 0,50/0,70/0,20 } & Muito limpo & 1,00 & 0,98 & 0,97 & 0,97 & 0,96 & 0,96 & 0,96 & 0,96 & 0,96 & 0,96 & 0,96 & 0,96 & 0,96 \\
\hline & Limpo & 1,00 & 0,95 & 0,94 & 0,93 & 0,93 & 0,93 & 0,93 & 0,93 & 0,93 & 0,93 & 0,93 & 0,93 & 0,93 \\
\hline & Normal & 1,00 & 0,91 & 0,89 & 0,89 & 0,89 & 0,89 & 0,89 & 0,89 & 0,89 & 0,89 & 0,89 & 0,89 & 0,89 \\
\hline & Sujo & 1,00 & 0,85 & 0,84 & 0,84 & 0,84 & 0,84 & 0,84 & 0,84 & 0,84 & 0,84 & 0,84 & 0,84 & 0,84 \\
\hline \multirow{4}{*}{$0,50 / 0,50 / 0,20$} & Muito limpo & 1,00 & 0,98 & 0,98 & 0,98 & 0,98 & 0,97 & 0,97 & 0,97 & 0,97 & 0,97 & 0,97 & 0,97 & 0,97 \\
\hline & Limpo & 1,00 & 0,97 & 0,96 & 0,95 & 0,95 & 0,95 & 0,95 & 0,95 & 0,95 & 0,95 & 0,95 & 0,95 & 0,95 \\
\hline & Normal & 1,00 & 0,94 & 0,92 & 0,92 & 0,92 & 0,92 & 0,92 & 0,92 & 0,92 & 0,92 & 0,92 & 0,92 & 0,92 \\
\hline & Sujo & 1,00 & 0,89 & 0,89 & 0,88 & 0,88 & 0,88 & 0,88 & 0,88 & 0,88 & 0,88 & 0,88 & 0,88 & 0,88 \\
\hline \multirow{4}{*}{ 0,50/0,30/0,20 } & Muito limpo & 1,00 & 0,99 & 0,99 & 0,98 & 0,98 & 0,98 & 0,98 & 0,98 & 0,98 & 0,98 & 0,98 & 0,98 & 0,98 \\
\hline & Limpo & 1,00 & 0,98 & 0,97 & 0,97 & 0,97 & 0,97 & 0,97 & 0,97 & 0,97 & 0,97 & 0,97 & 0,97 & 0,97 \\
\hline & Normal & 1,00 & 0,96 & 0,95 & 0,95 & 0,95 & 0,95 & 0,95 & 0,95 & 0,95 & 0,95 & 0,95 & 0,95 & 0,95 \\
\hline & Sujo & 1,00 & 0,93 & 0,92 & 0,92 & 0,92 & 0,92 & 0,92 & 0,92 & 0,92 & 0,92 & 0,92 & 0,92 & 0,92 \\
\hline
\end{tabular}

Fonte: CIE-97

Os valores encontrados nas tabelas anteriores serão utilizados para encontrar o fator de manutenção dos sistemas de iluminação no Capítulo 7. 


\subsection{Montagem da célula teste}

A célula teste utilizada para este experimento foi uma das salas do laboratório do departamento de tecnologia, localizado na própria Faculdade de Arquitetura e Urbanismo da Universidade de São Paulo, piso dos laboratórios.

A sala tem 2,95m x 3,94m, com pé-direito de 2,92m e altura de instalação das luminárias a 2,82m no perfilado existente, e a configuração de layout conforme Figura 11 a seguir.

Figura 11: Layout da sala teste

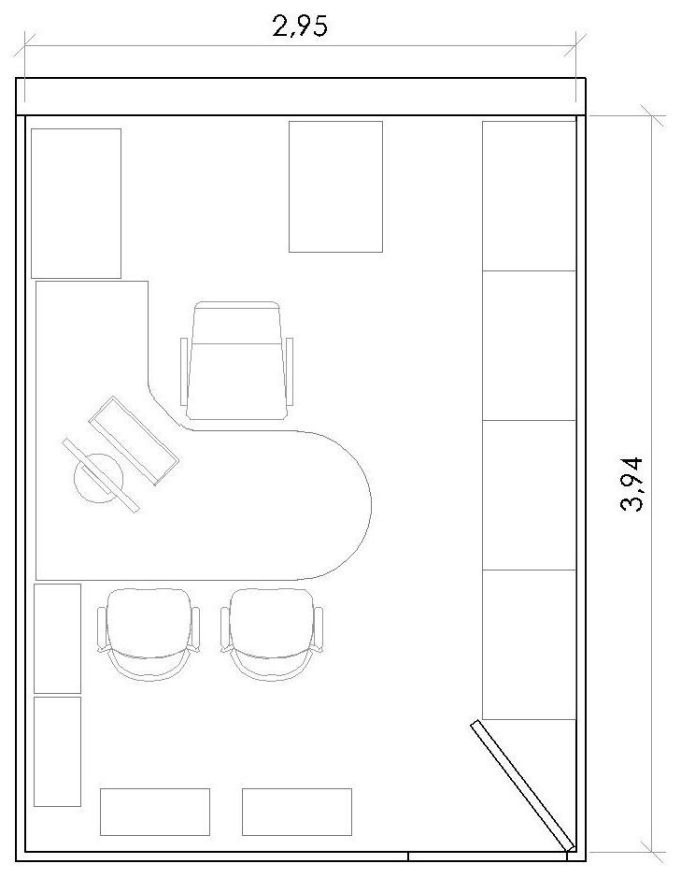

O acabamento da sala é: piso cor de caramelo, paredes de cor creme claro e teto em concreto. As estantes na sala contêm livros ou são armários fechados, conforme pode ser visto nas Figuras 12 e 13. 
Figura 12: Vista da sala da porta para janela

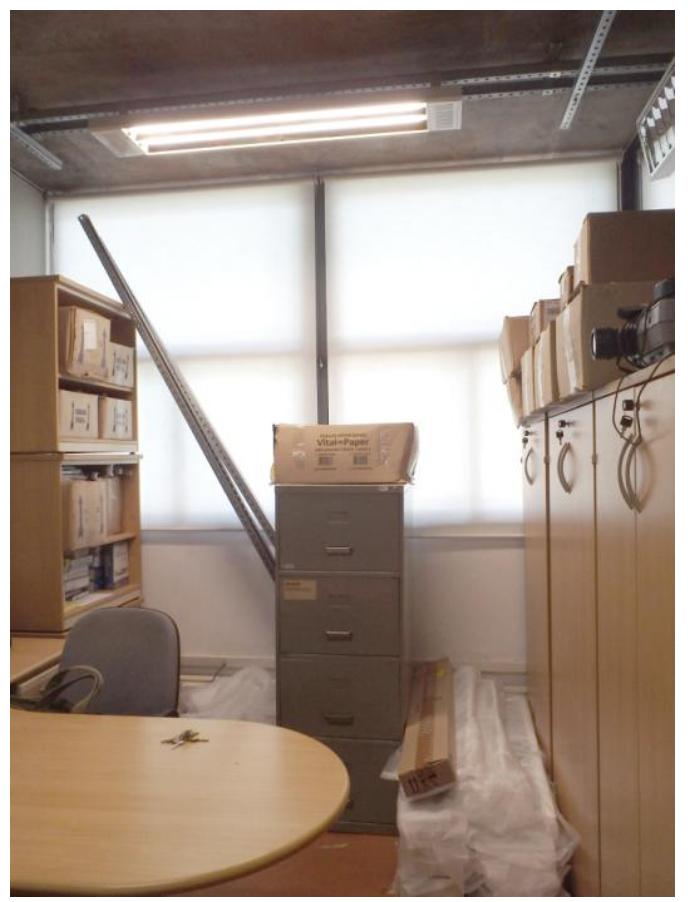

Figura 13: Vista da sala da janela para porta

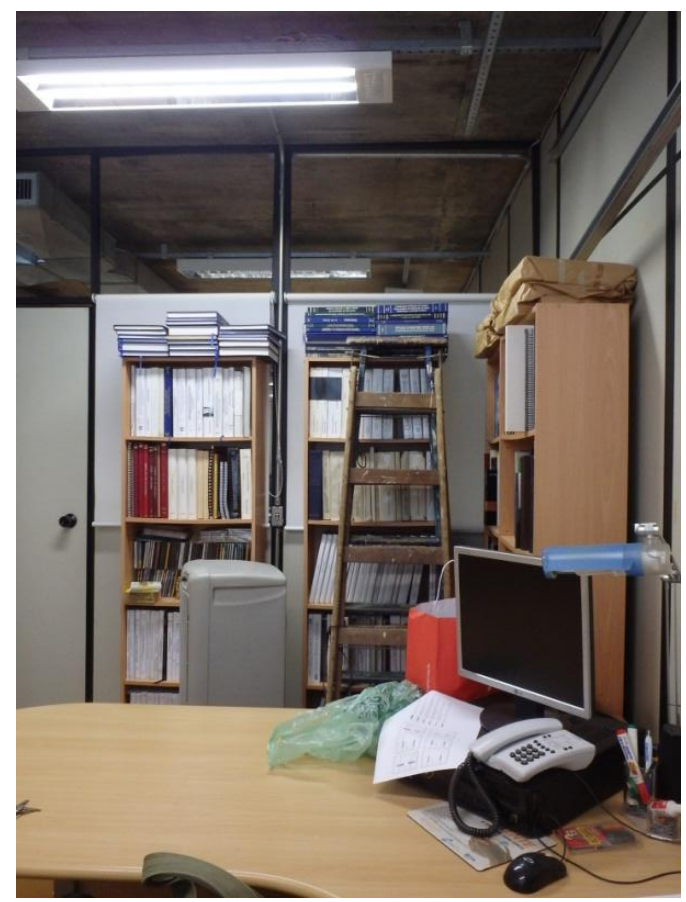

Como o fabricante disponibilizou apenas duas luminárias de cada modelo, os pontos onde as luminárias serão instaladas para medição serão os mesmos onde já estavam seus pontos de ligação. Os sistemas de iluminação serão instalados conforme Figura 14 a seguir.

Figura 14: Sala teste com posição de medição dos sistemas de iluminação

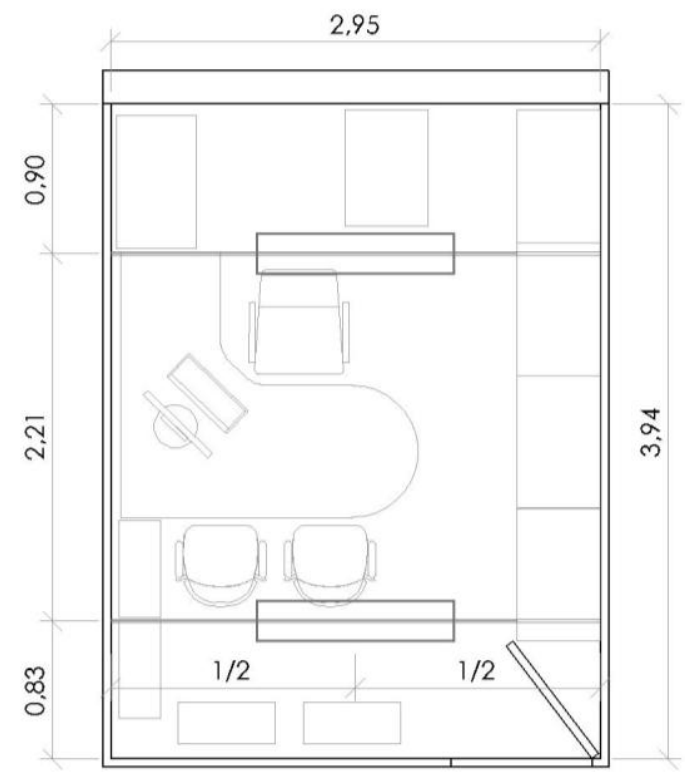


Como a célula teste faz divisão com outras salas, para não atrapalhar seus usuários, cobriu-se a abertura existente (vide Figura 13) com papel cartolina.

No início, foram fechadas apenas as aberturas que faziam divisão com uma das salas, pois visualmente os sistemas de iluminação não interferiam na outra sala. No entanto, por solicitação do usuário desta outra sala ao lado, após dois meses, fechou-se a outra divisória com papel paraná.

\subsection{Medições}

As medições foram realizadas conforme norma NBR-ISO/CIE 8995-1: lluminação de ambientes de trabalho. Parte 1: Interior, capítulo 6.

Segundo a norma, a distância entre os pontos a serem medidos é obtido com a seguinte fórmula, onde $p$ é o tamanho da malha e d é a maior dimensão do ambiente:

$$
p=0,2 \times 5^{\log _{10} d}
$$

No caso da célula teste, a maior dimensão é de 3,94m.

Substituindo os valores, encontramos que o tamanho da malha é de 0,52. Para facilitar as medições, considerou-se a distância dos pontos da malha de 0,50m. A norma ainda considera um número mínimo de pontos da malha de medição, que é dado pela relação de d (maior dimensão do ambiente) por p (tamanho da malha), onde é encontrado o valor mínimo de sete pontos.

Outro ponto da norma presente na pesquisa foi o acréscimo de uma faixa marginal de 0,50m ao redor do ambiente, onde é desconsiderado o valor de medição e/ou simulação. Dessa maneira, para a sala teste em questão, foram considerados os seguintes pontos de medição conforme pode ser observado na figura 15 a seguir: 
Figura 15: Planta da sala teste com malha de pontos de medição.

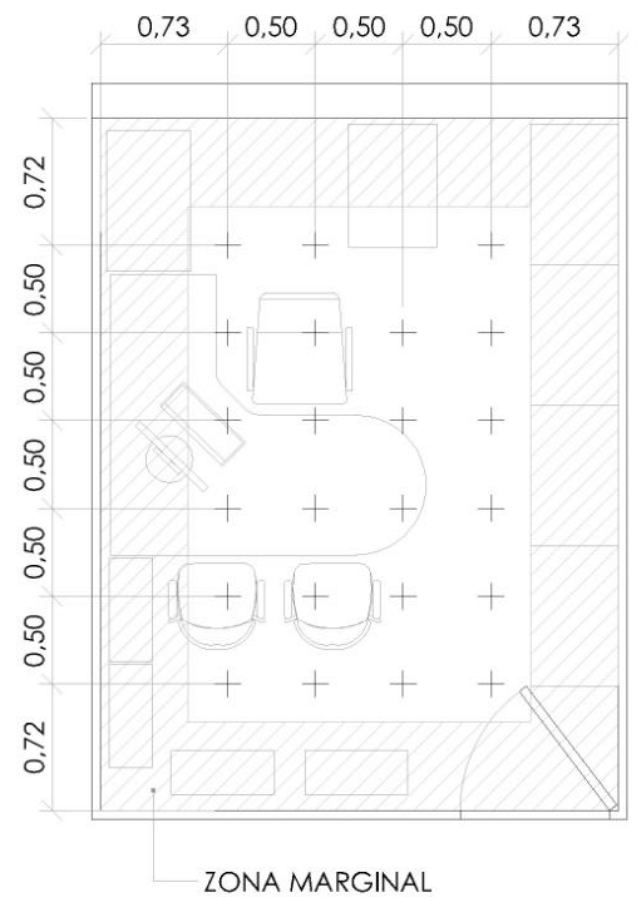

Uma base feita com cano de PVC com altura de $0,75 \mathrm{~m}$ permite que as medições realizadas sejam feitas todas na mesma altura. A mesa de trabalho também possui a mesma altura de $0,75 \mathrm{~m}$.

Figura 16: Base utilizada na célula teste para medições.

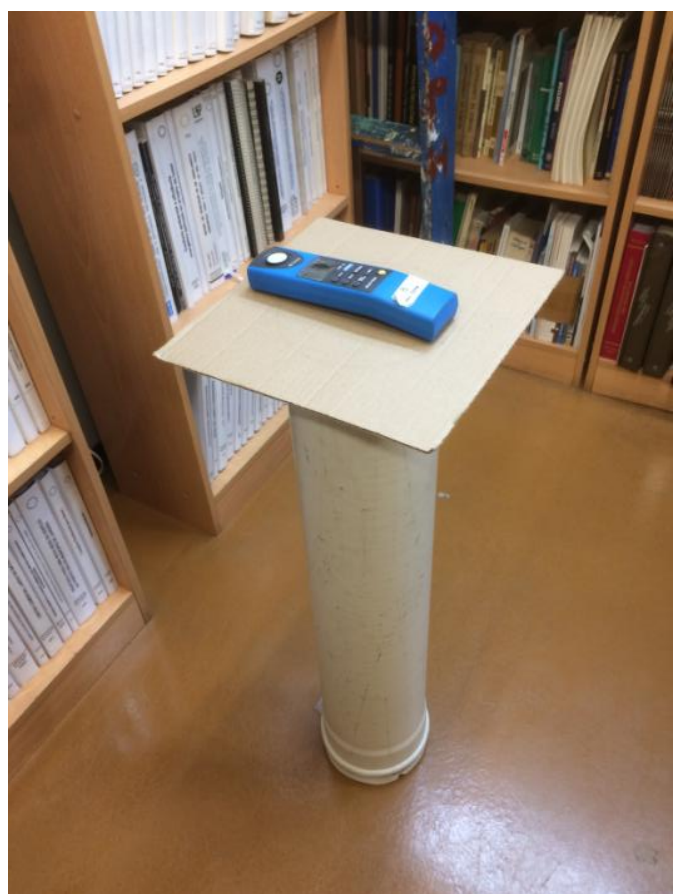


Para que as medições fossem feitas no mesmo ponto, foram feitas marcações no piso e no plano de trabalho.

Para medição do nível de iluminância foi utilizado um luxímetro do LABAUT (figura 17) da Minipa, modelo MLM-1020, e para a medição da tensão da rede foi utilizado um voltímetro.

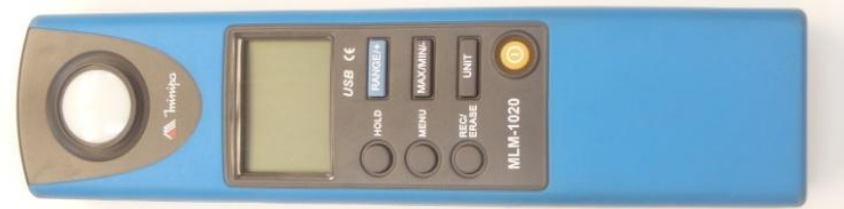

Os sistemas de iluminação permaneceram acesos durante 24 horas por dia, totalizando ao final do experimento 17.520 horas (aproximadamente 2 anos), pois desta maneira pudemos analisar a depreciação e vida útil real dos sistemas de iluminação do experimento.

Foram feitas medições dos seis sistemas de iluminação logo após instalação, um mês depois de serem instalados, e a cada três meses, totalizando dois anos. Os resultados das medições serão detalhados no Capítulo 3.

Como só havia uma célula teste, as medições ocorreram em datas distintas. A cada dia uma tipologia de sistema de iluminação foi posicionada conforme Figura 14. As demais peças foram instaladas em perfilados nas laterais da célula teste e desligadas no momento das medições.

\subsection{Ensaios em laboratório - iniciais}

Foram realizados ensaios fotométricos no laboratório do IEE com os sistemas de iluminação antes do uso no goniômetro e o fluxo luminoso foi medido a cada cinco graus. Antes de cada medição, aguardou-se a estabilização do mesmo na tensão de $127 \mathrm{~V}$. 
Os resultados dos ensaios geraram a curva fotométrica da cada um dos sistemas de iluminação empregados na pesquisa, estes que também serviram para as simulações.

\subsection{Simulações}

Segundo uma pesquisa realizada pela revista Lume Arquitetura no início de 2009, 56 profissionais em projetos de iluminação do Brasil foram questionados em relação ao uso de softwares de cálculo luminotécnico. Desses 56 profissionais, apenas três não utilizavam nenhum tipo de software, projetando à moda antiga. Os outros 53 profissionais utilizavam os softwares Relux, Dialux e Agi32, destes o Relux é o mais utilizado, seguido pelo Dialux e o Agi32.

Em uma votação do blog "Life and Light" de David Aloi, também de 2009, o resultado mostrou que o software mais utilizado é o Dialux com $41,8 \%$, em seguida o Relux Professional com 25,2\%, e por fim o Agi32 com 9,6\% dos votos.

Portanto, para realizar as simulações foram empregados os softwares mais conhecidos e utilizados por profissionais, tanto do mercado nacional quanto internacional: Dialux, Agi32 e Relux.

Foram simuladas três situações: uma considerando a sala vazia, outra mobiliado, com os móveis pertencentes em cada biblioteca fornecida pelo programa em questão. Quando não havia mobiliário na biblioteca, foi criado por meio de formas básicas como cubo, um volume para substituir o mobiliário e compor o ambiente. Por fim, foi considerado o ambiente com o mesmo mobiliário mais a cromaticidade dos mesmos e no ambiente, na tentativa de aproximar o modelo do real.

\subsubsection{Dialux}

O programa Dialux é um programa de origem alemã, desenvolvida pela empresa DIAL $\mathrm{GmbH}$ e é totalmente gratuito. Podemos encontrar duas versões desse programa de cálculo, o Dialux 4.12 e o Dialux EVO. 
A primeira versão do programa Dialux foi lançada em 2005, sendo o Dialux EVO de 2012. Como já não há mais atualizações do programa Dialux, a tendência é que o Dialux EVO o substitua. O Dialux EVO já está na versão 8.1.

Os programas calculam ambientes internos e externos, e simulam a iluminação natural, iluminação artificial ou ambas.

Está disponível em mais de 25 línguas e, segundo Souza (2011, p.39), a base de cálculo do software está de acordo com normas internacionais como a EN12464 ISO 8995, e os resultados estão validados conforme norma CIE 171:2006.

O programa possui um vasto banco de dados fotométricos, com mais de 100 fabricantes associados. Caso o fabricante do sistema de iluminação não seja associado, ou seja, não possua catálogo dentro do próprio programa, há a possibilidade de importar a fotometria nos formatos normatizados: IES, Eulumdat, CIBSE, TM14 e LTLi.

\subsubsection{AGi32}

O programa Agi32 é um programa norte-americano desenvolvido pela empresa Lighting Analysts Inc., e sua primeira versão foi lançada em 1992. É um programa de cálculo pago e seu valor atual é de 895 dólares.

Ele simula iluminação natural e/ou artificial e está disponível apenas em inglês. Um problema observado para a instalação e funcionamento do programa é que, por se tratar de um software americano, é necessário modificar as configurações do computador de região, idioma e sistema de unidades para o inglês. Sem essa alteração na configuração, o programa não funciona corretamente.

Para a escolha dos sistemas de iluminação que serão utilizados nos cálculos, não há nenhum fabricante associado, portanto os arquivos fotométricos devem ser todos importados nos formatos padronizados IES, Eulumdat e TM14.

A base de cálculo do programa segue as normas ABNT, CIE e IES.

\subsubsection{Relux}

O programa Relux é um programa suíço, desenvolvido pela empresa Relux Informatik AG. A versão ReluxSuite é gratuita, enquanto a versão ReluxPro é paga. 
Os programas calculam ambientes internos e externos, e simulam a iluminação natural e iluminação artificial.

Está disponível em 24 línguas e a base de cálculo do software está de acordo com a Comissão Internacional de lluminação (CIE).

O programa possui cerca de 70 fabricantes associados, onde é possível escolher o sistema de iluminação a ser utilizado no projeto por meio do Relux Net, que direciona o usuário às páginas da internet, permitindo inserir os sistemas de iluminação diretamente no programa, assim como o Dialux. Permite também a importação de arquivos fotométricos de fabricantes não associados, nos formatos normatizados IES e LTD.

\subsection{Comparações simulações $x$ experimentações}

A comparação dos resultados dos cálculos será realizada apenas com os sistemas de iluminação no momento da instalação, ou seja, sem considerar depreciações, tanto dos sistemas de iluminação quanto do ambiente.

Sabendo também que, por ser um programa de cálculo, baseado em matemática, a depreciação considerada influencia diretamente no resultado final. Ou seja, se o nível médio final sem depreciações é de " $y$ ", e considerando depreciação de 0,80 , o resultado do nível médio final será 0,80 sobre o mesmo valor " $y$ ".

O grid de cálculo considerado nas simulações será de $0,50 \mathrm{~m} \times 0,50 \mathrm{~m}$ de distância, com um entorno de $0,50 \mathrm{~m}$ da parede, conforme recomendações da norma NBR-ISO/CIE 8995-1 e conforme demarcação realizada na célula teste, para comparação entre simulação e experimentação.

A Tabela 7 a seguir foi utilizada para encontrar os índices de reflexão de teto, parede e piso.

Tabela 7: Coeficiente de reflexão de alguns materiais e cores.

\begin{tabular}{|l|l|}
\hline Materiais & $\%$ \\
\hline Rocha & 60 \\
\hline Tijolos & $5 \sim 25$ \\
\hline Cimento & $15 \sim 40$ \\
\hline Madeira clara & 40 \\
\hline Esmalte branco & $65 \sim 75$ \\
\hline Vidro transparente & $6 \sim 8$ \\
\hline Madeira aglomerada & $50 \sim 60$ \\
\hline Azulejos brancos & $60 \sim 75$ \\
\hline
\end{tabular}




\begin{tabular}{|l|l|}
\hline Madeira escura & $15 \sim 20$ \\
\hline Gesso & 80 \\
\hline Cores & \\
\hline Branco & $70 \sim 80$ \\
\hline Creme claro & $70 \sim 80$ \\
\hline Amarelo claro & $55 \sim 65$ \\
\hline Rosa & $45 \sim 50$ \\
\hline Verde claro & $45 \sim 50$ \\
\hline Azul celeste & $40 \sim 45$ \\
\hline Cinza claro & $40 \sim 45$ \\
\hline Bege & $25 \sim 35$ \\
\hline Amarelo escuro & $25 \sim 35$ \\
\hline Marrom claro & $25 \sim 35$ \\
\hline Verde oliva & $25 \sim 35$ \\
\hline Laranja & $20 \sim 25$ \\
\hline Vermelho & $20 \sim 35$ \\
\hline Cinza médio & $20 \sim 35$ \\
\hline Verde escuro & $10 \sim 15$ \\
\hline Azul escuro & $10 \sim 15$ \\
\hline Vermelho escuro & $10 \sim 15$ \\
\hline Cinza escuro & $10 \sim 15$ \\
\hline Azul marinho & $5 \sim 10$ \\
\hline Preto & $5 \sim 10$ \\
\hline
\end{tabular}

Fonte: Manual da Osram

Conforme tabela anterior e os acabamentos da célula teste onde foi realizada o experimento, foram considerados para teto $50 \%$ (teto escuro, concreto), paredes $50 \%$ (parede creme com presença de prateleiras e armários de madeira clara) e piso $20 \%$ (cor caramelo). Esses valores foram utilizados tanto nas simulações como para encontrar o fator de manutenção na norma CIE-97:2005.

\subsection{Ensaios em laboratório - depreciados}

Após a retirada dos sistemas de iluminação da célula teste, os mesmos foram ensaiados no goniômetro. Da mesma maneira que os ensaios iniciais, o fluxo luminoso medido foi a cada cinco graus.

Com a finalidade de comparar a depreciação das lâmpadas fluorescentes tubulares e tubo LED, cada uma foi ensaiada na esfera integradora separadas das luminárias e equipamento auxiliares. O reator utilizado para ensaiar as lâmpadas fluorescentes tubulares foi o de referência pertencente ao próprio laboratório, e para as lâmpadas tubo LED a alimentação foi direto em 127V. 


\subsection{Comparação Medições $x$ Norma}

Com os resultados da iluminância média medidos durante 2 anos, obteve-se 0 fator de manutenção real dos sistemas de iluminação instalados.

Os mesmos foram comparados com o fator de depreciação encontrados na norma CIE-97:2005.

\subsection{Verificação das hipóteses e conclusões}

Por meio da análise dos resultados das medições, comparações e ensaios em laboratório foram possíveis verificar as hipóteses e concluir aspectos importantes em relação aos sistemas de iluminação utilizados nesta pesquisa. 


\section{CAPÍTULO 3}

MEDIÇÕES NA CÉLULA TESTE 


\section{MEDIÇÕES NA CÉLULA TESTE}

\subsection{Considerações preliminares}

Este capítulo se refere somente as medições e aos seus resultados. As medições foram realizadas com o intuito de verificar a real depreciação de sistemas de iluminação.

Conforme metodologia descrita no Capítulo 2, item 2.6. e 2.7., foi montada uma célula teste e instalados seis sistemas de iluminação, que ficaram ligados $24 \mathrm{~h}$ por dia desde o dia 16 de novembro de 2016 até o dia 14 de novembro de 2018.

As medições ocorreram no momento da instalação, após cerca de 15 minutos de estabilização, e foram realizadas a cada 3 meses. Uma medição adicional ocorreu também um mês depois de as luminárias terem sido instaladas.

As medições ocorreram ao anoitecer para que não houvesse interferência da luz natural, salvo algumas exceções, onde ocorreram imprevistos como instalação do modelo errado na data prevista. Nesse caso, foram realizadas duas medições, uma considerando iluminação natural mais artificial, e outra somente com a iluminação natural. Assim, descontando uma pela outra, obtivemos os valores dos níveis da iluminação artificial.

O luxímetro utilizado tinha uma grande sensibilidade, dessa forma foi possível perceber que os valores de iluminância dos sistemas de iluminação em LED tiveram uma pequena variação de 1 a 5 lux, dependendo do ponto medido ou da tipologia do sistema de iluminação.

Os valores medidos foram apurados por um luxímetro calibrado com base em uma lâmpada incandescente, e isso significa que os valores tiveram variação em relação ao luxímetro calibrado dependendo do tipo de lâmpada medida. As lâmpadas fluorescentes tubulares T8 tiveram variação de 16\%; as lâmpadas fluorescentes tubulares T5 uma variação de $5 \%$ a $6 \%$; as lâmpadas tubo LED apresentaram maior diferença, com uma variação de $20 \%$ a $21 \%$; e as luminárias com LED aplicados, uma variação de $4 \%$ a $6 \%$.

Apesar de terem ocorrido variações em relação ao luxímetro calibrado, temos um resultado concreto, pois o aparelho utilizado durante toda a pesquisa não foi 
trocado, e a variação entre este e o luxímetro calibrado permaneceu constante. Então podemos afirmar que a depreciação medida durante os dois anos é válida.

\subsection{Medições realizadas}

A seguir, temos os valores medidos ponto a ponto no momento da instalação dos sistemas de iluminação separados por tipologia de lâmpada. Os valores apresentados foram corrigidos e estão de acordo com o luxímetro calibrado.

Figura 18: Medição do sistema de iluminação tipo 1 - lâmpada fluorescente tubular T5 28W - 0h

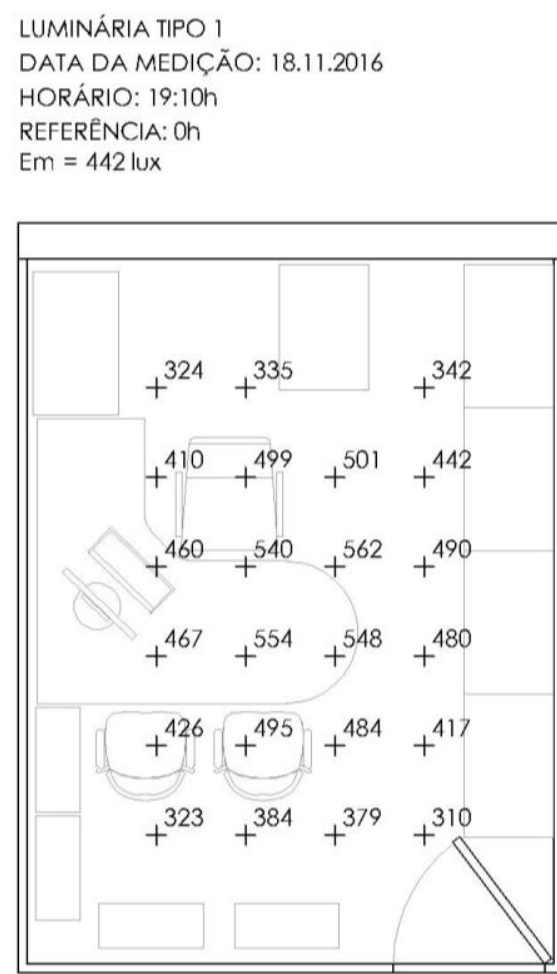


Figura 19: Medição do sistema de iluminação tipo 4 - lâmpada fluorescente tubular T5 28W - 0h

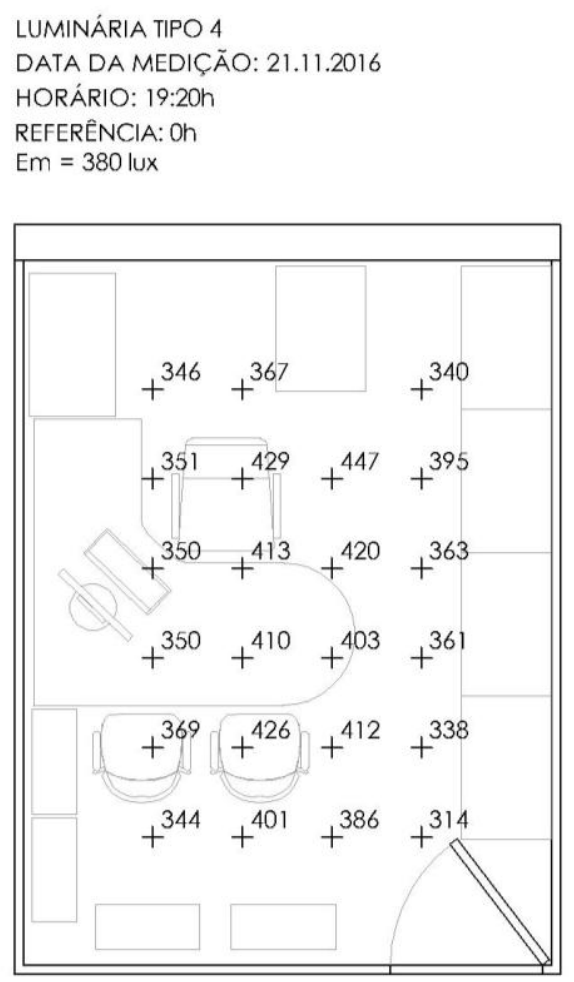

As medições apresentadas nas Figuras 18 e 19 são referentes aos sistemas de iluminação utilizando a tecnologia fluorescente tubular, mais especificamente a lâmpada fluorescente tubular T5 de 28W.

Figura 20: Medição do sistema de iluminação tipo 2 - lâmpada fluorescente tubular T8 32W - 0h
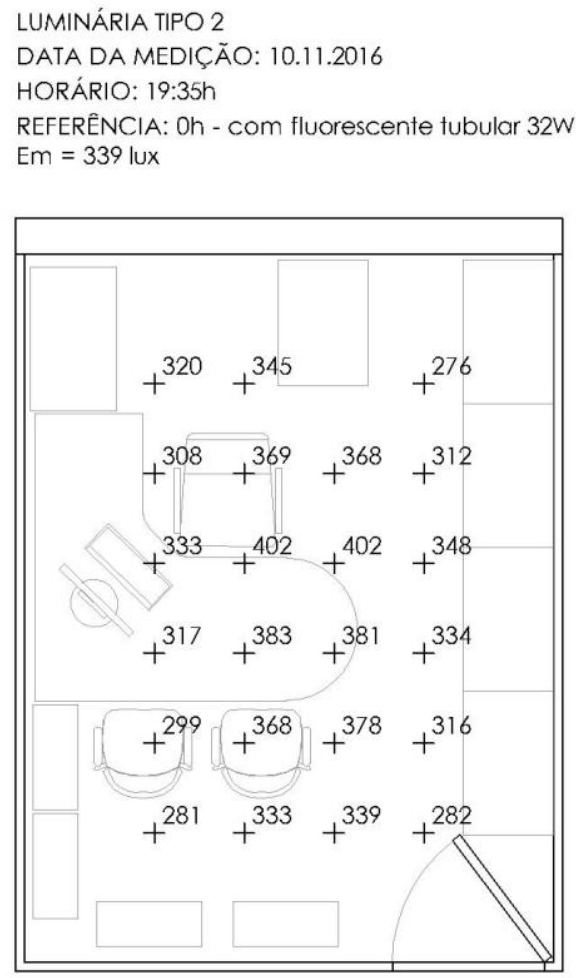
Figura 21: Medição do sistema de iluminação tipo 2 - lâmpada tubo LED 18W - 0h

LUMINÁRIA TIPO 2
DATA DA MEDIÇÃO:

ĀO: 17.11 .2016

HORÁRIO: 19:10h

REFERENCIA: Oh

$\mathrm{Em}=438 \mathrm{lux}$

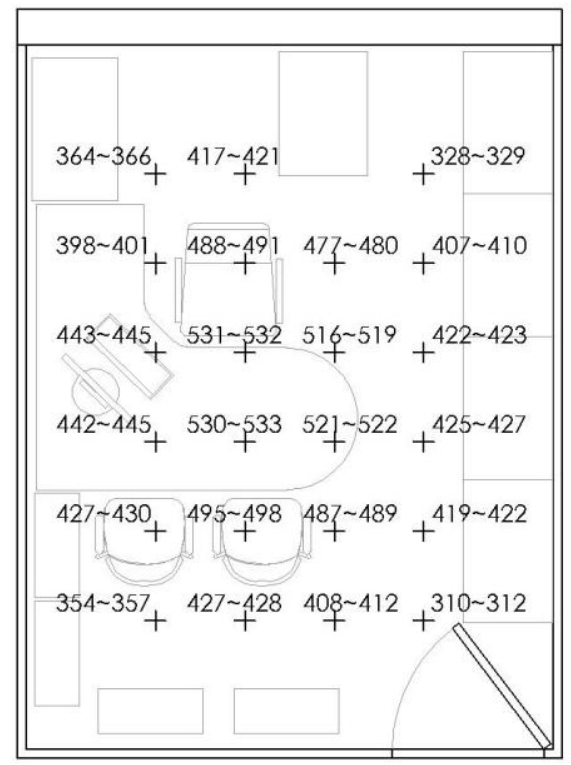

Figura 22: Medição do sistema de iluminação tipo 5 - lâmpada fluorescente tubular T8 32W - 0h

LUMINÁRIA TIPO 5

DATA DA MEDIÇÃO: 11.11 .2016

HORÁRIO: 19:21h

REFERENCIA: Oh - com fluorescente tubular $32 \mathrm{~W}$

$\mathrm{Em}=119$ lux

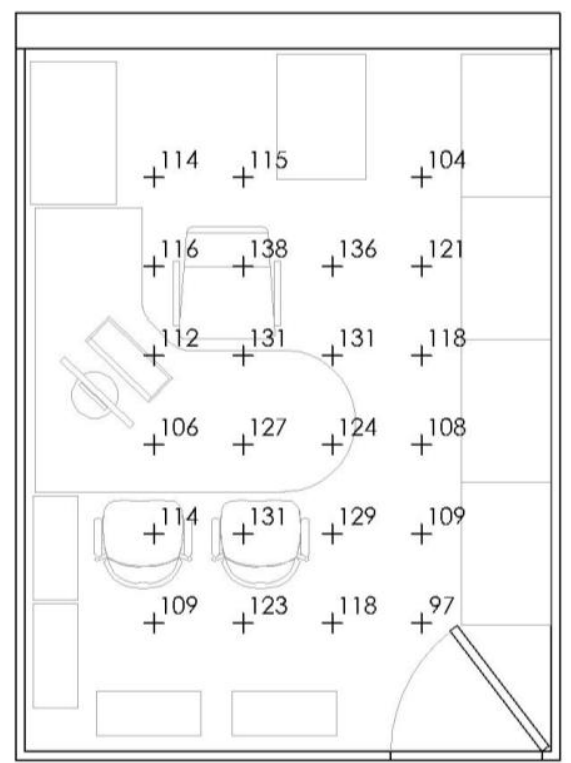


Figura 23: Medição do sistema de iluminação tipo 5 - lâmpada tubo LED 18W - 0h

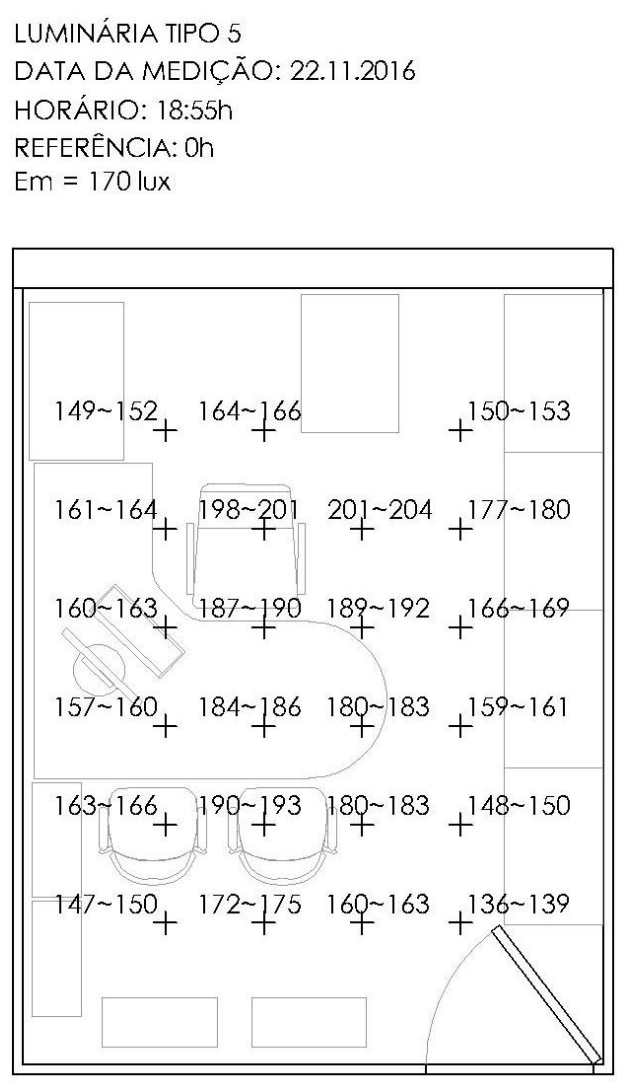

Analisando as medições realizadas com as luminárias tipo 2 e tipo 5 (Figuras 20 e 22 respectivamente) utilizando as lâmpadas fluorescente tubular T8 de 32W e as lâmpadas tubo LED 18W (Figuras 21 e 23), nota-se que o nível de iluminância ponto a ponto é maior nestas últimas.

Considerando que o fluxo luminoso de uma lâmpada tubo LED $18 \mathrm{~W}$ é de $2100 \mathrm{~lm}$ e o da fluorescente tubular T8 32W é de $2600 \mathrm{~lm}$, conclui-se que, apesar do fluxo total ser menor no caso da lâmpada tubo LED, ela apresentou níveis médios de iluminância maiores nos dois casos. Uma das causas deste fenômeno é que a luz proveniente da lâmpada tubo LED é direcionado para baixo, ou seja, para a área de tarefa, diferentemente da lâmpada fluorescente tubular onde a luz é direcionado para todos os lados $\left(360^{\circ}\right)$, havendo uma perda significativa para a área de trabalho.

Apesar do nível médio de iluminância ser maior no caso da utilização de lâmpadas tubo LED do que na utilização de lâmpadas fluorescentes tubulares T8, a simples substituição de uma pela outra deve ser analisada com cuidado, pois nem sempre haverá luz suficiente no plano de trabalho desejado. É necessário que o projetista refaça os cálculos nos casos de retrofit para evitar que o usuário seja prejudicado. 
Figura 24: Medição do sistema de iluminação tipo 3 - LED aplicado - 0h
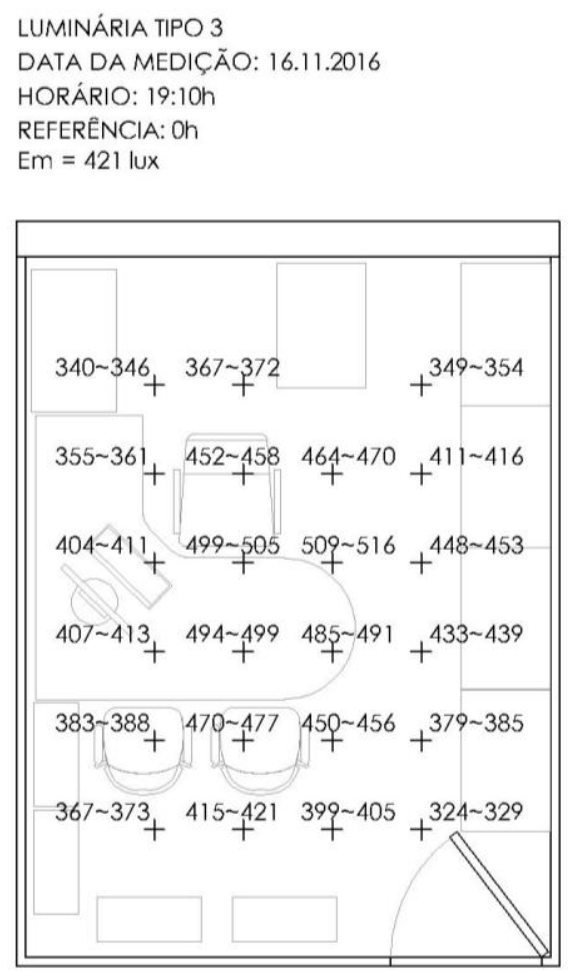

Figura 25: Medição do sistema de iluminação tipo 6 - LED aplicado - 0h

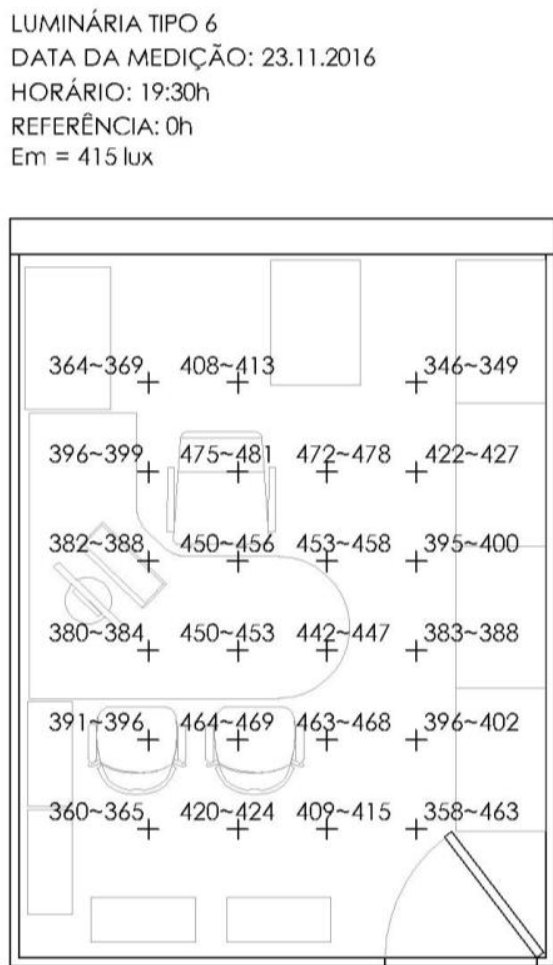

Nas figuras anteriores (Figura 24 e 25), temos o resultado das medições dos sistemas de iluminação das luminárias utilizando a tecnologia LED aplicada no próprio sistema, ou seja, o LED está integrado diretamente da luminária. 
Figura 26: Medição do sistema de iluminação tipo 1 - 1 mês

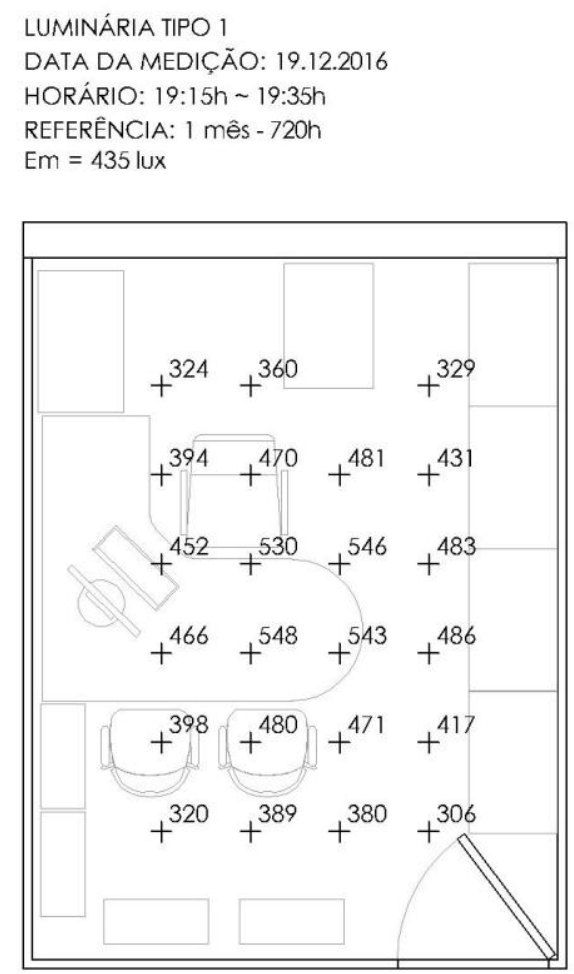

Figura 27: Medição do sistema de iluminação tipo 4 - 1 mês
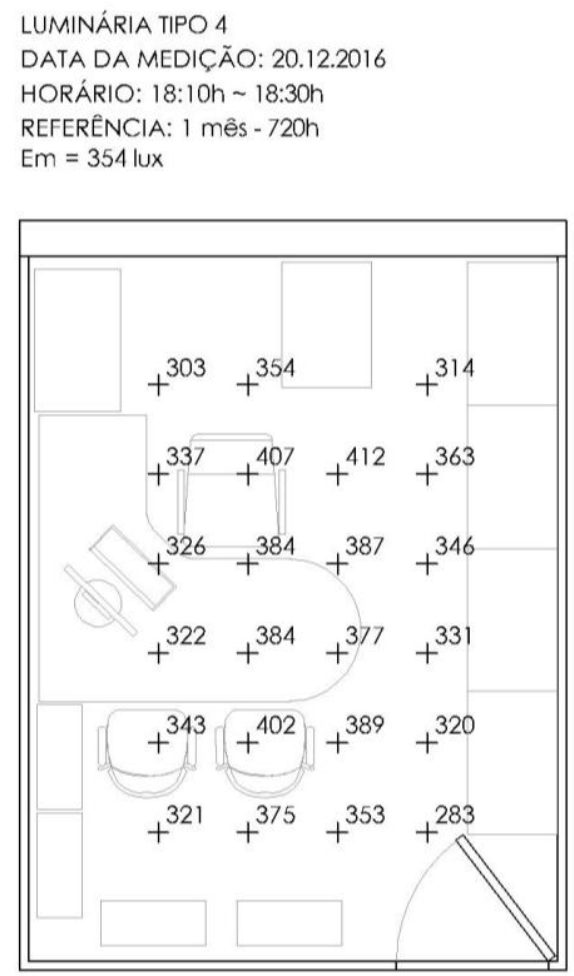

Um mês após a instalação dos sistemas de iluminação, foram realizadas medições ponto a ponto para verificar a perda do fluxo luminoso. Os sistemas permaneceram acesos $24 \mathrm{~h}$ por dia durante todo o período, totalizando 
aproximadamente $720 \mathrm{~h}$. A perda ocorrida no sistema de iluminação tipo 1 foi de $2 \%$ e a do tipo 4 foi de $7 \%$. As Figuras 26 e 27 mostram os resultados dessas medições.

Figura 28: Medição do sistema de iluminação tipo 2 - 1 mês

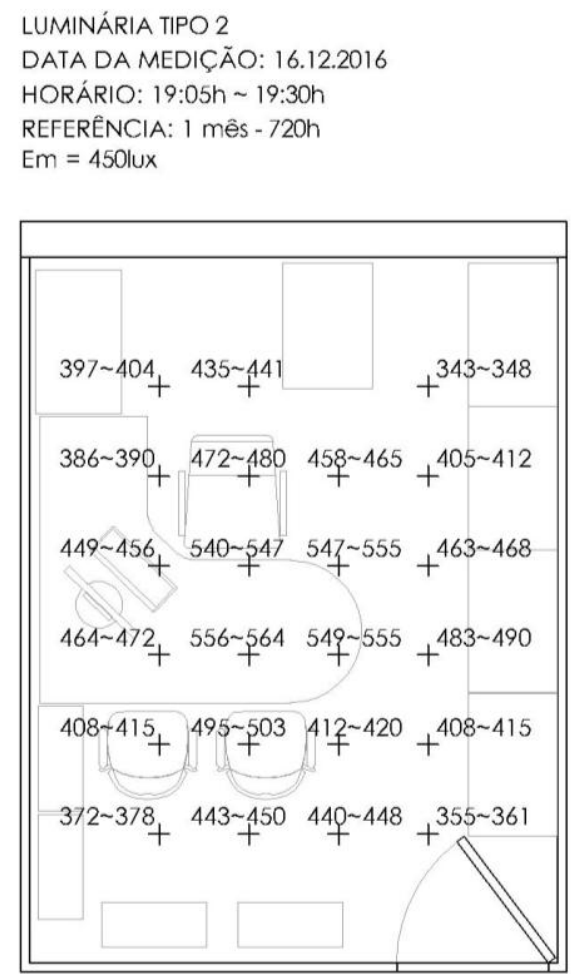

Figura 29: Medição do sistema de iluminação tipo 5 - 1 mês

LUMINÁRIA TIPO 5

DATA DA MEDIÇÃO: 21.12 .2016

HORÁRIO: 19:05h 19:30h

REFERÊNCIA: 1mês - 720h

$\mathrm{Em}=171 \mathrm{lux}$

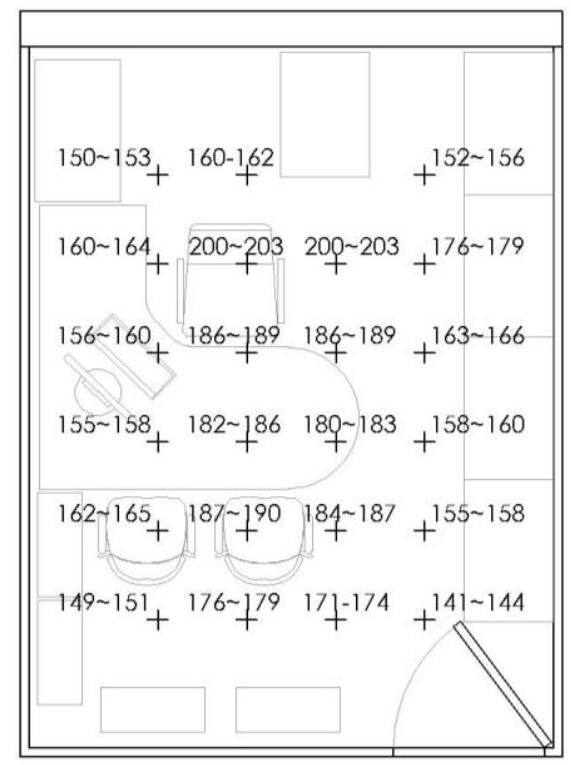


As Figuras 28 e 29 apresentam as medições realizadas no mesmo período em relação aos sistemas de iluminação com lâmpada tubo LED. Em ambos os casos houve um aumento no nível de iluminância média medida. $\mathrm{O}$ sistema tipo 2 teve aumento de $3 \%$ e o do tipo 5 de $1 \%$.

As medições em relação aos sistemas de iluminação com o LED aplicado na luminária mostram depreciação de $2 \%$ no sistema tipo 3 (Fig. 30) e manutenção do nível de iluminância no sistema tipo 6 (Fig. 31).

Figura 30: Medição do sistema de iluminação tipo 3 - 1 mês

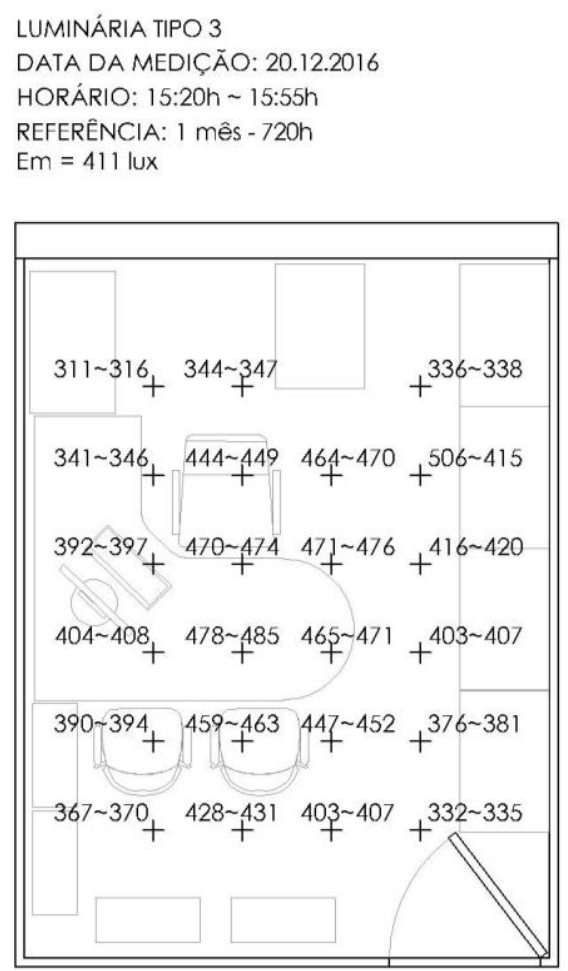


Figura 31: Medição do sistema de iluminação tipo 6 - 1 mês

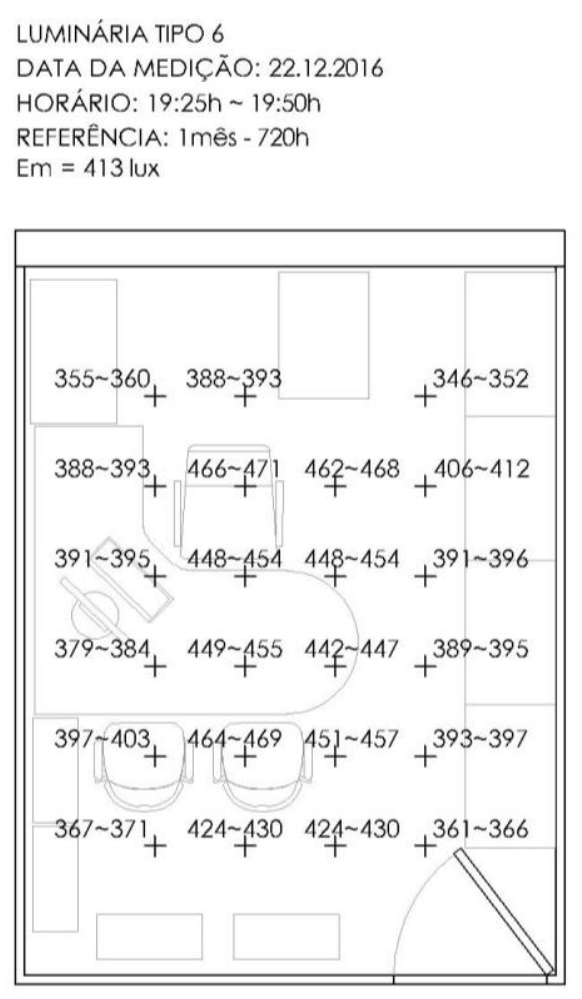

Após 3 meses permanecendo acesos, os sistemas de iluminação foram medidos novamente. Passaram-se aproximadamente $2.154 \mathrm{~h}$, já descontado o tempo em que os sistemas de iluminação ficaram apagados; ou seja, foi reduzido o tempo de medição de uma das tipologias, a troca de posição dos sistemas de iluminação pelo eletricista, e o tempo em que faltou energia no edifício.

As figuras seguintes mostram os resultados dessa medição. Observa-se que o nível de iluminação médio medido no sistema tipo 1 (Fig. 32) a depreciação foi de $8 \%$ e do tipo 4 (Fig. 33) foi de 13\%. Ambos os sistemas utilizam lâmpada fluorescente tubular T5.

No sistema tipo 2 (Fig. 34) houve um aumento de $1 \%$ no nível médio de iluminância e no sistema tipo 5 (Fig. 35) iniciou-se a depreciação do conjunto em 1\%. Ambos os sistemas utilizam lâmpada tubo LED.

Para os sistemas com o LED acoplado na própria luminária, houve no sistema tipo 3 (Fig. 36) uma depreciação de 4\% enquanto no tipo 6 (Fig. 37) o nível médio se manteve desde sua instalação. 
Figura 32: Medição do sistema de iluminação tipo 1 - 3 meses

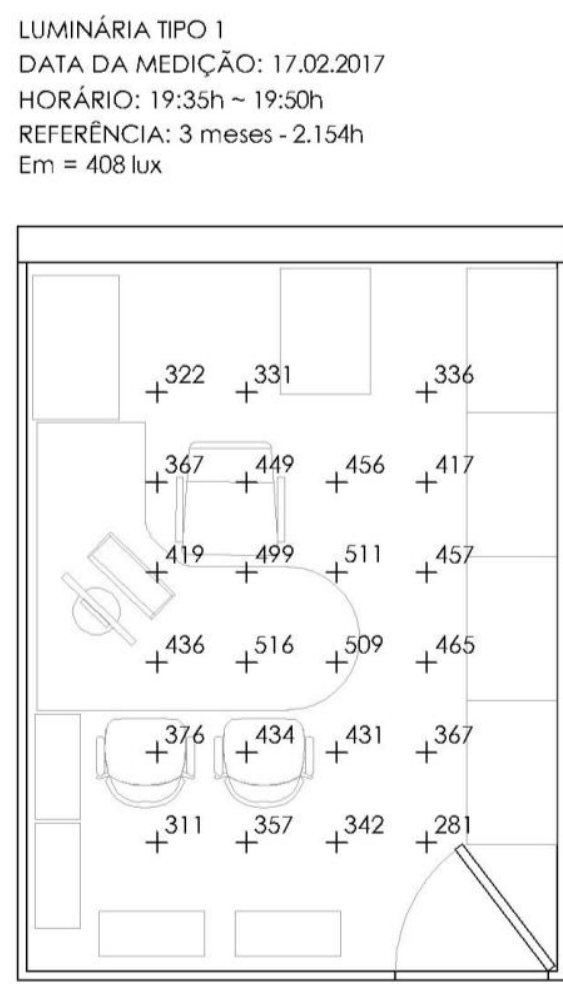

Figura 33: Medição do sistema de iluminação tipo 4 - 3 meses
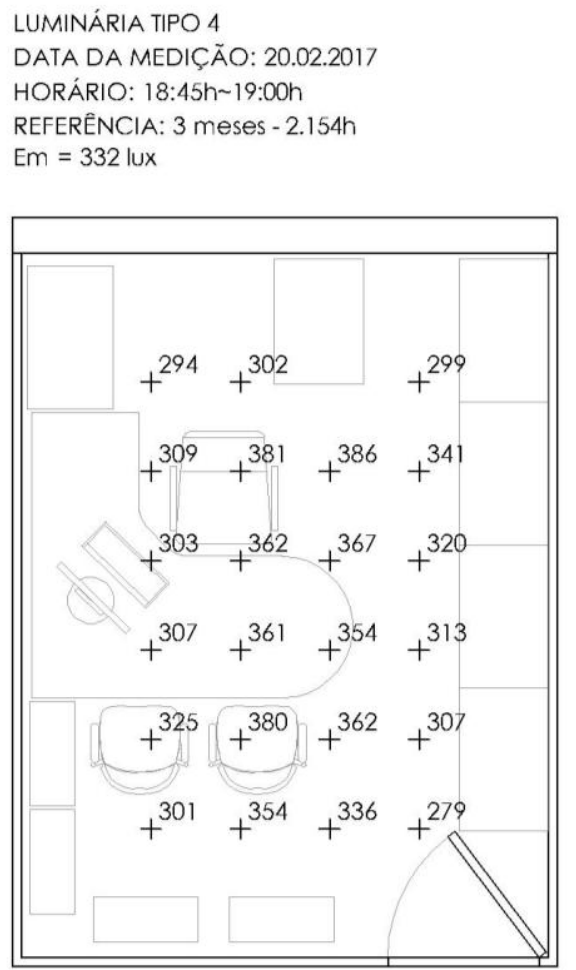
Figura 34: Medição do sistema de iluminação tipo 2 - 3 meses
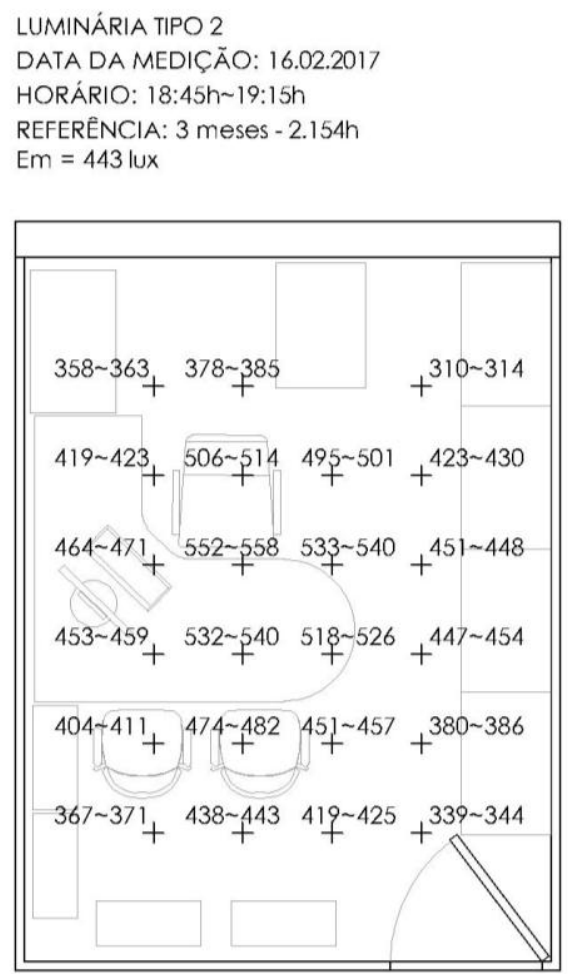

Figura 35: Medição do sistema de iluminação tipo 5 - 3 meses
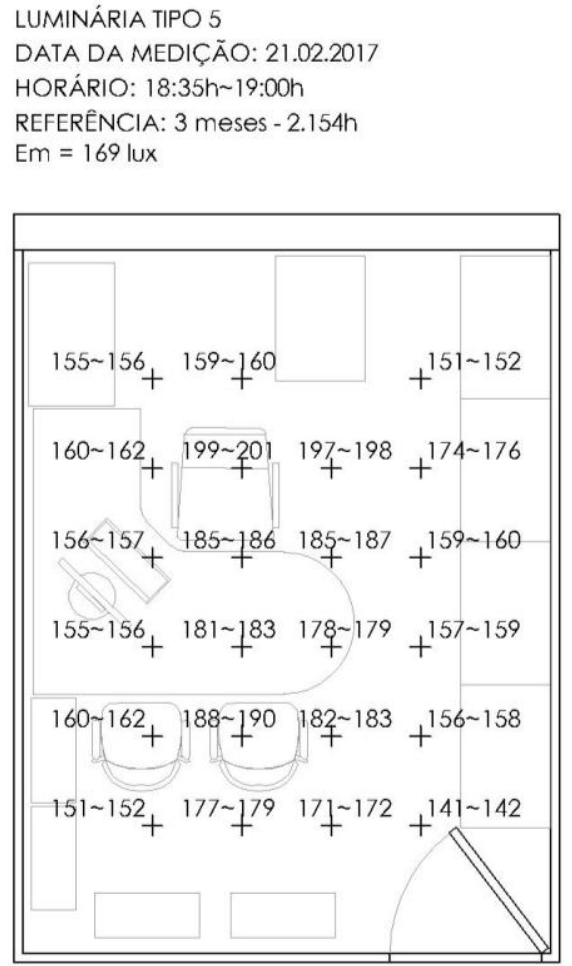
Figura 36: Medição do sistema de iluminação tipo 3 - 3 meses

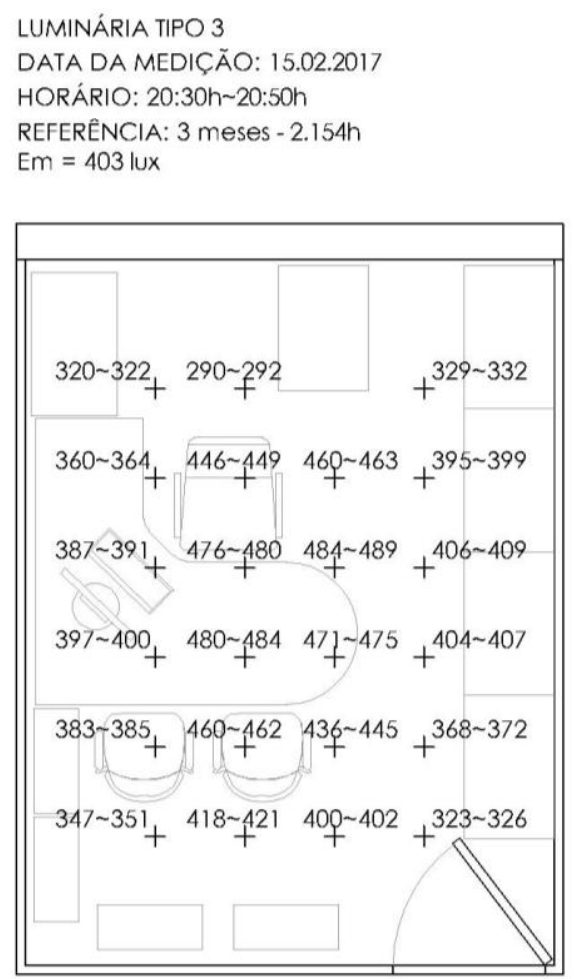

Figura 37: Medição do sistema de iluminação tipo 6 - 3 meses

$$
\begin{aligned}
& \text { LUMINÁRIA TIPO } 6 \\
& \text { DATA DA MEDIÇÃO: } 22.02 .2017 \\
& \text { HORÁRIO: 19:15h 19:35h } \\
& \text { REFERÊNCIA: } 3 \text { meses }-2.154 \mathrm{~h} \\
& \text { Em = } 415 \text { luX }
\end{aligned}
$$

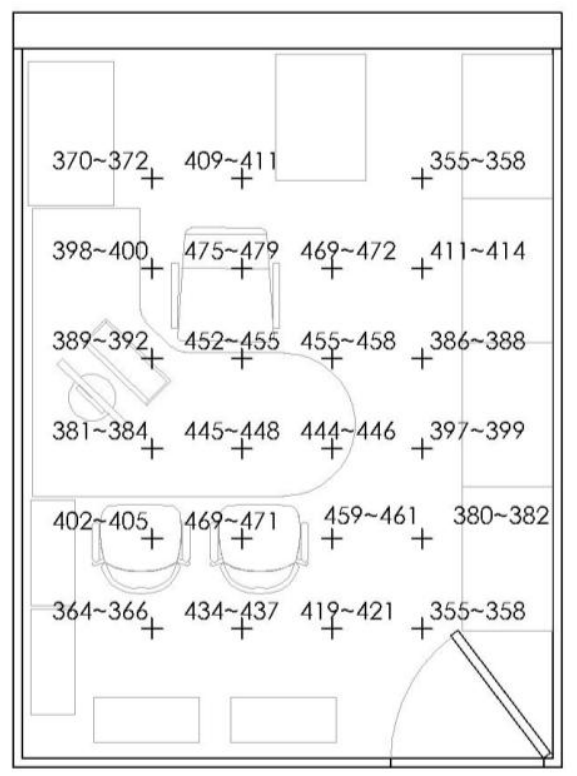

Após 6 meses de instalação foram realizadas novas medições. Nesse período, não houve depreciação em relação ao sistema tipo 1 (Fig. 38) e tipo 4 (Fig. 39) se 
comparadas às medições feitas aos 3 meses antes. Ambos os sistemas utilizam lâmpadas fluorescentes tubulares.

Figura 38: Medição do sistema de iluminação tipo 1 - 6 meses

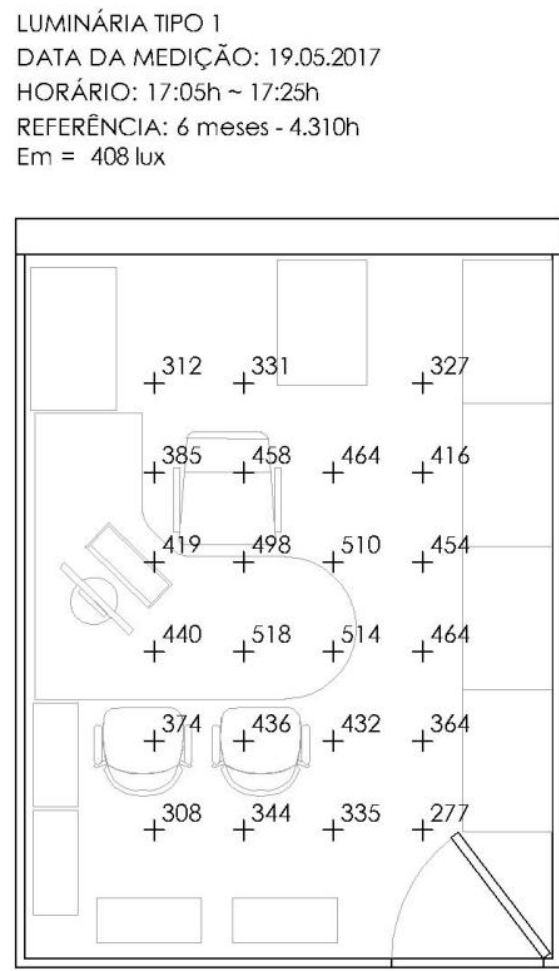

Figura 39: Medição do sistema de iluminação tipo 4 - 6 meses

LUMINÁRIA TIPO 4

DATA DA MEDIÇÃO: 22.05.2017

HORÁRIO: $17: 15 \mathrm{~h} \sim 17: 35 \mathrm{~h}$

REFERÊNCIA: 6 meses - 4.310h

$\mathrm{Em}=334$ lux

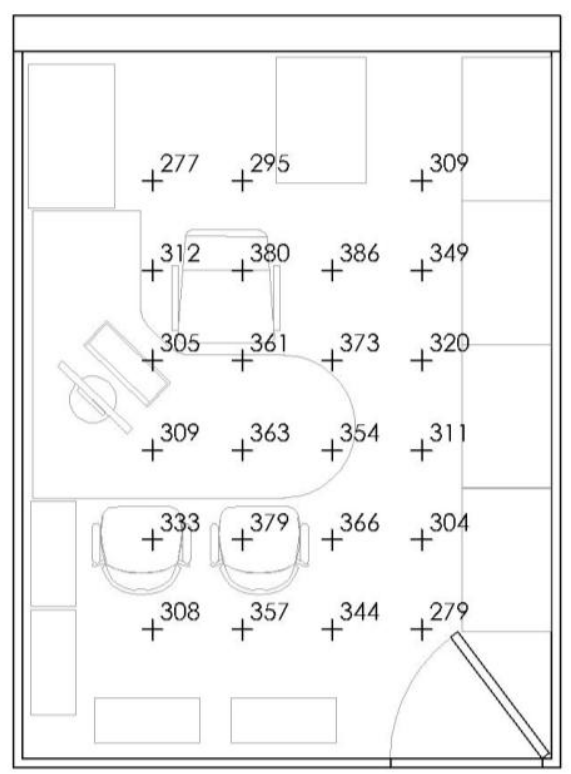


Nesse período, o nível de iluminância médio medido para os sistemas que utilizam lâmpadas tubo LED, também não apontou depreciação nos conjuntos instalados. A Figura 40 é referente ao sistema tipo 2 (com aletas) e a Figura 41 ao sistema tipo 5 (com difusor).

Figura 40: Medição do sistema de iluminação tipo 2 - 6 meses

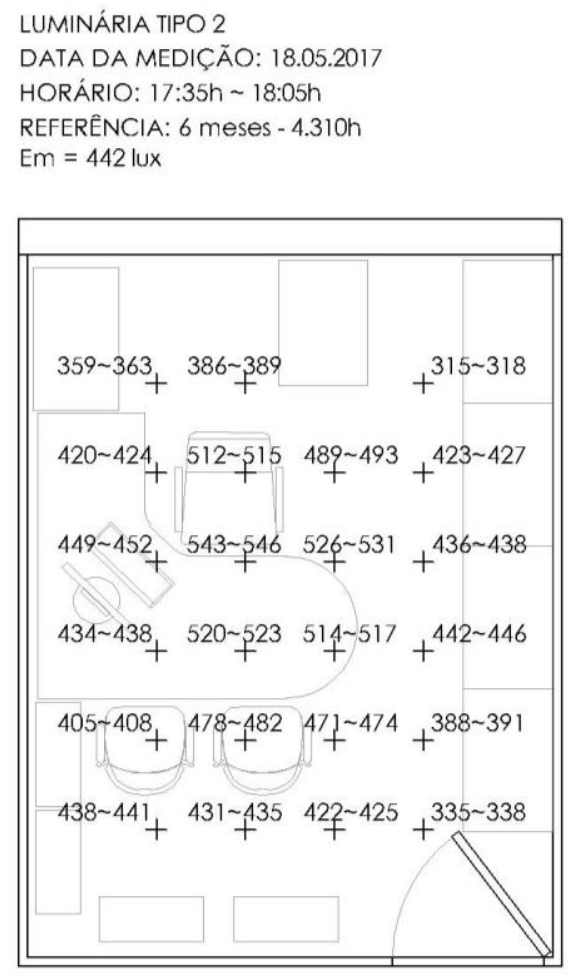

Figura 41: Medição do sistema de iluminação tipo 5 - 6 meses

LUMINÁRIA TIPO 5

DATA DA MEDIÇÃO: 23.05.2017

HORÁRIO: 17:40h 18:00h

REFERÊNCIA: 6 meses - $4.310 \mathrm{~h}$

$\mathrm{Em}=166 \mathrm{lux}$

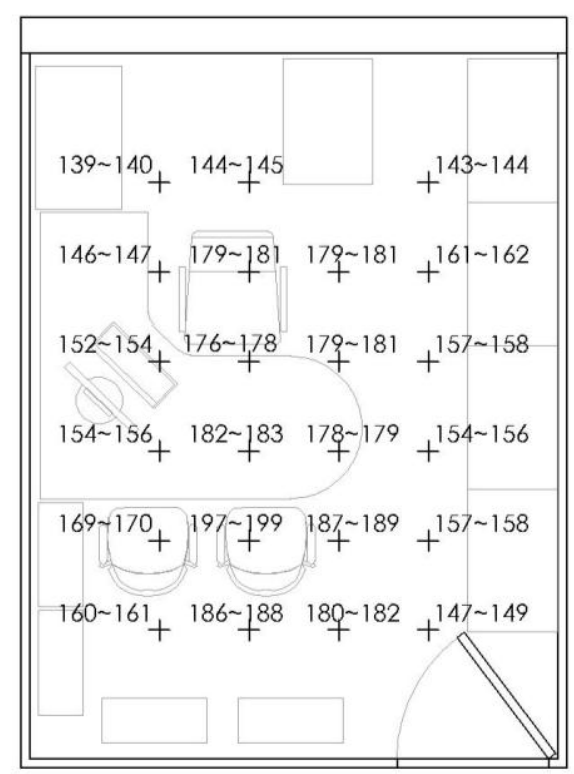


Assim como nos sistemas anteriores, as medições realizadas para os sistemas com o LED aplicado na luminária tipo 3 (Fig. 42) e tipo 6 (Fig. 43), não apresentaram depreciação.

Figura 42: Medição do sistema de iluminação tipo 3 - 6 meses

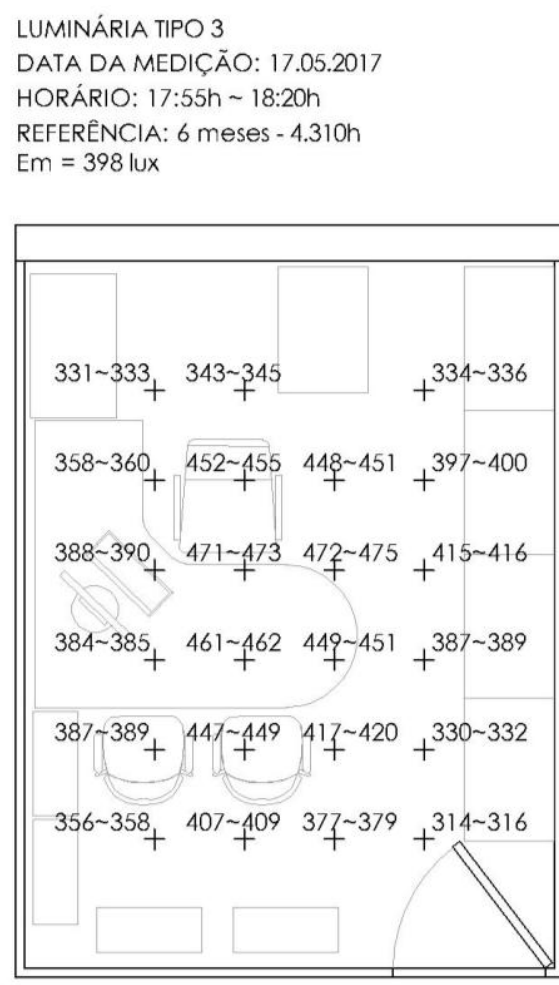

Figura 43: Medição do sistema de iluminação tipo 6 - 6 meses
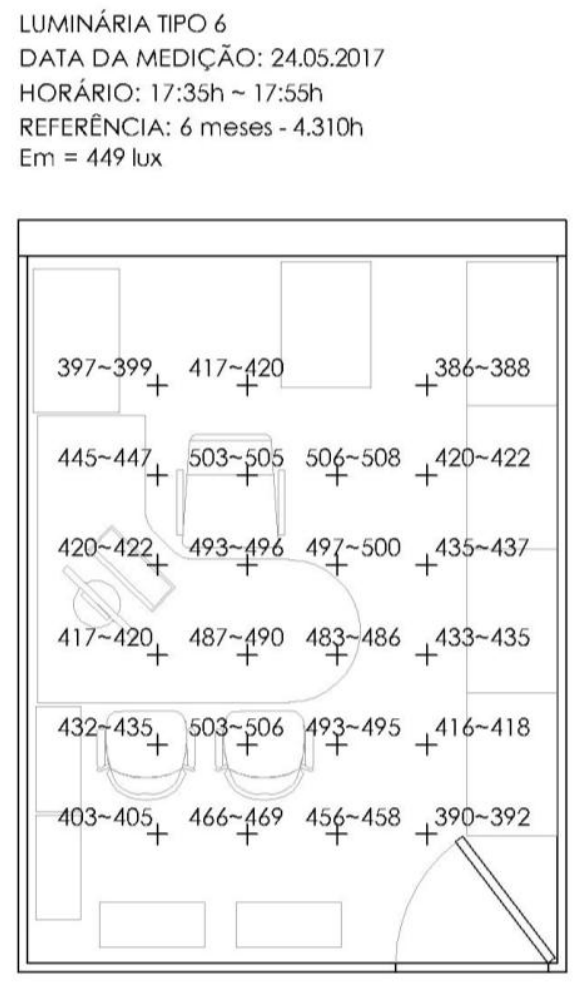
As figuras seguintes apresentam as medições após 9 meses, cerca de 6.400 horas, com os sistemas de iluminação acesos. Analisando o resultado da medição da Figura 44 a depreciação foi de 10\% para a luminária com aletas e de 16\% para a luminária com difusor (Fig. 45).

Figura 44: Medição do sistema de iluminação tipo 1 - 9 meses

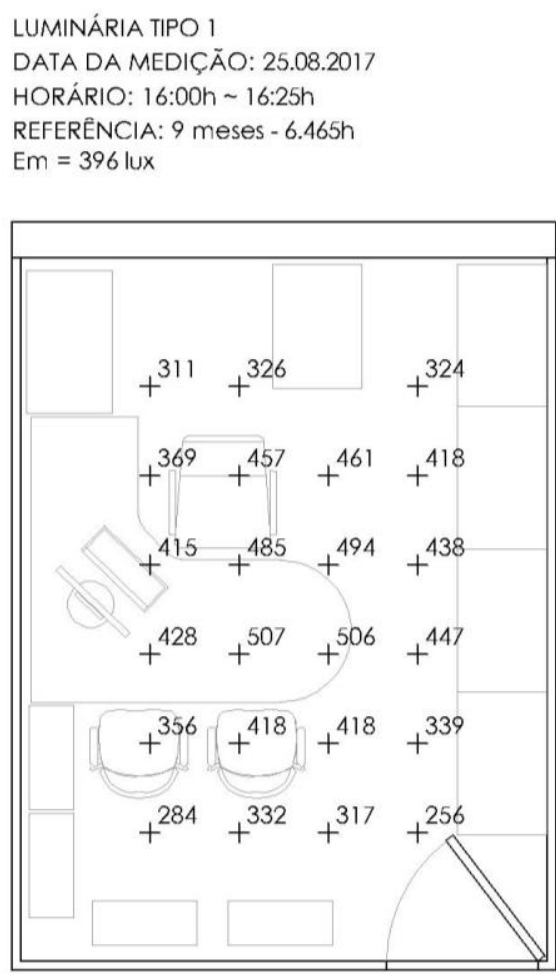

Figura 45: Medição do sistema de iluminação tipo 4 - 9 meses

LUMINÁRIA TIPO 4

DATA DA MEDIÇÃO: 28.08 .2017

HORÁRIO: 18:00h 18:20h

REFERÊNCIA: 9 meses $-6.465 \mathrm{~h}$

$\mathrm{Em}=321 \mathrm{lux}$

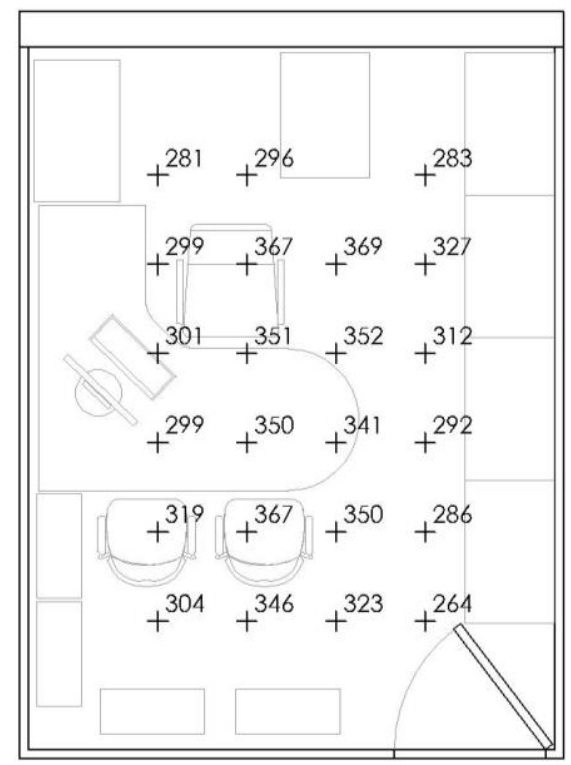


Nesses 9 meses, para os sistemas que utilizam lâmpada tubo LED, no caso do modelo com aletas (Fig.46), não houve depreciação, e no caso do modelo com difusor (Fig. 47) a depreciação chegou a 21\%.

Figura 46: Medição do sistema de iluminação tipo 2 - 9 meses

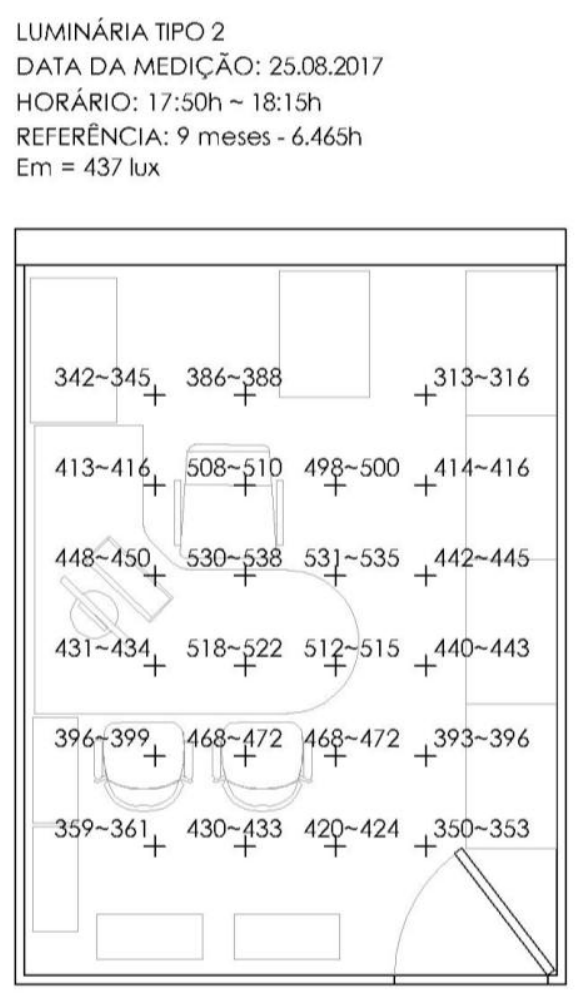

Figura 47: Medição do sistema de iluminação tipo 5 - 9 meses

LUMINÁRIA TIPO 5

DATA DA MEDIÇÃO: 23.08 .2017

HORÁRIO: 18:05h 18:25h

REFERENCIA: 9 meses $-6.465 \mathrm{~h}$

$\mathrm{Em}=134 \mathrm{lux}$

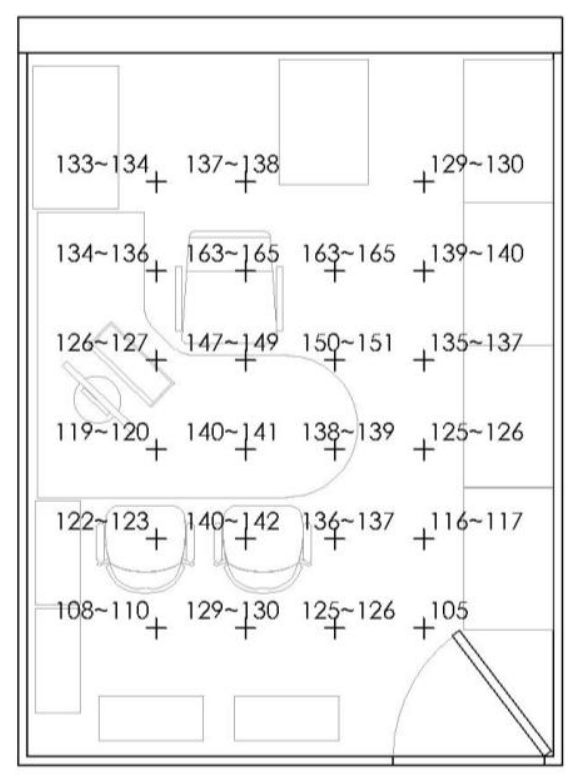


Para os sistemas de iluminação utilizando a tecnologia LED diretamente na luminária, os resultados da iluminância média das medições mostram que o modelo com aletas (Fig. 48) depreciou 7\% e o modelo com difusor (Fig. 49) não apresentou depreciação neste período.

Figura 48: Medição do sistema de iluminação tipo 3 - 9 meses

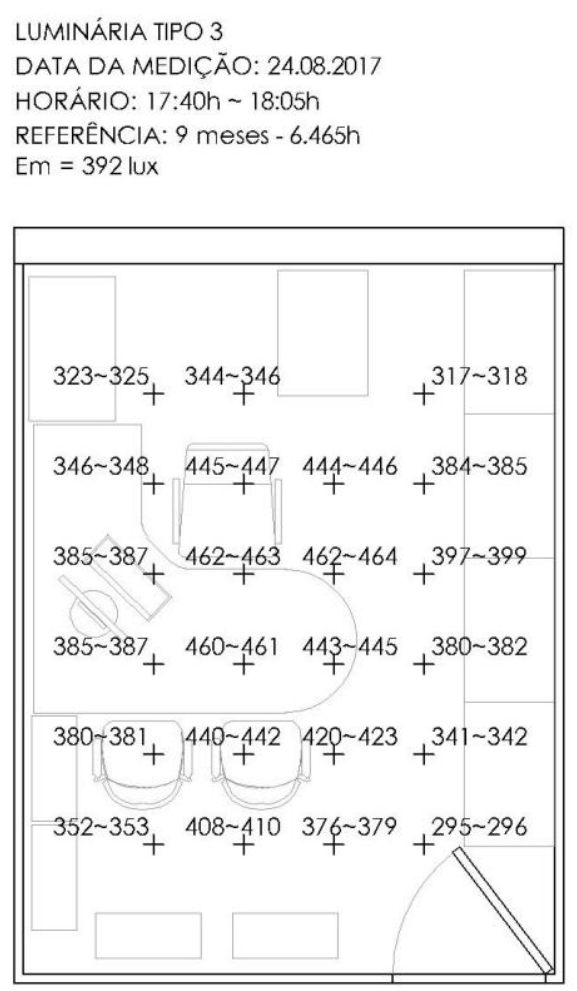

Figura 49: Medição do sistema de iluminação tipo 6 - 9 meses
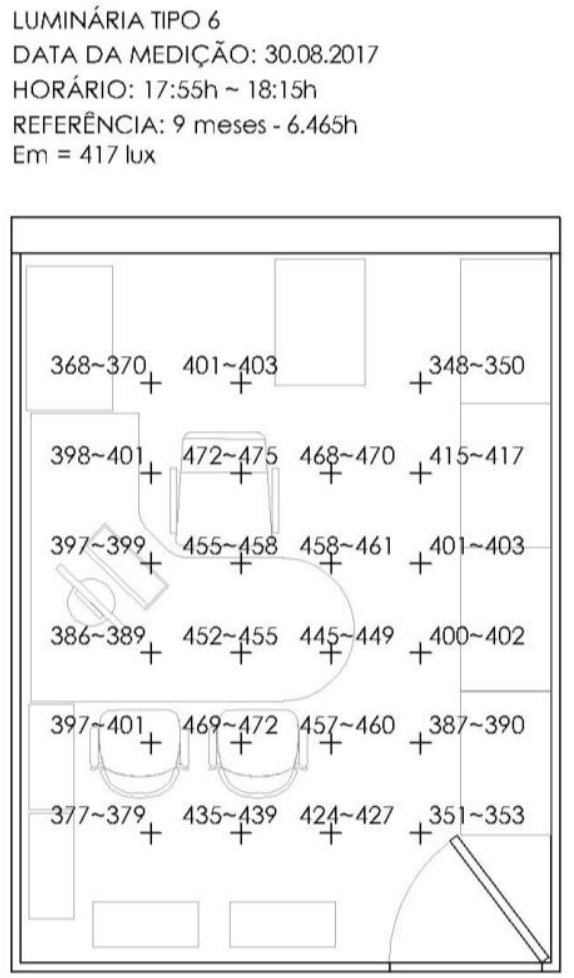
Após mais três meses do experimento, chegou-se a um ano de depreciação dos sistemas de iluminação, que corresponde a aproximadamente $8.600 \mathrm{~h}$. A medição dos sistemas de iluminação utilizando lâmpada fluorescente tubular não depreciou de 9 meses para 1 ano no modelo com aletas (tipo 1), porém no modelo com difusor (tipo 4) houve depreciação de mais $6 \%$ nesses 3 meses. As Figuras 50 e 51 mostram as medições ponto a ponto para os modelos citados anteriormente.

As Figuras 52 e 53 a seguir, mostram as medições dos sistemas de iluminação utilizando lâmpada tubo LED. Como pode ser visto, não houve depreciação do modelo com aletas (tipo 2), e o modelo com difusor (tipo 5) depreciou $6 \%$.

Comparando a depreciação ocorrida nas medições de 9 meses e de 1 ano do sistema de iluminação tipo 5, percebe-se que a depreciação mudou de $21 \%$ para $6 \%$ nesses 3 meses. Uma provável causa dessa brusca mudança pode ter sido ao erro humano. Uma vez que os sistemas de iluminação eram posicionados na data programada pelo eletricista responsável, o que ocorreu é que a troca pode ter ocorrido pouco antes da medição e a ocorrência não foi comunicada para a pesquisadora.

As medições dos sistemas de iluminação com o LED aplicado na luminária, apresentaram $7 \%$ de depreciação no modelo com aletas (tipo 3), e apenas $2 \%$ no modelo com difusor (tipo 6). As medições são mostradas nas Figura 54 e 55 respectivamente. Em ambas as medições, percebe-se que não houveram depreciações de 9 meses para 12 meses (1 ano). 
Figura 50: Medição do sistema de iluminação tipo 1 - 1 ano (12 meses)
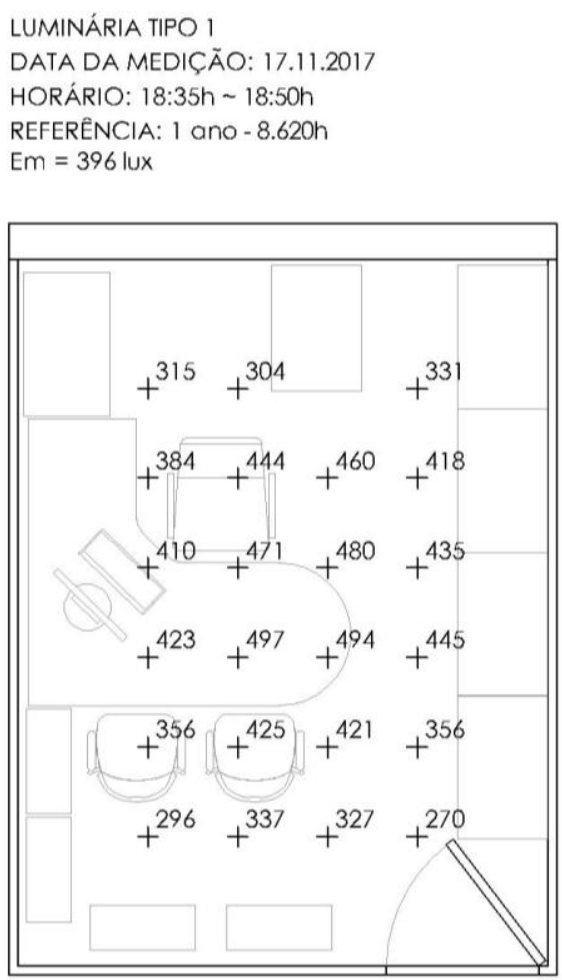

Figura 51: Medição do sistema de iluminação tipo 4 - 1 ano (12 meses)

LUMINÁRIA TIPO 4

DATA DA MEDIÇÃO: 21.11.2017

HORÁRIO: 18:30h 18:50h

REFERÊNCIA: 1 ano $-8.620 \mathrm{~h}$

$\mathrm{Em}=300 \mathrm{lux}$

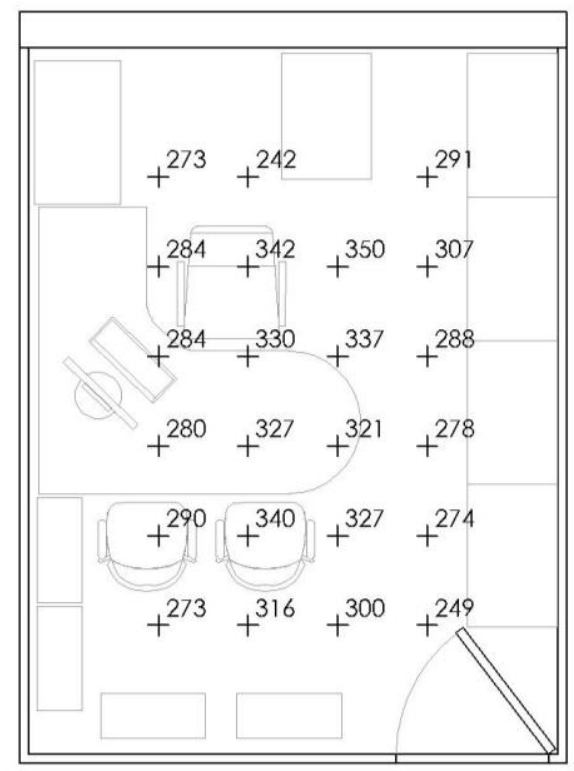


Figura 52: Medição do sistema de iluminação tipo 2 - 1 ano (12 meses)
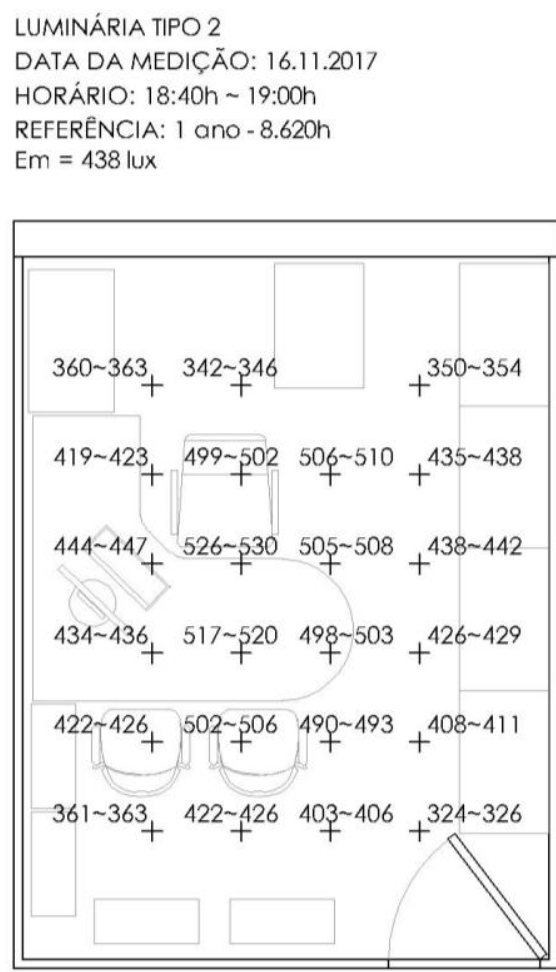

Figura 53: Medição do sistema de iluminação tipo 5 - 1 ano (12 meses)
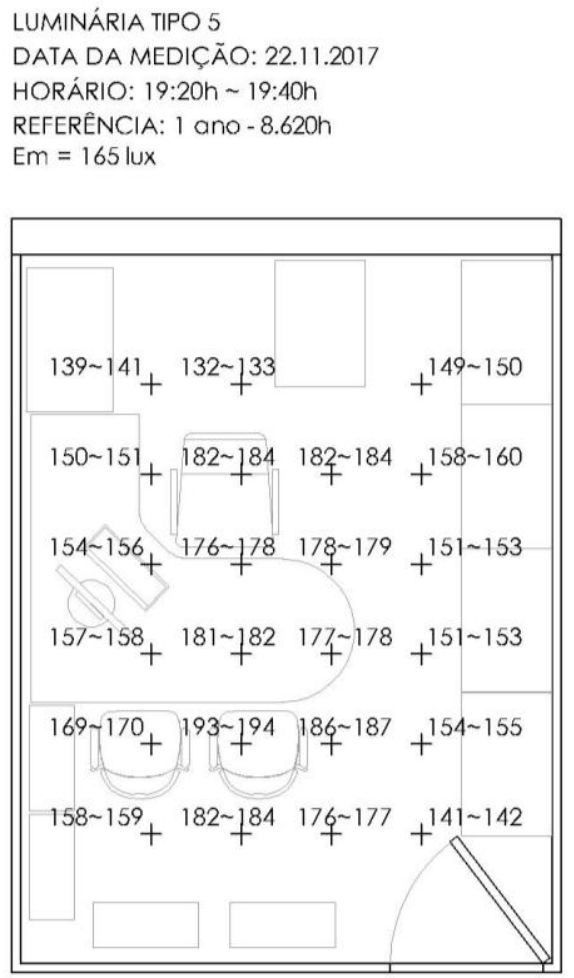
Figura 54: Medição do sistema de iluminação tipo 3 - 1 ano (12 meses)
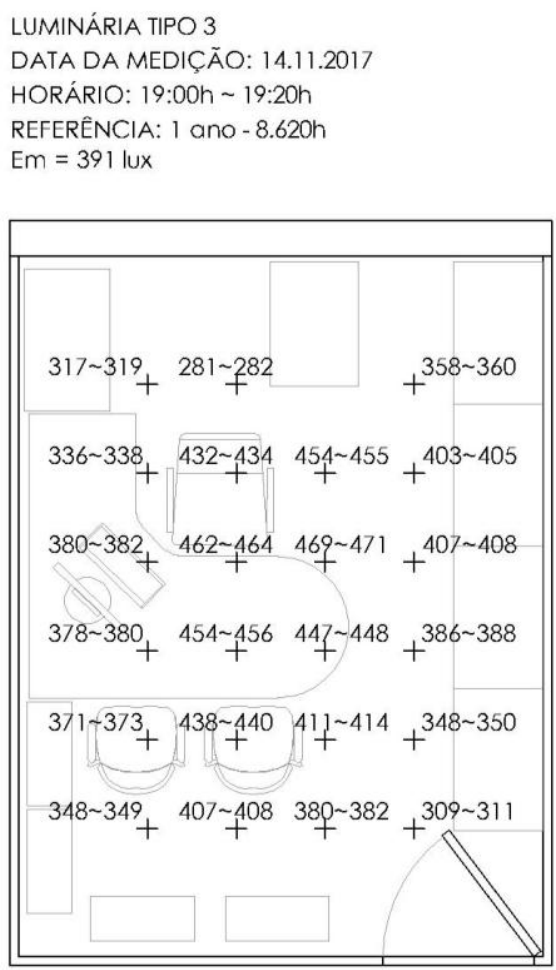

Figura 55: Medição do sistema de iluminação tipo 6 - 1 ano (12 meses)
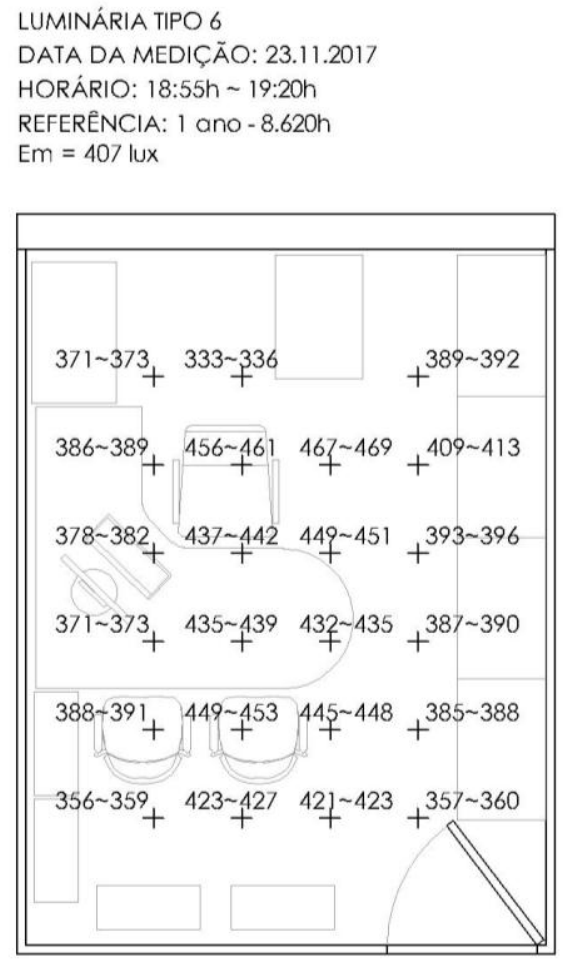

As Figuras 56 e 57 mostram os resultados das medições realizadas após 1 ano e meio dos sistemas de iluminação acesos, que correspondem à 
aproximadamente $10.770 \mathrm{~h}$ nos modelos que utilizam a lâmpada fluorescente tubular. A depreciação medida no modelo tipo 1 foi de $16 \%$ e no modelo do tipo 4 foi de $21 \%$.

Figura 56: Medição do sistema de iluminação tipo 1 - 1 ano e 3 meses (15 meses)

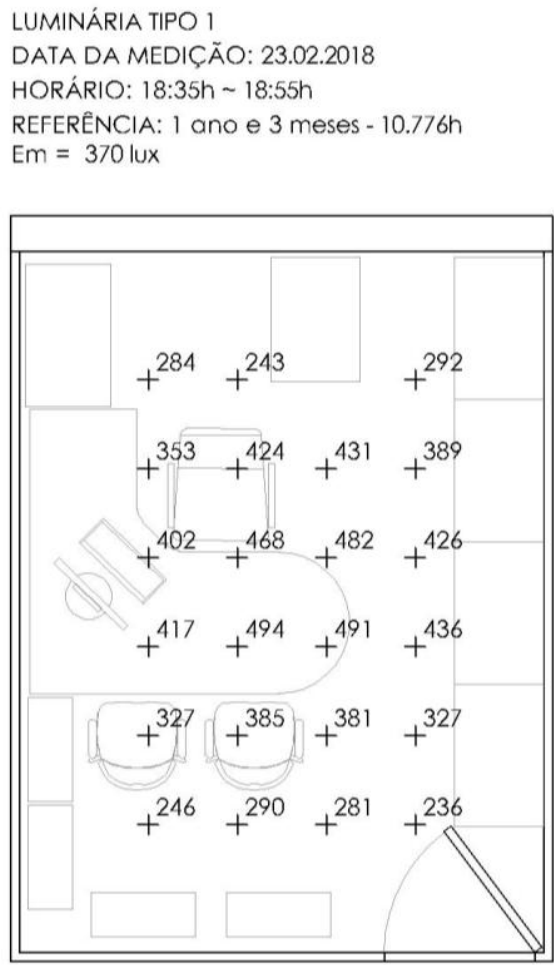

Figura 57: Medição do sistema de iluminação tipo 4 - 1 ano e 3 meses (15 meses)

LUMINÁRIA TIPO 4

DATA DA MEDIÇÃO: 26.02 .2018

HORÁRIO: 19:45h 20:00h

REFERÊNCIA: 1 ano e 3 meses - 10.776h

$\mathrm{Em}=301 \mathrm{lux}$

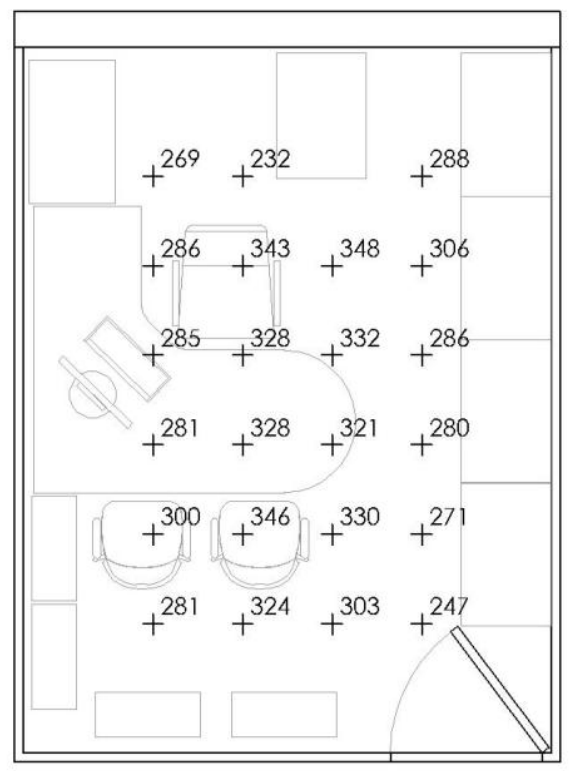


As Figura 58 e 59 mostram que após esse mesmo período a depreciação dos modelos que utilizaram lâmpada tubo LED foi de apenas $1 \%$ nos modelo tipo 2 , luminária com aletas e que mantiveram os $6 \%$ nos modelo tipo 5 , luminária com difusor.

Figura 58: Medição do sistema de iluminação tipo 2 - 1 ano e 3 meses (15 meses)

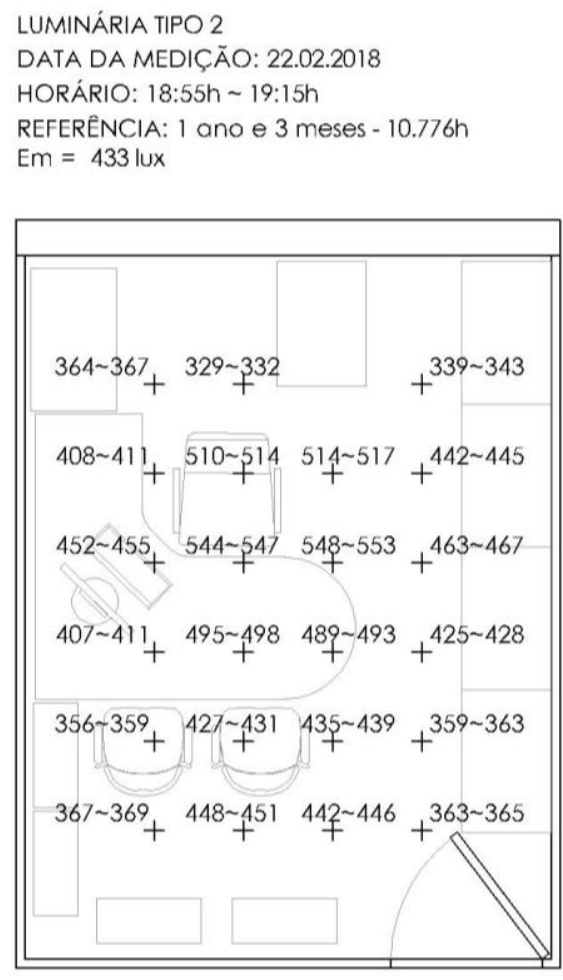

Figura 59: Medição do sistema de iluminação tipo 5 - 1 ano e 3 meses (15 meses)

LUMINÁRIA TIPO 5

DATA DA MEDIÇÃO: 27.02 .2018

HORÁRIO: 18:50h 19:05h

REFERENCIA: 1 ano e 3 meses - 10.776h

$\mathrm{Em}=160 \mathrm{lux}$

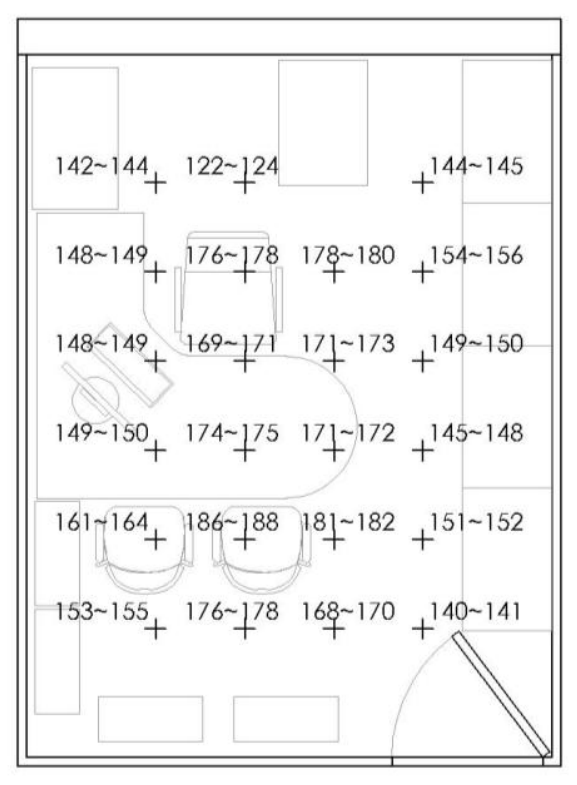


As Figuras 60 e 61 mostram os resultados ponto a ponto medidos nesse período das luminárias tipo 3 e 6 , modelos que utilizam a tecnologia LED diretamente sobre a luminária. A depreciação foi de $13 \%$ no modelo com aletas e de $2 \%$ no modelo com difusor.

Figura 60: Medição do sistema de iluminação tipo 3 - 1 ano e 3 meses (15 meses)

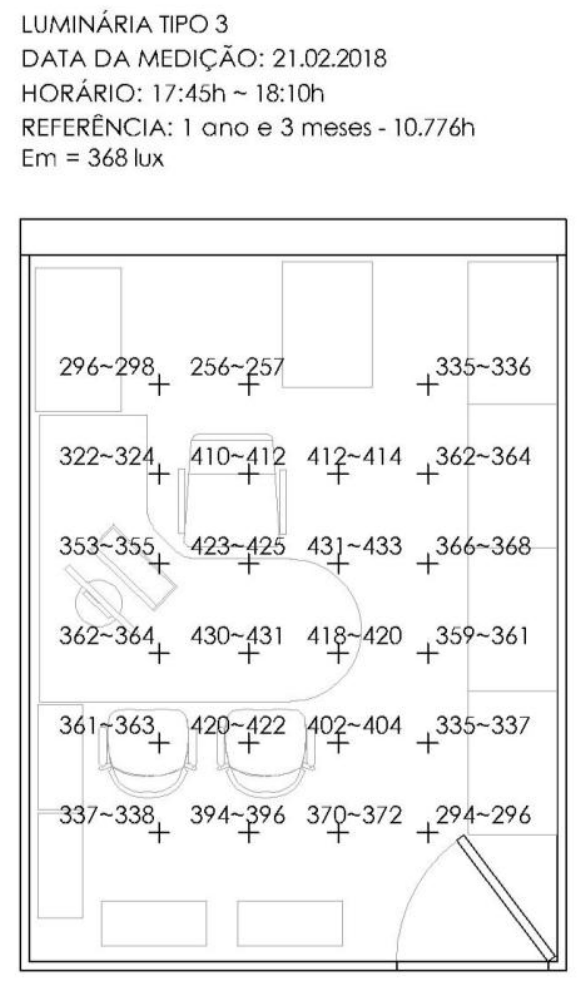

Figura 61: Medição do sistema de iluminação tipo 6 - 1 ano e 3 meses (15 meses)

LUMINÁRIA TIPO 6

DATA DA MEDIČÃO: 28.02 .2018

HORÁRIO: $18: 35 \mathrm{~h} \sim 18: 55 \mathrm{~h}$

REFERÊNCIA: 1 ano e 3 meses - 10.776h

$\mathrm{Em}=406$ lux

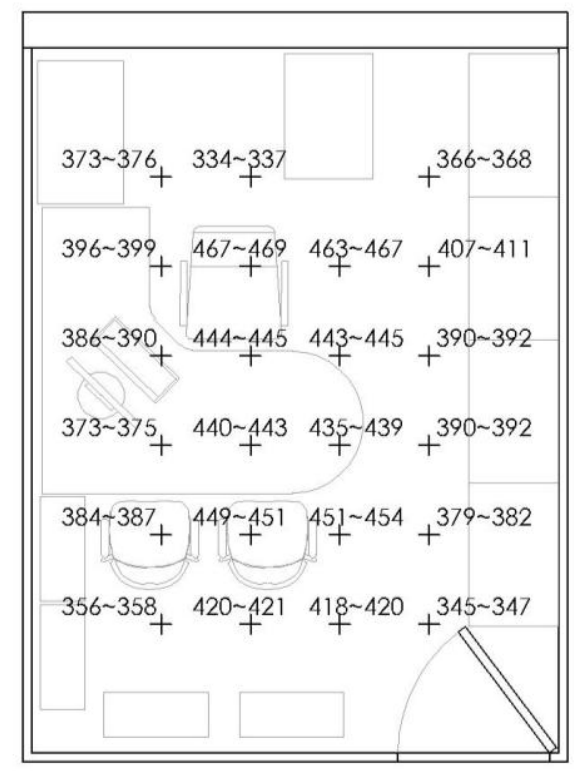


As figuras seguintes, mostram as medições ponto a ponto realizadas após 1 ano e meio ligadas, que correspondem à aproximadamente $12.930 \mathrm{~h}$.

As medições ocorreram na metade do mês de maio, e antes da medição, entre o final do mês de abril e inicio de maio, houve a queima de um dos componentes de um dos sistemas de iluminação tipo 4 .

Assim, foi realizada somente a medição correspondente ao sistema de iluminação tipo 1 (Fig. 62), que apresentou depreciação de 16\% após quase 13.000h, mantendo o nível médio de iluminância medido à 1 ano e 3 meses.

Figura 62: Medição do sistema de iluminação tipo 1 - 1 ano e 6 meses (18 meses)

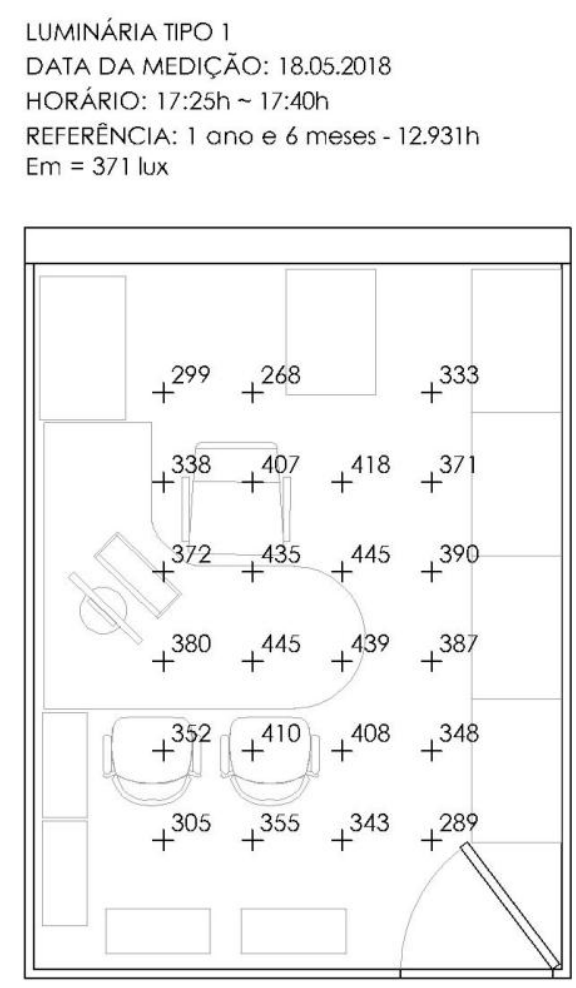

Em relação aos sistemas de iluminação que utilizavam a tecnologia fluorescente tubular, optou-se por retirar todas as luminárias que utilizavam essa tecnologia para posterior ensaio em laboratório e comparação dos resultados de depreciação relacionada apenas às lâmpadas.

Os sistemas de iluminação utilizando lâmpada tubo LED depreciaram conforme medições realizadas $1 \%$ na luminária modelo com aletas (Fig. 63) e 7\% nas luminárias modelo com difusor (Fig. 64). 
Figura 63: Medição do sistema de iluminação tipo 2 - 1 ano e 6 meses (18 meses)

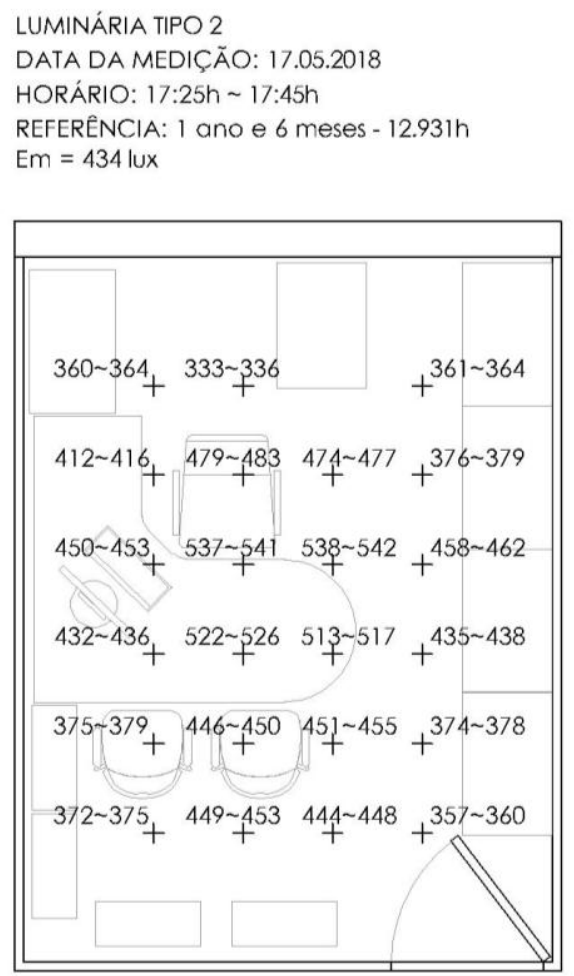

Figura 64: Medição do sistema de iluminação tipo 5 - 1 ano e 6 meses (18 meses)

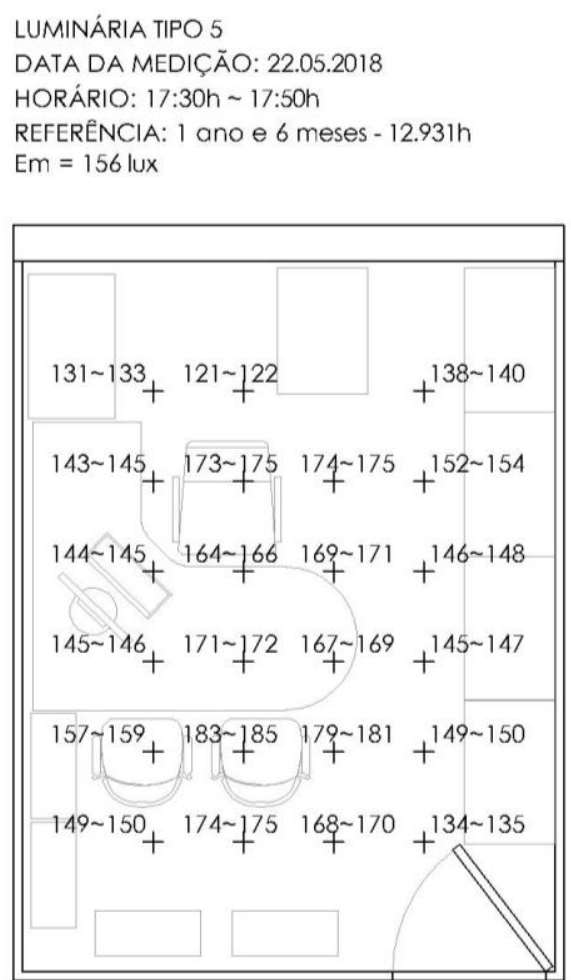

Já nos sistemas de iluminação com o LED aplicado na luminária, como mostram as figuras seguintes, a depreciação se manteve em $13 \%$ no modelo com aletas (Fig. 65) e 4\% no modelo com difusor (Fig. 66). 
Figura 65: Medição do sistema de iluminação tipo 3 - 1 ano e 6 meses (18 meses)

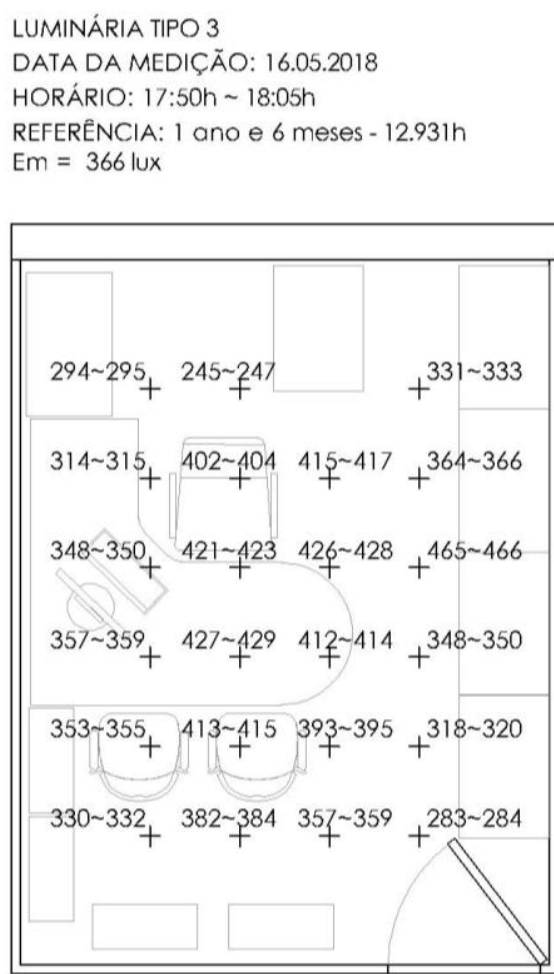

Figura 66: Medição do sistema de iluminação tipo 6 - 1 ano e 6 meses (18 meses)

\section{LUMINÁRIA TIPO 6}

DATA DA MEDIÇÃO: 23.05.2018

HORÁRIO: 18:55h 19:10h

REFERÊNCIA: 1 ano e 6 meses - 12.931h

$\mathrm{Em}=399 \mathrm{lux}$

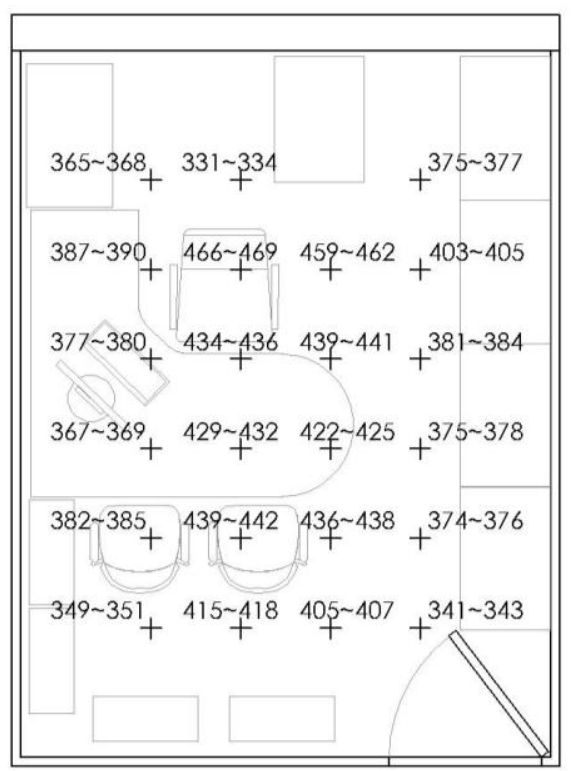


As Figuras 67 e 68 a seguir mostram as medições dos sistemas de iluminação que utilizam a tecnologia LED após 1 ano e 9 meses. As medições mostram que a do modelo tipo 2 foi de $2 \%$ e do modelo tipo 5 foi de $11 \%$.

Figura 67: Medição do sistema de iluminação tipo 2 - 1 ano e 9 meses (21 meses)

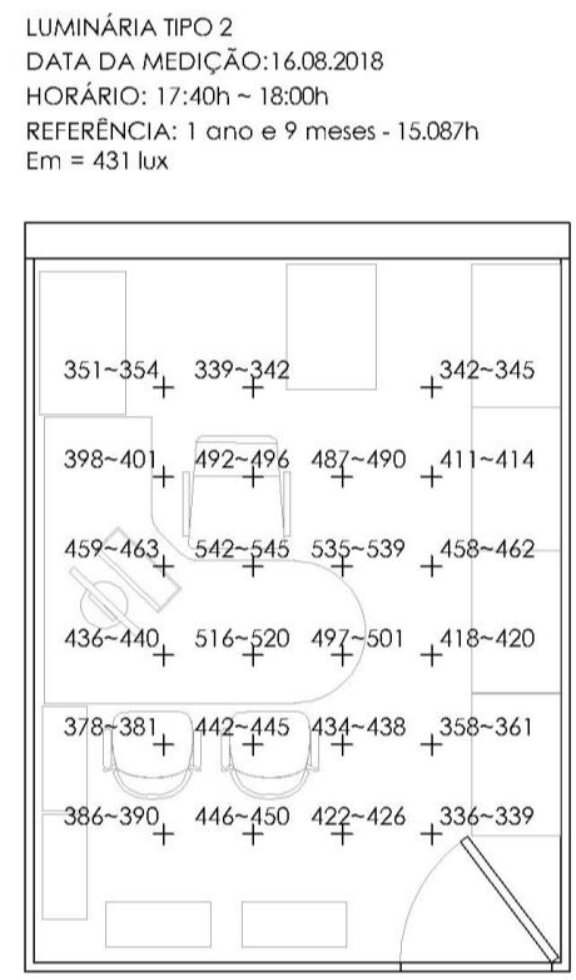

Figura 68: Medição do sistema de iluminação tipo 5 - 1 ano e 9 meses (21 meses)

LUMINÁRIA TIPO 5

DATA DA MEDIÇÃO: 21.08 .2018

HORÁRIO: 17:45h 18:05h

REFERENCIA: 1 ano e 9 meses $-15.087 \mathrm{~h}$

$\mathrm{Em}=152 \mathrm{lux}$

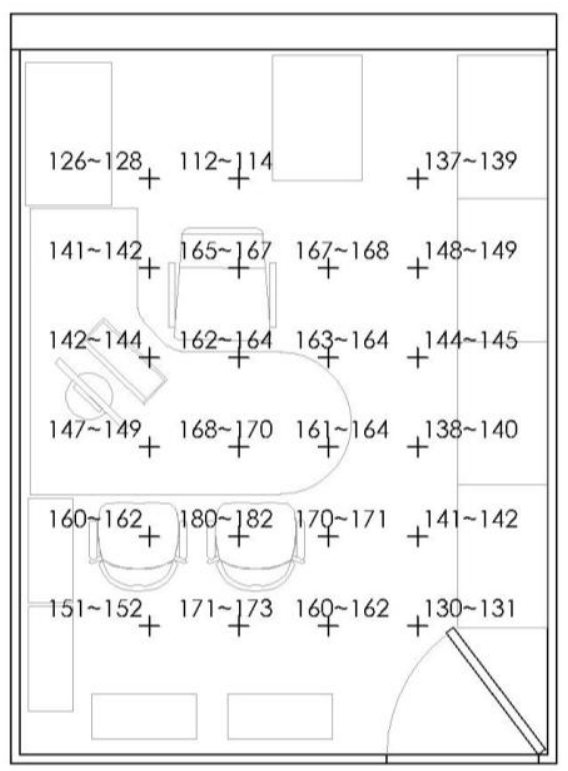


As medições apresentadas nas Figuras 69 e 70 mostram as medições ponto a ponto realizadas no mesmo período dos sistemas de iluminação com as luminárias em LED. O modelo tipo 3 manteve a depreciação em 13\% medida a 6 meses atrás e o modelo tipo 6 depreciou $6 \%$ no total.

Figura 69: Medição do sistema de iluminação tipo 3 - 1 ano e 9 meses (21 meses)

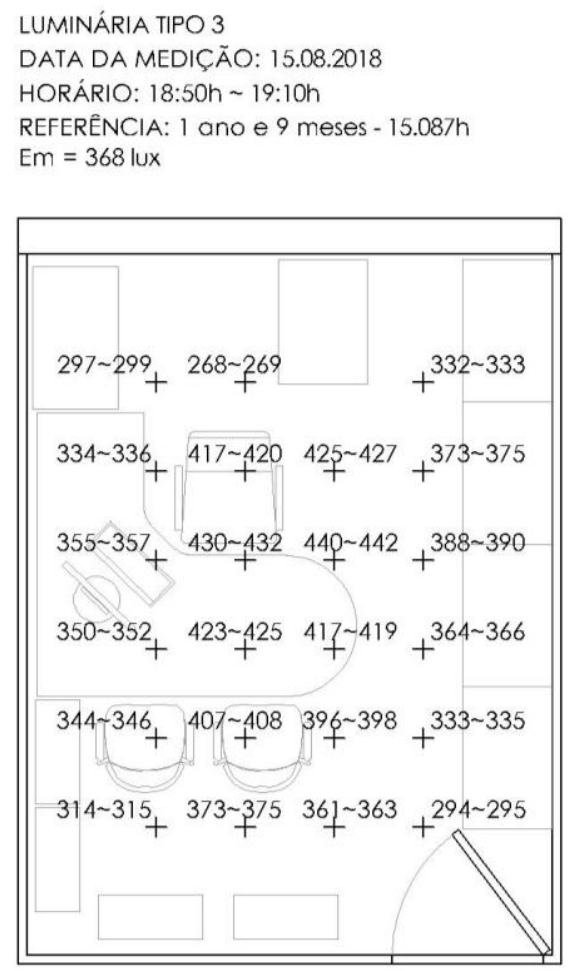

Figura 70: Medição do sistema de iluminação tipo 6 - 1 ano e 9 meses (21 meses)

LUMINÁRIA TIPO 6

DATA DA MEDIÇÃO: 22.08 .2018

HORÁRIO: 17:35h 17:55h

REFERÊNCIA: 1 ano e 9 meses - 15.087h

$\mathrm{Em}=392 \mathrm{lux}$

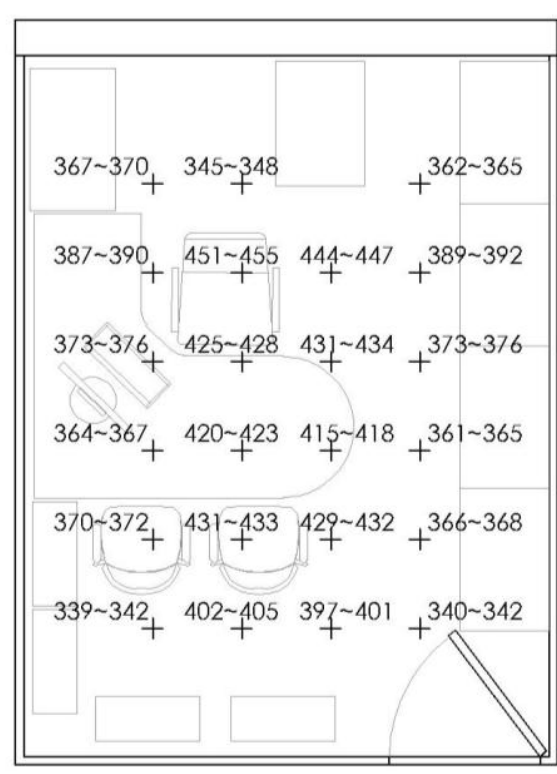


Por fim, as Figuras $71,72,73$ e 74 mostram os resultados das últimas medições realizadas na célula teste, em um total de $17.000 \mathrm{~h}$ com os sistemas de iluminação ligados.

Nos sistemas de iluminação que utilizavam lâmpada tubo LED, a depreciação em ambas as tipologias permaneceram constantes desde a medição realizada a 3 meses atrás.

Nos sistemas com o LED aplicado na luminária, houve depreciação total de $18 \%$ na tipo 3, com aletas (Fig. 73) e de 7\% na tipo 6, com difusor (Fig. 74).

Figura 71: Medição do sistema de iluminação tipo 2 - 2 anos (24 meses)

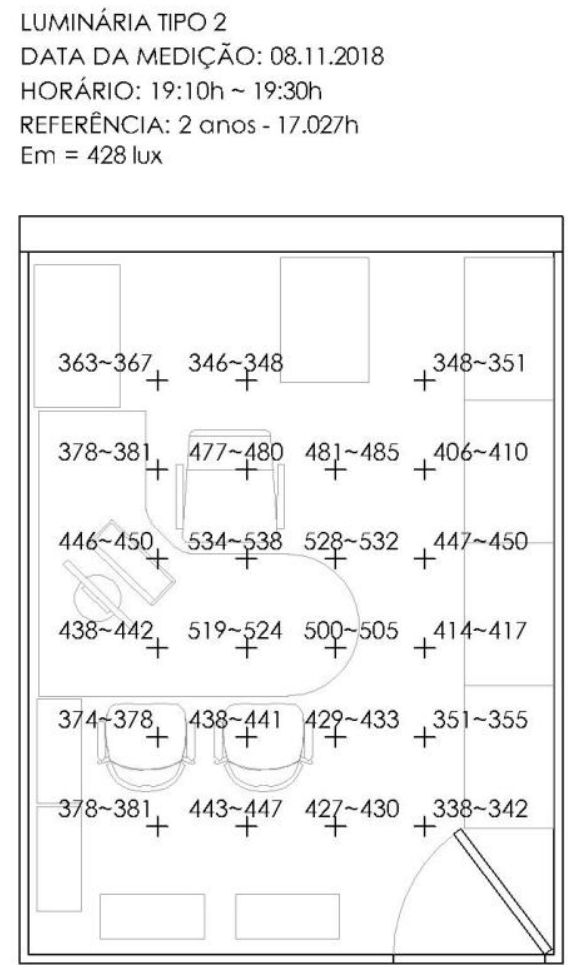


Figura 72: Medição do sistema de iluminação tipo 5 - 2 anos (24 meses)
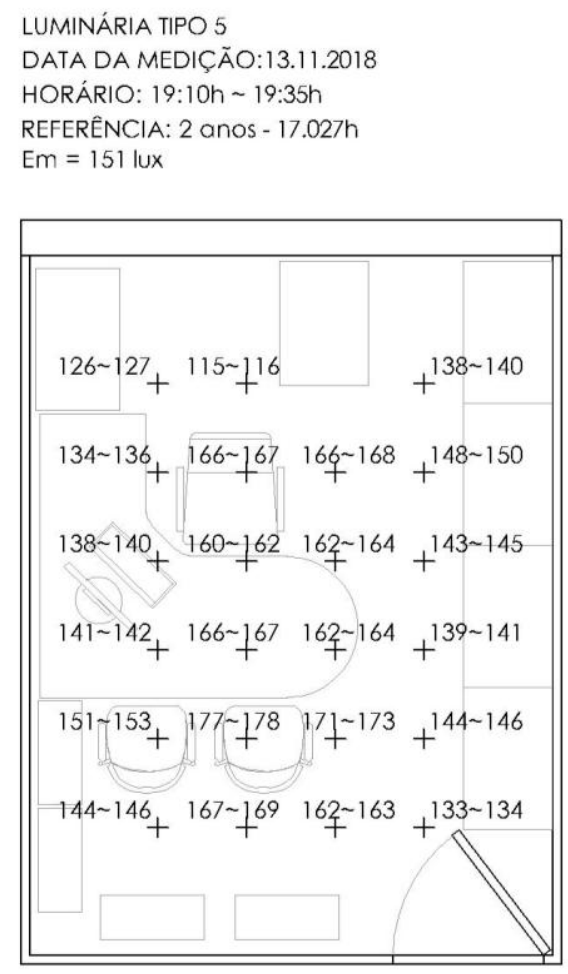

Figura 73: Medição do sistema de iluminação tipo 3 - 2 anos (24 meses)
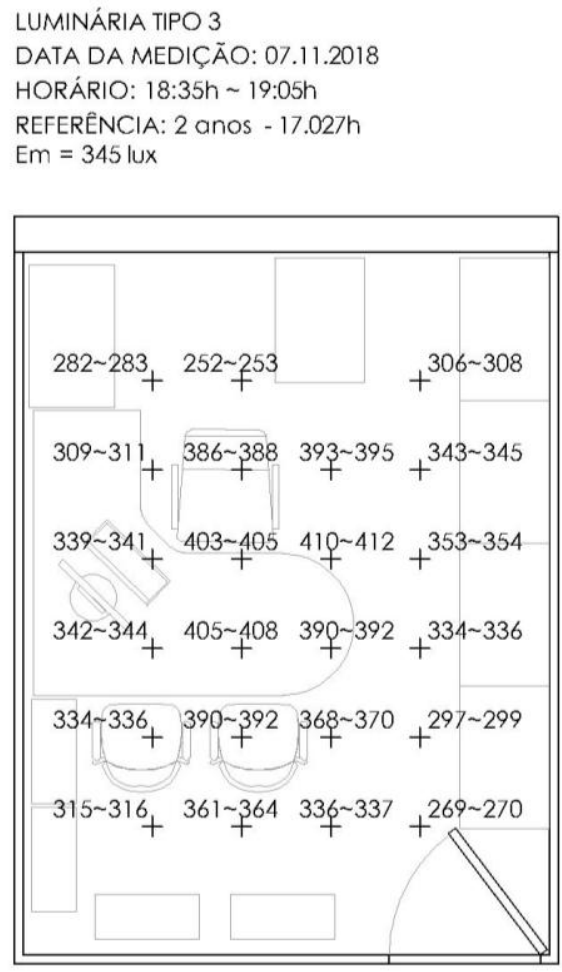
Figura 74: Medição do sistema de iluminação tipo 6 - 2 anos (24 meses)

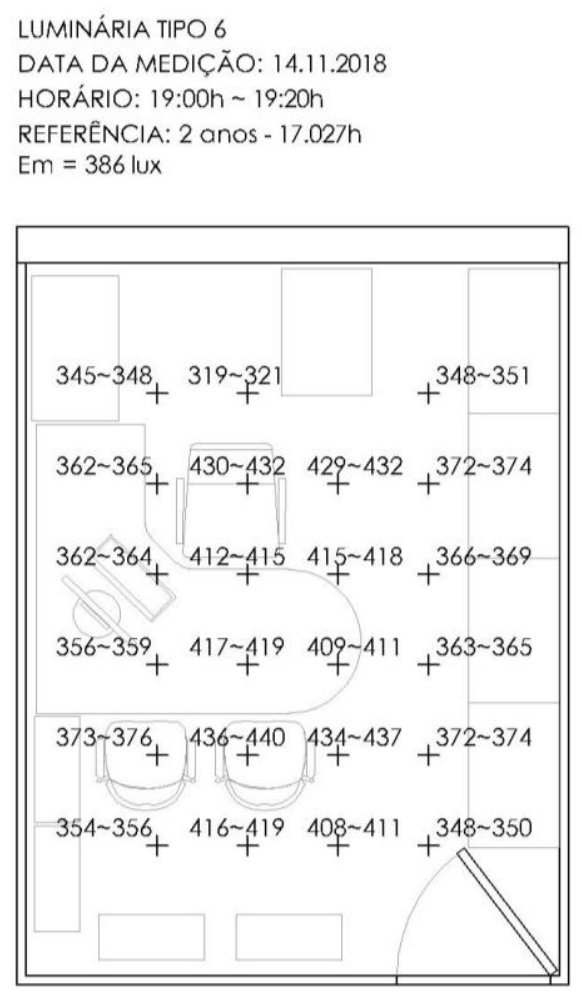

Outro aspecto constatado durante as medições foi que os sistemas de iluminação em LED não estabilizam em um único valor. O gráfico abaixo mostra a variação das medições comparando a lâmpada fluorescente tubular, o tubo LED e a luminária em LED em uma das medições realizadas.

Figura 75: Gráfico da variação do nível de iluminância das tecnologias utilizadas

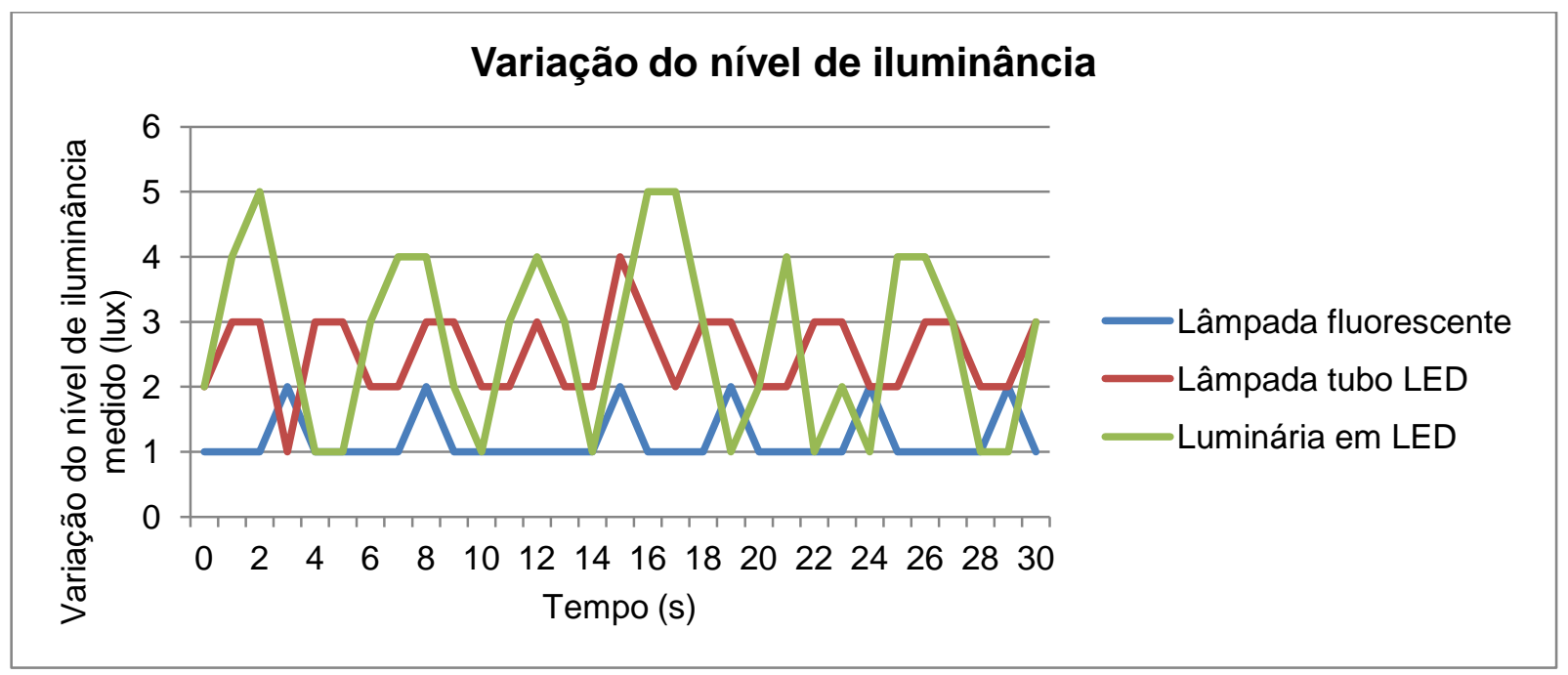


Observando o gráfico mostrado na Figura 75, percebe-se que as maiores variações são da tecnologia LED, sendo que a oscilação da luminária em LED é maior que a da luminária utilizando lâmpada tubo LED.

A variação da lâmpada fluorescente é mínima, e em determinados pontos, ela chega a ser nula.

Apesar de os resultados serem específicos para os produtos dos fabricantes utilizados na pesquisa, pode-se questionar se o indivíduo que fica exposto pelo menos 8 horas por dia a essas pequenas oscilações da tecnologia LED pode vir a apresentar algum problema de saúde, tal como stress e dores de cabeça.

Lembrando que os componentes dos sistemas de iluminação utilizados para esta pesquisa são um dos mais conhecidos e renomados no mercado nacional.

A tensão medida em alguns momentos não apresentou grandes variações, os valores apresentados variavam de $122 \mathrm{~V}$ e $125 \mathrm{~V}$.

\subsection{Resultados das medições}

Por meio do experimento, observou-se que houve depreciação nos sistemas de iluminação que utilizavam a tecnologia fluorescente e menos acentuada na que utilizam a tecnologia LED.

A seguir, temos uma tabela mostrando o nível de iluminância média resultante das medições realizadas.

Tabela 8: Iluminância média das medições realizadas 0h até 2 anos de depreciação.

\begin{tabular}{|c|c|c|c|c|c|c|}
\hline \multirow{2}{*}{$\begin{array}{l}\text { Período } \\
\text { das } \\
\text { medições }\end{array}$} & \multicolumn{6}{|c|}{ SISTEMAS DE ILUMINAÇÃO } \\
\hline & TIPO 1 & TIPO 2 & TIPO 3 & TIPO 4 & TIPO 5 & TIPO 6 \\
\hline Oh & 442 lux & $438 \operatorname{lux}$ & 421 lux & 380 lux & 170 lux & 415 lux \\
\hline 1 mês & 435 lux & 450 lux & 411 lux & $354 \operatorname{lux}$ & 171 lux & $413 \operatorname{lux}$ \\
\hline 3 meses & $408 \operatorname{lux}$ & 443 lux & 403 lux & $332 \operatorname{lux}$ & 169 lux & $415 \operatorname{lux}$ \\
\hline 6 meses & $408 \operatorname{lux}$ & $442 \operatorname{lux}$ & 398 lux & 334 lux & 166 lux & 449 lux \\
\hline 9 meses & 396 lux & 437 lux & $392 \operatorname{lux}$ & 321 lux & 134 lux & 417 lux \\
\hline 12 meses & 396 lux & 438 lux & 391 lux & 300 lux & 165 lux & 407 lux \\
\hline 15 meses & $370 \operatorname{lux}$ & $433 \operatorname{lux}$ & $368 \operatorname{lux}$ & $301 \operatorname{lux}$ & $160 \operatorname{lux}$ & $406 \operatorname{lux}$ \\
\hline 18 meses & 371 lux & $434 \operatorname{lux}$ & 366 lux & & 156 lux & 399 lux \\
\hline 21 meses & & 431 lux & 368 lux & & 152 lux & 392 lux \\
\hline 24 meses & & 428 lux & 345 lux & & 151 lux & 386 lux \\
\hline
\end{tabular}


Observa-se que ao final de 1 ano e meio de experimento, cerca de 13.000h, para os sistemas de iluminação que utilizaram a tecnologia fluorescente, houve depreciação total de $16 \%$ no caso das luminárias modelo com aletas e cerca de $21 \%$ nas luminárias modelo com difusor. Essa última, utilizando a medição em cerca de 11.000h. Após 1 ano e meio, é possível que a depreciação ficasse por volta de $25 \%$.

E após 2 anos de experimento, cerca de 17.000h, para os sistemas de iluminação que utilizavam a tecnologia LED, obtemos as seguintes depreciações totais, no caso das que utilizavam lâmpada tubo LED na luminária, a depreciação do conjunto das luminárias modelo com aletas foi de apenas $2 \%$ e do conjunto das luminárias modelo com difusor foi de $11 \%$.

A partir dos resultados anteriores, podemos concluir no caso onde as luminárias recebem as lâmpadas, a depreciação é maior nos sistemas de iluminação com difusor, onde as mesmas ficam confinadas, e é menor nos sistemas de iluminação com aletas, onde a dissipação de calor é maior.

Nos modelos em que as luminárias foram projetadas para receber a tecnologia LED direto nela, no caso da pesquisa, chamada de luminária com o LED aplicado, a depreciação do conjunto das luminárias modelo com aletas foi de $18 \%$ e no conjunto das luminárias modelo com difusor foi de $7 \%$.

É possível que, pelo fato do sistema de iluminação com aletas possuir um difusor a mais no conjunto, ela tenha depreciado mais. Outra possível causa seria o próprio projeto da luminária. 


\section{CAPÍTULO 4}

\section{ENSAIOS EM LABORATÓRIO}




\section{ENSAIOS EM LABORATÓRIO}

\subsection{Considerações preliminares}

Este capítulo abordará os ensaios iniciais em 0 hora e os ensaios dos sistemas de iluminação depreciados.

Todos os sistemas de iluminação utilizados no experimento foram ensaiados no laboratório do IEE, que é acreditado pelo INMETRO, para que estivessem padronizados para a realização das simulações. Este ensaio preliminar foi importante uma vez que, no início da pesquisa, o fabricante ainda não havia ensaiado os sistemas de iluminação com a utilização das lâmpadas tubo LED.

Devido ao prazo da pesquisa e a demanda de serviço do laboratório, o ensaio inicial foi realizado com novas luminárias adquiridas, em parceria com o próprio IEE, posteriormente ao início das medições do experimento para que não houvesse prejuízo no andamento do estudo. Foram solicitadas pelo IEE, exclusivamente para uso no ensaio, novas peças do mesmo modelo utilizado no experimento.

As lâmpadas fluorescentes e as lâmpadas tubo LED utilizadas no ensaio inicial foram do mesmo lote utilizado no experimento.

Além de verificar a depreciação dos sistemas de iluminação por meio das medições, após o final do experimento, os mesmos sistemas de iluminação foram levados novamente ao laboratório do IEE para serem ensaiados depois da depreciação.

\subsection{Ensaios fotométricos iniciais}

Os ensaios iniciais foram realizados por partes, devido à demanda de serviço do laboratório.

As lâmpadas fluorescentes tubulares utilizadas no ensaio inicial passaram por um período anterior de $100 \mathrm{~h}$ de sazonamento, que é a estabilização do fluxo luminoso das lâmpadas.

Os primeiros sistemas de iluminação a serem ensaiados foram os de modelo tipo 2 e tipo 5, que utilizavam lâmpada tubo LED. Os ensaios ocorreram no dia 05 de 
dezembro de 2017 para o modelo tipo 2, e no dia 07 de dezembro de 2017 para o modelo tipo 5 .

No entanto, houve um problema percebido ao final da tese. Ao comparar os resultados dos sistemas de iluminação iniciais e finais depreciados, observou-se que o fluxo luminoso inicial do conjunto tipo 5 era muito maior que o depreciado.

Ao avaliar lado a lado os sistemas de iluminação do mesmo modelo, percebeu-se que os difusores eram diferentes. Infelizmente, esse foi um problema originário da fábrica, pois os códigos das luminárias eram os mesmos, apesar de terem sido solicitados em épocas distintas.

Decidiu-se, para aproximar os valores, realizar novo ensaio, onde seria aplicado o conjunto luminária e lâmpadas novas, com o difusor cuidadosamente limpo de uma das luminárias utilizadas no experimento. Os dados utilizados nesta pesquisa são referentes ao novo ensaio efetuado em 11 de fevereiro de 2019.

A estabilização de cada sistema de iluminação, ou seja, o tempo necessário para que o fluxo do conjunto se mantivesse estável para ensaio, durou 60 minutos no primeiro modelo e 75 minutos no segundo.

As Figuras 76 e 77 a seguir mostram a curva fotométrica obtida nos primeiros ensaios em dezembro de 2017 e a Figura 78 a curva fotométrica resultante do ensaio realizado em fevereiro de 2019.

Figura 76: Foto e curva fotométrica ensaiada em laboratório - sistema de iluminação tipo 02
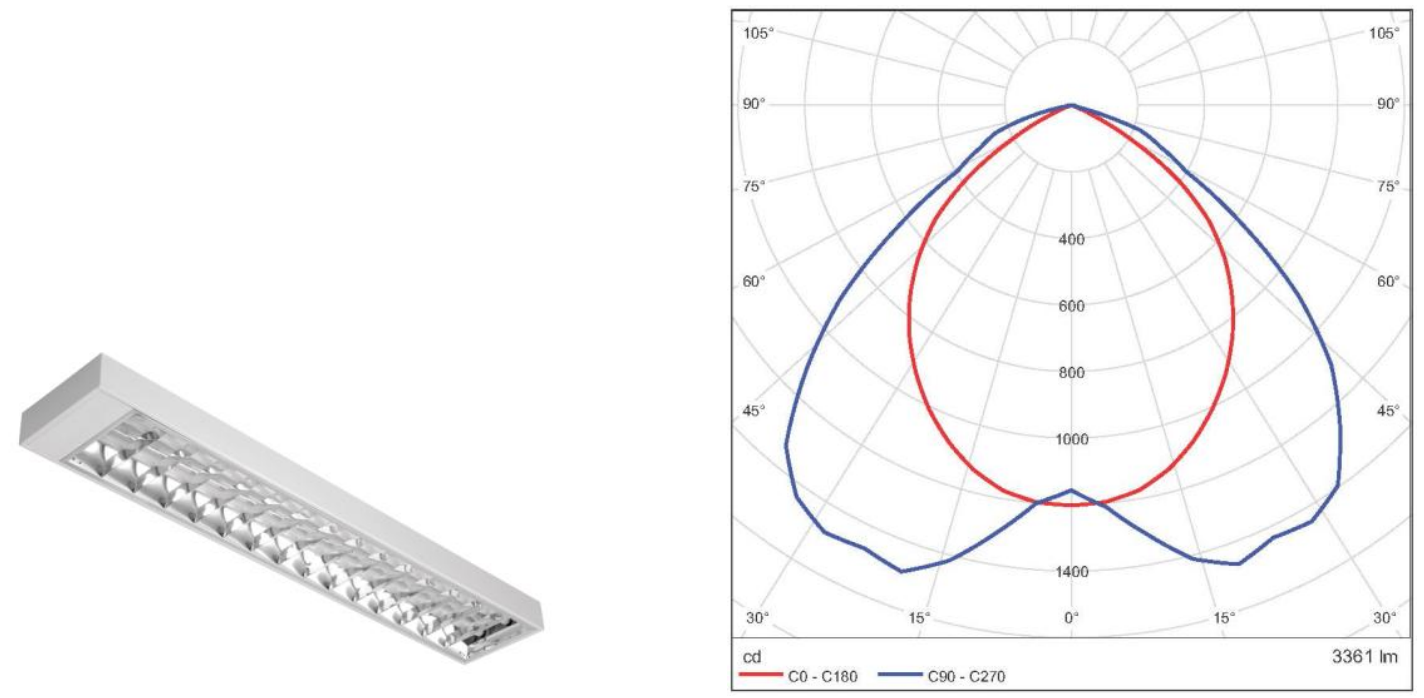
Figura 77: Foto e curva fotométrica ensaiada em laboratório - sistema de iluminação tipo 05 (07.dez.2017)

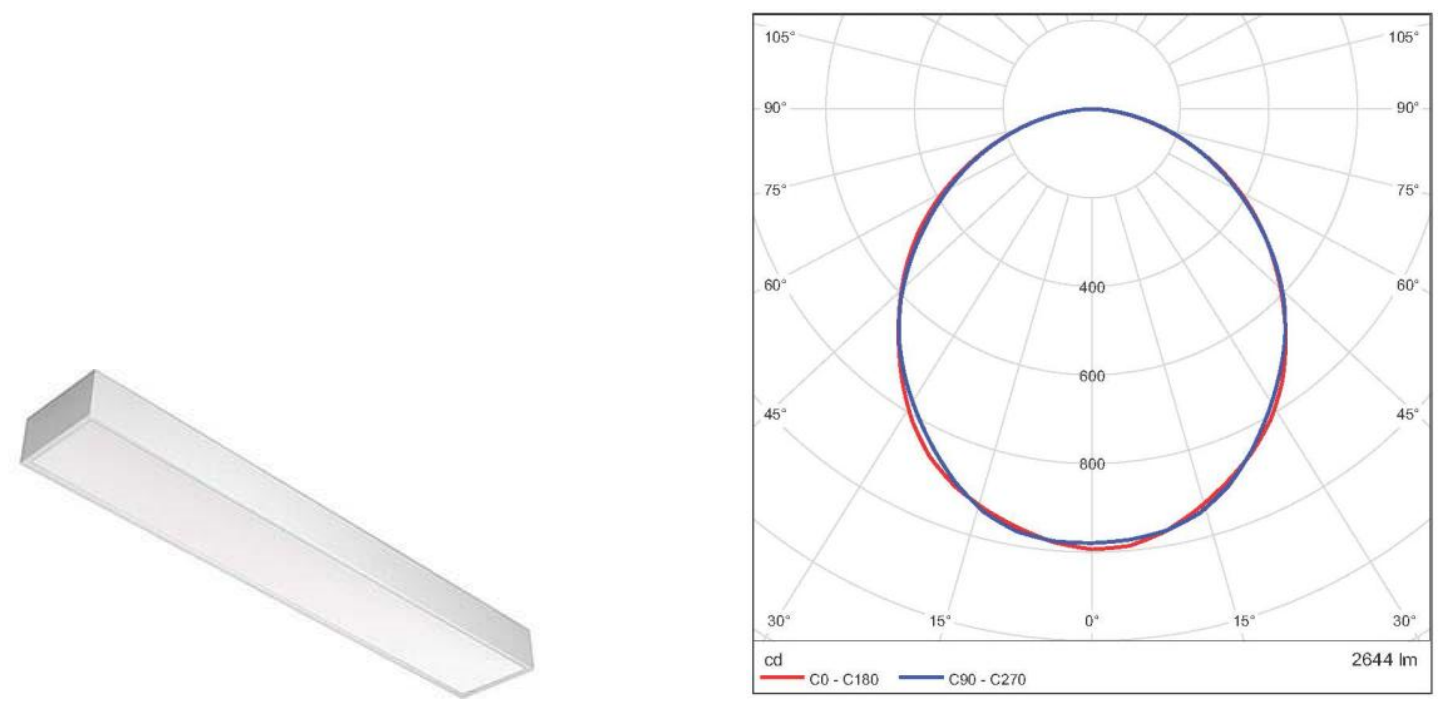

Figura 78: Foto e curva fotométrica ensaiada em laboratório - sistema de iluminação tipo 05 (11.fev.2019)

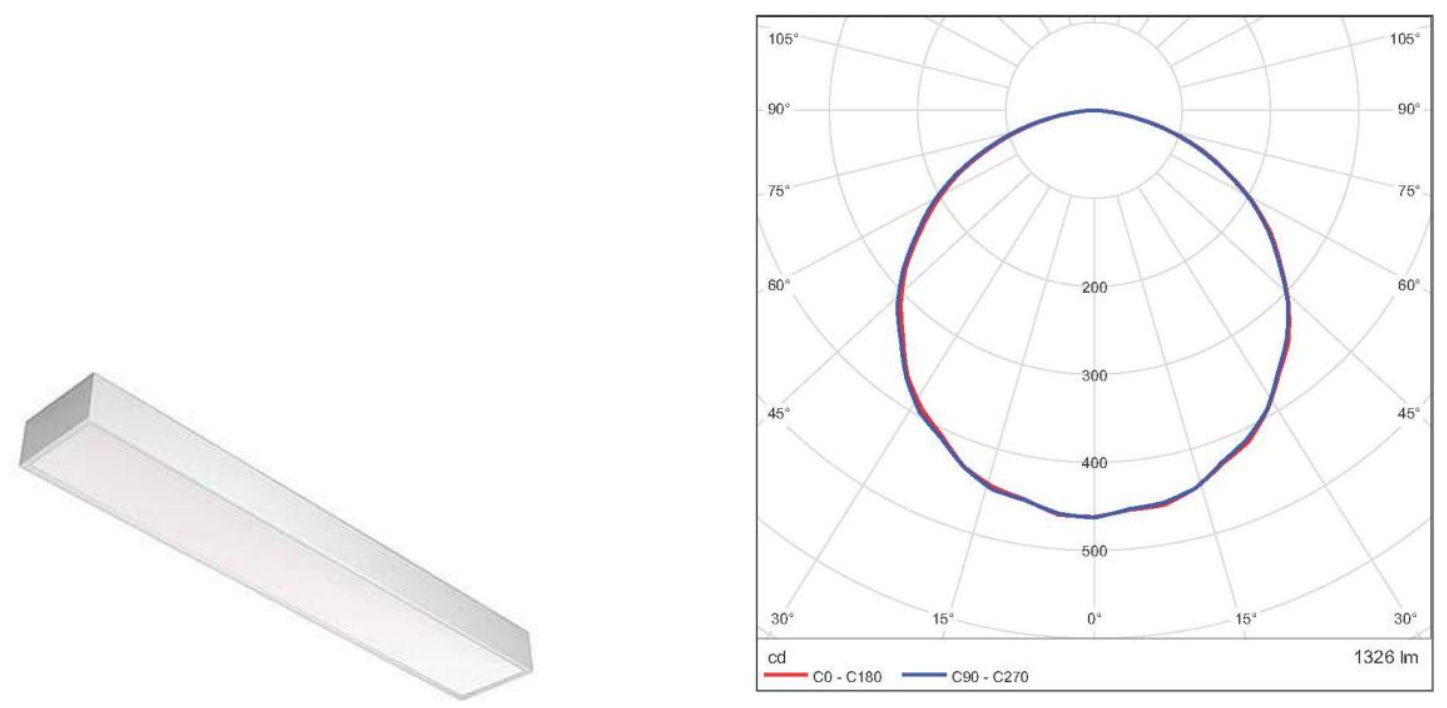

O fluxo luminoso do sistema de iluminação tipo 02 foi de 3361 lúmens, e do tipo 05 foi de 2644 lúmens no primeiro ensaio e 1326 lúmens no segundo. A temperatura de cor medida foi de $6205 \mathrm{~K}, 6321 \mathrm{~K}$ e $5888 \mathrm{~K}$, respectivamente.

Comparando as curvas fotométricas resultantes dos ensaios (Figuras 77 e 78), percebe-se que além do fluxo luminoso, as curvas são diferentes.

No dia 23 de janeiro de 2018, foi realizado o ensaio fotométrico do sistema de iluminação tipo 03 e a estabilização da peça ocorreu após 1 hora. O fluxo luminoso encontrado foi de 2928 lúmens e a temperatura de cor medida foi de 3968K. A Figura 79 mostra a curva fotométrica encontrada em ensaio. 
Figura 79: Foto e curva fotométrica ensaiada em laboratório - sistema de iluminação tipo 03
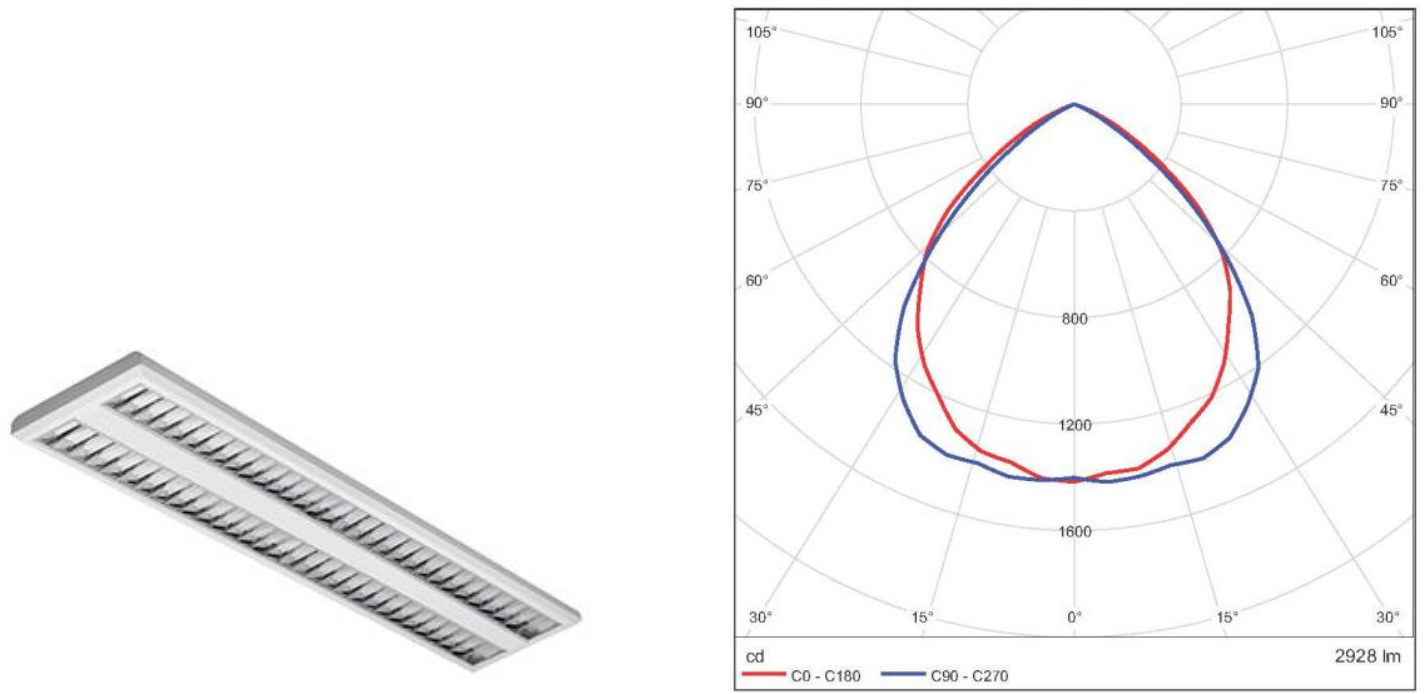

O próximo ensaio com o sistema de iluminação tipo 06 ocorreu no mesmo dia, 23 de janeiro de 2018, e a estabilização do fluxo luminoso também demorou 1 hora. A Figura 80 mostra o resultado da curva fotométrica encontrada após ensaio. Como pode ser visto, o fluxo foi de 4033 lúmens e a temperatura de cor medida foi de $3903 \mathrm{~K}$.

Figura 80: Foto e curva fotométrica ensaiada em laboratório - sistema de iluminação tipo 06

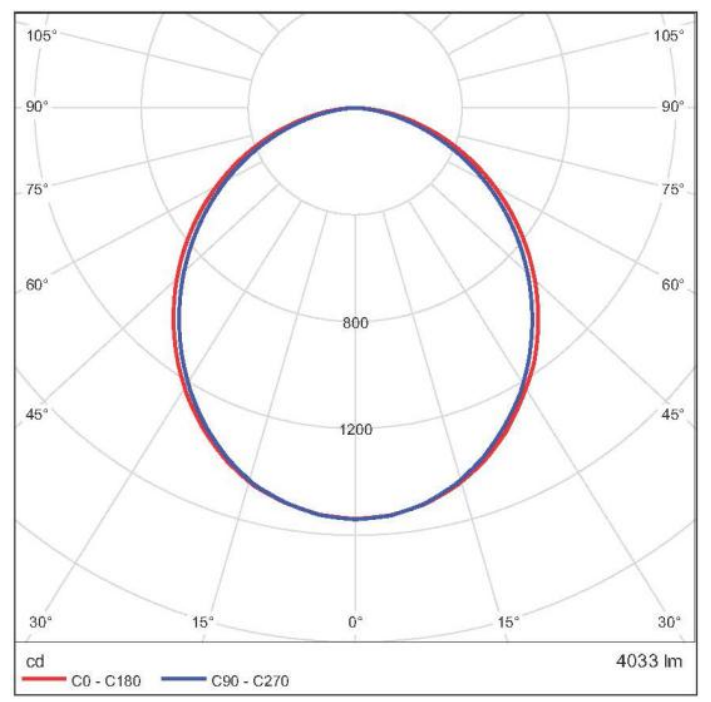

Os ensaios dos sistemas de iluminação utilizando a tecnologia fluorescente ocorreram no final de fevereiro e início de março de 2018. O modelo tipo 04 foi ensaiado no dia 22 de fevereiro e sua estabilização durou 1 hora e 45 minutos. 0 
fluxo encontrado foi de 3265 lúmens e a temperatura de cor de $3879 \mathrm{~K}$. A figura 81 mostra o resultado do ensaio realizado.

Figura 81: Foto e curva fotométrica ensaiada em laboratório - sistema de iluminação tipo 04
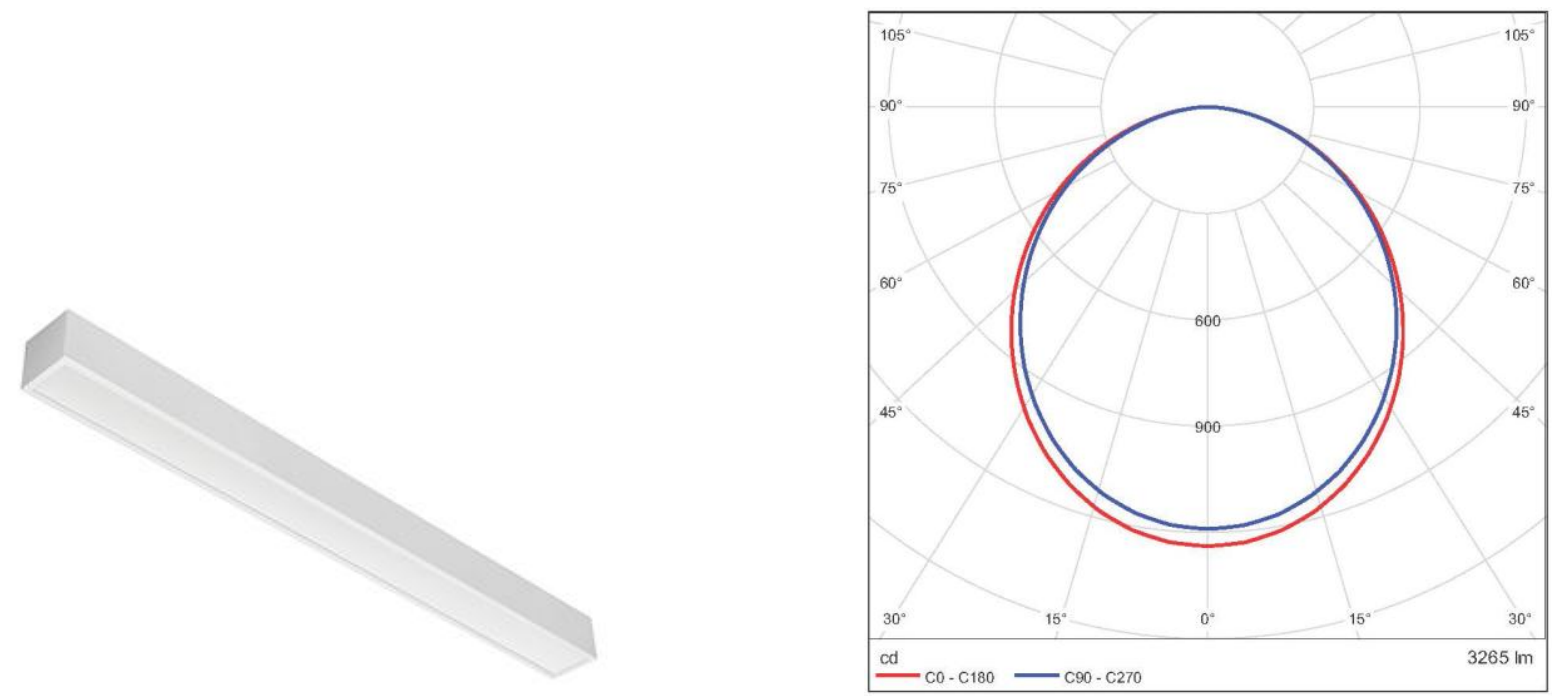

O último ensaio relacionado aos sistemas de iluminação em $0 \mathrm{~h}$ foi realizado no dia 01 de março de 2018 com o modelo tipo 01. A estabilização ocorreu após 30 minutos e o fluxo luminoso obtido do conjunto foi de 3831 lúmens e $3977 \mathrm{~K}$, e a curva fotométrica resultante está ilustrada na Figura 82.

Figura 82: Foto e curva fotométrica ensaiada em laboratório - sistema de iluminação tipo 01
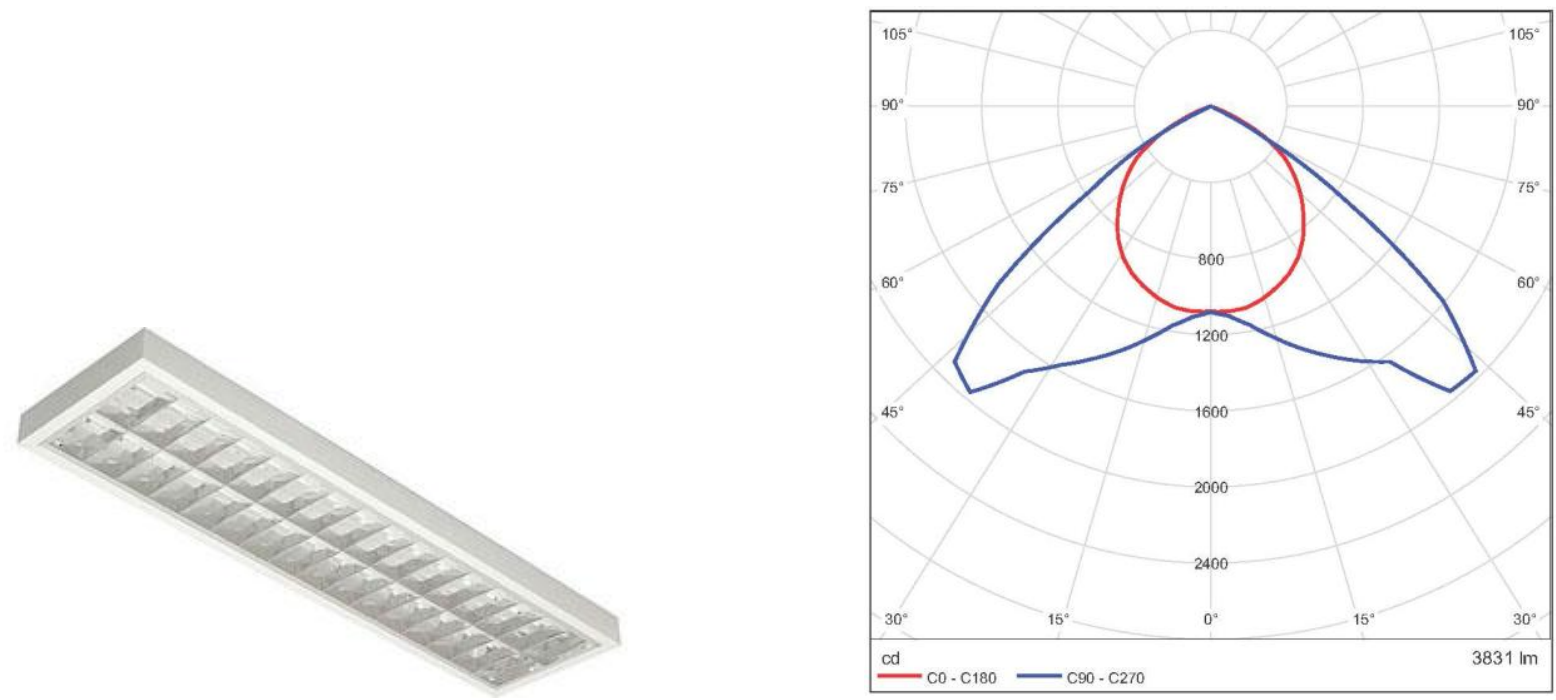
Os arquivos fotométricos gerados com esses ensaios iniciais foram utilizados nas simulações descritas no Capítulo 05. Em relação ao arquivo do conjunto do modelo tipo 5, foi empregado o arquivo fotométrico obtido no ensaio refeito.

\subsection{Ensaios fotométricos finais depreciados}

No final do experimento, os sistemas de iluminação depreciados foram ensaiados novamente com o intuito de verificar sua real depreciação e comparar com os ensaios iniciais realizados. Para cada modelo de luminária, ensaiou-se as duas luminárias usadas no experimento para efeito de comparação. Com o intuito de conferir a depreciação somente da luminária, ensaiaram-se também os mesmos sistemas de iluminação utilizando as lâmpadas novas.

Separadamente, conforme descrito na metodologia, foram também ensaiadas somente as lâmpadas na esfera integradora, com o objetivo de verificar se as mesmas depreciam mais nos modelos com difusores do que nos modelos com aletas.

A Figura 83 mostra a depreciação ocorrida em relação às curvas fotométricas ensaiadas. Fica claro que houve depreciação principalmente na curva fotométrica da luminária 1 do conjunto depreciado, tendo como referência a curva fotométrica inicial. Além disso, podemos observar também que os valores da intensidade luminosa diminuíram.

A temperatura de cor inicial dos sistemas modelo tipo 1 medida foi de 3977K e as luminárias depreciadas apresentaram temperatura de cor de $3834 \mathrm{~K}$ e $3817 \mathrm{~K}$. 
Figura 83: Curvas fotométricas - luminárias modelo tipo 1

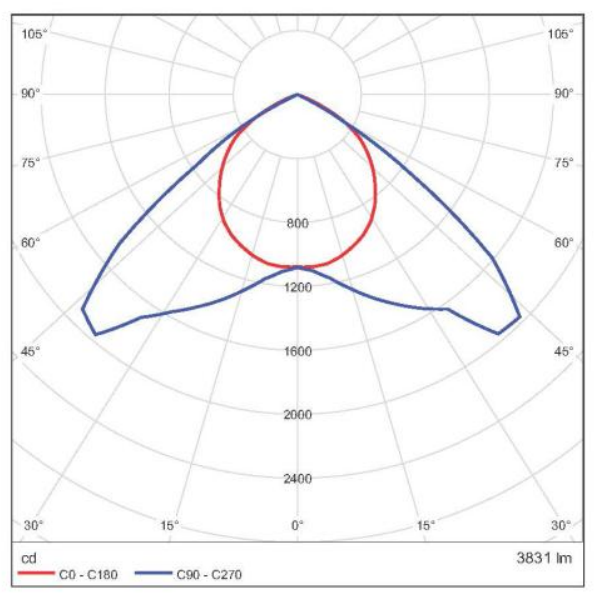

Curva fotométrica inicial

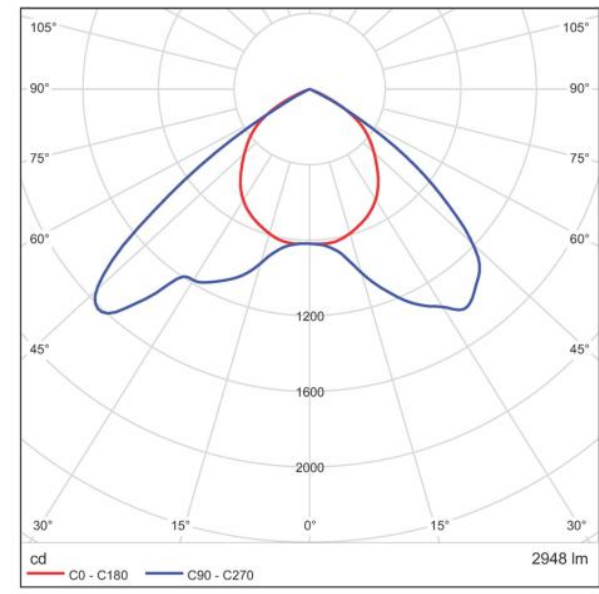

Curva fotométrica depreciada - 1

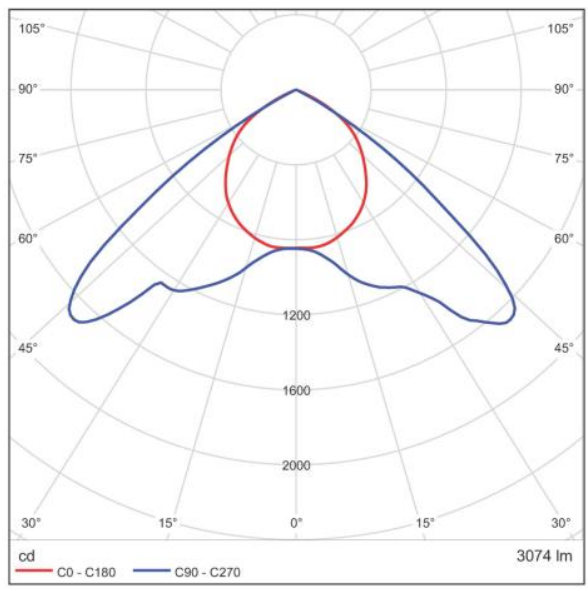

Curva fotométrica depreciada - 2

A Figura 84 ilustra as curvas dos sistemas de iluminação tipo 4 ensaiados. Como há presença de difusor nesse modelo, as curvas mantêm o mesmo formato, porém é possível observar que a intensidade luminosa diminui nos dois conjuntos depreciados.

A temperatura de cor medida no ensaio inicial foi de $3879 \mathrm{~K}$ e as depreciadas apresentaram temperatura de cor de $3668 \mathrm{~K}$ e $3689 \mathrm{~K}$.

Apesar da luminária número 1 ter sofrido falha em um dos componentes, foi possível realizar os ensaios das 2 peças do modelo tipo 4. Verificou-se em laboratório que o reator do sistema de iluminação da luminária número 1 queimou durante o experimento. Dessa forma, para realizar o ensaio, foi utilizado o reator da luminária número 2 do mesmo modelo. 
Figura 84: Curvas fotométricas - luminárias modelo tipo 4

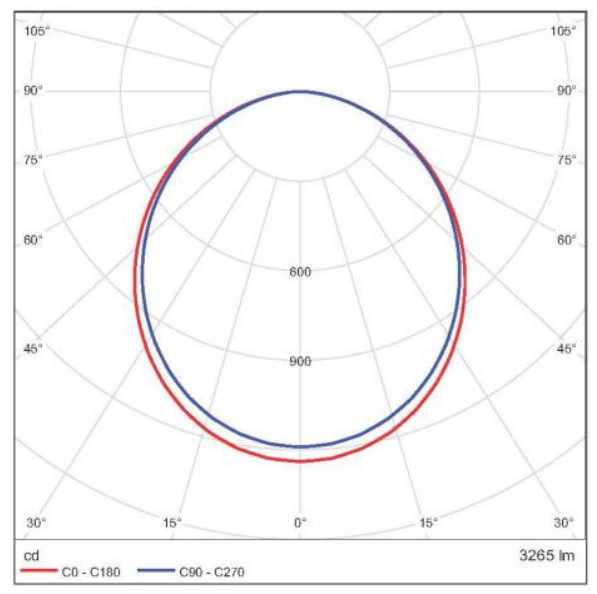

Curva fotométrica inicial

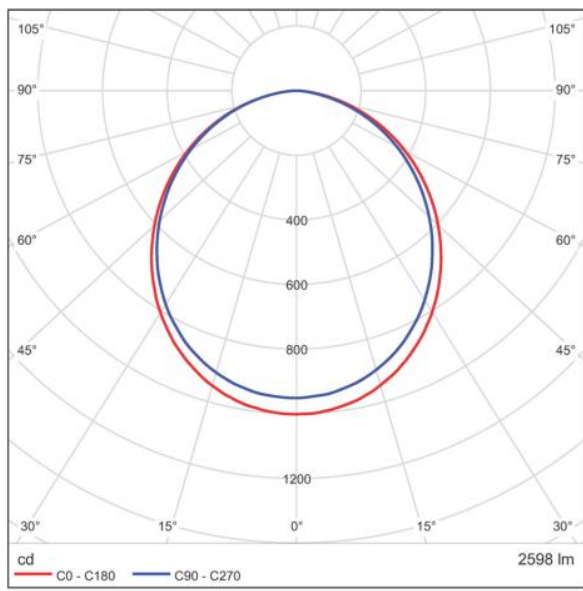

Curva fotométrica depreciada - 1

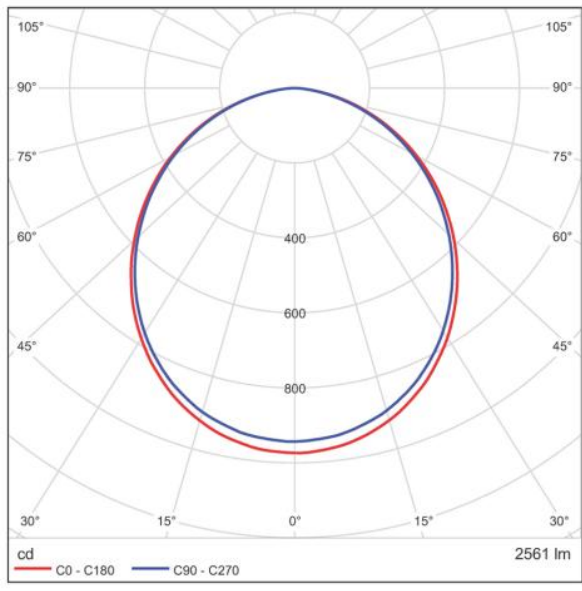

Curva fotométrica depreciada - 2

A seguir compararemos os resultados dos conjuntos que utilizam lâmpadas tubo LED.

A Figura 85 compara a curva fotométrica ensaiada inicialmente e após a depreciação. Observa-se que, nas curvas fotométricas dos conjuntos depreciados, há falhas em um dos lados das curvas de intensidade luminosa. A temperatura de cor inicial era de $6205 \mathrm{~K}$ e as depreciadas apresentaram 6440K e 6470K. 
Figura 85: Curvas fotométricas - luminárias modelo tipo 2

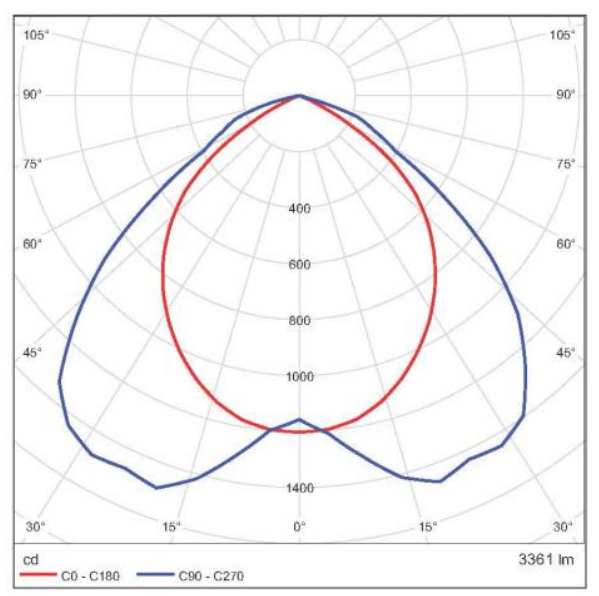

Curva fotométrica inicial

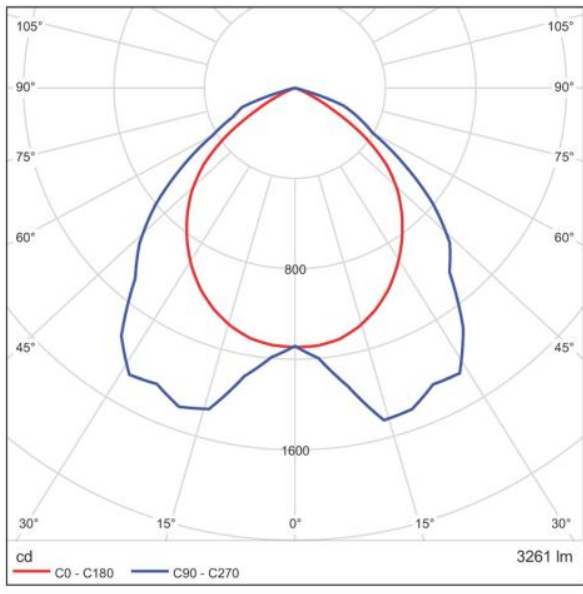

Curva fotométrica depreciada - 1

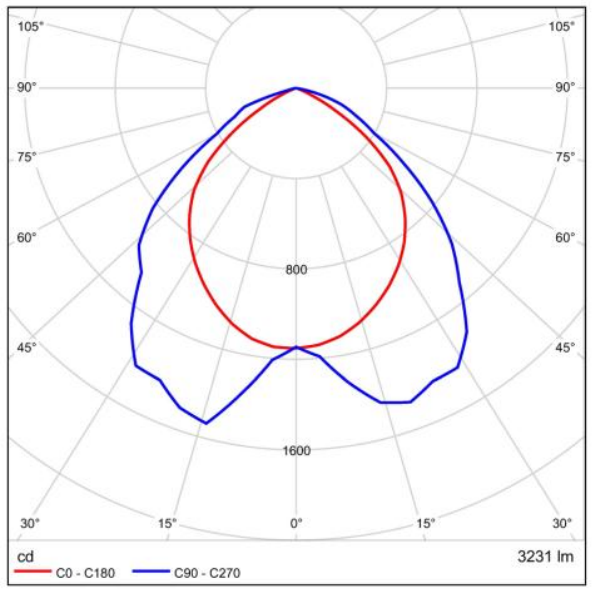

Curva fotométrica depreciada - 2

A Figura 86 mostra as curvas fotométricas dos sistemas de iluminação tipo 5. Percebe-se que a luminária 2 tem a curva de intensidade luminosa depreciada em relação à curva fotométrica inicial. Porém, devido ao fato de os difusores enviados serem diferentes, descartaremos o resultado dos ensaios desse modelo de luminária. A temperatura de cor inicial era de $5888 \mathrm{~K}$ e as depreciadas apresentaram temperatura de cor de $6187 \mathrm{~K}$ e $6058 \mathrm{~K}$.

$\mathrm{Na}$ figura a seguir, a curva fotométrica inicial considerada foi a realizada em feveireiro de 2019. 
Figura 86: Curvas fotométricas - luminárias modelo tipo 5

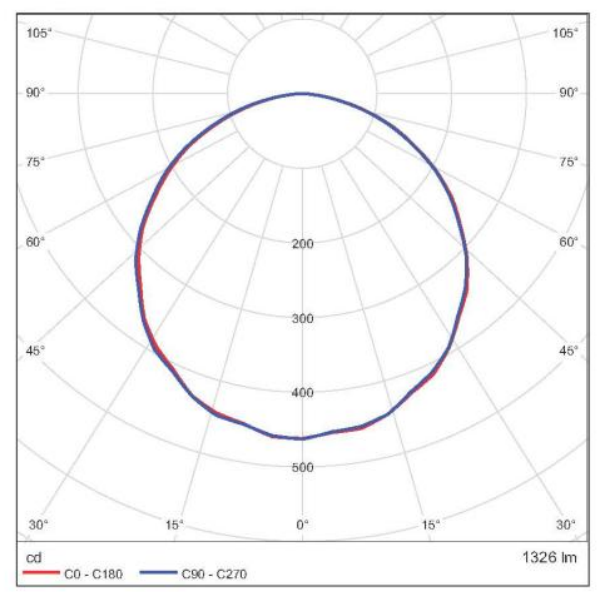

Curva fotométrica inicial

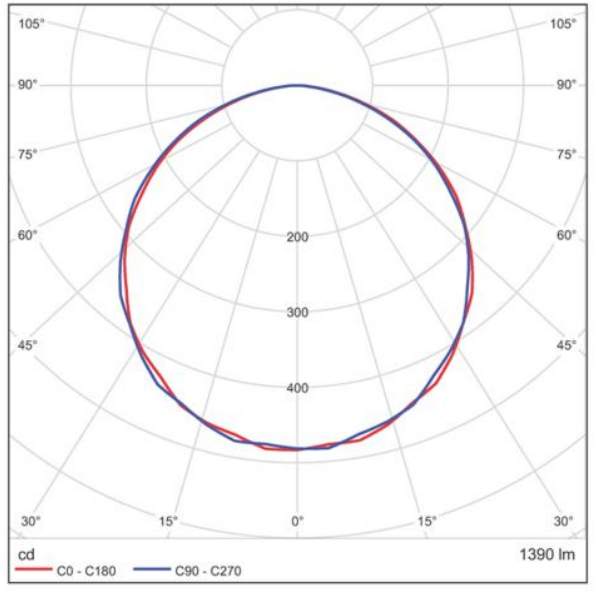

Curva fotométrica depreciada - 1

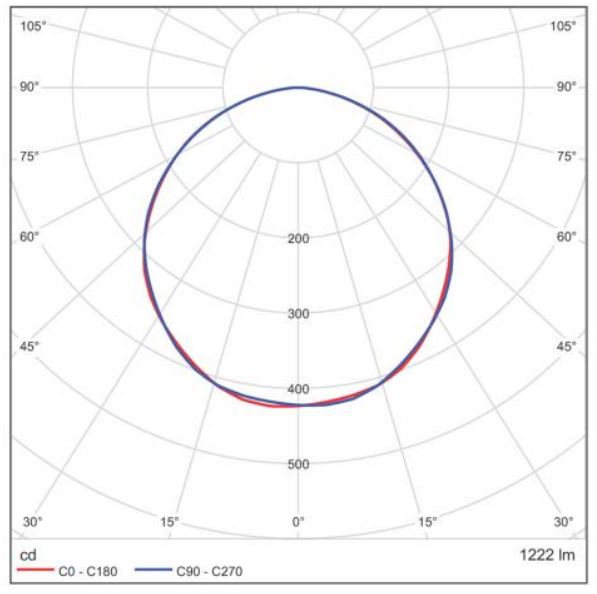

Curva fotométrica depreciada - 2

Por fim, foram ensaiados os sistemas de iluminação onde a tecnologia LED está inserida na própria luminária. Nesse caso, só foi possível ensaiar duas situações: sistema de iluminação Oh - luminárias novas, e sistemas de iluminação depreciadas em 2 anos.

A Figura 87 ilustra as curvas fotométricas dos sistemas de iluminação modelo tipo 3, com LED aplicado na própria luminária. Apesar de o modelo ser com aletas, a peça apresenta um difusor entre as aletas e o LED fixado no corpo da luminária.

Percebe-se, observando as imagens, que houve perda nas curvas do fluxo luminoso medido. A temperatura de cor apresentada no ensaio inicial foi de $3968 \mathrm{~K} \mathrm{e}$, após o experimento, apresentaram temperatura de cor de 4010K e 3992K. 
Figura 87: Curvas fotométricas - luminárias modelo tipo 3

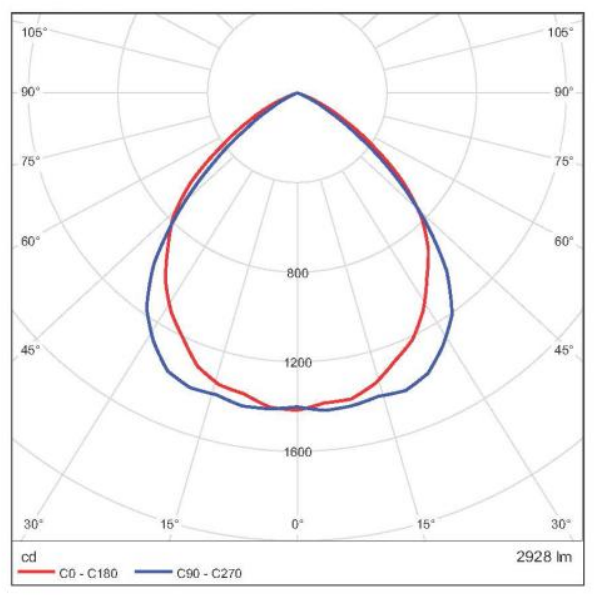

Curva fotométrica inicial

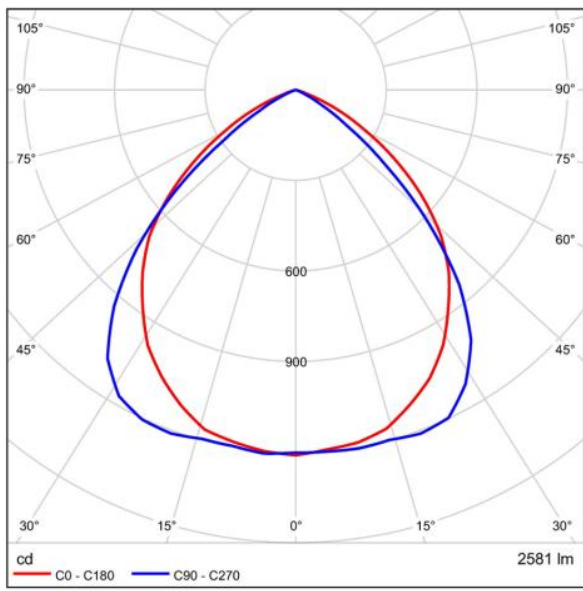

Curva fotométrica depreciada - 1

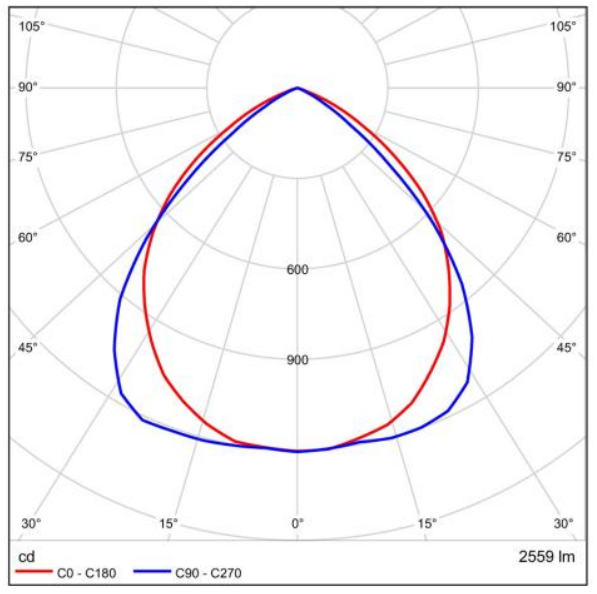

Curva fotométrica depreciada - 2

A figura 88 mostra as curvas fotométricas dos sistemas de iluminação tipo 6 , onde também se percebe-se uma redução nas curvas de fluxo luminoso nos ensaios dos conjuntos depreciados. A temperatura de cor apresentada no ensaio inicial foi de 3903K e, após depreciados, apresentaram temperatura de cor de 3914K e 3909K. 
Figura 88: Curvas fotométricas - luminárias modelo tipo 6

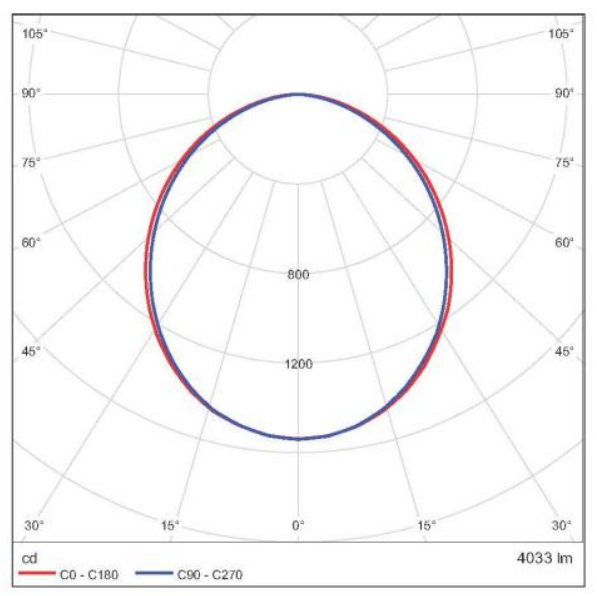

Curva fotométrica inicial

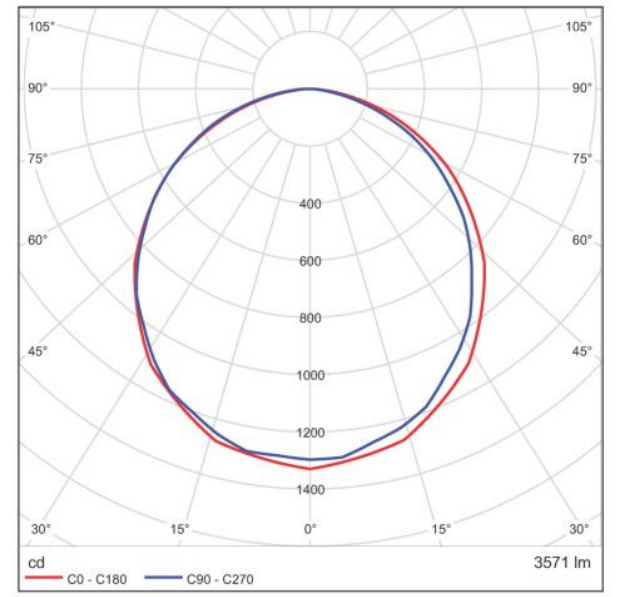

Curva fotométrica depreciada - 1

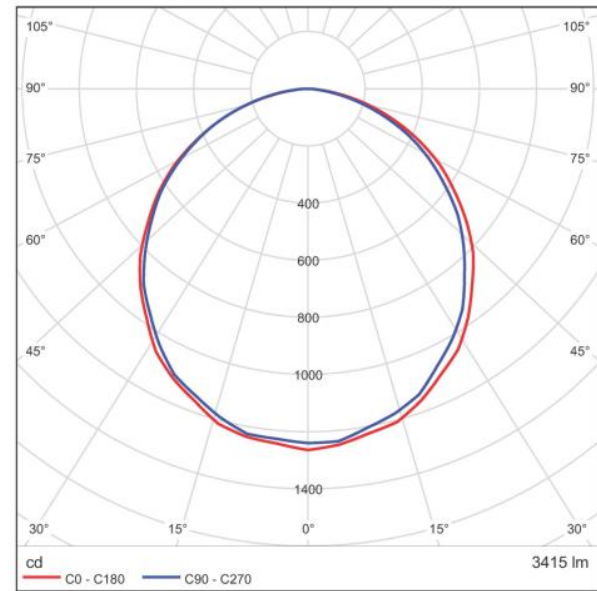

Curva fotométrica depreciada - 2

\subsection{Resultados dos ensaios}

As tabelas a seguir mostram os resultados do fluxo luminoso, em lumens, dos ensaios realizados. Os valores são resultantes dos ensaios iniciais com o sistema de iluminação novo, adquirido após início do experimento, como mencionado anteriormente, e o ensaio das duas luminárias utilizadas para medição em duas situações: uma com todo o sistema de iluminação depreciado (luminária, lâmpada e equipamento auxiliar) e outra com a troca somente das lâmpadas depreciadas por novas.

Todas as lâmpadas do experimento também foram ensaiadas na esfera integradora. Nas tabelas, são mostradas o fluxo luminoso médio obtido por meio de 
ensaio das duas lâmpadas novas e o fluxo de cada lâmpada utilizada no experimento e em cada conjunto de luminária.

Tabela 9: Tabela de fluxo luminoso em lumens dos sistemas de iluminação com lâmpadas fluorescentes tubulares

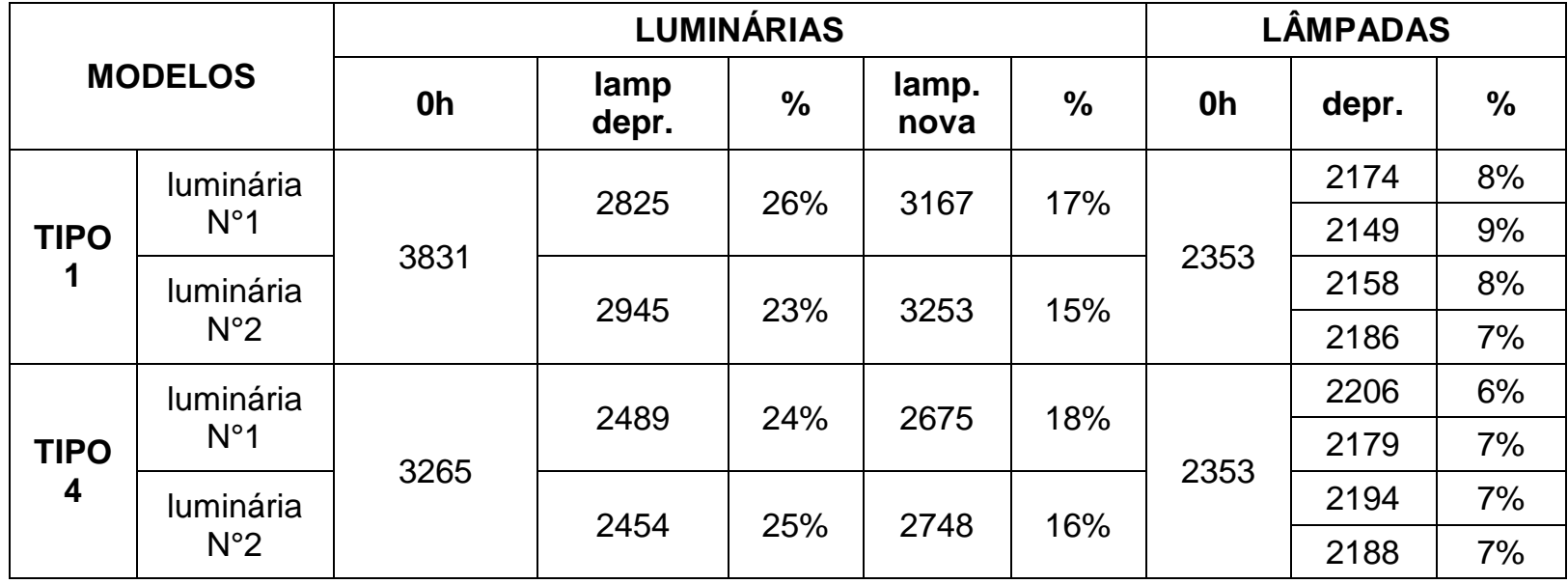

A Tabela 9 é o resultado dos sistemas de iluminação que utilizam a tecnologia fluorescente tubular. Esses foram retirados da célula teste e ensaiados após 18 meses acesos.

No caso desses sistemas de iluminação, não se poderá comparar a porcentagem da depreciação do conjunto luminárias mais lâmpadas com a porcentagem depreciação somente das lâmpadas, pois há uma diferença nos resultados decorrente das lâmpadas terem sido ensaiadas com o reator de referência e as luminárias com as lâmpadas terem sido ensaiadas com o reator do experimento. No entanto, o que será considerado é a depreciação do fluxo total em si.

Observa-se nos resultados dos ensaios dos sistemas de iluminação utilizando a tecnologia fluorescente, que houve entre $23 \%$ e $25 \%$ de depreciação no sistema de iluminação tipo 1 , e entre $24 \%$ e $25 \%$ de depreciação no tipo 4 , ou seja, a depreciação do conjunto foi próxima entre os modelos com aletas e com difusor.

Se considerar apenas a depreciação da luminária, os índices observados nos modelos tipo 1 foram de 15\% com a luminária 1 e 17\% com a luminária 2 e, nos modelos tipo 4, foram de 16\% com a luminária 1 e 18\% com a luminária 2 , implicando em apenas 1\% de diferença na depreciação das luminárias. As lâmpadas sofreram entre $5 \%$ e $9 \%$ de depreciação no fluxo medido em esfera. 
Com esses resultados, podemos concluir que, no experimento realizado com lâmpadas fluorescentes tubulares, a depreciação dos modelos com aletas e com difusor é bem próxima. Logo, não há depreciação maior no modelo onde o sistema de iluminação está fechado pelo difusor, como era esperado no que diz respeito às lâmpadas e aos sistemas de iluminação.

Tabela 10: Tabela de fluxo luminoso em lumens dos sistemas de iluminação com lâmpadas tubo LED

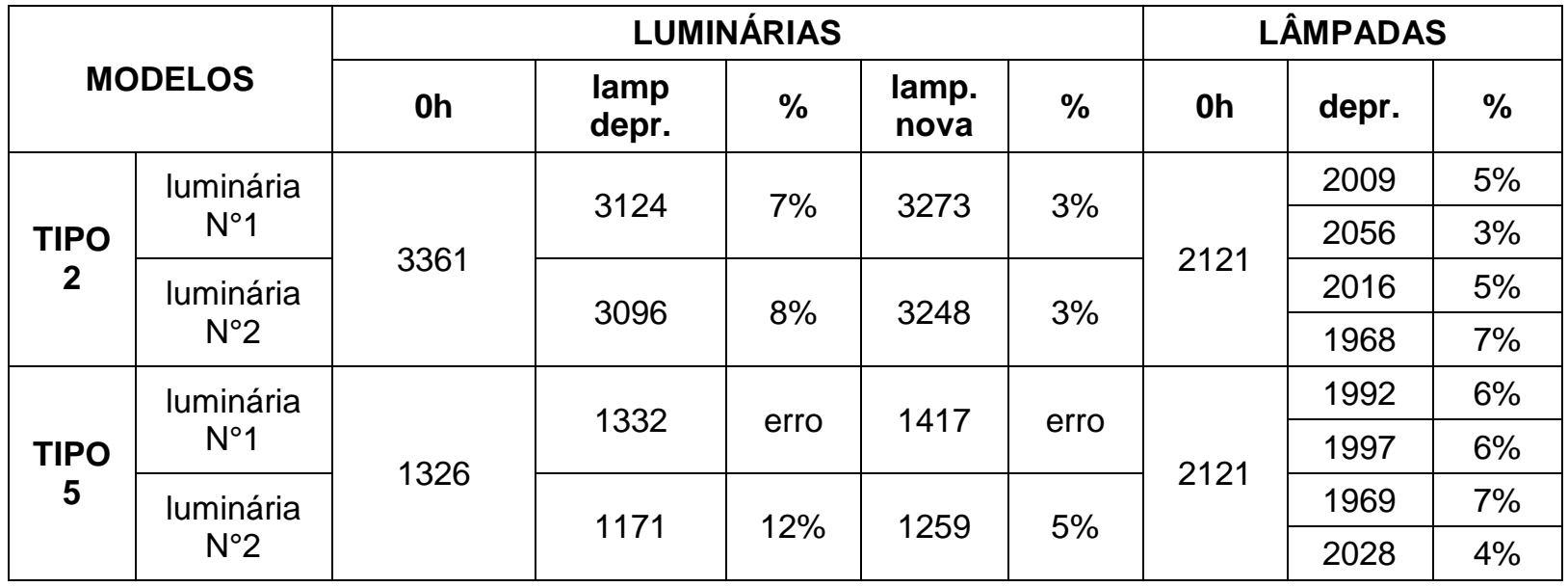

A Tabela 10 apresenta os resultados obtidos em ensaio dos sistemas de iluminação utilizando lâmpada tubo LED após 2 anos depreciados.

Analisando a depreciação do conjunto dos sistemas de iluminação no modelo tipo 2, a depreciação foi de $7 \%$ (luminária 1) e $8 \%$ (luminária 2) no conjunto de luminárias mais lâmpadas depreciadas. A depreciação da luminária ficou em 3\% nas duas luminárias no ensaio onde foram utilizadas as lâmpadas novas.

A análise do conjunto do modelo 5 foi descartada devido ao problema do difusor que veio diferente na solicitação realizada pelo IEE. Pelos dados obtidos, é provável que ainda haja diferença entre os difusores nas luminárias utilizadas no experimento. Na comparação de valores do fluxo luminoso, observa-se uma grande diferença entre a luminária número um e número dois.

Utilizando o novo fluxo luminoso obtido com o novo ensaio realizado, descrito neste capítulo, subitem 4.2. Ensaios fotométricos iniciais, percebeu-se talvez os difusores da luminária número um e dois fossem diferentes. Um segundo ensaio seria necessário para comprovar essa teoria. No entanto, devido aos outros serviços do laboratório, não foram possíveis de serem realizados dentro do prazo para 
finalização desta pesquisa. Assim, um erro no resultado foi gerado, pois o fluxo final das luminárias depreciadas ficou maior que o inicial.

A depreciação das lâmpadas dos sistemas de iluminação tipo 2, modelo com aletas, foi entre $3 \%$ e $7 \%$, e nas lâmpadas dos sistemas de iluminação tipo 5 , modelo com difusor, foi entre $4 \%$ e $7 \%$. Podemos dizer que, para as lâmpadas tubo LED, a depreciação somente das lâmpadas é praticamente a mesma.

Tabela 11: Tabela de fluxo luminoso em lumens dos sistemas de iluminação com LED acoplado

\begin{tabular}{|c|c|c|c|c|}
\hline \multicolumn{2}{|c|}{} & \multicolumn{3}{c|}{ LUMINÁRIAS } \\
\cline { 5 - 5 } & \multirow{2}{*}{ Oh } & luminária depreciada & $\%$ \\
\hline \multirow{2}{*}{ TIPO 3 } & luminária N¹ & \multirow{2}{*}{2928} & 2473 & $15 \%$ \\
\cline { 2 - 3 } & luminária N² & & 2452 & $16 \%$ \\
\cline { 5 - 5 } & & 3422 & $15 \%$ \\
\hline \multirow{2}{*}{ TIPO 6 } & luminária N¹ & \multirow{2}{*}{4033} & 3272 & $19 \%$ \\
\cline { 2 - 3 } & luminária N² & & & \\
\cline { 4 - 5 } & &
\end{tabular}

A Tabela 11 mostra que o sistema de iluminação do modelo com aletas (tipo 3) depreciou $15 \%$ com a luminária 1 e $16 \%$ com a luminária 2, enquanto o modelo com difusor (tipo 6) depreciou 15\% com a luminária 1 e 19\% com a 2. Neste caso, esperava-se que a luminária tipo 3 depreciasse mais que a tipo 6 devido à presença de aletas e difusor, no entanto os percentuais de depreciação apresentaram-se muito semelhantes.

Infelizmente, pelo problema ocorrido com o difusor em um dos modelos de luminárias fornecidos, e pelo fato da depreciação encontrada no modelo tipo $6 \mathrm{em}$ ensaio ser bem maior que a encontrada nas medições, os resultados não foram conclusivos no tocante ensaios dos modelos com difusor.

No entanto, são válidas para a análise dos modelos com aletas e para a comparação dos resultados somente das lâmpadas.

Comparando os resultados dos ensaios observa-se que a porcentagem maior da depreciação dos sistemas de iluminação com aletas provêm da depreciação das lâmpadas, e uma parcela provêm do acúmulo de sujeira no próprio sistema. 


\section{CAPÍTULO 5}

SIMULAÇÕES 


\section{SIMULAÇÕES}

\subsection{Considerações preliminares}

Neste capítulo, foram comparados os resultados das simulações de três programas de cálculo luminotécnico mais utilizados no Brasil em relação à confiabilidade de dados e aos recursos oferecidos. São eles: Dialux EVO, AGi32 e Relux.

O objetivo foi verificar se há diferenças nos seus resultados. Foram comparadas três situações: uma com a sala vazia considerando as reflexões de teto, parede e piso, conforme definido no Capítulo 3 de metodologia; uma com a presença de mobiliários nas salas, estes fornecidos pela própria biblioteca de cada programa; e por fim as salas com a presença de mobiliários com acabamentos e cores aplicados tanto no ambiente como no mobiliário.

Os resultados principais encontram-se nas figuras a seguir, e o memorial de cálculo encontra-se no Anexo II, III e IV, respectivamente dos programas Dialux EVO, AGi32 e Relux.

\subsection{Simulações com ambiente vazio}

A grande maioria dos arquitetos e lighting designers apresentam um quantitativo final do sistema de iluminação de um ambiente baseado em cálculos considerando a sala vazia, o qual, em alguns casos, é realizado por meio do método das eficiências ou método dos lumens.

Os cálculos são realizados nesta situação, pois na maior parte dos casos, os mobiliários e acabamentos dos ambientes ainda não foram definidos e/ou não há tempo hábil para apresentação das simulações com um grande detalhamento.

Os arquivos fotométricos utilizados foram os ensaiados pela pesquisadora no laboratório do IEE, considerando zero depreciação. 
Figura 89: Resultado cálculo ponto a ponto - luminária tipo 1 - sala vazia

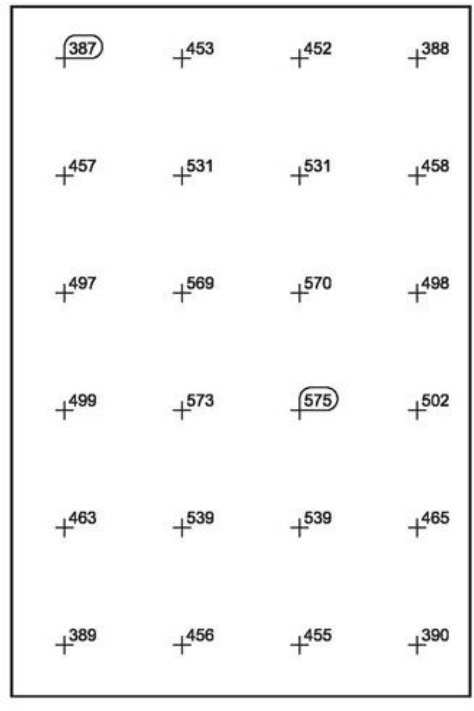

Programa Dialux EVO

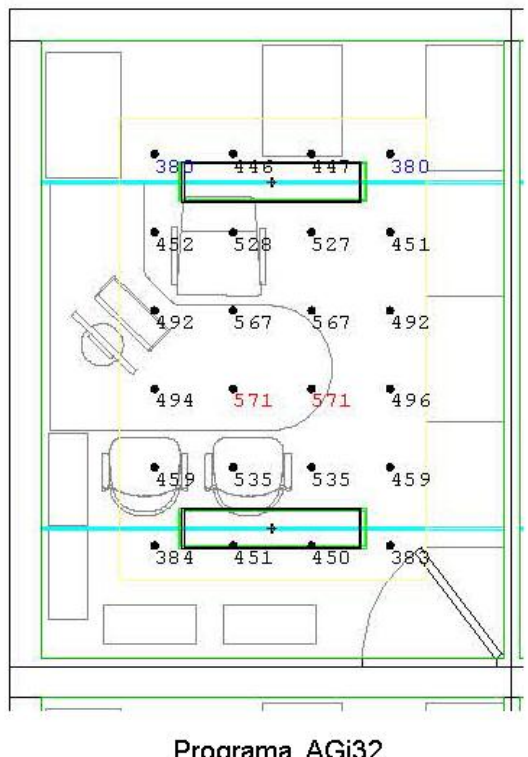

Programa AGi32

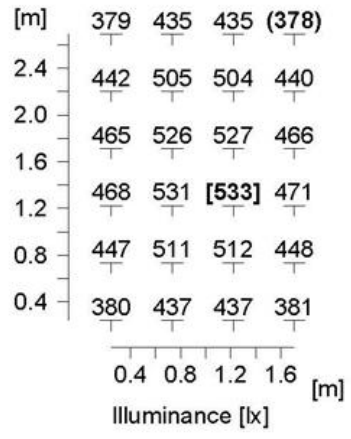

Programa Relux

A Figura 89, mostra os resultados ponto a ponto calculados nos programas Dialux EVO, Agi32 e Relux, respectivamente, utilizando a luminária tipo 1. Como pode ser visto, a diferença do nível de iluminância é no máximo de $5 \%$ comparando os resultados do programa Dialux EVO com o Relux. A diferença cai para $1 \%$ se comparados os resultados entre o programa Dialux EVO e Agi32.

As Figuras 90, 91, 92, 93 e 94 mostram os resultados ponto a ponto das luminárias tipo 2, 3, 4, 5 e 6, respectivamente. A diferença do nível de iluminância se mantém no máximo entre $4 \%$ e $5 \%$.

Figura 90: Resultado cálculo ponto a ponto - luminária tipo 2 - sala vazia

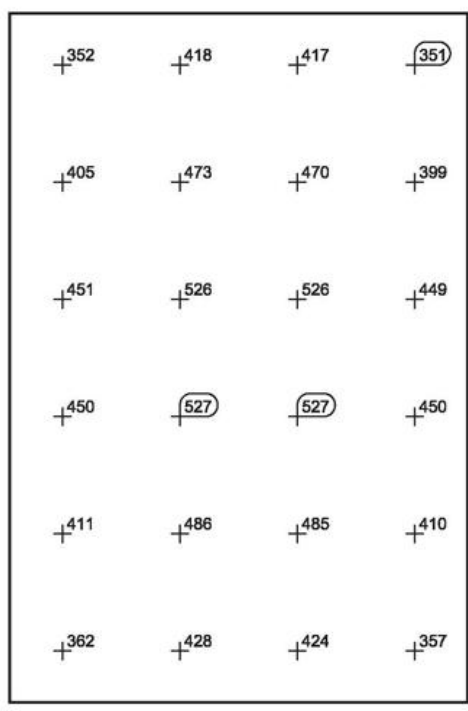

Programa Dialux EVO

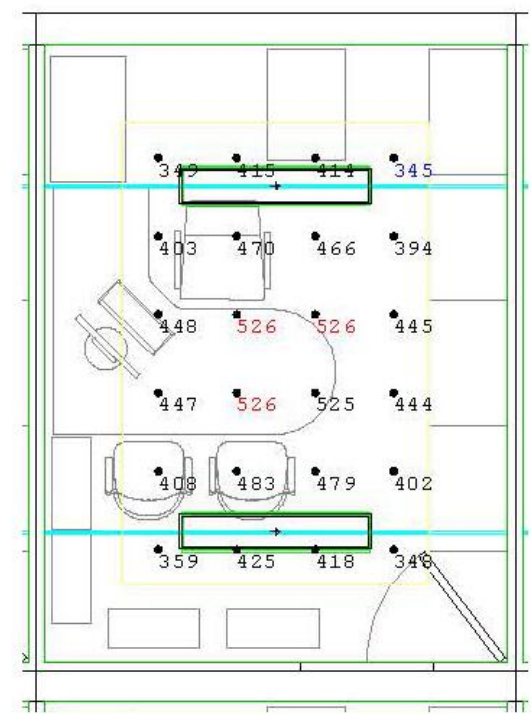

Programa AGi32

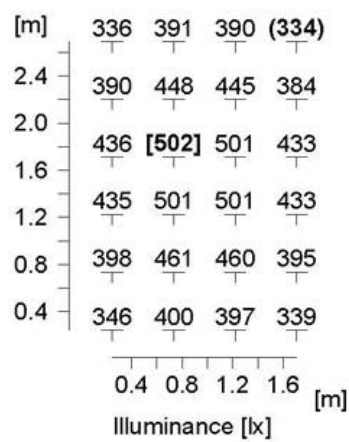

Programa Relux 
Figura 91: Resultado cálculo ponto a ponto - luminária tipo 3 - sala vazia

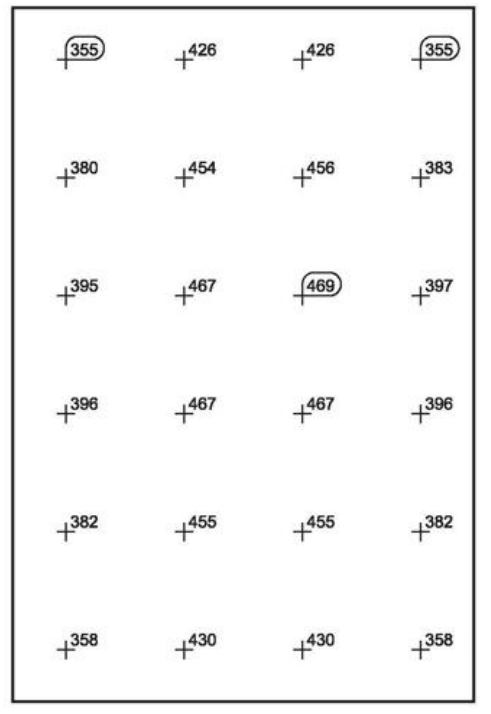

Programa Dialux EVO

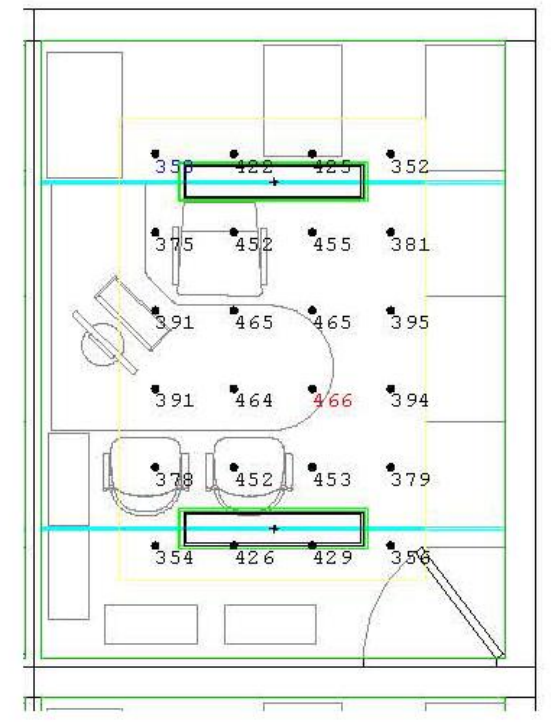

Programa AGi32 [m] (340) $401 \quad 401 \quad 342$

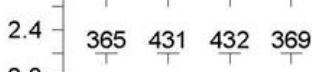
$384 \quad 447$ [450] 388 $\begin{array}{lllll}385 & 448 & 448 & 386\end{array}$ $\begin{array}{llll}368 & 431 & 431 & 369\end{array}$ $\begin{array}{llll}341 & 403 & 404 & 342\end{array}$ $\begin{array}{lllllll}0.4 & 0.8 & 1.2 & 1.6 & {[\mathrm{~m}]}\end{array}$ Illuminance [lx]

Programa Relux

Figura 92: Resultado cálculo ponto a ponto - luminária tipo 4 - sala vazia

\begin{tabular}{cccc}
$t^{346}$ & $t^{404}$ & $t^{406}$ & $t^{350}$ \\
$t^{362}$ & $f^{417}$ & $t^{415}$ & $t^{359}$ \\
$t^{347}$ & $t^{394}$ & $t^{394}$ & $f^{345}$ \\
$f^{345}$ & $t^{392}$ & $t^{392}$ & $f^{345}$ \\
$t^{358}$ & $t^{414}$ & $t^{415}$ & $t^{361}$ \\
$t^{355}$ & $t^{414}$ & $t^{412}$ & $t^{351}$ \\
\hline
\end{tabular}

Programa Dialux EVO

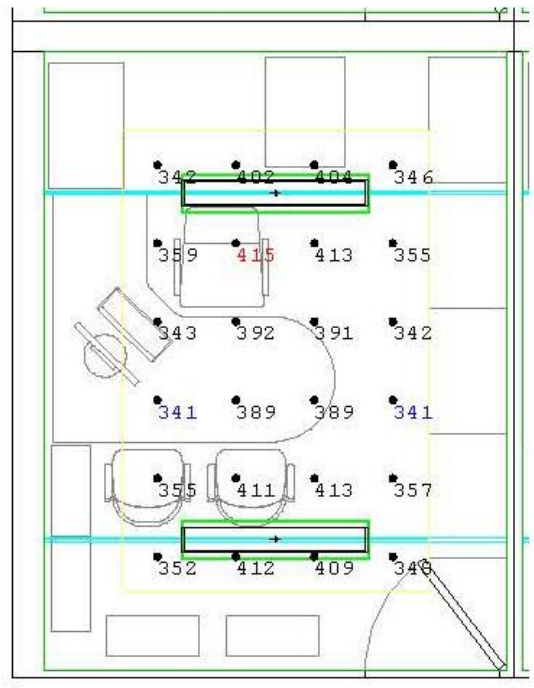

Programa AGi32 [m] (328) $\begin{array}{llll}378 & 381 & 333\end{array}$ $2.4-344$ [391] $390 \quad 342$ $\begin{array}{lllll}2.0 & 333 & 375 & 375 & 333\end{array}$ 1.2 - $\frac{332}{T} \quad \frac{374}{T} \quad \frac{374}{T} \quad \frac{332}{T}$ 0.8 - $\begin{array}{lllll}341 & 389 & 390 & 343\end{array}$ $0.4-337 \quad 386 \quad 384 \quad 333$ $\begin{array}{llllll}0.4 & 0.8 & 1.2 & 1.6 & {[\mathrm{~m}]}\end{array}$ Illuminance $[\mathrm{l} x]$

Programa Relux 
Figura 93: Resultado cálculo ponto a ponto - luminária tipo 5 - sala vazia

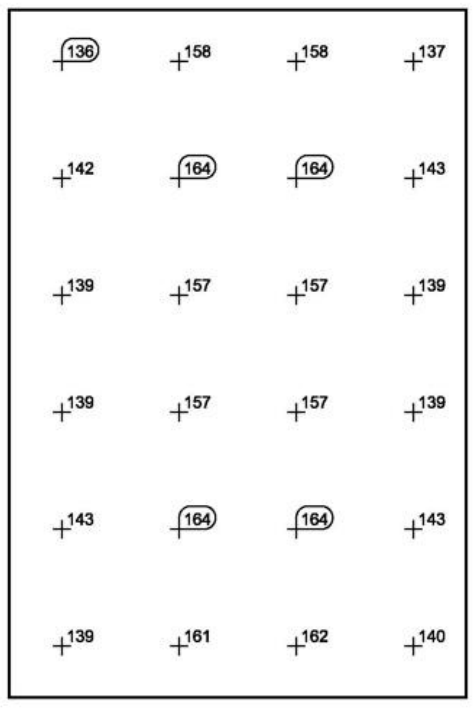

Programa Dialux EVO

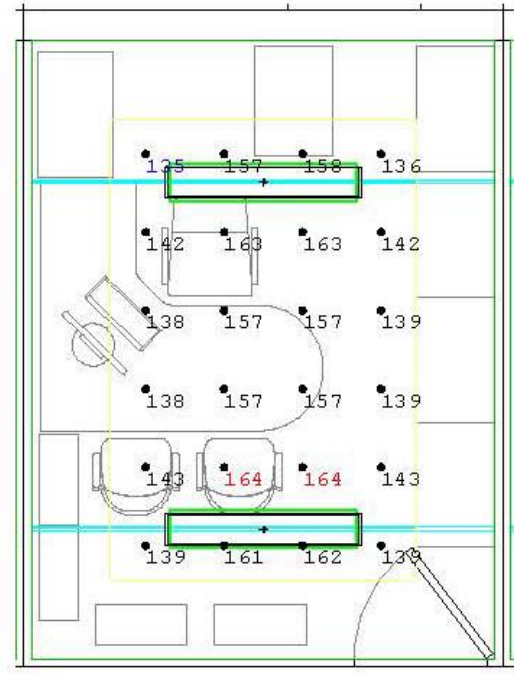

Programa AGi32 [m] (132) $150 \quad 150$ (132)

$2.4-138$ - $157 \quad 157 \quad 139$

$\begin{array}{llll}136 & 153 & 153 & 137\end{array}$

$\begin{array}{llll}136 & 153 & 153 & 137\end{array}$

139 [158] $157 \quad 139$

\begin{tabular}{l|llll}
0.4 & 135 & 154 & 154 & 135
\end{tabular}

$\begin{array}{llllll}0.4 & 0.8 & 1.2 & 1.6 & {[\mathrm{~m}]}\end{array}$

Illuminance $[\mathrm{l} x]$

Programa Relux

Figura 94: Resultado cálculo ponto a ponto - luminária tipo 6 - sala vazia

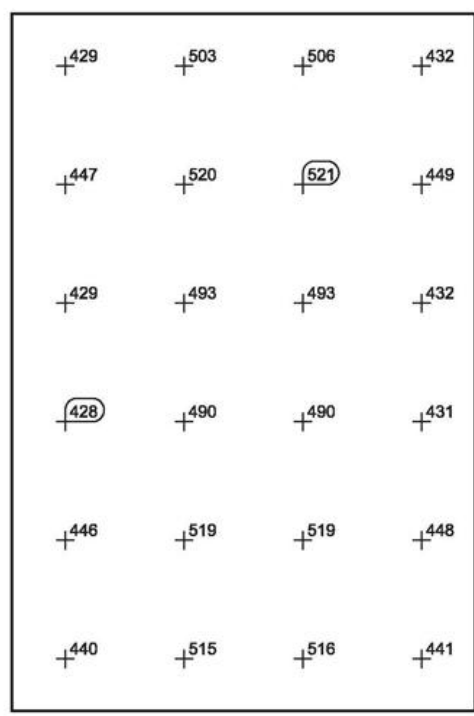

Programa Dialux EVO

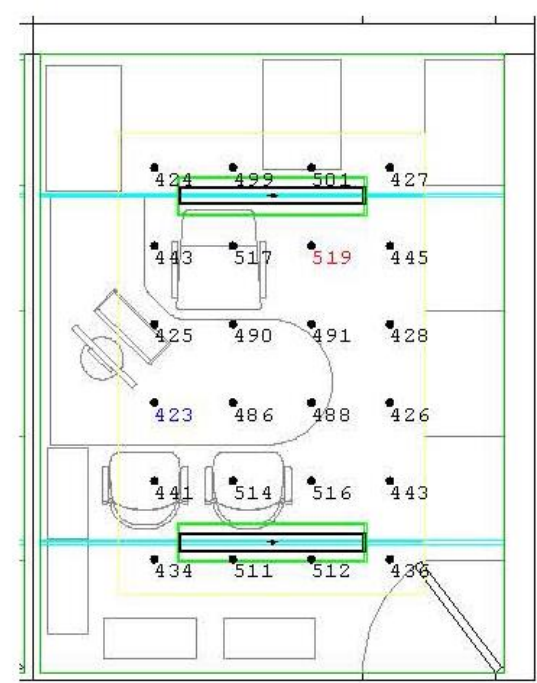

Programa AGi32 [m] (408) $473 \quad 473 \quad 410$

$2.4-427$ [489] $\frac{488}{T} \quad 426$ $\begin{array}{llll}415 & 471 & 471 & 416\end{array}$ $414 \quad 469 \quad 470 \quad 416$

$0.8-424 \quad 487 \quad 488 \quad 427$

$0.4-415 \quad 479 \quad 481 \quad 417$ $\begin{array}{llllll}0.4 & 0.8 & 1.2 & 1.6 & {[\mathrm{~m}]}\end{array}$ Illuminance [lx]

Programa Relux

Observa-se que os resultados obtidos pelos cálculos dos programas Dialux EVO, Relux e Agi32 não apontaram grande diferença. Ou seja, o usuário pode escolher, dentre esses, o programa de cálculo que melhor se adaptar ao seu uso. 


\subsection{Simulações com mobiliário}

A seguir, foram simulados os mesmos ambientes com o acréscimo de mobiliários. A finalidade de simular com mobiliário foi verificar se há grande diferença em inseri-los no cálculo luminotécnico e qual a diferença no resultado. Como foi dito anteriormente, em muitos casos o layout do projeto ainda não foi definido e não entra na etapa de cálculo.

Os mobiliários ou objetos inseridos em cálculo foram os fornecidos por cada programa. Desta maneira, cada mobiliário acrescentado tem sua particularidade e seu acabamento.

As figuras seguintes mostram os resultados ponto a ponto dos cálculos. $O$ primeiro ambiente é referente ao cálculo ponto a ponto do Dialux EVO, o segundo do Agi32, e o terceiro do Relux.

Figura 95: Resultado do cálculo ponto a ponto - luminária 1 - sala mobiliada

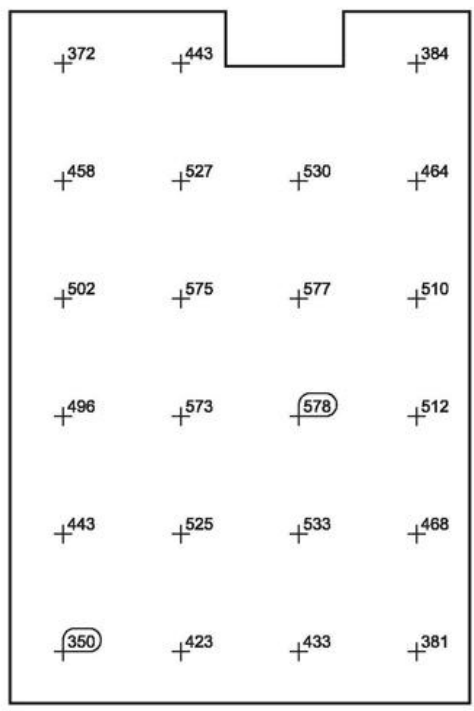

Programa Dialux EVO

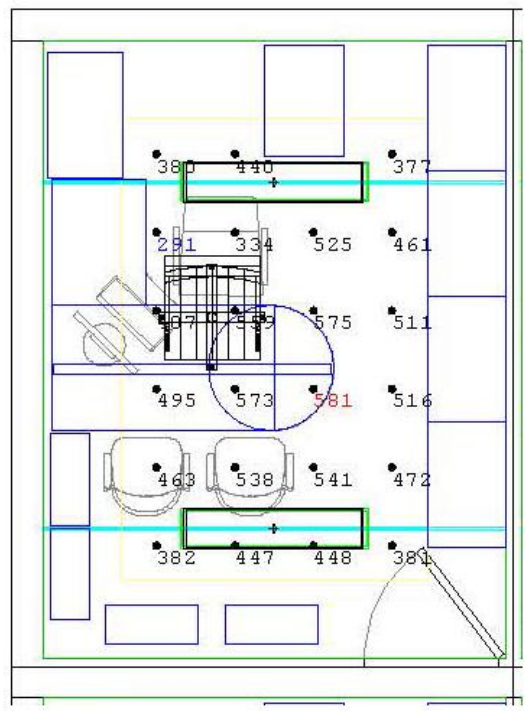

Programa AGi32

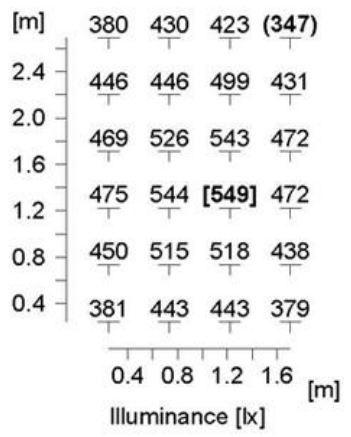

Programa Relux 
Figura 96: Resultado do cálculo ponto a ponto - luminária tipo 2 - sala mobiliada

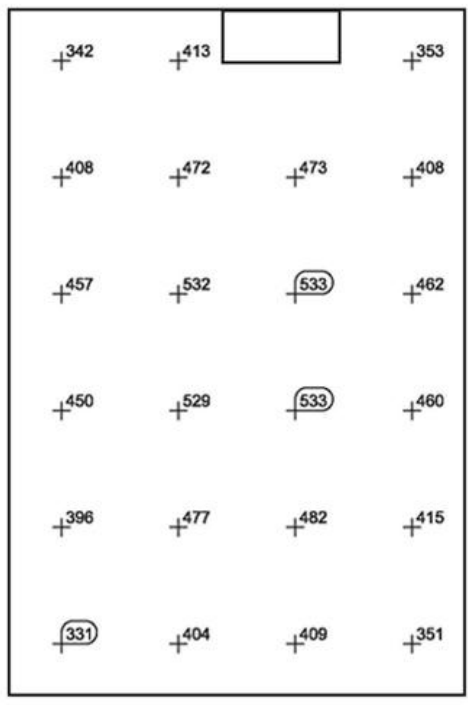

Programa Dialux EVO

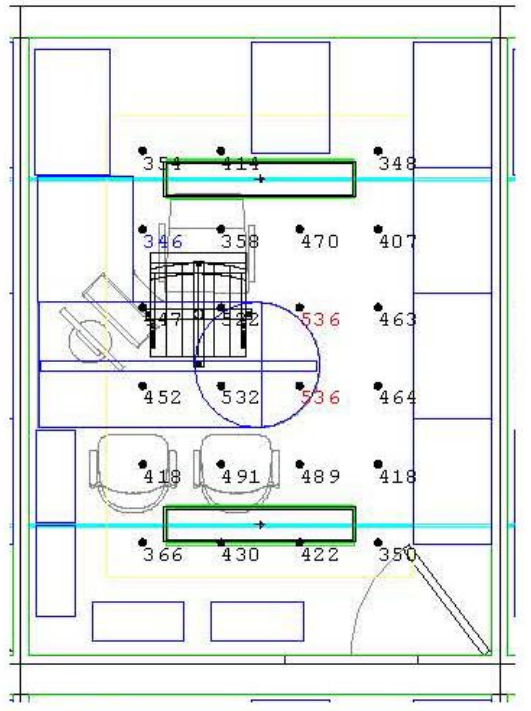

Programa AGi32

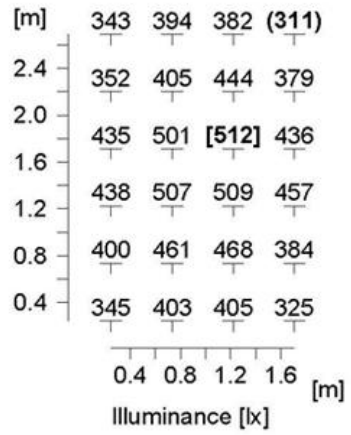

Programa Relux

Figura 97: Resultado do cálculo ponto a ponto - luminária tipo 3 - sala mobiliada

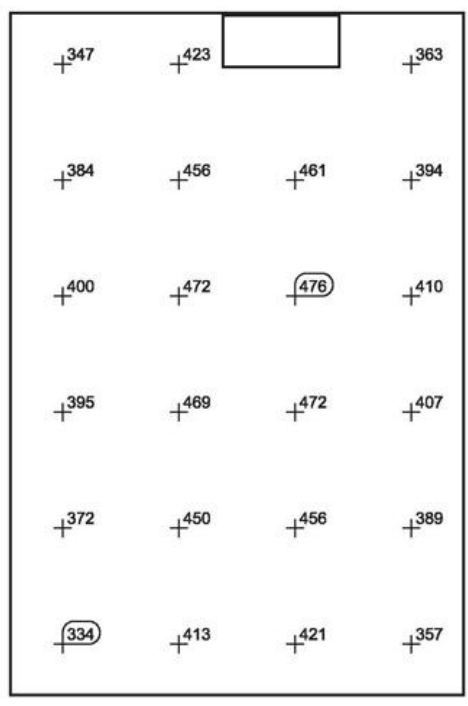

Programa Dialux EVO

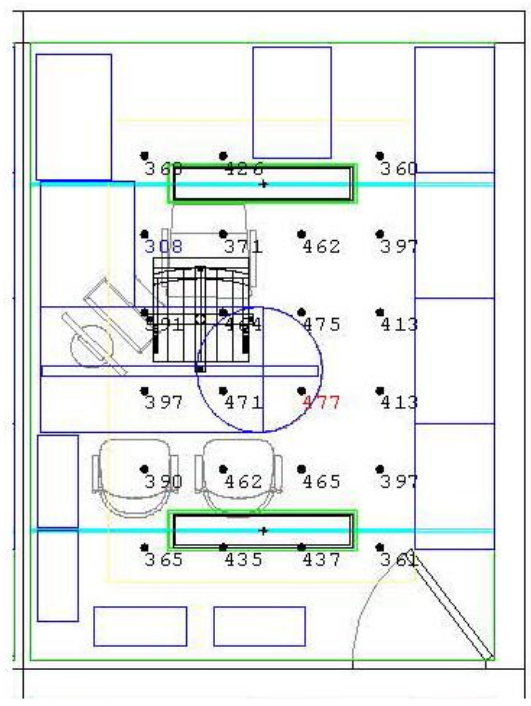

Programa AGi32 [m] $332 \quad 393 \quad 393 \quad(321)$

$2.4-335 \quad 396 \quad 431 \quad 368$

2.0 - $383 \quad 449$ [459] 394

$1.2-\frac{390}{T} \quad \frac{453}{T} \quad \frac{458}{T} \quad \frac{405}{T}$

$0.8-\frac{372}{T} \quad \frac{431}{T} \quad 440 \quad 383$

$\begin{array}{llllll}0.4 & 340 & 403 & 410 & 348\end{array}$

$\begin{array}{llllll}0.4 & 0.8 & 1.2 & 1.6 & {[\mathrm{~m}]}\end{array}$

Illuminance [lx]

Programa Relux 
Figura 98: Resultado do cálculo ponto a ponto - luminária tipo 4 - sala mobiliada

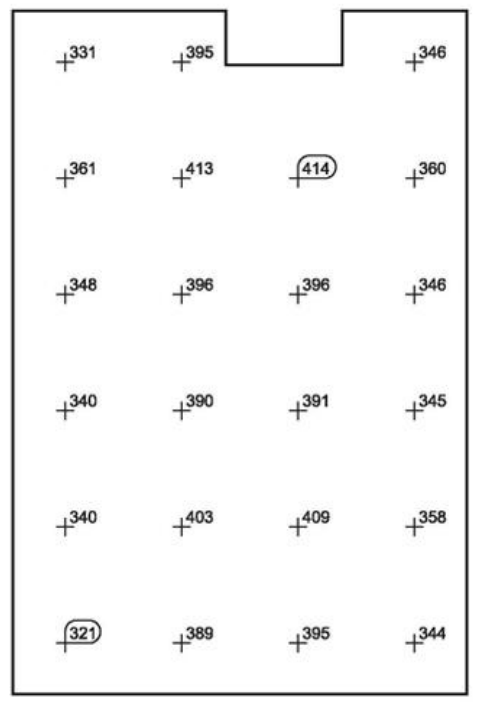

Programa Dialux EVO

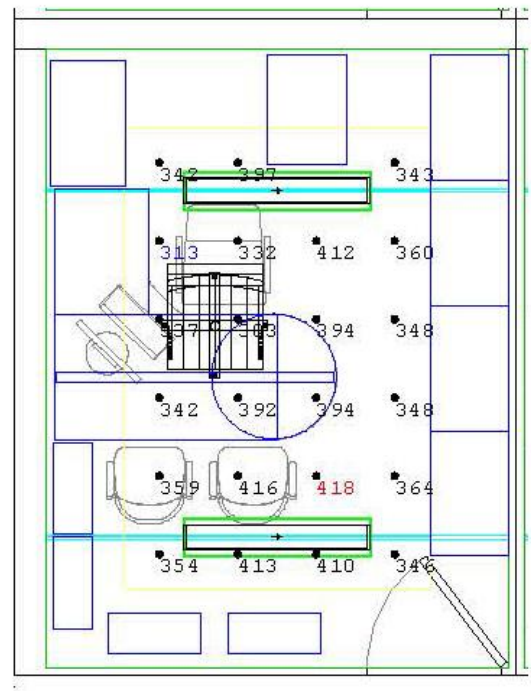

Programa AGi32 [m] $\begin{array}{llll}315 & 370 & 367 & (301)\end{array}$

$2.4-335 \quad 359 \quad 387 \quad 331$

$2.0-334 \quad 375 \quad 384 \quad 331$

$1.2-\frac{336}{T} \quad \frac{376}{T} \quad \frac{377}{T} \quad \frac{337}{T}$

$0.8-\frac{335}{T} 390$ [396] 339

$0.4-\begin{array}{llll}315 & 367 & 374 & 317\end{array}$

$\begin{array}{llllll}0.4 & 0.8 & 1.2 & 1.6 & {[\mathrm{~m}]}\end{array}$

Illuminance [lx]

Programa Relux

Figura 99: Resultado do cálculo ponto a ponto - luminária tipo 5 - sala mobiliada

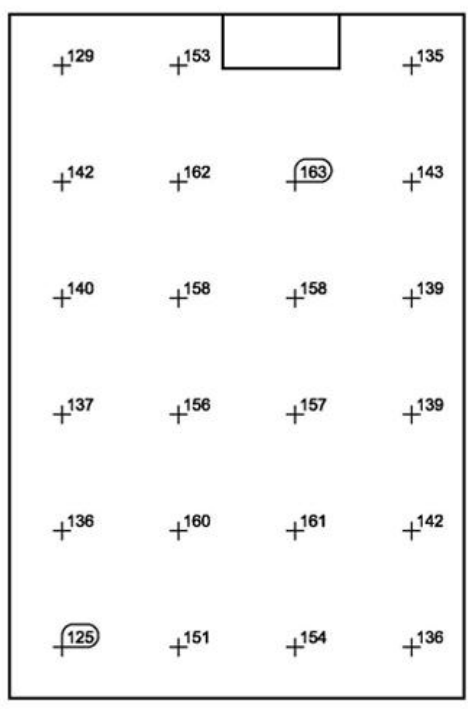

Programa Dialux EVO

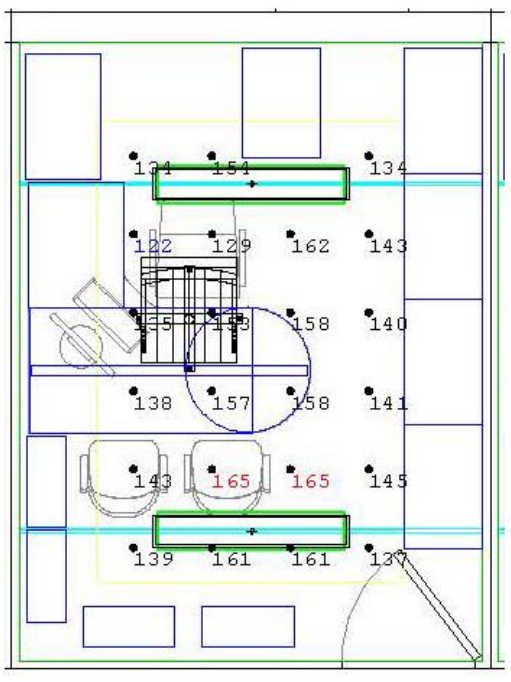

Programa AGi32

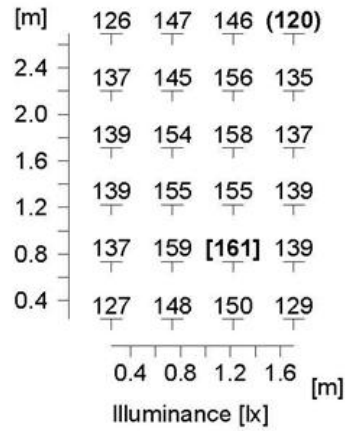

Programa Relux 
Figura 100: Resultado do cálculo ponto a ponto - luminária tipo 6 - sala mobiliada

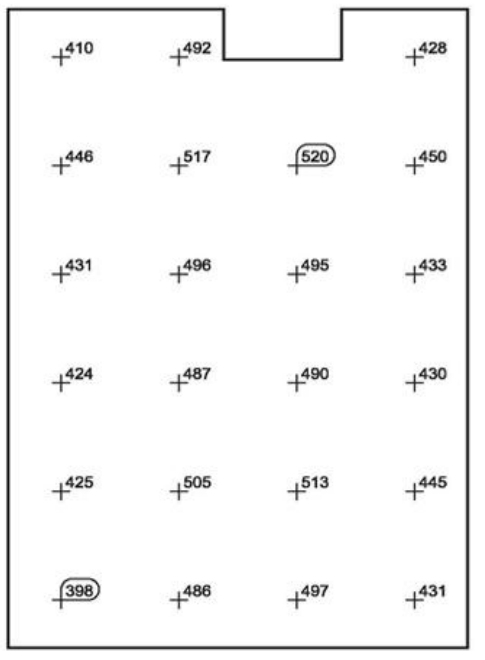

Programa Dialux EVO

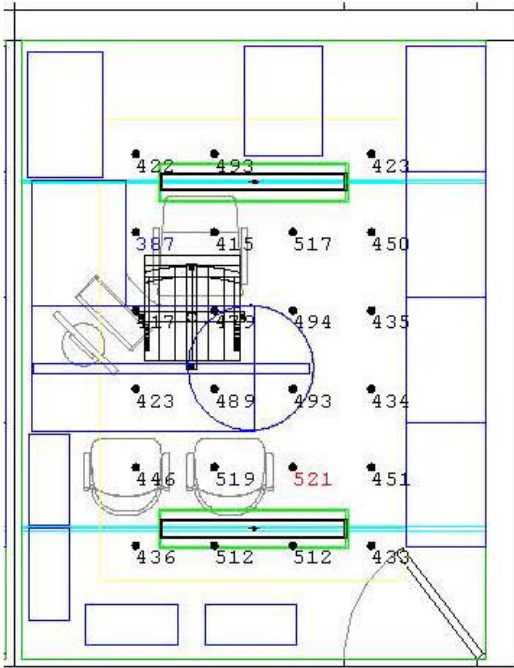

Programa AGi32

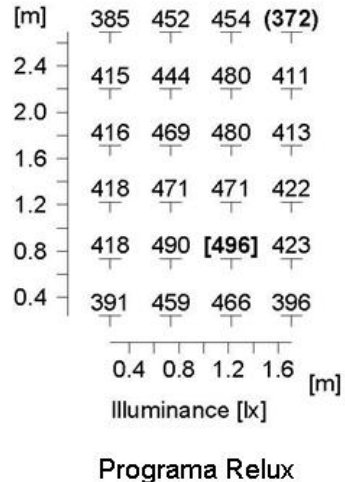

Programa Relux

Analisando os resultados das Figuras 95 a 100, observa-se que a diferença do resultado da iluminância permanece no máximo em $5 \%$ se comparados os programas Dialux EVO e Agi32 com o Relux. Entre os programas Dialux EVO e Relux, a diferença fica no máximo em $1 \%$.

Como podem ser observados nas figuras anteriores, os programas Dialux EVO e Agi32 permitem retirar os pontos onde temos a presença de mobiliários. Já no programa Relux, como a distância entre os pontos ficou em aproximadamente 0,49 m, os pontos não coincidiram com o mobiliário. Por isso temos 24 pontos totais no programa Relux, ao invés de 23 pontos como nos outros programas.

\subsection{Simulação com mobiliário e cromaticidade}

Por fim, para comparar os resultados das simulações e da experimentação, os ambientes foram modelados o mais próximo possível da célula teste.

Para determinar a cor mais próxima do real foi utilizado o programa Adobe Kuler que, por meio de uma foto da célula teste, consegue verificar a composição de cores RGB ou HEX. Com base em uma imagem ou foto é possível analisar a cor aproximada de um objeto. 
A Figura 101 a seguir mostra as cores encontradas por meio da foto da sala utilizada.

Figura 101: Imagem da célula teste no programa Adobe Kuler

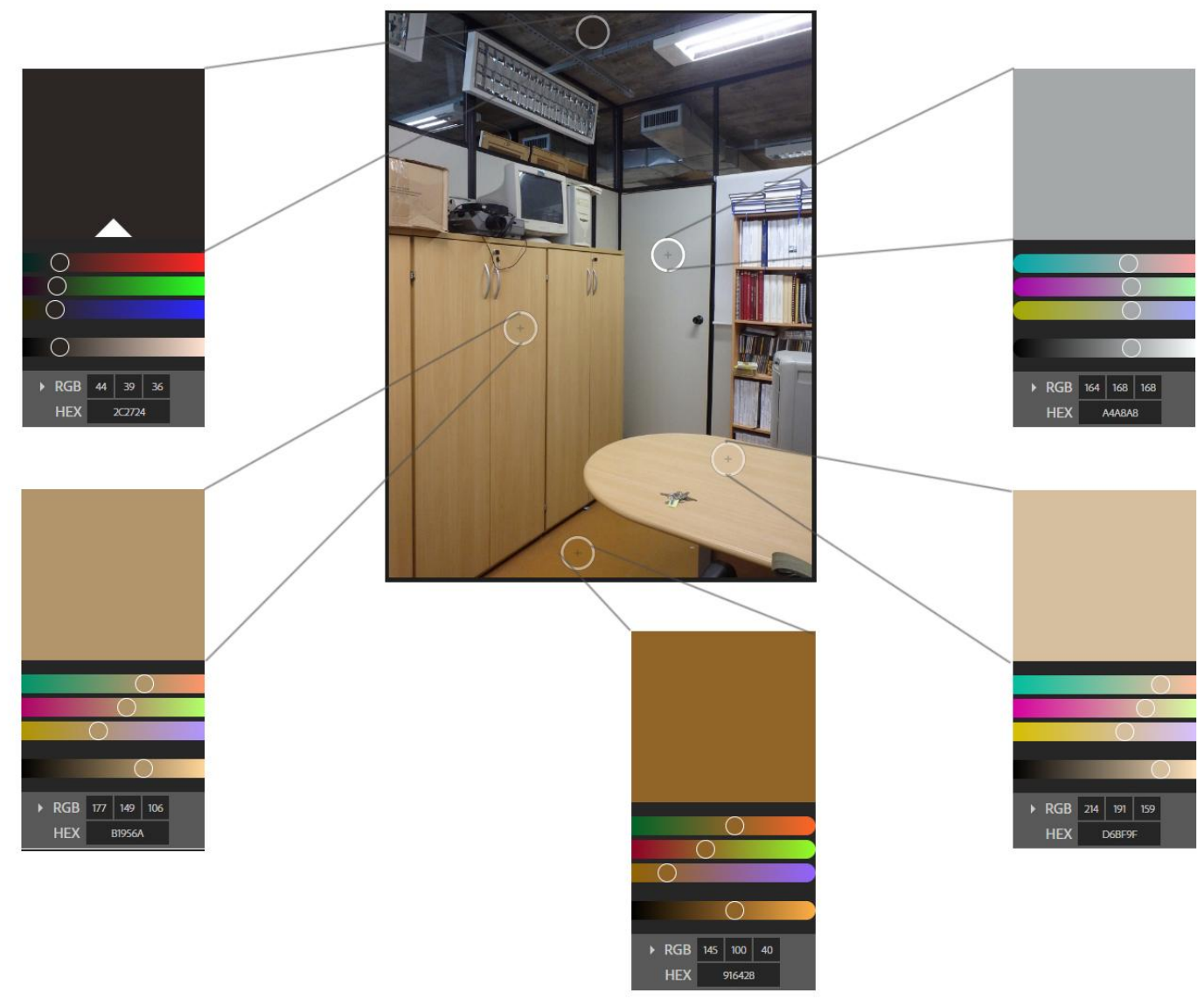

Com base nos dados obtidos, as cores da mesa, armários, parede, piso e teto foram aplicados no programa de cálculo luminotécnico.

As figuras seguintes 102 a 107 mostram o resultado ponto a ponto de cada modelo de luminária. 
Figura 102: Resultado do cálculo ponto a ponto luminária tipo 1 - sala mobiliada com cromaticidade

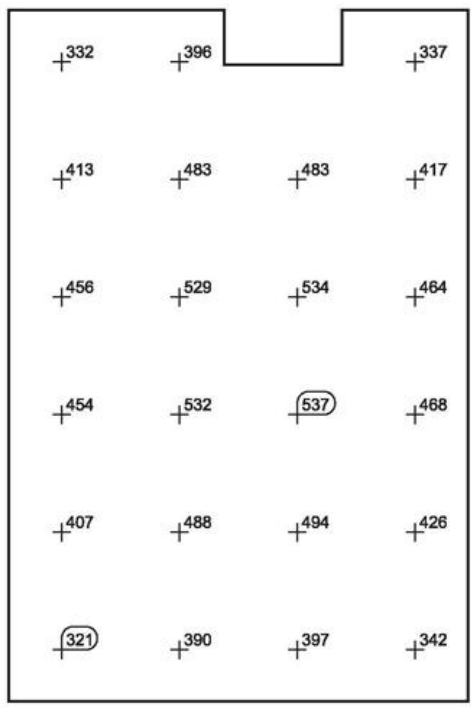

Programa Dialux EVO

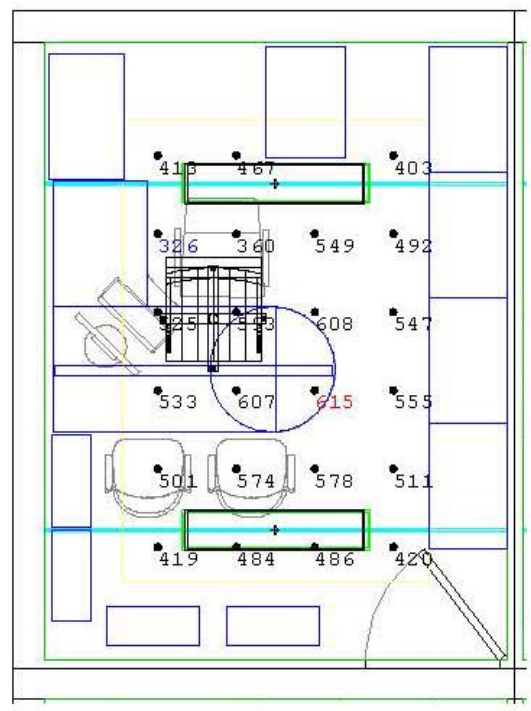

Programa AGi32

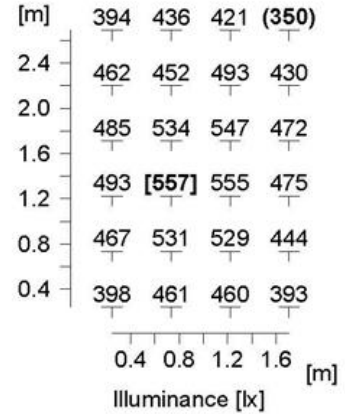

Programa Relux

Figura 103: Resultado do cálculo ponto a ponto luminária tipo 2 - sala mobiliada com cromaticidade

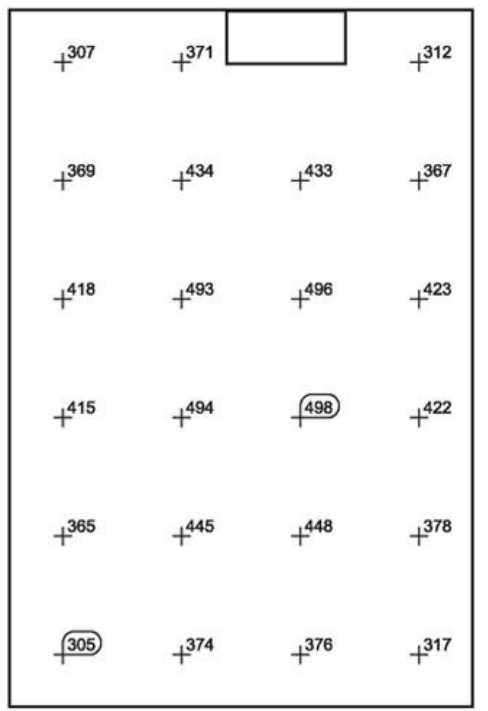

Programa Dialux EVO

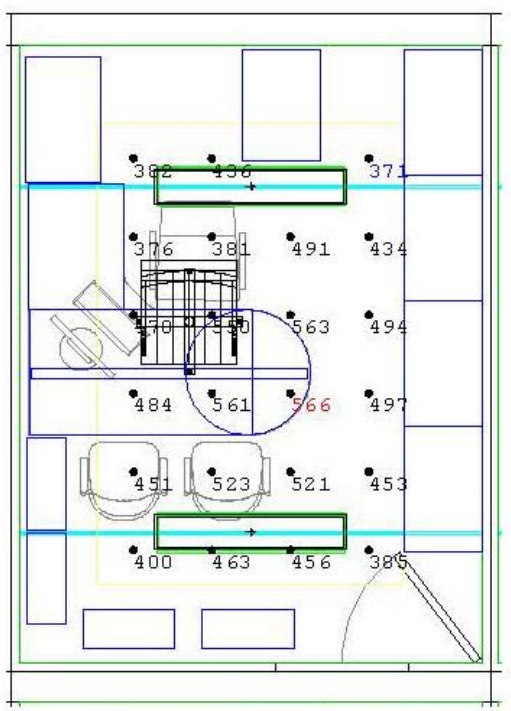

Programa AGi32

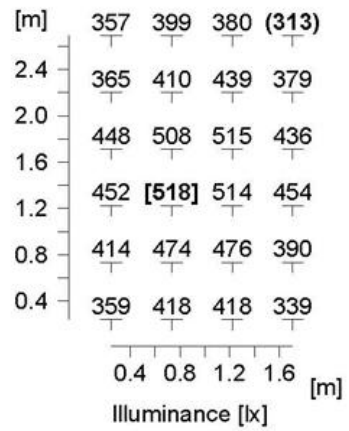

Programa Relux 
Figura 104: Resultado do cálculo ponto a ponto luminária tipo 3 - sala mobiliada com cromaticidade

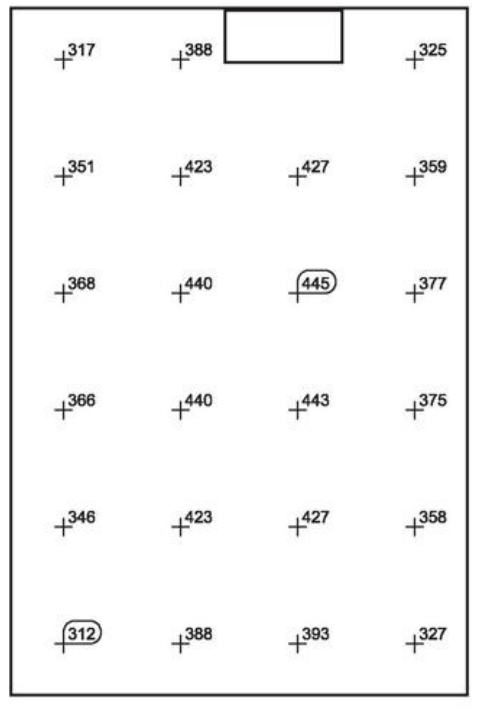

Programa Dialux EVO

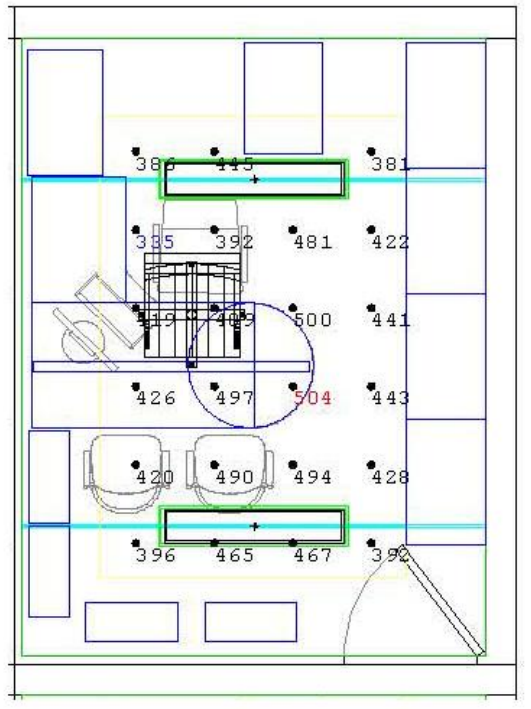

[m] $342 \quad 396 \quad 391 \quad$ (321)

2.4 - $\begin{array}{lllll}345 & 399 & 427 & 366\end{array}$

$2.0-393 \quad 453$ [461] 394

1.6 - 401 [461] [461] 399

$0.8-382 \quad 440 \quad 445 \quad 383$

$0.4-351 \quad 415 \quad 420 \quad 357$

$\begin{array}{llllll}0.4 & 0.8 & 1.2 & 1.6 & {[\mathrm{~m}]}\end{array}$

Illuminance [lx]

Programa Relux

Programa AGi32

Figura 105: Resultado do cálculo ponto a ponto luminária tipo 4 - sala mobiliada com cromaticidade

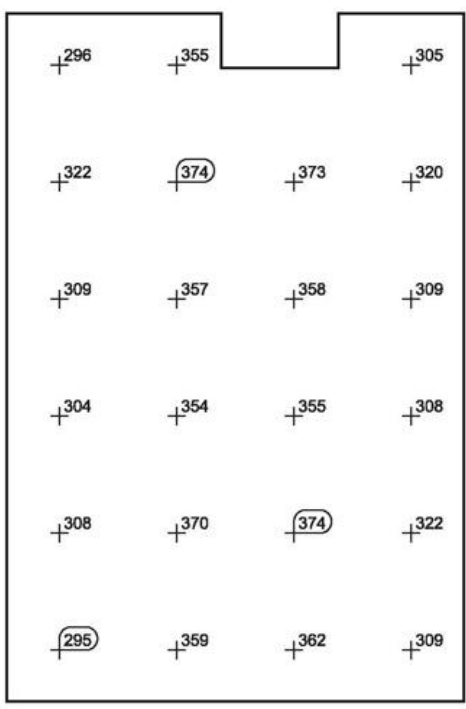

Programa Dialux EVO

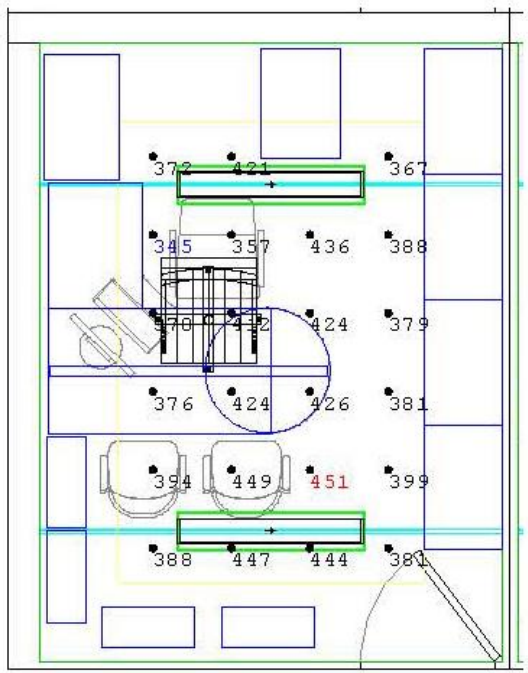

[m] $329 \quad 378 \quad 369(305)$

2.4 - $352 \quad \frac{168}{T} \quad \frac{187}{T} \quad \frac{333}{T}$

$\begin{array}{lllll}2.0 & -350 & 386 & 393 & 336\end{array}$

1.2 - $\begin{array}{llll}351 & 390 & 385 & 337\end{array}$

$0.8-\frac{348}{\top} \quad \frac{405}{1}$ [407] 345

$0.4-324 \quad 379 \quad 386 \quad 330$

$\begin{array}{lllllll}0.4 & 0.8 & 1.2 & 1.6 & {[\mathrm{~m}]}\end{array}$

Illuminance $[\mathrm{l} x]$

Programa Relux

Programa AGi32 
Figura 106: Resultado do cálculo ponto a ponto luminária tipo 5 - sala mobiliada com cromaticidade

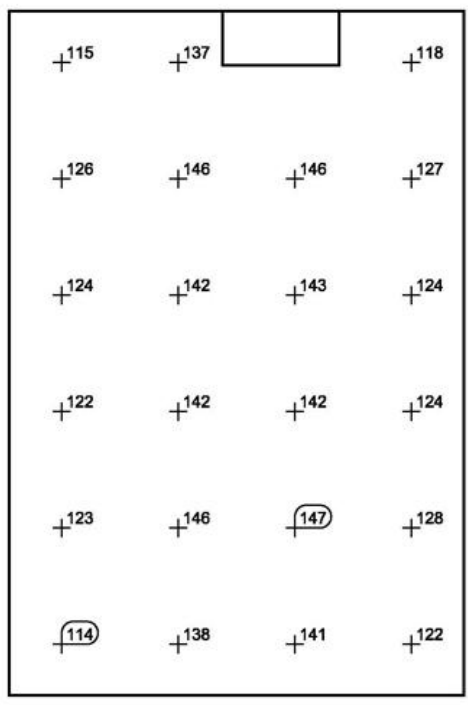

Programa Dialux EVO

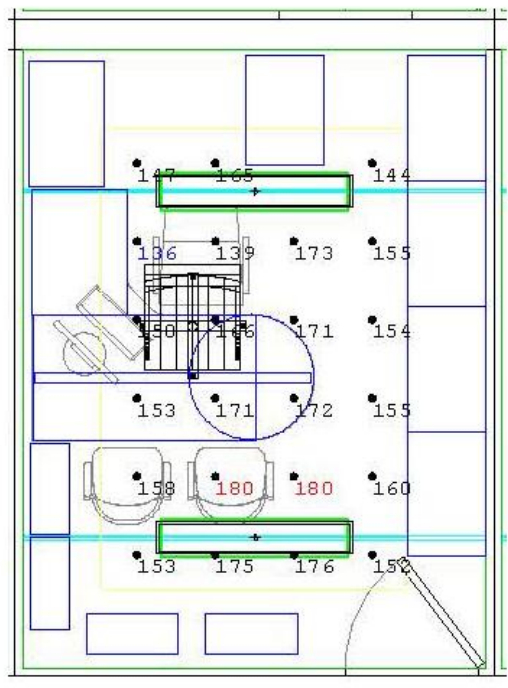

Programa AGi32

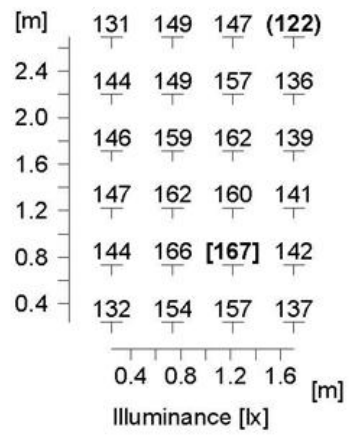

Programa Relux

Figura 107: Resultado do cálculo ponto a ponto luminária tipo 6 - sala mobiliada com cromaticidade

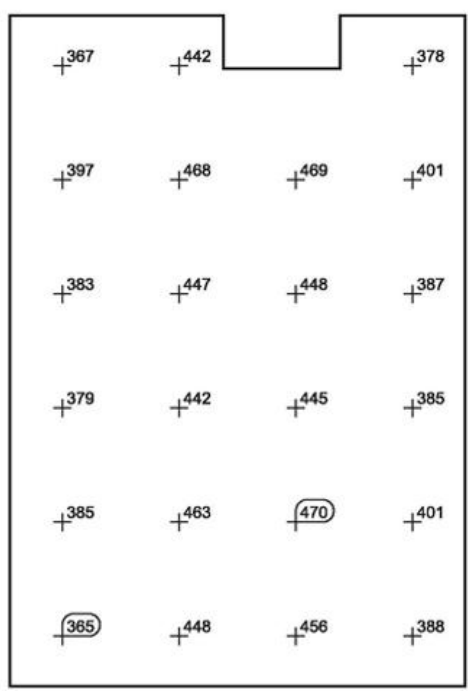

Programa Dialux EVO

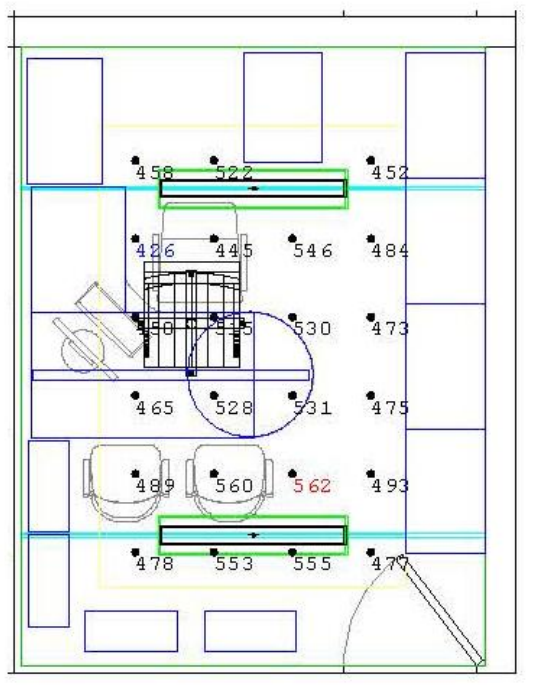

[m] $396 \quad 458 \quad 454$ (375)

$2.4-429 \quad 451 \quad 479 \quad 412$

2.0 - $432 \quad 480 \quad 489 \quad 415$

$1.6-\begin{array}{cccc}1 & 1 & & \\ 435 & 486 & 480 & 423\end{array}$

$1.2-\frac{435}{T} \quad \frac{486}{T} \quad \frac{480}{T} \quad \frac{423}{T}$

$0.8-432506$ [509] 429

$0.4-402 \quad 473 \quad 480 \quad 411$

$\begin{array}{llllll}0.4 & 0.8 & 1.2 & 1.6 & {[\mathrm{~m}]}\end{array}$

Illuminance $[\mathrm{l} x]$

Programa Relux

Programa AGi32

Analisando os cálculos anteriores, a diferença nos resultados aumentou. Se comparado o programa Dialux EVO com o Agi32, a variação ficou entre 13\% e 17\%, que significa uma discrepância de 54 lux no caso de $17 \%$.

A diferença entre os programas Agi32 e Relux variou de 7\% a 10\% e, entre o Dialux EVO e o Relux, a diferença verificada é de $4 \%$ a $10 \%$.

O que pode ser observado é que, mesmo aplicando as cores utilizando o sistema RGB obtidas pelo programa Adobe Kuler, a reflexão dada por cada 
programa varia. Optou-se por manter a reflexão fornecida pelo programa de cálculo, pois em geral, os usuários utilizam somente um dos programas de cálculo.

No caso do programa Agi32 e do Relux, os níveis de iluminância com cores aplicadas e presença de mobiliário aumentaram devido à elevação da reflexão dos mobiliários.

\subsection{Comparação dos resultados das simulações}

A Tabela 12 mostra o resumo dos resultados da iluminância média obtida em cada situação e em cada programa de cálculo utilizado.

A situação 1 corresponde aos ambientes vazios, considerando as reflexões de 50, 50 e 20 (teto, parede e piso). A situação 2 corresponde aos ambientes com a presença de mobiliário fornecido pelo próprio programa, ou no caso do programa Agi32, foi inserido um volume com as medidas do mobiliário.

A situação 3 corresponde aos ambientes considerando a presença dos mesmos mobiliários acrescidos com cromaticidade utilizando o programa Adobe Kuler, porém mantendo as reflexões dadas automaticamente por cada programa de cálculo.

Tabela 12: Tabela comparativa do nível de iluminância média entre os programas de cálculo

\begin{tabular}{|c|c|c|c|c|c|c|c|}
\hline \multicolumn{8}{|c|}{ Resultados Simulações - Nível iluminância média - Instalação Oh } \\
\hline & & Modelo 1 & Modelo 2 & Modelo 3 & Modelo 4 & Modelo 5 & Modelo 6 \\
\hline \multirow{3}{*}{ 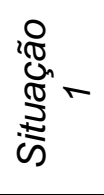 } & Dialux EVO & 485 lux & $440 \operatorname{lux}$ & 414 lux & 379 lux & 150 lux & $472 \operatorname{lux}$ \\
\hline & Agi32 & 480 lux & $436 \operatorname{lux}$ & 411 lux & $375 \operatorname{lux}$ & 150 lux & $468 \operatorname{lux}$ \\
\hline & Relux & 461 lux & $419 \operatorname{lux}$ & 396 lux & 359 lux & 145 lux & 448 lux \\
\hline \multirow{3}{*}{ 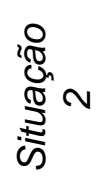 } & Dialux EVO & $481 \operatorname{lux}$ & $439 \operatorname{lux}$ & $414 \operatorname{lux}$ & 371 lux & 147 lux & $463 \operatorname{lux}$ \\
\hline & Agi32 & $469 \operatorname{lux}$ & $436 \operatorname{lux}$ & $413 \operatorname{lux}$ & $370 \operatorname{lux}$ & 147 lux & $461 \operatorname{lux}$ \\
\hline & Relux & $459 \operatorname{lux}$ & $417 \operatorname{lux}$ & $395 \operatorname{lux}$ & $352 \operatorname{lux}$ & 143 lux & 438 lux \\
\hline \multirow{3}{*}{ 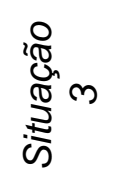 } & Dialux EVO & 439 lux & $403 \operatorname{lux}$ & $383 \operatorname{lux}$ & $335 \operatorname{lux}$ & $132 \operatorname{lux}$ & 418 lux \\
\hline & Agi32 & $503 \operatorname{lux}$ & 466 lux & $440 \operatorname{lux}$ & 401 lux & 145 lux & $499 \operatorname{lux}$ \\
\hline & Relux & 468 lux & 424 lux & $400 \operatorname{lux}$ & 361 lux & 160 lux & 447 lux \\
\hline
\end{tabular}

Resumindo e comparando os dados da tabela anterior, podemos concluir que os três programas de cálculo utilizados fornecem o nível de iluminância médio 
próximo, ou seja, com diferença mínima de até $5 \%$ no caso de os ambientes estarem vazios ou com acréscimo de mobiliário. Portanto o projetista pode escolher o programa de cálculo que mais se adapta ao seu trabalho.

No caso de acréscimo de acabamentos de cores além do mobiliário, cada programa forneceu uma reflexão distinta, modificando e aumentando a diferença no resultado final.

Os dados de inserção no programa sofrem variações, pois acabam sendo subjetivos no que se refere à cor. Mesmo utilizando um programa que possibilita a verificação da cor mais próxima do real por meio da imagem, já que os fornecedores de mobiliário e tinta não fornecem a real cor aplicada em porcentagem RGB e nem a reflexão de cada uma delas.

Assim, pode-se dizer que os programas de cálculo podem ser utilizados para ter uma base da quantidade de iluminância desejada em um ambiente, considerando uma margem de erro de aproximadamente $15 \%$ a $20 \%$. 


\section{CAPÍTULO 6}

\section{COMPARAÇÕES:}

SIMULAÇÃO x EXPERIMENTAÇÃO 


\section{COMPARAÇÕES: SIMULAÇÃO x EXPERIMENTAÇÃO}

A primeira comparação será dos resultados dos sistemas de iluminação medidos e simulados, obtendo dessa maneira a margem de erro a ser considerada no cálculo luminotécnico.

Observamos no Capítulo 6 que, incluso mobiliário e cores de piso, parede e teto, os resultados variam bastante, pois os fabricantes ainda não fornecem os valores de cor exatos, seja em RGB ou HEX. O mesmo vale para o tipo de acabamento e dados de reflexão, entre outros necessários para criar o ambiente real dentro do simulador. O que foi simulado na pesquisa está o mais próximo do real de acordo com os recursos disponíveis.

A Tabela 13 a seguir mostra o nível de iluminância médio dado em cada programa acrescido do nível de iluminância médio medido "in loco" no momento da instalação.

Tabela 13: Tabela resumo do nível de iluminância medido e simulado

\begin{tabular}{|c|c|c|c|c|c|c|}
\hline & TIPO 1 & TIPO 2 & TIPO 3 & TIPO 4 & TIPO 5 & TIPO 6 \\
\hline$E_{\text {med }}$ medido & $442 \operatorname{lu} x$ & $438 \operatorname{lux}$ & $421 \operatorname{lu} x$ & 380 lux & $170 \operatorname{lux}$ & $415 \operatorname{lux}$ \\
\hline $\mathrm{E}_{\text {med }}$ Dialux EVO vazio & $485 \operatorname{lux}$ & 440 lux & $414 \operatorname{lu} x$ & $379 \operatorname{lux}$ & $150 \operatorname{lux}$ & $472 \operatorname{lux}$ \\
\hline $\mathrm{E}_{\text {med }}$ Dialux EVO mob & $481 \operatorname{lux}$ & $439 \operatorname{lux}$ & $414 \operatorname{lux}$ & 371 lux & 147 lux & $463 \operatorname{lux}$ \\
\hline$E_{\text {med }}$ Dialux EVO mob e mat & $439 \operatorname{lux}$ & 403 lux & $383 \operatorname{lux}$ & $335 \operatorname{lux}$ & $132 \operatorname{lux}$ & $418 \operatorname{lux}$ \\
\hline$E_{\text {med }}$ AGi 32 vazio & $480 \operatorname{lux}$ & $436 \operatorname{lux}$ & $411 \operatorname{lux}$ & 376 lux & $150 \operatorname{lux}$ & $468 \operatorname{lux}$ \\
\hline $\mathrm{E}_{\text {med }}$ AGi32 mob & $469 \operatorname{lux}$ & $436 \operatorname{lux}$ & $413 \operatorname{lux}$ & $370 \operatorname{lux}$ & $147 \operatorname{lux}$ & 461 lux \\
\hline $\mathrm{E}_{\text {med }}$ AGi32 mob e mat & 503 lux & 466 lux & 440 lux & $401 \operatorname{lux}$ & 160 lux & $499 \operatorname{lux}$ \\
\hline$E_{\text {med }}$ Relux vazio & $461 \operatorname{lux}$ & $419 \operatorname{lux}$ & $396 \operatorname{lux}$ & $359 \operatorname{lux}$ & $145 \operatorname{lux}$ & $448 \operatorname{lux}$ \\
\hline$E_{\text {med }}$ Relux mob & $459 \operatorname{lux}$ & 417 lux & $395 \operatorname{lux}$ & 352 lux & $143 \operatorname{lux}$ & $438 \operatorname{lux}$ \\
\hline $\mathrm{E}_{\text {med }}$ Relux mob e mat & $468 \operatorname{lux}$ & $424 \operatorname{lux}$ & $400 \operatorname{lux}$ & $361 \operatorname{lux}$ & $145 \operatorname{lux}$ & 447 lux \\
\hline
\end{tabular}

Com o intuito de facilitar a visualização dos resultados, seguem nas Figuras 108 e 109 os gráficos comparativos com os resultados da experimentação (medição) e das três situações simuladas no Capítulo 5 mostrados anteriormente.

O gráfico da Figura 108 é referente aos sistemas de iluminação com aletas (tipo 1, tipo 2 e tipo 3) e o da Figura 109 aos sistemas com difusor (tipo 4, tipo 5 e tipo 6). 
Figura 108: Gráfico comparativo Experimentação x Simulação - Sistemas de iluminação com aletas

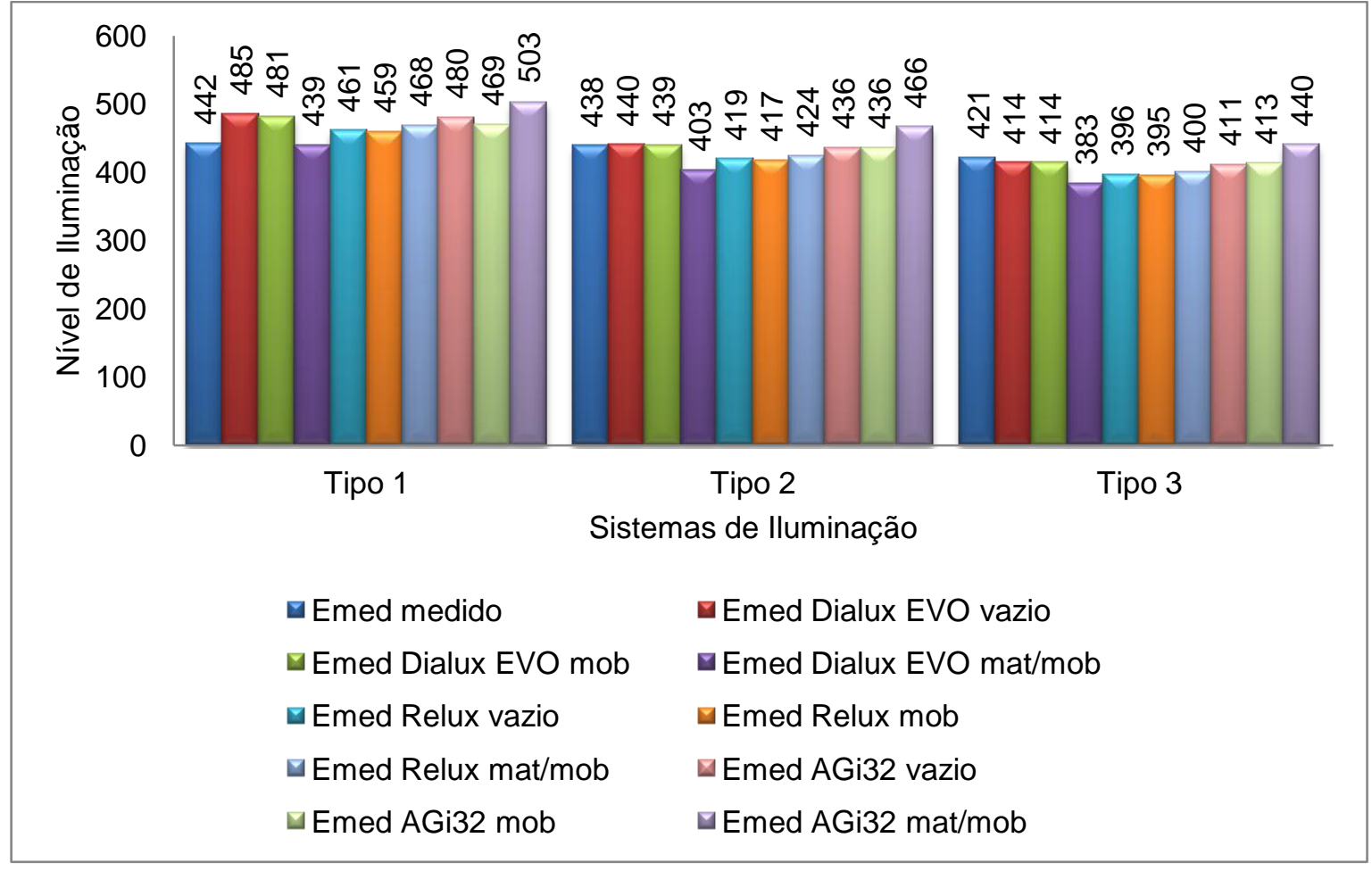

Figura 109: Gráfico comparativo Experimentação x Simulação - Sistema de iluminação com difusor

\begin{tabular}{|c|c|c|}
\hline 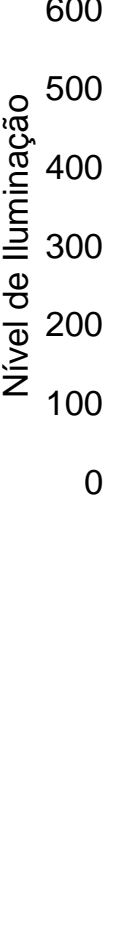 & $\begin{array}{l}\text { Tipo } 4 \\
\text { घEmed medido } \\
\square \text { Emed Dialux EVO mob } \\
\square \text { Emed Relux vazio } \\
\square \text { Emed Relux mat/mob } \\
\square \text { Emed AGi32 mob }\end{array}$ & $\begin{array}{l}\text { Tipo } 5 \\
\text { as de lluminação } \\
\text { घEmed Dialux EVO vazio } \\
\text { घEmed Dialux EVO mat/mob } \\
\text { घEmed Relux mob } \\
\square \text { Emed AGi32 vazio } \\
\square \text { Emed AGi32 mat/mob }\end{array}$ \\
\hline
\end{tabular}

Analisando os gráficos das Figuras 108 e 109, observa-se que a diferença entre os resultados da medição e da simulação não ultrapassa 50 lux para cada 
tipologia de iluminação, com exceção do resultado da simulação com mobiliário e materiais aplicados no programa AGi32, que ficou acima dos demais valores encontrados em todas as situações. Seria interessante uma pesquisa mais detalhada para verificar as possíveis causas deste fenômeno.

Dependendo do programa de cálculo e a situação simulada, observamos que o nível médio encontrado é praticamente igual ao medido. No entanto, não é possível afirmar que, colocando os dados de entrada de maneira detalhada, encontraremos o nível de iluminância simulado igual ao medido após a instalação dos sistemas de iluminação.

Apesar das diferenças encontradas nos resultados, podemos sim ter uma ideia do nível de iluminância que será medido após a instalação. Os softwares de cálculo são uma ferramenta importante na etapa projetual de arquitetura e, por meio das comparações realizadas, podemos dizer que são confiáveis. A margem de erro entre os programas de cálculo e a experimentação está por volta de 10\%. 


\section{CAPÍTULO 7}

\section{COMPARAÇÕES:}

MEDIÇÕES x NORMA 


\section{COMPARAÇÕES: MEDIÇÕES x NORMA}

\subsection{Considerações preliminares}

A importância de verificar a real depreciação dos sistemas que utilizam a tecnologia LED deriva do fato de que esses sistemas são muito recentes, e desta forma, o fator de depreciação apresenta-se como uma variável quando deveria ser uma constante conhecida.

Segundo os manuais de iluminação da Osram e Philips, sabe-se que a vida útil de uma lâmpada é o número de horas decorridas até que ela deprecie $30 \%$ do fluxo luminoso inicial.

A vida útil de uma lâmpada fluorescente tubular é dada pelos fabricantes como cerca de 20.000h. No caso de uma lâmpada tubo LED, a vida útil é, segundo o INMETRO (Portaria número 389), a partir de $25.000 \mathrm{~h}$, sendo que o valor informado é diferente para cada fornecedor.

Sabe-se também, conforme norma internacional CIE-97:2005, que o valor de depreciação do sistema de iluminação depende não somente do tipo de lâmpada e suas características particulares, mas também do modelo de luminária que acomoda as lâmpadas e da manutenção das superfícies de um ambiente.

O projeto luminotécnico deve levar em consideração, portanto, o fator de perdas. Em longo prazo, a falta de iluminância na área de tarefa pode acarretar problemas como erros ou atraso na conclusão de tarefas a serem realizadas, e até perda da visão parcial. Assim, além da limpeza programada das luminárias e das superfícies da sala, é prudente calcular a depreciação do conjunto dos sistemas de iluminação instalados.

A Tabela 14 seguinte é resultado do cruzamento de dados conforme metodologia apresentada no Capítulo 2 descrita no Item 2.5. Determinação do fator de manutenção referente à norma CIE 97:2005. 
Tabela 14: Tabela de fator de manutenção dos sistemas de iluminação do experimento.

\begin{tabular}{|c|c|c|c|c|c|c|c|}
\hline & Tempo & Horas & LLMF & LSF & LMF & RSMF & MF \\
\hline \multirow{10}{*}{ 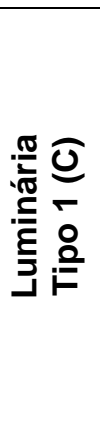 } & 0 meses & 0 horas & 1,00 & 1,00 & 1,00 & 1,00 & 1,00 \\
\hline & 1 mês & 720 horas & 0,99 & 1,00 & 1,00 & 1,00 & 0,99 \\
\hline & 3 meses & 2154 horas & 0,97 & 1,00 & 1,00 & 1,00 & 0,97 \\
\hline & 6 meses & 4310 horas & 0,93 & 1,00 & 0,93 & 0,97 & 0,84 \\
\hline & 9 meses & 6465 horas & 0,92 & 0,99 & 0,91 & 0,97 & 0,80 \\
\hline & 1 ano & 8620 horas & 0,90 & 0,98 & 0,89 & 0,96 & 0,75 \\
\hline & 15 meses & 13128 horas & 0,90 & 0,98 & 0,87 & 0,96 & 0,74 \\
\hline & 1,5 ano & 13128 horas & 0,90 & 0,96 & 0,84 & 0,95 & 0,69 \\
\hline & 21 meses & 15087 horas & 0,90 & 0,94 & 0,82 & 0,95 & 0,66 \\
\hline & 2 anos & 17520 horas & 0,90 & 0,92 & 0,80 & 0,95 & 0,63 \\
\hline \multirow{10}{*}{ 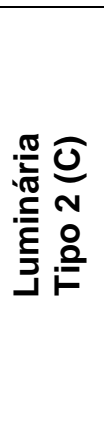 } & 0 meses & 0 horas & 1,00 & 1,00 & 1,00 & 1,00 & 1,00 \\
\hline & 1 mês & 720 horas & $1,00^{*}$ & $1,00^{*}$ & 1,00 & 1,00 & 1,00 \\
\hline & 3 meses & 2154 horas & $1,00^{*}$ & $1,00^{*}$ & 1,00 & 1,00 & 1,00 \\
\hline & 6 meses & 4310 horas & $1,00^{*}$ & $1,00^{*}$ & 0,93 & 0,97 & 0,90 \\
\hline & 9 meses & 6465 horas & $1,00^{*}$ & $1,00^{*}$ & 0,91 & 0,97 & 0,88 \\
\hline & 1 ano & 8620 horas & $0,98^{*}$ & $1,00^{*}$ & 0,89 & 0,96 & 0,84 \\
\hline & 15 meses & 10776 horas & $0,98^{*}$ & $1,00^{*}$ & 0,87 & 0,96 & 0,82 \\
\hline & 1,5 ano & 13128 horas & $0,97^{*}$ & $0,99^{*}$ & 0,84 & 0,95 & 0,77 \\
\hline & 21 meses & 15087 horas & $0,97^{*}$ & $0,99^{*}$ & 0,82 & 0,95 & 0,75 \\
\hline & 2 anos & 17520 horas & $0,96^{*}$ & $0,98^{*}$ & 0,80 & 0,95 & 0,72 \\
\hline \multirow{10}{*}{ 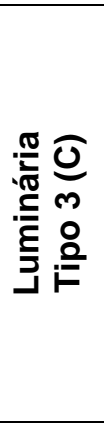 } & 0 meses & 0 horas & 1,00 & 1,00 & 1,00 & 1,00 & 1,00 \\
\hline & 1 mês & 720 horas & $1,00^{*}$ & $1,00^{*}$ & 1,00 & 1,00 & 1,00 \\
\hline & 3 meses & 2154 horas & $1,00^{*}$ & $1,00^{*}$ & 1,00 & 1,00 & 1,00 \\
\hline & 6 meses & 4310 horas & $1,00^{*}$ & $1,00^{*}$ & 0,93 & 0,97 & 0,90 \\
\hline & 9 meses & 6465 horas & $1,00^{*}$ & $1,00^{*}$ & 0,91 & 0,97 & 0,88 \\
\hline & 1 ano & 8620 horas & $0,98^{*}$ & $1,00^{*}$ & 0,89 & 0,96 & 0,84 \\
\hline & 15 meses & 13128 horas & $0,98^{*}$ & $1,00^{*}$ & 0,87 & 0,96 & 0,82 \\
\hline & 1,5 ano & 13128 horas & $0,97^{*}$ & $0,99^{*}$ & 0,84 & 0,95 & 0,77 \\
\hline & 21 meses & 15087 horas & $0,97^{*}$ & $0,99^{*}$ & 0,82 & 0,95 & 0,75 \\
\hline & 2 anos & 17520 horas & $0,96^{*}$ & $0,98^{*}$ & 0,80 & 0,95 & 0,72 \\
\hline \multirow{10}{*}{ 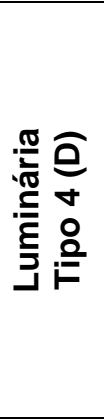 } & 0 meses & 0 horas & 1,00 & 1,00 & 1,00 & 1,00 & 1,00 \\
\hline & 1 mês & 720 horas & 0,99 & 1,00 & 1,00 & 1,00 & 0,99 \\
\hline & 3 meses & 2154 horas & 0,97 & 1,00 & 1,00 & 1,00 & 0,97 \\
\hline & 6 meses & 4310 horas & 0,93 & 1,00 & 0,92 & 0,97 & 0,83 \\
\hline & 9 meses & 6465 horas & 0,92 & 0,99 & 0,90 & 0,97 & 0,80 \\
\hline & 1 ano & 8620 horas & 0,90 & 0,98 & 0,88 & 0,96 & 0,75 \\
\hline & 15 meses & 13128 horas & 0,90 & 0,98 & 0,87 & 0,96 & 0,74 \\
\hline & 1,5 ano & 13128 horas & 0,90 & 0,96 & 0,85 & 0,95 & 0,70 \\
\hline & 21 meses & 15087 horas & 0,90 & 0,94 & 0,83 & 0,95 & 0,67 \\
\hline & 2 anos & 17520 horas & 0,90 & 0,92 & 0,83 & 0,95 & 0,65 \\
\hline \multirow{10}{*}{ 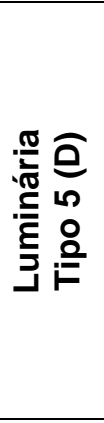 } & 0 meses & 0 horas & 1,00 & 1,00 & 1,00 & 1,00 & 1,00 \\
\hline & 1 mês & 720 horas & $1,00^{*}$ & $1,00^{*}$ & 1,00 & 1,00 & 1,00 \\
\hline & 3 meses & 2154 horas & $1,00^{*}$ & $1,00^{*}$ & 1,00 & 1,00 & 1,00 \\
\hline & 6 meses & 4310 horas & $1,00^{*}$ & $1,00^{*}$ & 0,92 & 0,97 & 0,89 \\
\hline & 9 meses & 6465 horas & $1,00^{*}$ & $1,00^{*}$ & 0,90 & 0,97 & 0,87 \\
\hline & 1 ano & 8620 horas & $0,98^{*}$ & $1,00^{*}$ & 0,88 & 0,96 & 0,83 \\
\hline & 15 meses & 13128 horas & $0,98^{*}$ & $1,00^{*}$ & 0,87 & 0,96 & 0,82 \\
\hline & 1,5 ano & 13128 horas & $0,97^{*}$ & $0,99^{*}$ & 0,85 & 0,95 & 0,78 \\
\hline & 21 meses & 15087 horas & $0,97^{*}$ & $0,99^{*}$ & 0,83 & 0,95 & 0,76 \\
\hline & 2 anos & 17520 horas & $0,96^{*}$ & $0,98^{*}$ & 0,83 & 0,95 & 0,74 \\
\hline \multirow{5}{*}{ 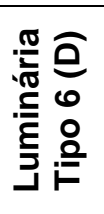 } & 0 meses & 0 horas & 1,00 & 1,00 & 1,00 & 1,00 & 1,00 \\
\hline & 1 mês & 720 horas & $1,00^{*}$ & $1,00^{*}$ & 1,00 & 1,00 & 1,00 \\
\hline & 3 meses & 2154 horas & $1,00^{*}$ & $1,00^{*}$ & 1,00 & 1,00 & 1,00 \\
\hline & 6 meses & 4310 horas & $1,00^{*}$ & $1,00^{*}$ & 0,92 & 0,97 & 0,89 \\
\hline & 9 meses & 6465 horas & $1,00^{*}$ & $1,00^{*}$ & 0,90 & 0,97 & 0,87 \\
\hline
\end{tabular}




\begin{tabular}{|l|l|l|l|l|l|l|l|}
\hline & 1 ano & 8620 horas & $0,98^{*}$ & $1,00^{*}$ & 0,88 & 0,96 & $\mathbf{0 , 8 3}$ \\
\cline { 2 - 7 } & 15 meses & 13128 horas & $0,98^{*}$ & $1,00^{*}$ & 0,87 & 0,96 & $\mathbf{0 , 8 2}$ \\
\cline { 2 - 7 } & 1,5 ano & 13128 horas & $0,97^{*}$ & $0,99^{*}$ & 0,85 & 0,95 & $\mathbf{0 , 7 8}$ \\
\cline { 2 - 7 } & 21 meses & 15087 horas & $0,97^{*}$ & $0,99^{*}$ & 0,83 & 0,95 & $\mathbf{0 , 7 6}$ \\
\cline { 2 - 7 } & 2 anos & 17520 horas & $0,96^{*}$ & $0,98^{*}$ & 0,83 & 0,95 & $\mathbf{0 , 7 4}$ \\
\hline
\end{tabular}

* considerando que o LED deprecia a partir de 1 ano

Fonte: CIE-97

Os valores do fator de manutenção (MF) encontrados na Tabela 14 são os valores a serem utilizados na fase de projeto luminotécnico, dependendo do tempo em horas que se deseja manter um nível de iluminância, segundo a norma CIE97:2005.

A grande maioria dos projetistas utiliza somente o valor padrão que é sugerido em manuais de iluminação. Para uma sala limpa considera-se 0,80 , para sala de média limpeza 0,70, e para sala suja o valor de 0,60 (PHILIPS,1981). Pela experiência da pesquisadora, infelizmente alguns projetistas não incluem o fator de manutenção ou, em outros casos, os projetos que vêm de fábricas ampliam esse valor para aumentar a venda de peças.

Os valores de 0,80, 0,70 e 0,60 são recomendados pelo manual da Philips quando não há dados suficientes sobre depreciação da lâmpada e luminária, o que atualmente é quase impossível de ocorrer, pois essas informações são facilmente encontradas em catálogos impressos e mesmo na internet.

\subsection{Resultados da comparação}

Um dos resultados mais importantes foi a determinação dos valores de depreciação dos sistemas de iluminação por meio das medições realizadas ao longo de dois anos, onde foi possível observar o quanto a tecnologia fluorescente e a tecnologia LED depreciam ao longo do tempo, sob as mesmas condições.

A tabela seguinte foi criada para comparar os valores dos fatores de manutenção (MF) preconizados pela norma CIE-97:2005 e os valores encontrados nas medições. 
Tabela 15: Tabela comparativa de fatores de manutenção

\begin{tabular}{|c|c|c|c|c|c|c|}
\hline & Tempo & Horas & MF CIE:97 & $\begin{array}{l}\text { Iluminância } \\
\text { Esperada }\end{array}$ & $\begin{array}{l}\text { Iluminância } \\
\text { Medida }\end{array}$ & $\begin{array}{l}\text { MF } \\
\text { encontrado }\end{array}$ \\
\hline \multirow{8}{*}{ 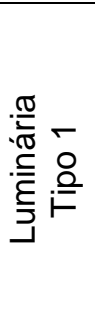 } & Inicio & Oh & 1.00 & 442 lux & 442 lux & 1.00 \\
\hline & 1 mês & $720 \mathrm{~h}$ & 0.99 & 438 lux & 435 lux & 0.98 \\
\hline & 3 meses & $2154 h$ & 0.97 & 429 lux & 408 lux & 0.92 \\
\hline & 6 meses & 4310h & 0.84 & 371 lux & 408 lux & 0.92 \\
\hline & 9 meses & $6465 h$ & 0.80 & 355 lux & 396 lux & 0.90 \\
\hline & 12 meses & $8620 h$ & 0.75 & 333 lux & 396 lux & 0.90 \\
\hline & 15 meses & 10776h & 0.74 & 326 lux & 370 lux & 0.84 \\
\hline & 18 meses & $12931 \mathrm{~h}$ & 0.69 & 305 lux & 371 lux & 0.84 \\
\hline \multirow{10}{*}{ 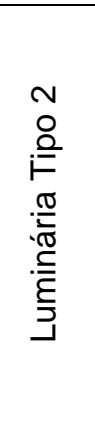 } & Inicio & Oh & 1.00 & 438 lux & 438 lux & 1.00 \\
\hline & 1 mês & 720h & 1.00 & 438 lux & 443 lux & 1.01 \\
\hline & 3 meses & $2154 h$ & 1.00 & 438 lux & 442 lux & 1.01 \\
\hline & 6 meses & 4310h & 0.90 & 395 lux & 442 lux & 1.01 \\
\hline & 9 meses & $6465 \mathrm{~h}$ & 0.88 & 387 lux & 437 lux & 1.00 \\
\hline & 12 meses & $8620 h$ & 0.84 & 367 lux & 438 lux & 1.00 \\
\hline & 15 meses & 10776h & 0.82 & 359 lux & 433 lux & 0.99 \\
\hline & 18 meses & $12931 \mathrm{~h}$ & 0.77 & 336 lux & 434 lux & 0.99 \\
\hline & 21 meses & $15087 \mathrm{~h}$ & 0.75 & 328 lux & 431 lux & 0.98 \\
\hline & 24 meses & 17027h & 0.72 & 313 lux & 428 lux & 0.98 \\
\hline \multirow{10}{*}{ 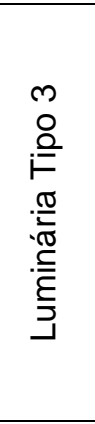 } & Inicio & Oh & 1.00 & 421 lux & 421 lux & 1.00 \\
\hline & 1 mês & 720h & 1.00 & 421 lux & 411 lux & 0.98 \\
\hline & 3 meses & $2154 h$ & 1.00 & 421 lux & 403 lux & 0.96 \\
\hline & 6 meses & 4310h & 0.90 & 380 lux & 398 lux & 0.95 \\
\hline & 9 meses & $6465 \mathrm{~h}$ & 0.88 & 372 lux & 392 lux & 0.93 \\
\hline & 12 meses & 8620h & 0.84 & 353 lux & 391 lux & 0.93 \\
\hline & 15 meses & 10776h & 0.82 & 345 lux & 368 lux & 0.87 \\
\hline & 18 meses & $12931 \mathrm{~h}$ & 0.77 & 323 lux & 366 lux & 0.87 \\
\hline & 21 meses & 15087h & 0.75 & 315 lux & 368 lux & 0.87 \\
\hline & 24 meses & 17027h & 0.72 & 301 lux & 345 lux & 0.82 \\
\hline \multirow{8}{*}{ 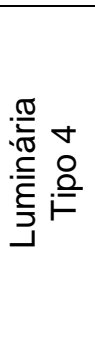 } & Inicio & Oh & 1.00 & 380 lux & 380 lux & 1.00 \\
\hline & 1 mês & $720 \mathrm{~h}$ & 0.99 & 376 lux & 354 lux & 0.93 \\
\hline & 3 meses & $2154 h$ & 0.97 & 369 lux & 332 lux & 0.97 \\
\hline & 6 meses & 4310h & 0.83 & 315 lux & 334 lux & 0.88 \\
\hline & 9 meses & $6465 h$ & 0.80 & 302 lux & 321 lux & 0.84 \\
\hline & 12 meses & 8620h & 0.75 & 283 lux & 300 lux & 0.79 \\
\hline & 15 meses & 10776h & 0.74 & 280 lux & 301 lux & 0.79 \\
\hline & 18 meses & 12931h & 0.70 & 265 lux & - & - \\
\hline \multirow{10}{*}{ 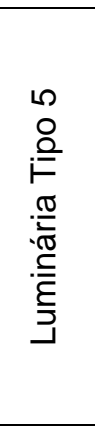 } & Inicio & Oh & 1.00 & 170 lux & 170 lux & 1.00 \\
\hline & 1 mês & 720h & 1.00 & 170 lux & 171 lux & 1.01 \\
\hline & 3 meses & $2154 h$ & 1.00 & 170 lux & 169 lux & 0.99 \\
\hline & 6 meses & 4310h & 0.89 & 152 lux & 166 lux & 0.98 \\
\hline & 9 meses & 6465h & 0.87 & 148 lux & 134 lux & 0.79 \\
\hline & 12 meses & $8620 h$ & 0.83 & 141 lux & $165 \operatorname{lux}$ & 0.94 \\
\hline & 15 meses & 10776h & 0.82 & 139 lux & 160 lux & 0.94 \\
\hline & 18 meses & 12931h & 0.78 & 132 lux & 156 lux & 0.92 \\
\hline & 21 meses & 15087h & 0.76 & $129 \operatorname{lux}$ & $152 \operatorname{lux}$ & 0.89 \\
\hline & 24 meses & 17027h & 0.74 & 126 lux & 151 lux & 0.89 \\
\hline \multirow{8}{*}{ 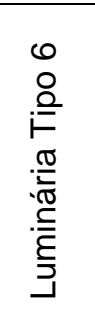 } & Inicio & Oh & 1.00 & 415 lux & 415 lux & 1.00 \\
\hline & 1 mês & 720h & 1.00 & 415 lux & 413 lux & 1.00 \\
\hline & 3 meses & $2154 h$ & 1.00 & 415 lux & 415 lux & 1.00 \\
\hline & 6 meses & 4310h & 0.89 & 370 lux & 449 lux & 1.08 \\
\hline & 9 meses & $6465 \mathrm{~h}$ & 0.87 & 362 lux & $417 \operatorname{lux}$ & 0.98 \\
\hline & 12 meses & $8620 h$ & 0.83 & 344 lux & 407 lux & 0.98 \\
\hline & 15 meses & 10776h & 0.82 & 340 lux & 406 lux & 0.98 \\
\hline & 18 meses & $12931 \mathrm{~h}$ & 0.78 & 322 lux & 399 lux & 0.96 \\
\hline
\end{tabular}




\begin{tabular}{|l|l|l|l|l|l|l|}
\hline & 21 meses & $15087 \mathrm{~h}$ & 0.76 & $314 \operatorname{lux}$ & $392 \operatorname{lux}$ & $\mathbf{0 . 9 4}$ \\
\cline { 2 - 7 } & 24 meses & $17027 \mathrm{~h}$ & 0.74 & $308 \operatorname{lux}$ & $386 \operatorname{lux}$ & $\mathbf{0 . 9 3}$ \\
\hline
\end{tabular}

Ao analisar as depreciações ocorridas durante o período do experimento, verificou-se que houve depreciação em todos os sistemas de iluminação instalados.

Observa-se que após três meses da instalação dos sistemas de iluminação, as luminárias tipo 1 e 4, com a tecnologia fluorescente tubular, depreciaram mais do que o esperado. Assim como ocorreu com o sistema de iluminação tipo 3 com o LED acoplado na luminária, modelo com aletas e difusor.

Curiosamente, o sistema de iluminação tipo 2, utilizando uma lâmpada tubo LED, apresentou aumento no nível médio esperado. SCOPACASA (2016) mostra em um relatório de uma amostra LED que, após $6.000 \mathrm{~h}$, o fluxo do LED aumenta, logo, pode-se dizer que a medição realizada esta dentro do padrão.

Os sistemas de iluminação do tipo 5 e 6 apresentaram resultados de acordo com o esperado.

Em 6 meses, observa-se que nos sistemas de iluminação com lâmpada fluorescente, a depreciação medida começa a ser menor que a esperada. De 3 a 6 meses, praticamente não houve depreciação em nenhum dos sistemas e, além disso, o valor medido na iluminância média do sistema de iluminação tipo 6 apresentou um aumento.

Em relação aos sistemas de iluminação com a tecnologia LED, esperava-se que os modelos com lâmpadas tubo LED e com o LED aplicado depreciassem do mesmo modo, no entanto encontramos diferença nos resultados.

Continuando a análise da Tabela 15, podemos observar que em 1 ano e meio de experimento, os valores de depreciação medidos continuam menores que os esperados.

Se o componente do sistema de iluminação tipo 4 estivesse em funcionamento ao final de 18 meses (1 ano e meio), poderíamos estipular que a depreciação ficaria menor do que o esperado. Se não houvesse ocorrido a queima do reator, poderíamos manter os conjuntos acesos por mais tempo, além das 13.000h, uma vez que os fabricantes de lâmpadas garantem que a vida útil da lâmpada pode chegar a 20.000h.

Após 2 anos de pesquisa, comparando os fatores de manutenção e depreciação obtidos com a norma CIE-97:2005, percebe-se que, ao final, a 
depreciação ocorrida no experimento foi menor que a norma prevê em todas as situações. 


\section{CAPÍTULO 8}

\section{VERIFICAÇÃO DAS HIPÓTESES}




\section{VERIFICAÇÃO DAS HIPÓTESES}

A tese possui três hipóteses:

Hipótese 1: Existe depreciação do fluxo luminoso na tecnologia LED quando comparada com a tecnologia fluorescente

A hipótese 1 foi comprovada conforme os resultados obtidos nas medições durante dois anos, esses estão detalhados no Capítulo 3.

A expectativa era que os sistemas de iluminação que utilizam a tecnologia LED depreciassem em uma proporção maior, próxima à tecnologia fluorescente, e que fosse mais intensa nos modelos com difusor.

Nos sistemas de iluminação utilizando lâmpadas tanto fluorescente tubular como tubo LED, a depreciação resultante das medições foi maior no modelo com difusor (fechadas) do que no modelo com aletas (semiabertas).

Porém, quando o LED está aplicado na luminária, o resultado é inverso. O motivo pode ser a presença do difusor mais as aletas, ou pode ser causado pelo design da própria luminária.

Hipótese 2: Existe depreciação do fluxo luminoso na tecnologia LED, sendo mais intensa na lâmpada tubo LED quando comparada ao LED acoplado na própria luminária

A hipótese 2 foi parcialmente comprovada. No modelo com difusor, a depreciação do fluxo luminoso medido no plano de trabalho foi maior nos sistemas de iluminação que utilizam lâmpada tubo LED, quando comparadas ao LED aplicado na própria luminária. A primeira depreciou $11 \%$ e a segunda depreciou $7 \%$.

No caso dos modelos com aletas, a depreciação das medições nos sistemas de iluminação que utilizavam lâmpada tubo LED foi de $2 \%$, e nas que o LED está aplicado na luminária, foi de $18 \%$. 
Hipótese 3: Os dados de depreciação preconizados pela norma CIE97:2005 não correspondem à realidade, pois as depreciações reais são maiores que a norma

A hipótese 3 foi parcialmente comprovada, como pode ser observado na Tabela 15 do Capítulo 7.

Até 3 meses, os valores medidos utilizando a tecnologia fluorescente estavam maiores que os calculados a partir da norma, portanto até esse período, a hipótese se comprovou. No entanto, após 6 meses, o nível de iluminância medido passa a ser maior, ou seja, a depreciação total foi menor.

As figuras a seguir demonstram os resultados das medições com a depreciação verificada a partir da norma.

Figura 110: Gráfico comparativo dos sistemas de iluminação utilizando tecnologia fluorescente

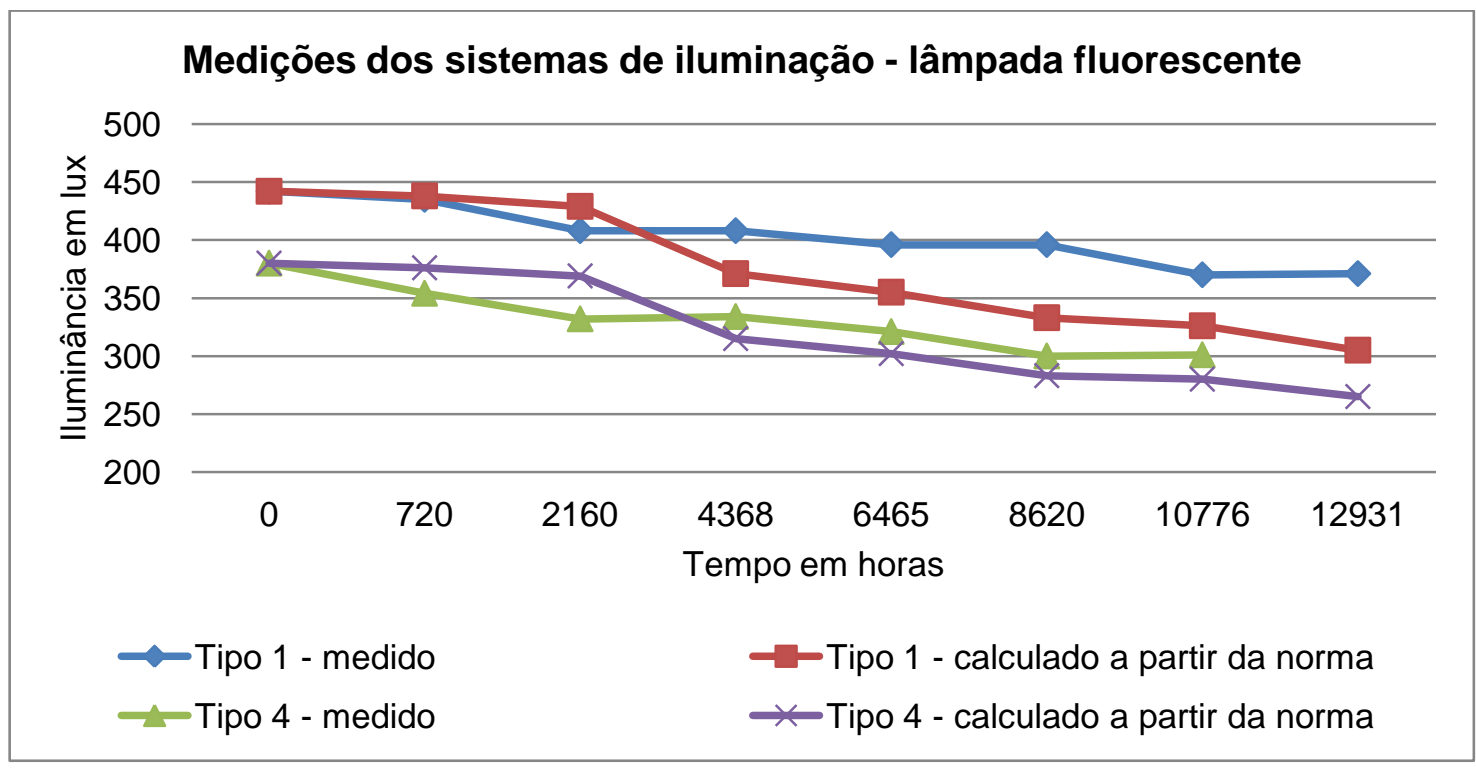


Figura 111: Gráfico comparativo dos sistemas de iluminação utilizando tecnologia LED: lâmpada tubo LED

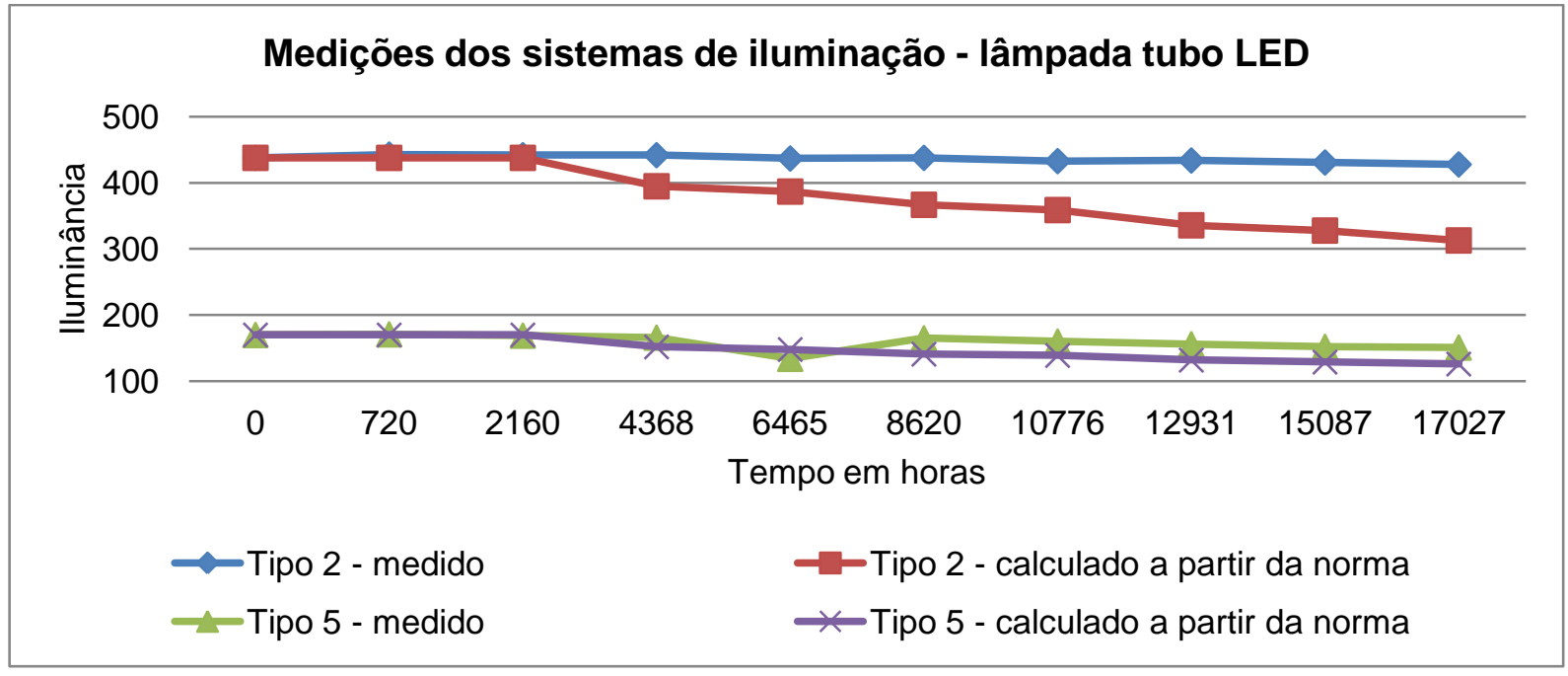

Figura 112: Gráfico comparativo dos sistemas de iluminação utilizando tecnologia LED, aplicado na luminária

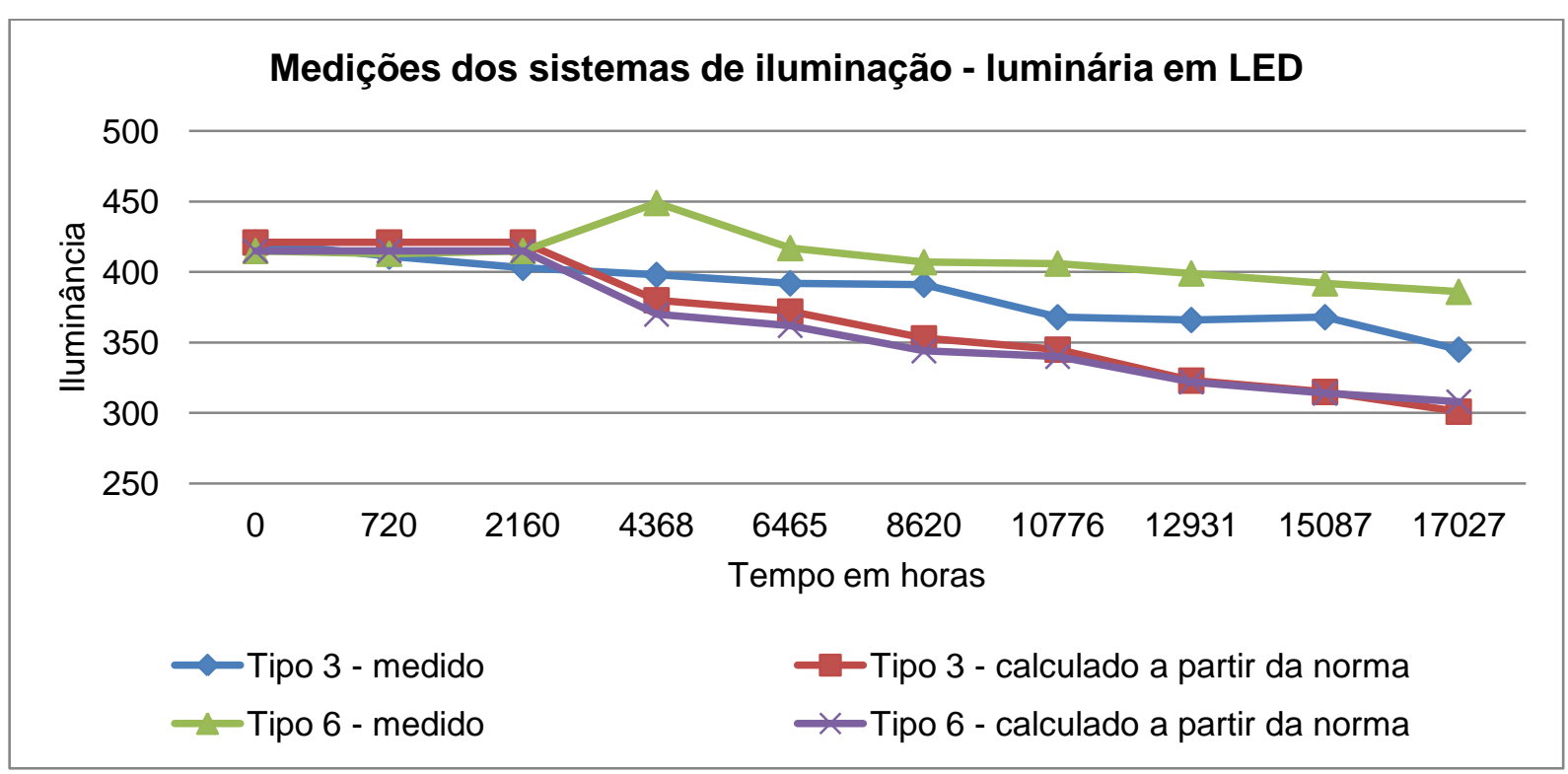

As confirmações ou não dessas hipóteses são válidas para os sistemas de iluminação utilizadas nesta pesquisa, dos fabricantes Lumicenter e Philips, que gentilmente doaram os produtos para ensaios e medições. 


\section{CAPÍTULO 9}

$\overline{\text { CONCLUSÕES }}$ 


\section{CONCLUSÕES}

Por meio da experimentação, isto é, das medições realizadas, observou-se que houve depreciação em todos os sistemas de iluminação. Ela foi menos acentuada nos sistemas que utilizavam tecnologia LED comparada à tecnologia fluorescente, e mais intensa nos modelos com difusor do que nos modelos de aletas, com exceção dos sistemas de iluminação com LED aplicado na luminária.

Um dos possíveis motivos dessa inversão de resultados seria a presença de um difusor entre o LED e as aletas, causando um aquecimento maior neste modelo de luminária, e, logo, o aceleramento da depreciação da tecnologia LED. O desenho do próprio projeto da luminária também pode ter causado essa maior depreciação.

Apesar do experimento que utilizava lâmpadas fluorescentes ter terminado após 13.000h devido à queima de um dos reatores, é provável que, se os conjuntos estivessem ligados, as medições poderiam ter finalizado junto com as medições que utilizavam a tecnologia LED, uma vez que os fabricantes afirmam que a vida útil das lâmpadas fluorescentes é de 20.000h.

Durante as comparações realizadas entre as medições e os ensaios laboratoriais, notou-se que os difusores de um dos modelos de luminárias fornecidos eram diferentes. Primeiro pelo resultado do próprio ensaio, segundo pela comparação visual entre peças.

Embora tenha sido realizado um segundo ensaio utilizando corpo e lâmpadas novas e o difusor de uma das luminárias utilizadas no experimento, e devidamente limpo, chegou-se à conclusão que havia diferença entre os difusores provenientes dos sistemas de iluminação utilizados no experimento. O fluxo luminoso medido em laboratório teve uma diferença de $12 \%$ entre eles.

A partir desse problema encontrado, não foi possível verificar por meio dos ensaios laboratoriais a real depreciação dos sistemas de iluminação com difusor.

No entanto, o resultado dos ensaios das lâmpadas mostrou que a sua depreciação dentro dos modelos com difusor e com aletas é praticamente o mesmo, ou seja, podemos concluir que a maior parcela da depreciação do modelo com difusor provém do acúmulo de sujeira no próprio corpo da peça.

Com relação às simulações, comparando os três programas utilizados (Dialux EVO, AGi32 e Relux) a diferença nos resultados foi de $5 \%$ na situação em que os 
ambientes estão vazios, e as reflexões padrões estão sendo utilizadas. Por reflexão padrão, entende-se que seja considerado $70 \%$ para acabamentos claros, $50 \%$ para acabamento médios, e de $10 \%$ a $20 \%$ para acabamentos escuros.

Caso haja acréscimo de mobiliários e acabamentos próximos ao modelo real, a diferença no resultado final aumenta e varia entre os programas de cálculo. Obteve-se uma diferença de $15 \%$ a $20 \%$ entre os programas nessas situações.

Ao comparar todos os resultados da iluminância média alcançada nos programas de cálculo com a iluminância média das medições, observou-se que a diferença não ultrapassou 50 lux, o que significa uma variação de no máximo 10\% nos resultados.

Apenas um dos resultados obtidos apresentou diferença maior que essa, porém, como foi mencionado anteriormente no Capítulo 5, ainda não é possível inserir os dados de entrada, tais como cromaticidade, reflexão e o próprio mobiliário, exatamente como os existentes. Assim, os dados de saída acabam sendo modificados.

A maior diferença entre os resultados na comparação das simulações, ocorreu devido os dados da reflexão de mobiliários que cada programa considerou distinto ao inserir a cromaticidade. Infelizmente as informações exatas de reflexão e cromaticidade não são fornecidas pelos fabricantes.

Embora haja diferenças nos resultados, os softwares de cálculo luminotécnico são uma ferramenta importante na etapa projetual de arquitetura e pelos resultados obtidos na comparação desses programas com as medições, pode-se afirmar que os resultados são confiáveis, considerando uma margem de erro de apenas 10\%.

Por fim, ao comparar a depreciação do nível de iluminância média das medições realizadas com a depreciação esperada conforme norma CIE-97:2005, foi possível concluir que para o período de até 3 meses, a depreciação do primeiro é maior que o segundo, tanto em relação à tecnologia fluorescente, como no caso da tecnologia LED.

Após 6 meses, observou-se que a depreciação real medida foi menor do que a norma CIE-97:2005 prediz, e esse comportamento continuou até o final do experimento. Especificamente no caso do modelo 3, a proporção da depreciação do seguiu a norma, no entanto, em valores absolutos, ela continuou menor que a norma.

Por meio das medições, foi possível verificar que os sistemas de iluminação que utilizam lâmpadas, sejam elas fluorescentes tubulares ou tubo LED, têm maior 
perda do fluxo luminoso nos modelos com difusor do que nos que possuem aletas e são semiabertos. Embora haja essa perda maior nos sistemas fechados com difusor, eles trazem mais conforto visual aos usuários.

A pesquisa foi importante, pois pôde mostrar o real fator de manutenção ou depreciação que pode ser considerado no projeto luminotécnico. A própria norma CIE-97:2005 não coloca os dados relacionados à depreciação do fluxo luminoso da lâmpada (LLMF) e efeito de falha de envelhecimento da lâmpada (LSF) dos LEDs, justificando que os dados do LED mudam constantemente.

Esta tese proporciona o desenvolvimento de outras pesquisas, na mesma área, que aprofundem a análise da depreciação dos diversos tipos de tecnologias dos sistemas de iluminação. Um exemplo seria aumentar o tempo de medição da depreciação, seja por meio de medições ou por meio de ensaios, uma vez que talvez haja depreciação da tecnologia LED de maneira brusca em algum momento de sua vida útil.

As medições e os ensaios também poderiam ser realizados com outros modelos de sistemas de iluminação, ou mesmo comparando diversos fabricantes, pois os resultados do experimento apresentado por esta tese são específicos dos fabricantes utilizados.

A importância maior da pesquisa foi encontrar os dados de depreciação que cada sistema de iluminação pode trazer, pois eles devem ser levados em consideração no projeto luminotécnico. Esses índices afetam diretamente o nível de iluminância do plano de trabalho, que caso esteja muito alto ou muito baixo, afeta os usuários finais.

Quando os sistemas de iluminação forem instalados, o nível de iluminância pode estar cerca de 30\% maior que o recomendado pela norma NBR/ISO CIE89951, para que ao longo do tempo permaneça dentro desses valores e que traga conforto visual aos usuários. Deve-se estabelecer o tempo de troca dos sistemas de iluminação e seus componentes, assim como programar sua limpeza.

Além de os resultados adquiridos nesta pesquisa serem úteis para os arquitetos e lighting designers, a pesquisa também mostrou o cuidado necessário ao se projetar uma luminária em LED. Esta pode aumentar ou reduzir a vida útil do sistema de iluminação em questão, dependendo da forma como o sistema é montado e a escolha dos componentes e materiais utilizados para a composição dele. 
A pesquisa revelou que a depreciação da tecnologia LED é menor que a da tecnologia fluorescente tubular na maioria dos casos, no entanto, como mostram estudos relacionados à saúde e exposição constante ao LED, questiona-se o real motivo da substituição atual dessas tecnologias. Poderia ser uma questão de economia de energia ou de aumento da produtividade e conforto dos usuários. Seria para obter uma certificação no edifício ou seria realmente uma melhoria das condições de trabalho dos usuários.

Acredito que ainda há potencial para a realização de muitos estudos a serem sobre essa nova tecnologia, e é importante que seus resultados sejam amplamente divulgados na comunidade científica e para os profissionais envolvidos em projetos de iluminação. 
REFERÊNCIAS BIBLIOGRÁFICAS 
10. BIBLIOGRAFIA

\subsection{Bibliografia referenciada}

ASSOCIAÇÃO BRASILEIRA DE NORMAS TÉCNICAS. NBR ISO/CIE 8995-1:2013

- lluminação de ambientes de trabalho. Parte 1: Interior. São Paulo, 2013. 46p.

Commission Internationale de l'eclairage. CIE-097:2005. Guide on the maintenance of indoor electric lighting systems. $2^{\text {nd }}$ Edition, Austria, 2005. 28p.

CNN. Cable News Network.25.novembro.2017. Por Manisha Ganguly. Loss of the night: Light pollution rising rapidly on a global scale. Acesso em: 15.dez.2018.

ELETROBRAS. Relatório de Avaliação do Mercado de Eficiência Energética no Brasil - Sumário Executivo. Rio de Janeiro: ELETROBRAS; PROCEL, 2009. 77p.

EPE. Empresa de Pesquisa Energética. Consumo anual de energia elétrica por classe (nacional). Disponível em:

$<$ http://www.epe.gov.br/pt/publicacoes-dados-abertos/publicacoes/Consumo-Anualde-Energia-Eletrica-por-classe-nacional> consulta em dezembro/2018

GARCIA, Leandro Henrique Cascaldi. A reestruturação do setor elétrico brasileiro e a crise do racionamento (1981-2002). Trabalho final de graduação. Faculdade de Economia, Administração e Contabilidade de Ribeirão Preto da Universidade de São Paulo. São Paulo, SP, 2011. 72p.

IESNA, LM-57 - Calculating Coefficcients of Utilization, Wall and Ceiling Cavity Exitance

JACOB, Edson. Manual de Utilização de Leds e Fontes de Alimentação.

KYBA, C., KÜSTER, T. SÁNCHES de Miguel, A., BAUGH, K., JECHOW, A., HÖLKER, F. BENNIE, J., ELVIDGE, C. D., GASTON, K.J., GUANTER, L.. 
Artificially lit surface of Earth at night increasing in radiance and extent. Science Advances, Vol 3, N¹1, 22.nov.2017.

Disponível em: < http://advances.sciencemag.org/content/3/11/e1701528>

MERCOLA, J.M., WUNSCH, Alexander. How LED Lighting may compromise your health. Em MERCOLA, Take Control of your Health. 23.Outubro.2016

Disponível em: < https://articles.mercola.com/sites/articles/archive/2016/10/23/nearinfrared-led-lighting.aspx> Acessado em: 27.Ago.2018

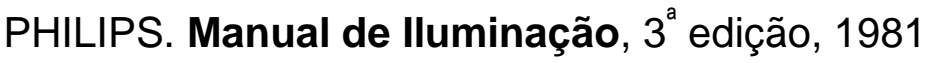

ROSER, Max. “Light” em OurWorLdlnData.org., 2019. Disponível em: <https://ourworldindata.org/light>. Acesso em: 06.fev.2019

SCOPACASA, Vicente A. Entendendo a IESNA LM80-08 e TM-21-11. Revista 0 Setor Elétrico, capítulo XII - LED - Evolução e inovação, São Paulo, Edição 131, dezembro 2016. P. 30-33.

SOARES, Ruy Barbosa. Resposta humana à luz: alterações não visuais e o projeto luminotécnico residencial com LEDs. Dissertação de mestrado. Faculdade de Arquitetura e Urbanismo da Universidade de São Paulo. São Paulo, SP, 2018. $152 \mathrm{p}$.

SOUZA, Dennis Flores de. DIALux uma ferramenta em constante evolução. Revista Lume Arquitetura, São Paulo, N49, abril/maio 2011. P.38-46.

\subsection{Bibliografia consultada}

9 COBEE, 2012, Centro de convenções Frei Caneca. Avaliação da Tecnologia LED - Estudos. São Paulo. Disponível em:

<http://www.osetoreletrico.com.br/web/documentos/fasciculos/Ed77_fasc_sistemas_i luminacao_cap6.pdf>. Acessado em abril de 2014. 
AMORIN, Claudia Naves David. Relatório técnico - comparação dos níveis de iluminância recomendados em diversas normas. Faculdade de Arquitetura e Urbanismo da Universidade de Brasília. Brasília, DF, 2010. 15p.

ASSOCIAÇÃO BRASILEIRA DE NORMAS TÉCNICAS. IEC/PAS 62612:2013 Lâmpadas LED com dispositivo de controle incorporado para serviços de iluminação geral - Requisitos de desempenho. São Paulo, 2013. 12p.

ASSOCIAÇÃO BRASILEIRA DE NORMAS TÉCNICAS. IEC/TS 62504:2012 Termos e definições para LEDs e os módulos de LED de iluminação geral. São Paulo, 2013. 12p.

ASSOCIAÇÃO BRASILEIRA DE NORMAS TÉCNICAS. NBR 16026:2012 Dispositivo de controle eletrônico c.c. ou c.a. para módulos de LED - Requisitos de desempenho. São Paulo, 2012. 13p.

ASSOCIAÇÃO BRASILEIRA DE NORMAS TÉCNICAS. NBR 16205-1:2013 Lâmpadas LED sem dispositivo de controle incorporado de base única. Parte 1: Requisitos de segurança. São Paulo, 2013. 9p.

ASSOCIAÇÃO BRASILEIRA DE NORMAS TÉCNICAS. NBR 16205-2:2013 Lâmpadas LED sem dispositivo de controle incorporado de base única. Parte 2: Requisitos de desempenho. São Paulo, 2013. 9p.

ASSOCIAÇÃO BRASILEIRA DE NORMAS TÉCNICAS. NBR 61347-2-13:2012 Dispositivo de controle da lâmpada. Parte 2-13: Requisitos particulares para dispositivos de controle eletrônicos alimentados em c.c. ou c.a. para os módulos de LED. São Paulo, 2012. 33p.

ASSOCIAÇÃO BRASILEIRA DE NORMAS TÉCNICAS. NBR IEC 62031:2013 Módulos de LED para iluminação em geral - Especificações de segurança. São Paulo, 2013. 11p. 
ASSOCIAÇÃO BRASILEIRA DE NORMAS TÉCNICAS. NBR IEC 62560:2013 Lâmpadas LED com dispositivos de controle incorporado para serviços de iluminação geral para tensão > 50V - Especificações de segurança. São Paulo, 2013. $19 p$.

BARBOSA, Alessandra da Costa. Estudo fotométrico de lâmpada de LED. In: I Workshop de lluminação a LED, Centro de Pesquisas de Energia Elétrica - CEPEL. Outubro de 2012.

BIGONI, Silvia. Eficiência dos conjuntos óticos de alumínio especular de alto desempenho energético. 2013. 252p. Dissertação (Mestrado) - Faculdade de Arquitetura e Urbanismo da Universidade de São Paulo, São Paulo, 2013.

CHOW, Michael. Engineering a successful lighting retrofit. Ohio, USA, 2012. Disponível em: <http://www.csemag.com/home/single-article/engineering-asuccessful-lighting-retrofit/8b8e4eeec4f0c6e6c81cf81ab518b22b.html> . Acesso em 14/abril/2015.

EPE, disponível em:

$<$ http://www.epe.gov.br/pt/publicacoes-dados-abertos/publicacoes/Consumo-Anualde-Energia-Eletrica-por-classe-nacional> consulta em dezembro/2018

EDIRISINGHE, U A S K. Study to evaluate the effectiveness of lighting system by using LED technology in Commercial buildings. 2012, 79p. Dissertação (mestrado) em Engenharia. Department of Energy Technology, Royal Institute of Technology, Suécia. 2012.

FARIA, Nara. NBR 5413: 0 que e por que deve mudar? Revista Lumière, São Paulo, № 21, p.56-59, 2008.

FERREIRA, Juliana Zandova. Estudo comparativo entre lâmpadas fluorescentes tubulare T8 e tubulares de LED. 2014, 59p. Monografia de especialização Universidade Tecnológica Federal do Paraná, Curitiba, 2014. 
FREITAS, Paula Campos Fadul. Luminotécnica e lâmpadas elétricas. Faculdade de Engenharia elétrica da Universidade Federal de Uberlândia

GALVÃO, Walter; D'OTTAVIANO, Camila. A luz na arquitetura e na cidade. Cienc. Cult. São Pauloa, v. 67, n.3, p. 48-50, Setembro 2015. Disponível em: $<$ http://cienciaecultura.bvs.br/scielo.php?script=sci_arttext\&pid=S000967252015000300015> Acessado em outubro/2018

GANSLANDT, R.; HOFMANN, H.. Handbook of Lighting Design, Erco Edition, Germany, $1^{\text {st }}$. Edition, 1992. 289p.

IESNA Iluminating Engineergint Society of North America. Lighting Handbook. $10^{\text {th }}$ Edition. New York, IESNA, 2010.

IWASHITA, Juliana. Eficiência energética em sistemas de iluminação de interiores: análise de luminárias comerciais. 2004. 205p. Dissertação (Mestrado) - Escola Politécnica, departamento de Engenharia de Energia e Automação Elétricas da Universidade de São Paulo, São Paulo, 2004.

LANCELLE, Luis. Softwares para projetos de iluminação, São Paulo. Disponível em: http://www.lumearquitetura.com.br/softwares.html

MIQUELIN, Juliana Zimbardi. Análise de desempenho de lâmpadas LEDs e LFCs como alternativas em iluminação residencial em função da implementação da portaria ministerial № 1007 que limita o uso de lâmpadas incandescentes no Brasil. 2011. 75p. Trabalho de graduação em Engenharia Elétrica - Universidade Estadual Paulista, Faculdade de Engenharia de Guaratinguetá, Guaratinguetá, 2011.

MODENA, B.R.; CAMPOS, D.P. de; REIS, F.A.B. Viabilidade da transição fluorescente para LED no ambiente industrial. Revista Ciências do Ambiente OnLine, Volume 7, Número 2, Julho, 2011. Disponível em:

http://www2.ib.unicamp.br/revista/be310/index.php/be310/article/viewFile/301/234 
OSRAM. Manual Osram, Iluminação: Conceitos e projetos. Impresso em 22.12.2006.

PEREIRA, Daniela Cardoso Laudares. Modelos Físicos reduzidos: uma ferramenta para avaliação da iluminação natural. 2006. 246p. Dissertação (Mestrado) - Faculdade de Arquitetura e Urbanismo, Universidade de São Paulo, São Paulo, 2006.

PHILIPPI, A.; ROMERO, M. A.; BRUNA, G. C. Curso de Gestão Ambiental. São Paulo. SP. Editora Manole, 2004. 1045p.

PROCEL. Disponível em: <http://www.procelinfo.com.br/main.asp>

SÁ, Claúdia. Softwares de iluminação. Revista Lume Arquitetura, São Paulo, N40, outubro/novembro 2009. P.32-38.

STRAVORAVDIS, Spyros. Lighting Offices with LEDs: A Study on Retrofitting Solutions. 2013, 211p. Tese (doutorado) - Welsh Schoof of Architecture, 2013.

STREletS, K.; PERlOVA E.; PlatONOVA, M.; PANKOVA A.; ROMERO, M.; ALSHABAB, M. S.. Post Occupancy Evaluation (POE) and Energy Conservation Opportunities (ECOs) Study for Three Facilities in SPbPU in Saint Petersburg. In: $15^{\text {th }}$ Internacional scientific conference "Underground Urbanisaton as a Prerequisite for Sustainable Development”. 2016. Disponível em: $<$ https://www.sciencedirect.com>

REVISTA Lume Arquitetura. Disponível em: http://www.lumearquitetura.com.br/lume/ e revistas impressas.

ROIZENBLATT, Isac. Critérios da Iluminação Elétrica Urbana. 2009. 196p. Tese (Doutorado) - Universidade Presbiteriana Mackenzie, São Paulo, 2009.

ROMERO, M. A.; REIS, L. B. Eficiência energética em edifícios. São Paulo: Manole, 2011 (no prelo). 195p. 
ROY, Geoffrey G. A comparative study of lighting simulation packages suitable for use in architectural design. Murdoch University - School of Engineering, October 2000.

SARGENT, Robert G. Verification and Validation of Simulation Models. Proceedings of the 2011 Winter Simulation Conference, 2011. P. 183-198.

TEIXEIRA, I.; RIVERA, R.; REIFF, L.O.. Iluminação LED: sai Edison entram Haitz e Moore - benefícios e oportunidades para o país. BNDES Setorial 43, p.363-412, março, 2016.

THE CLIMATE GROUP. The LED lighting wave is reaching Brazil, says Antonio Barbalho, World Bank. Disponível em:

$<$ https://www.theclimategroup.org/news/led-lighting-wave-reaching-brazil-saysantonio-barbalho-world-bank> Acesso em outubro/2018

VIANNA, Nelson; GONÇALVES, Joana Carla Soares. Iluminação e Arquitetura. Virtus S/C Ltda, São Paulo, SP, 2001. 378p. 
ANEXO I

FICHA TÉCNICA DAS LUMINÁRIAS 


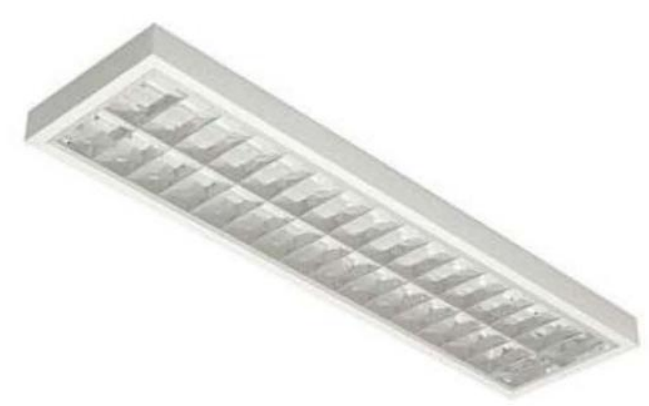

\section{Descrição}

Luminária comercial de sobrepor, na versão para 2 lâmpadas fluorescentes tubulares bulbo T5 de 28W / 54W. Corpo confeccionado em chapa de aço tratada e fosfatizada \#26. Reator alojado na parte interna do corpo da luminária. Pintura eletrostática poliester à pó branco liso. Conjunto ótico constituído de refletor e aletas parabólicos em alumínio anodizado brilhante de alta pureza e refletância. Soquetes anti-vibratórios em policarbonato com proteção contra raios UV, com sistema de engate rápido para os fios, rotor de segurança e contatos em bronze fósforo, fixação ao corpo da luminária por meio de encaixe.

\section{Informações Técnicas}

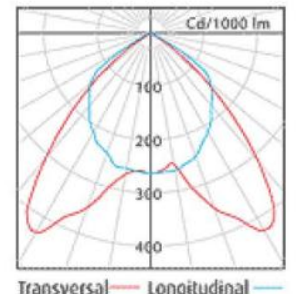

\section{DIALux}

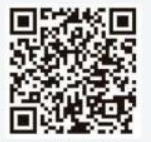

Link para download

Plugin Lumicenter

para Dialux

Grupo Lumicenter Lighting

Av, Rui Barbosa, 3770 , Afonso

Pena, São José dos Pinhas - PR.

Pena, Säo José dos
+55 (41) 2103.2750

Iransversal- Longitudinal-

unw. lumicenter.com
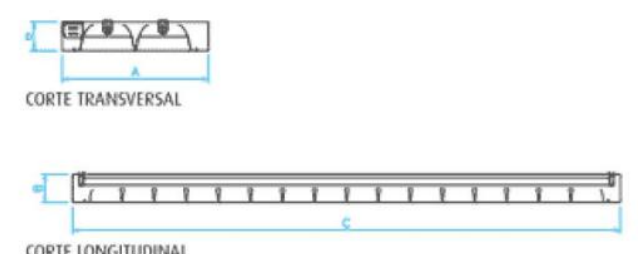

CORTE IONGITUDINAL

\begin{tabular}{|c|c|c|c|c|c|c|c|}
\hline Código & Potência & Fluxo & Lâmpada & Rend. & $\mathrm{A}(\mathrm{mm})$ & $\mathrm{B}(\mathrm{mm})$ & $\mathrm{C}(\mathrm{mm})$ \\
\hline FAA04-S228 & $66 \mathrm{~W}$ & $58001 \mathrm{~m}$ & $28 \mathrm{~W}$ & $76 \%$ & 313 & 61 & 1195 \\
\hline
\end{tabular}




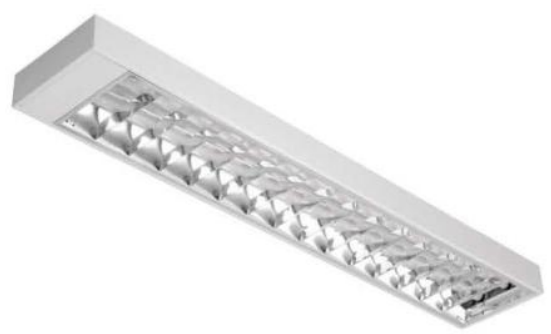

\section{Descrição}

Luminária comercial de sobrepor, na versão para 2 lâmpadas fluorescentes tubulares bulbo T8 de $32 \mathrm{~W}$. Corpo confeccionado em chapa de aço tratada e fosfatizada \#26, pintura eletrostática pó poliéster com camada mínima de 80 micra. Reator alojado na parte interna do corpo da luminária. Conjunto ótico constituído de refletor e aletas parabólicos em alumínio anodizado brilhante com $99,85 \%$ de pureza, proporcionando excelente controle de ofuscamento. Soquetes anti-vibratórios em policarbonato com proteção contra raios UV, com sistema de engate rápido para os fios, rotor de segurança e contatos em bronze fósforo, fixação ao corpo da luminária por meio de encaixe. Rendimento $74 \%$. IP20.

\section{Informações técnicas}

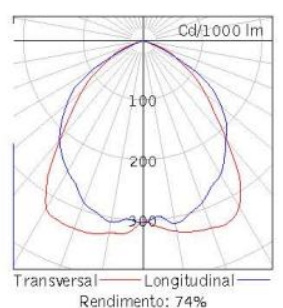

\section{DIALux}

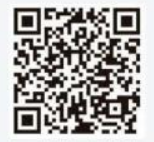

Link para download

Plugin Lumicenter

para Dialux

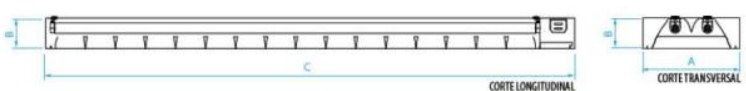

\begin{tabular}{|c|c|c|c|c|c|}
\hline Código & Lâmpada & Rend & $\mathbf{A}(\mathbf{m m})$ & $\mathrm{B}(\mathbf{m m})$ & $\mathrm{C}(\mathbf{m m})$ \\
\hline CAA02-S232 & $2 \times 32 \mathrm{~W}$ & $74 \%$ & 244 & 75 & 1317 \\
\hline
\end{tabular}

Grupo Lumicenter Lighting

Av, Rui Barbosa, 3770 Afonso

Av. Rui Barbosa, 3770 , Afonso
Pena, São José dos Pinhas - PR.

+55 (41) 2103.2750 


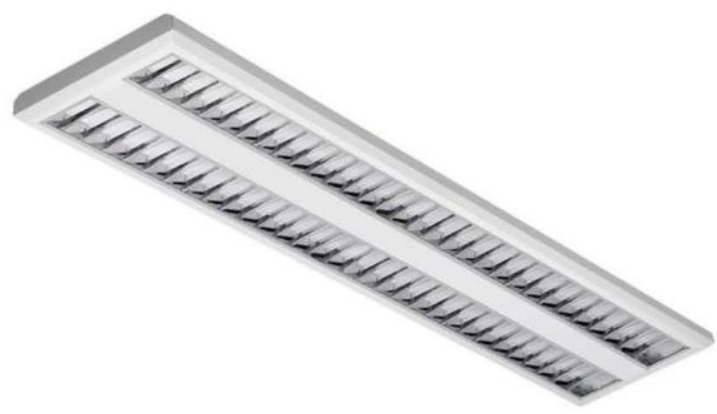

\section{Descrição}

Luminária comercial de sobrepor a LED. Corpo em chapa de aço \#26, tratada superficialmente. Pintura eletrostática branca microtexturizada, a pó poliéster. Refletor e aletas parabólicas em alumínio de alto brilho. Difusores em acrílico leitoso (PMMA) para melhor controle de ofuscamento e difusão da luz. Equipada com 2 linhas paralelas com LEDs SMD com consumo total de $37 \mathrm{~W}$ e $3400 \mathrm{~lm}$ de fluxo luminoso, eficácia de $91 \mathrm{~lm} / \mathrm{W}$ com temperatura de cor $4000 \mathrm{~K}$ e IRC85. Manutenção de $70 \%$ do fluxo inicial em $30.000 \mathrm{~h}$ de uso. Equipada com driver full-range de $100 \mathrm{~V}$ à $250 \mathrm{~V}$ integrado à luminária, com eficiência mínima de $90 \%$, THD $<10 \%$, fator de potência $>0,98$ e conector de engate rápido à rede elétrica. IP20.

\section{Informações técnicas}
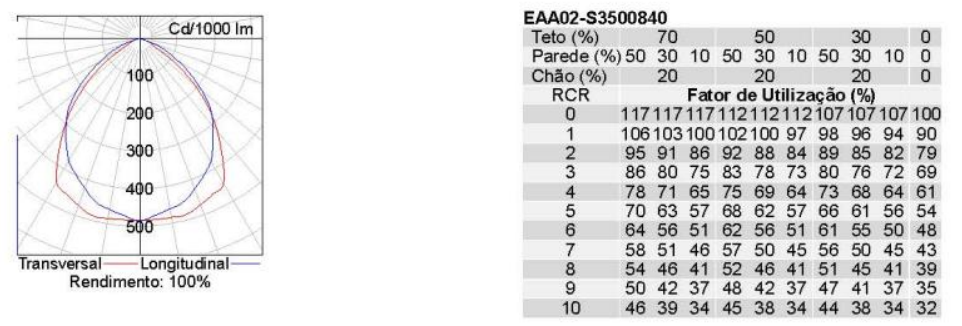

\section{DIALux

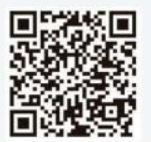

Link para download

Plugin Lumicenter

para Dialux

Grupo Lumicenter Lighting

Rua Salomão Miguel Nasser, 1200

Guatupê, São José dos Pinhas - PR.

+55 (41) 2103.2750 


\section{Descrição}

Luminária comercial de sobrepor, na versão para 2 lâmpada fluorescentes tubulares bulbo T5 de $28 \mathrm{~W}$ ou $54 \mathrm{~W}$. Corpo confeccionado em chapa de aço tratada e fosfatizada \#26. Pintura eletrostática em pó poliéster com camada mínima de 80 micra na cor branca microtexturizada. Reator alojado na parte interna do corpo da luminária. Difusor em acrílico leitoso (PMMA). Soquetes anti-vibratórios em policarbonato com proteção contra raios UV, com sistema de engate rápido para os fios, rotor de segurança e contatos em bronze fósforo, fixação ao corpo da luminária por meio de encaixe. IP20.

\section{Informações técnicas}

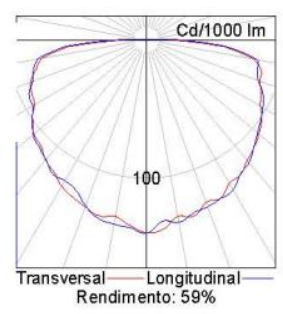

\section{DIALux}

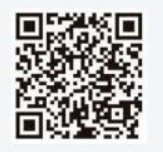

Link para download

Plugin Lumicenter

para Dialux

Grupo Lumicenter Lighting

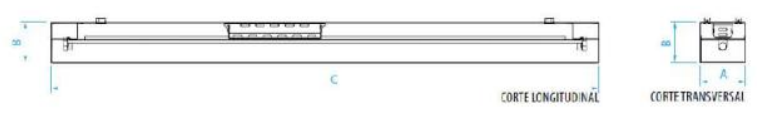

\begin{tabular}{|c|c|c|c|c|}
\hline Código & Lâmpada & A & B & C \\
\hline FHT07-S228 & $2 \times 28 / 54$ W T5 & 160 & 100 & 1180 \\
\hline
\end{tabular}




\section{Descrição}

Luminária comercial de sobrepor, na versão para 2 lâmpadas fluorescentes tubulares bulbo T8 de $32 \mathrm{~W}$. Corpo confeccionado em chapa de aço tratada e fosfatizada \#26. Pintura eletrostática em pó poliéster com camada mínima de 80 micra. Cor branca. Reator alojado na parte interna do corpo da luminária. Difusor em poliestireno leitoso. Soquetes anti-vibratórios em policarbonato com proteção contra raios UV, com sistema de engate rápido para os fios, rotor de segurança e contatos em bronze fósforo, fixação ao corpo da luminária por meio de encaixe.

\section{Informações técnicas}

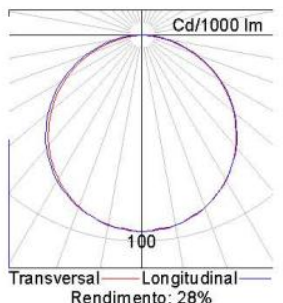

\section{DIALux}

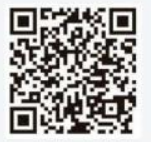

Link para domnload

Plugin Lumicenter

para Dialux

Grupo Lumicenter Lighting

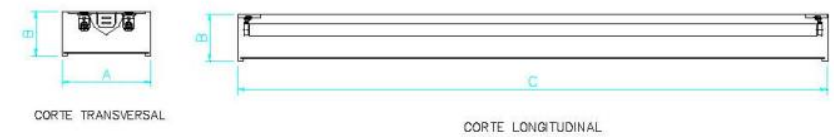

\begin{tabular}{|c|c|c|c|c|}
\hline Código & Lâmpada & A & B & C \\
\hline CHT10-5232CL & $2 \times 32$ W T8 & 200 & 100 & 1243 \\
\hline
\end{tabular}




\section{Descrição}

Luminária comercial de sobrepor a LED. Tecnologia Lumicenter. Corpo e refletor produzido em chapa de aço fosfatizada e pintada eletrostaticamente, tinta pó poliéster na cor branca microtexturizada. Proteção em acrílico leitoso $2 \mathrm{~mm}$ de espessura (PMMA). Equipada com LEDs SMD de alto brilho, aplicados sobre placas de metalcore. Consumo total de $36,5 \mathrm{~W}$, fluxo luminoso total de $3850 \mathrm{~lm}$, eficácia de $105 \mathrm{Im} / \mathrm{W}$. Temperatura de cor $4000 \mathrm{~K}$, IRC85. Driver multitensão (100 250V) integrado à luminária. Possui conector de engate rápido para instalação elétrica. IP20.

\section{Informações técnicas}
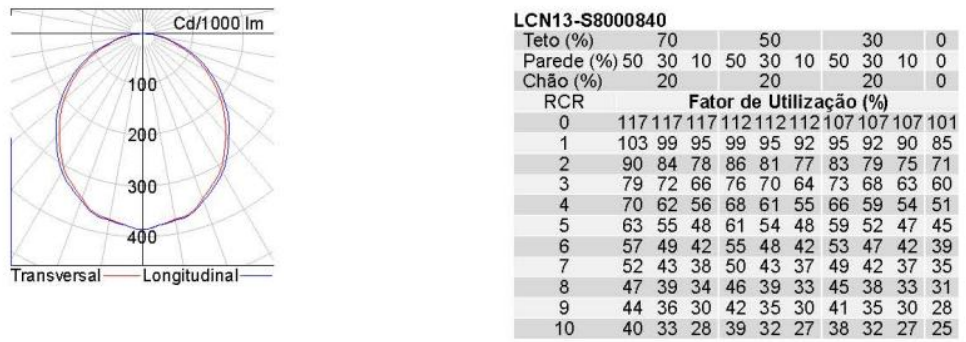

\section{DIALux}

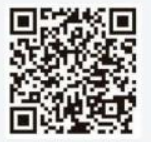

Link para download

Plugin Lumicenter

para Dialux

Grupo Lumicenter Lighting

Av Rui Barbosa, 3770, Afonso

Av. Rui Barbosa, 3770 , Afonso
Pena, São José dos Pinhas - PR.

+55 (41) 2103.2750

unw.lumicenter.com

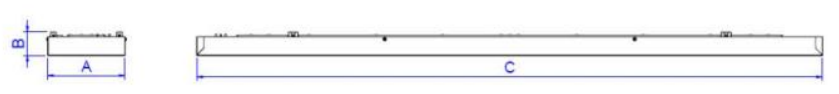

\begin{tabular}{|c|c|c|c|c|c|c|c|}
\hline Código & Potência* & Fluxo** & Temp. Cor & IRC & A & B & C \\
\hline LCN13-S4000840 & $36,5 \mathrm{~W}$ & $3850 \mathrm{~lm}$ & $4000 \mathrm{~K}$ & 85 & 160 & 50 & 1300 \\
\hline
\end{tabular}




\section{ANEXO II}

MEMORIAIS DE CÁLCULOS PROGRAMA DIALUX EVO 

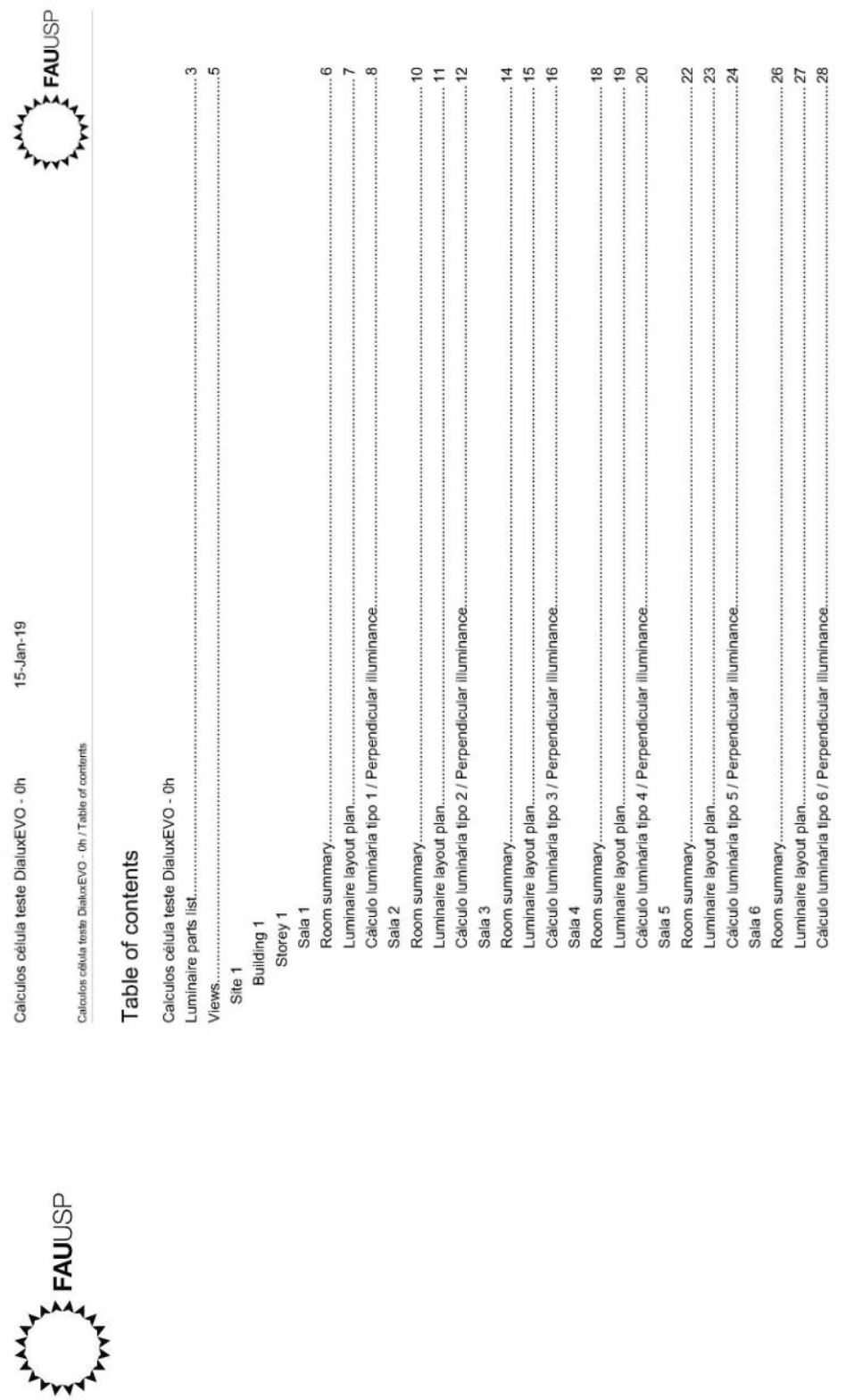

善毫

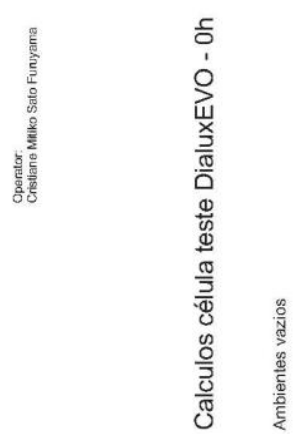



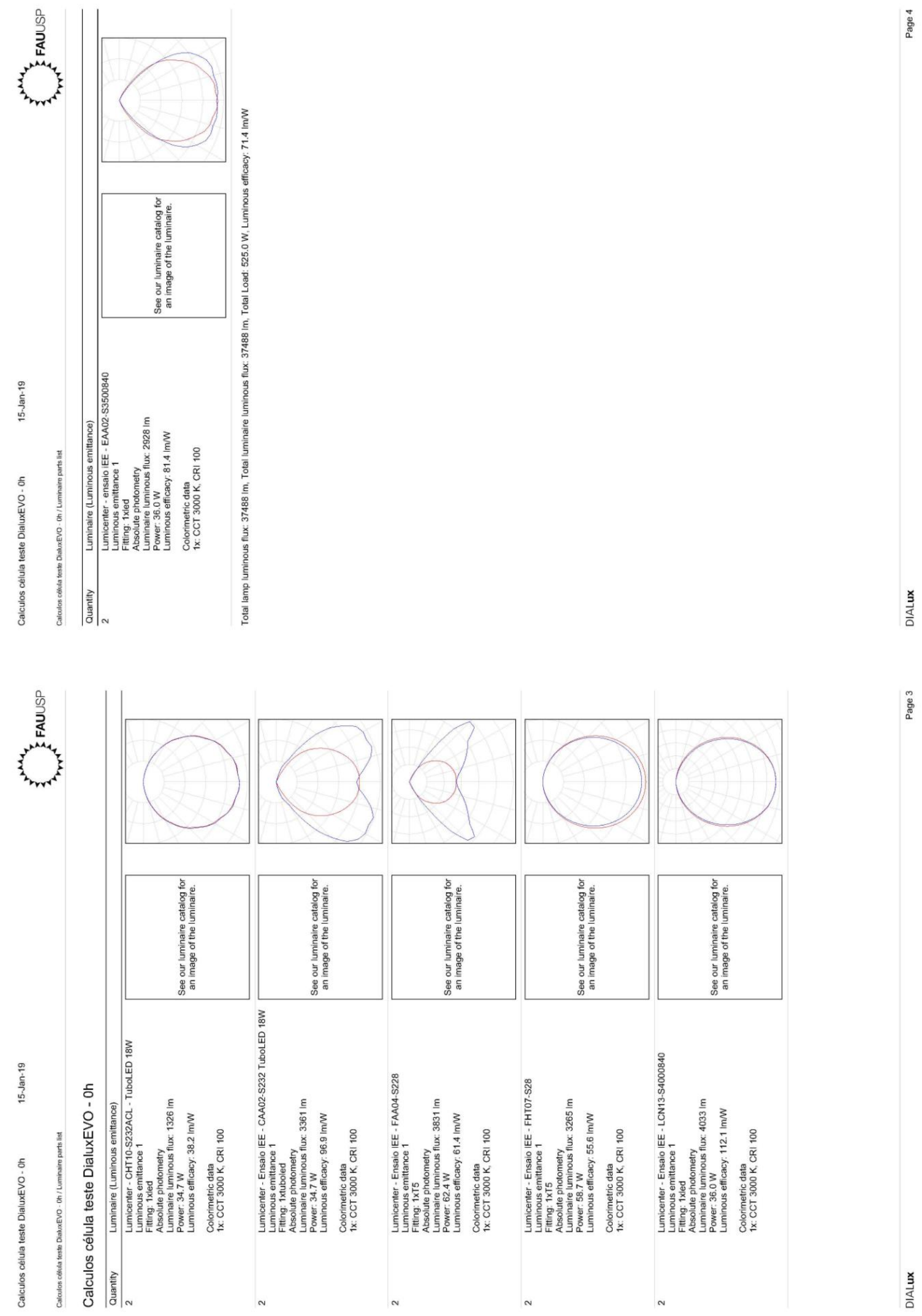

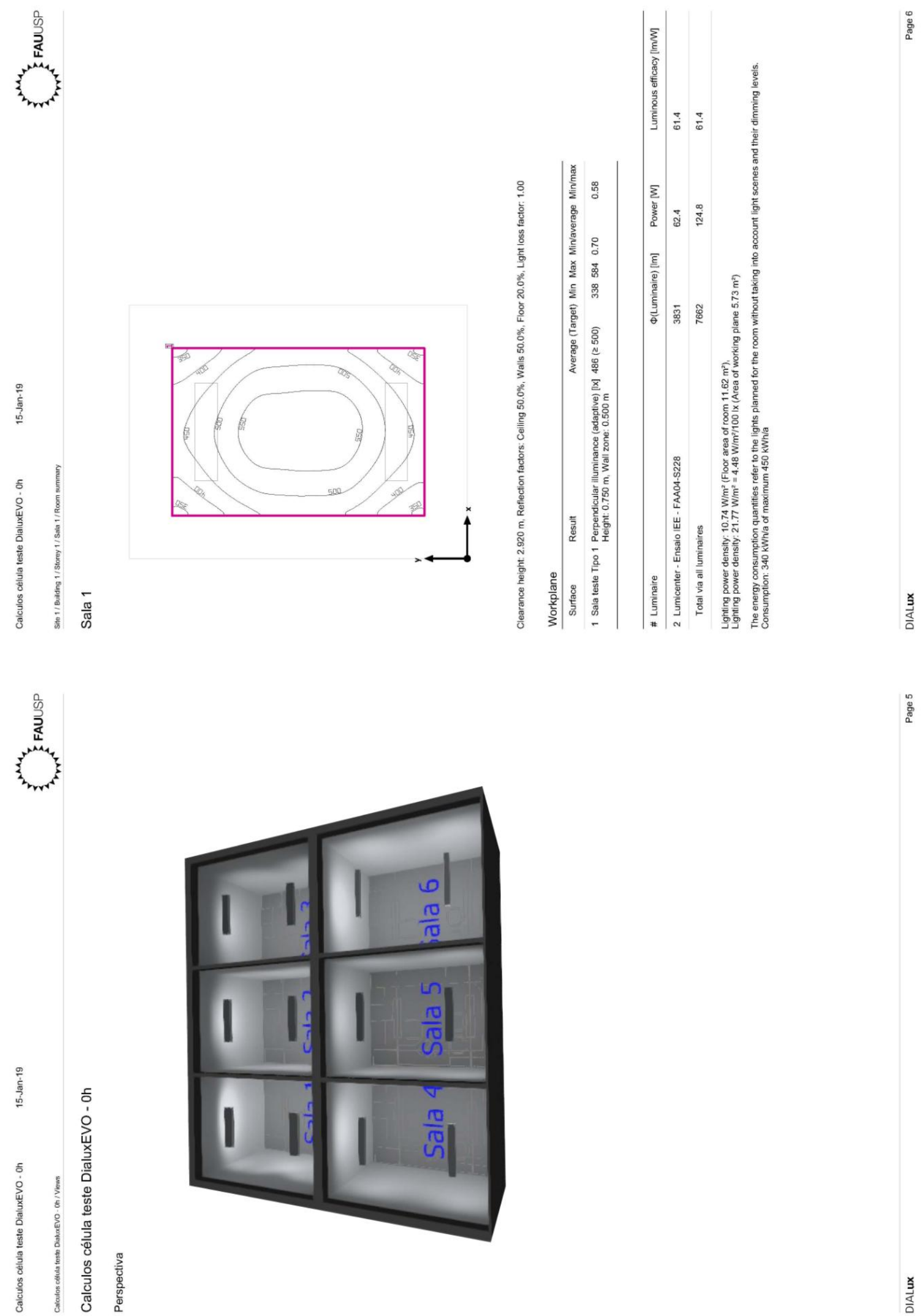


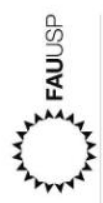
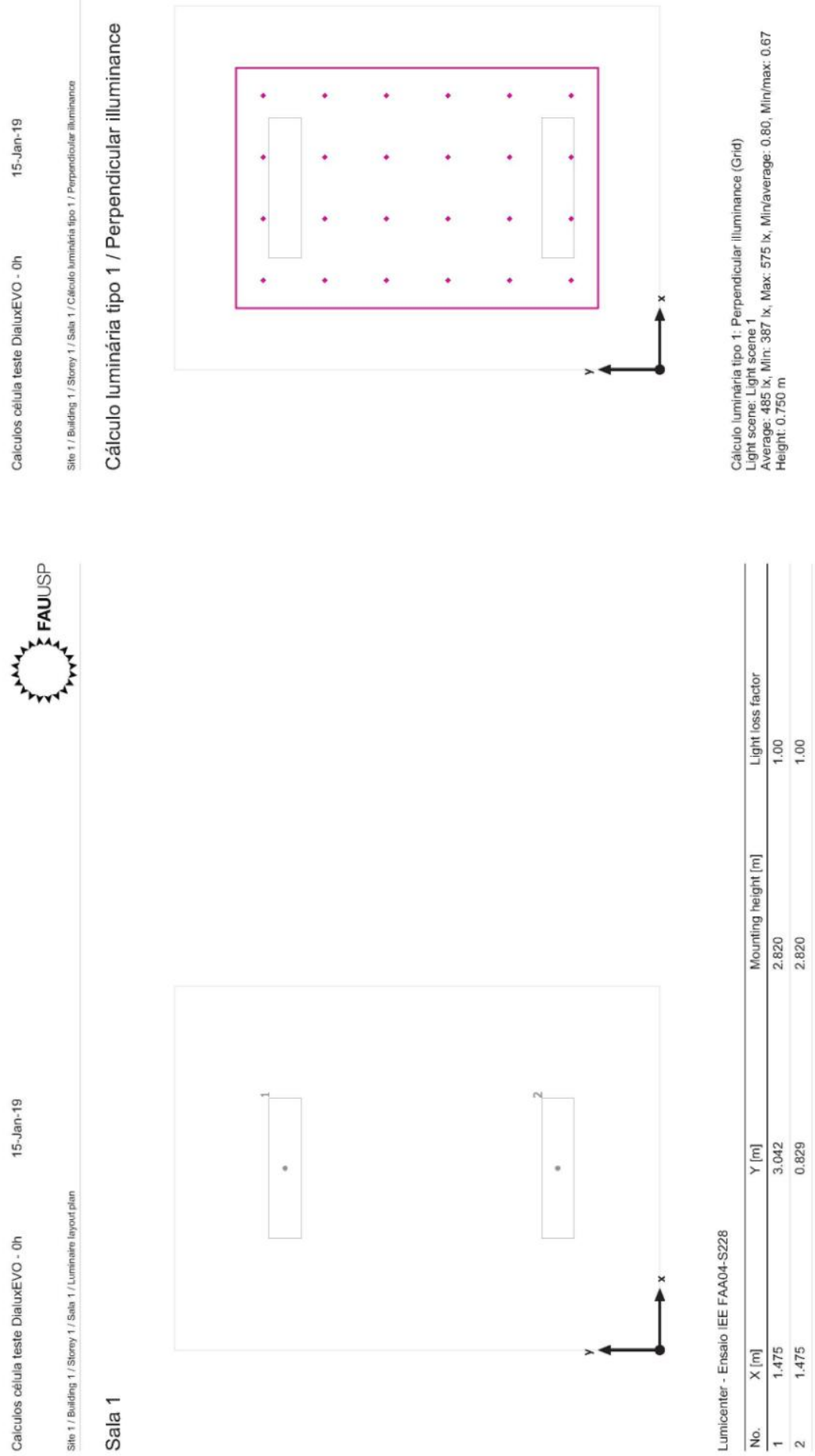


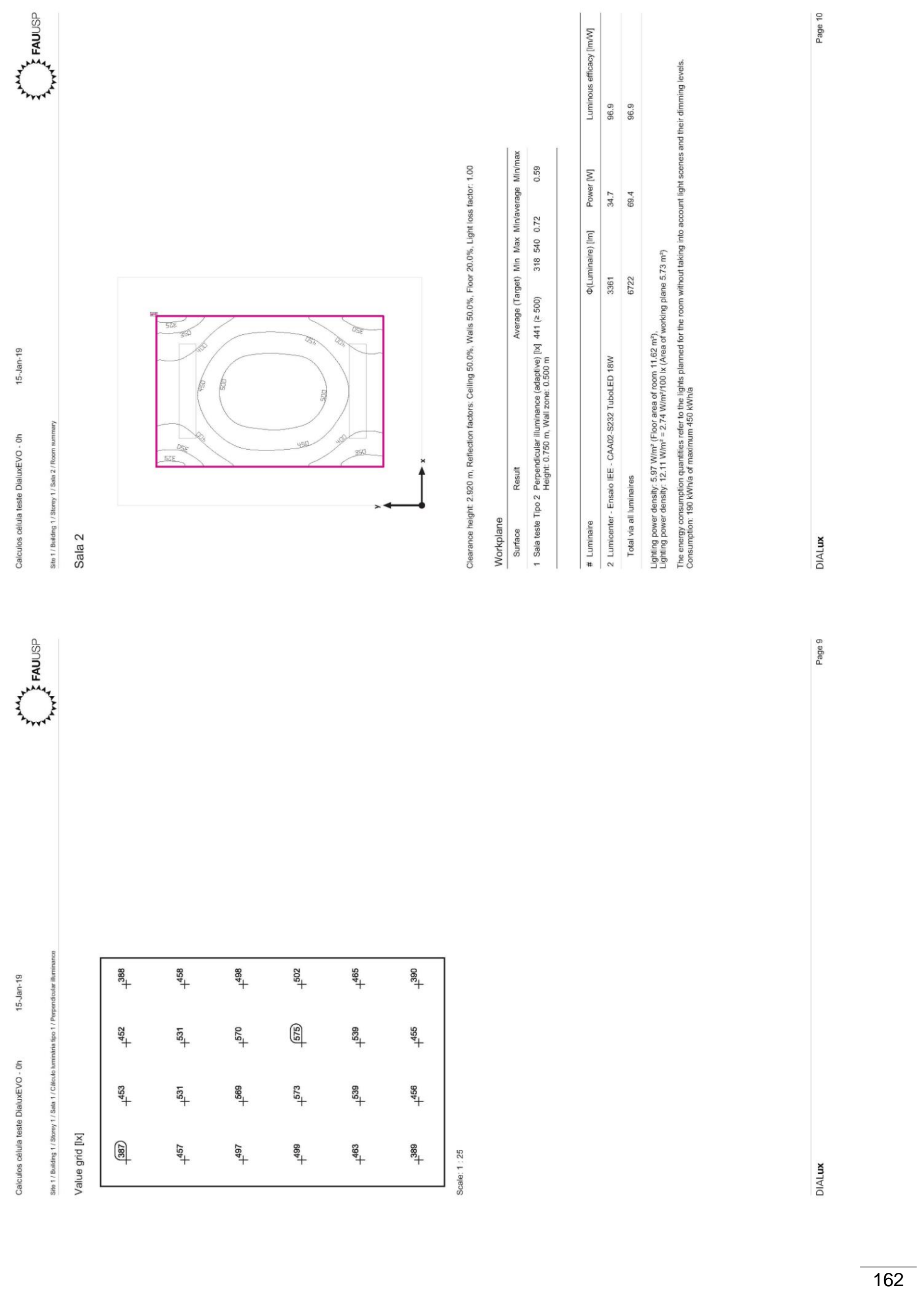




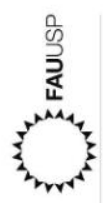
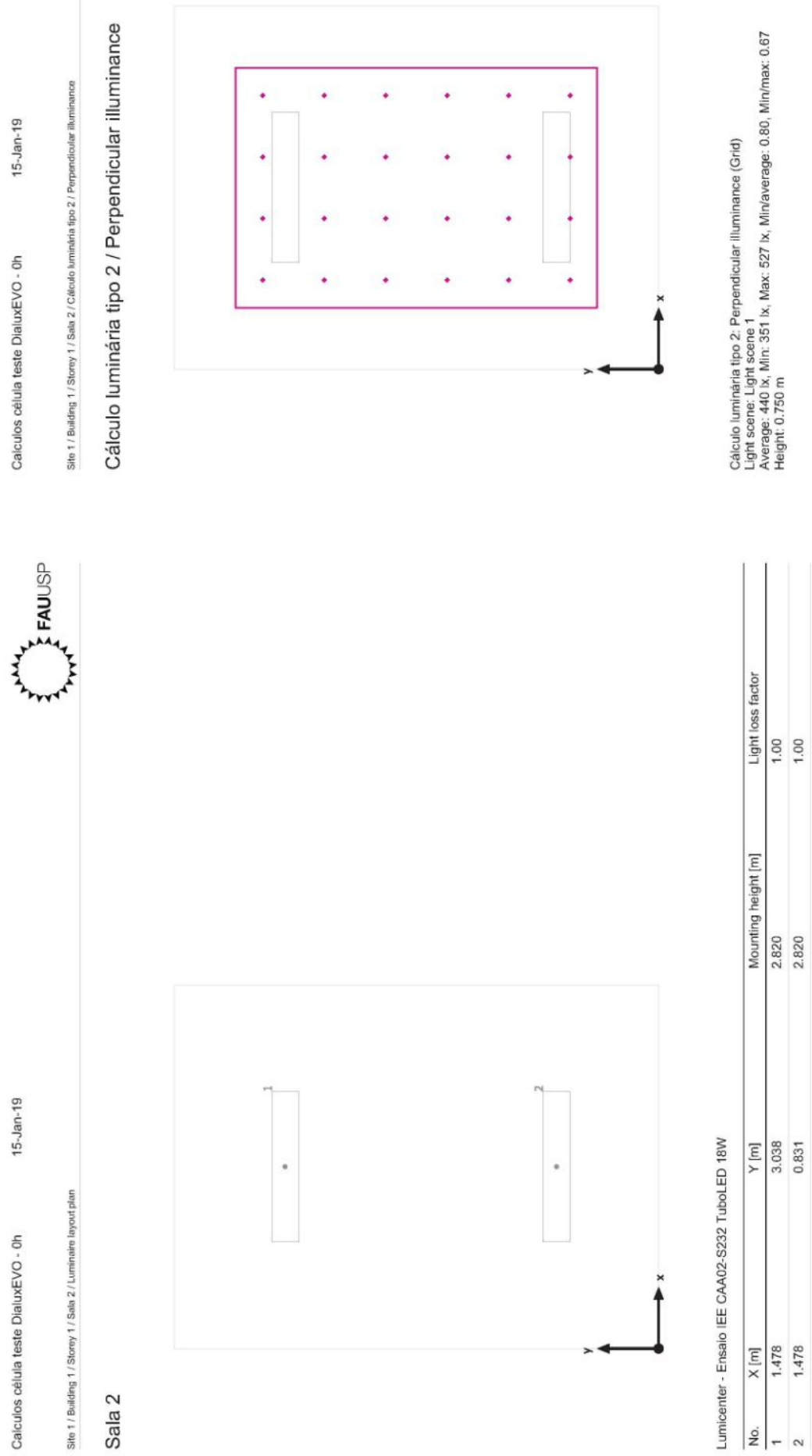

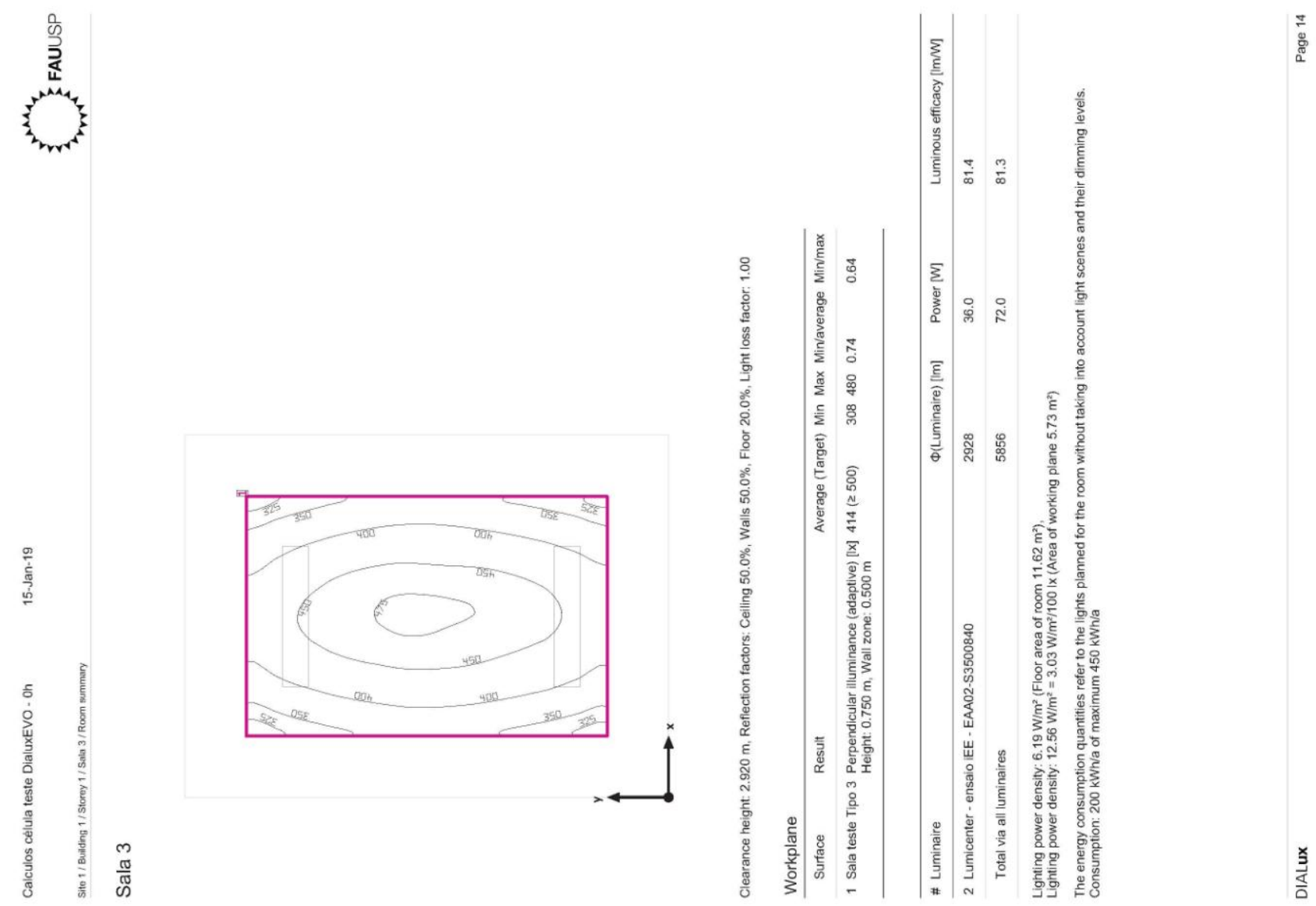

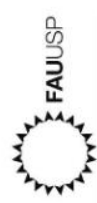

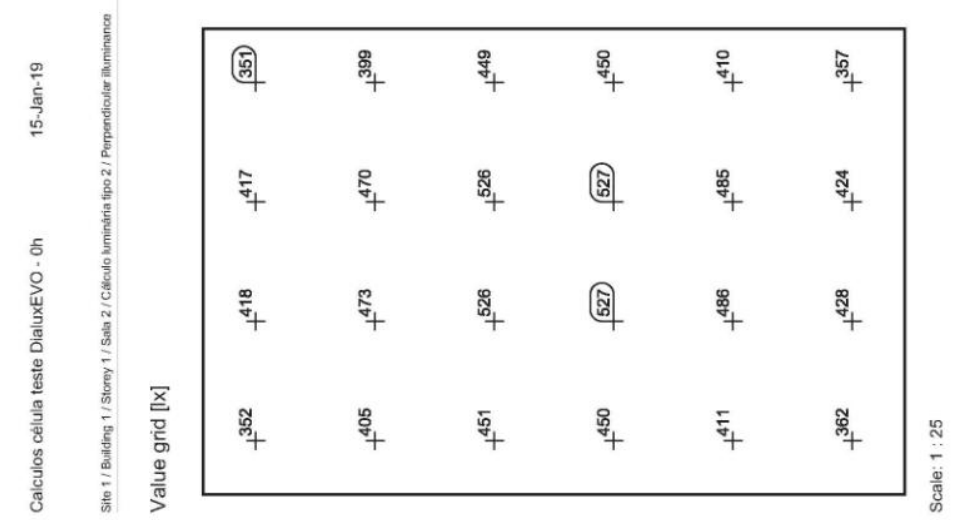




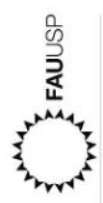
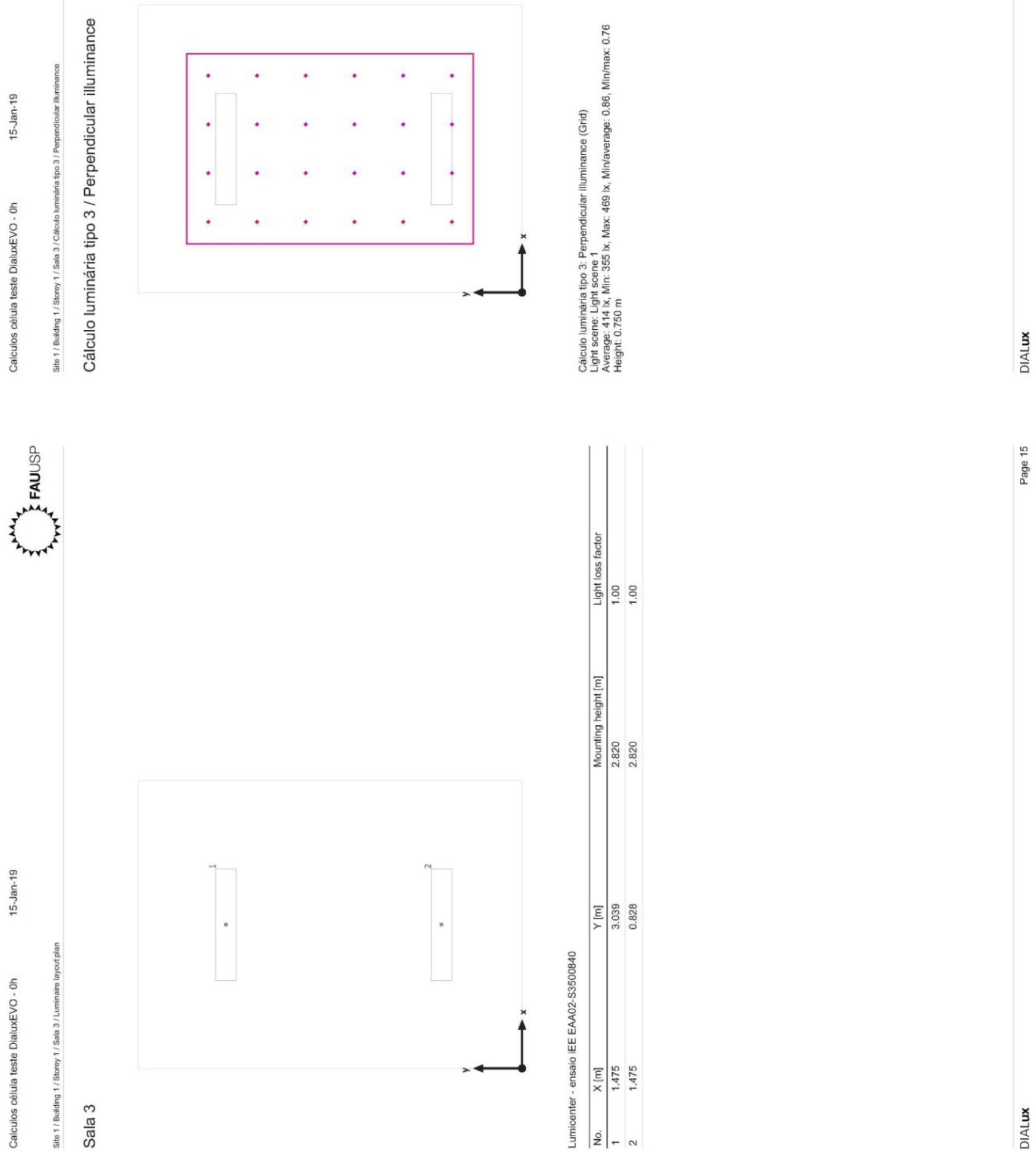

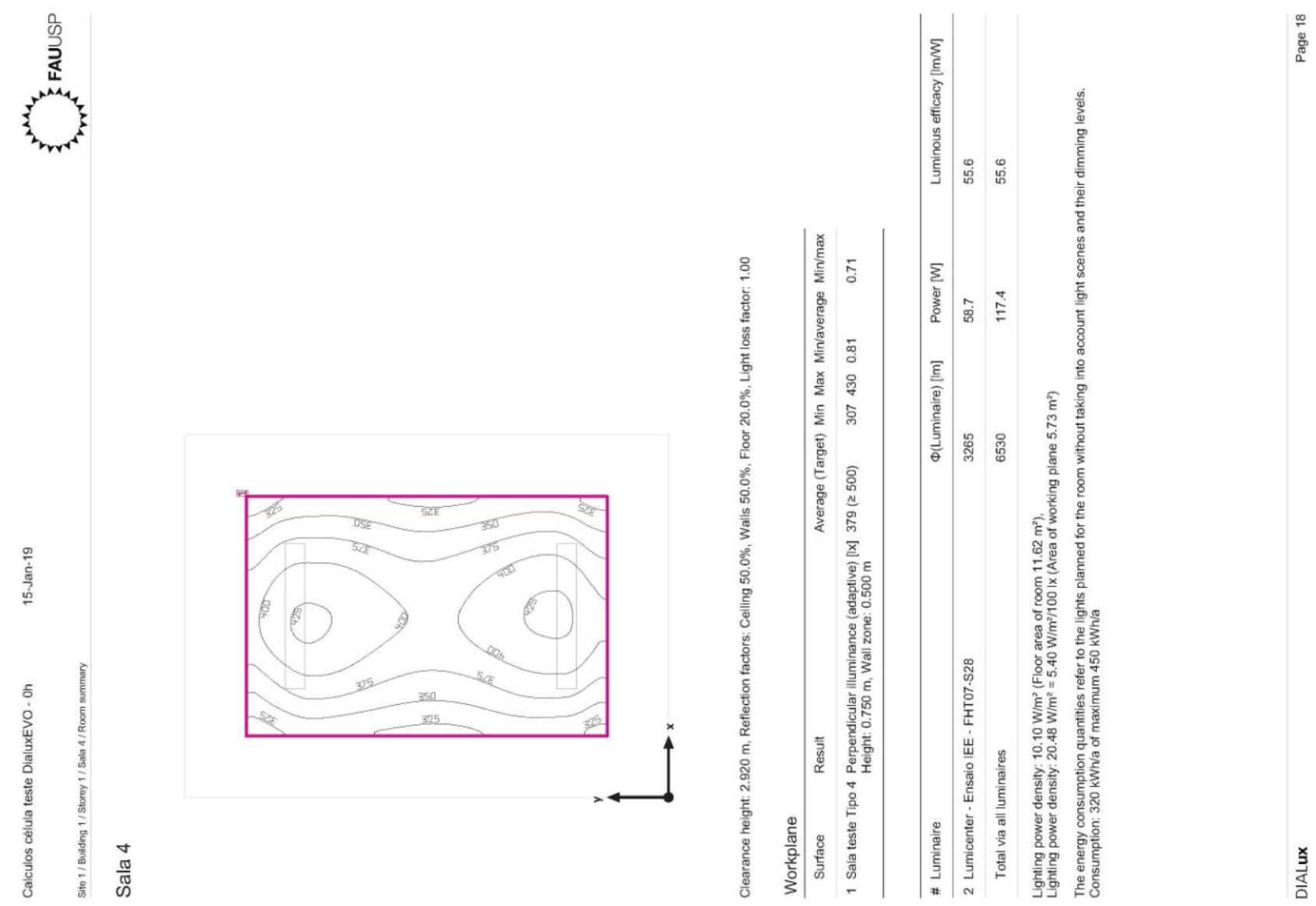

年

壹

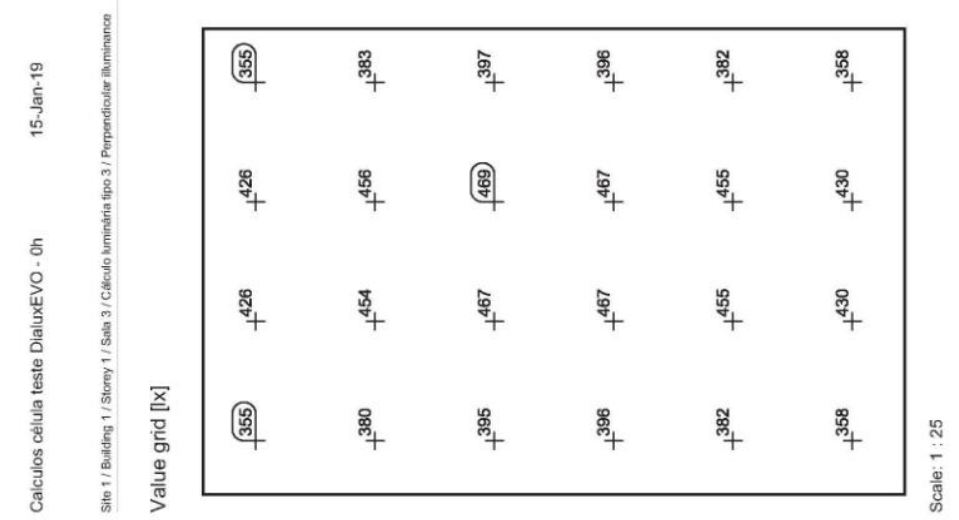




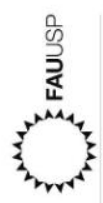
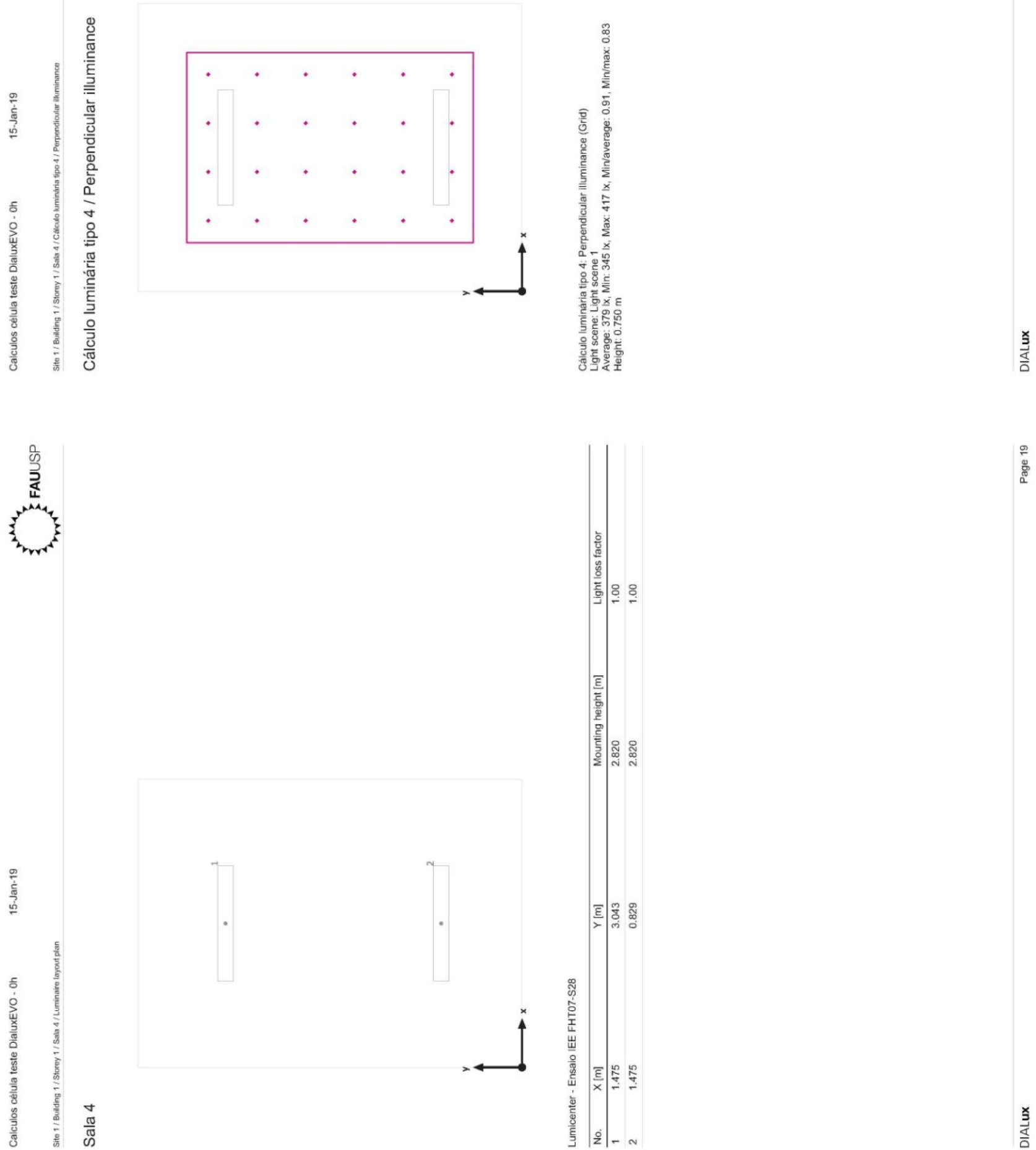

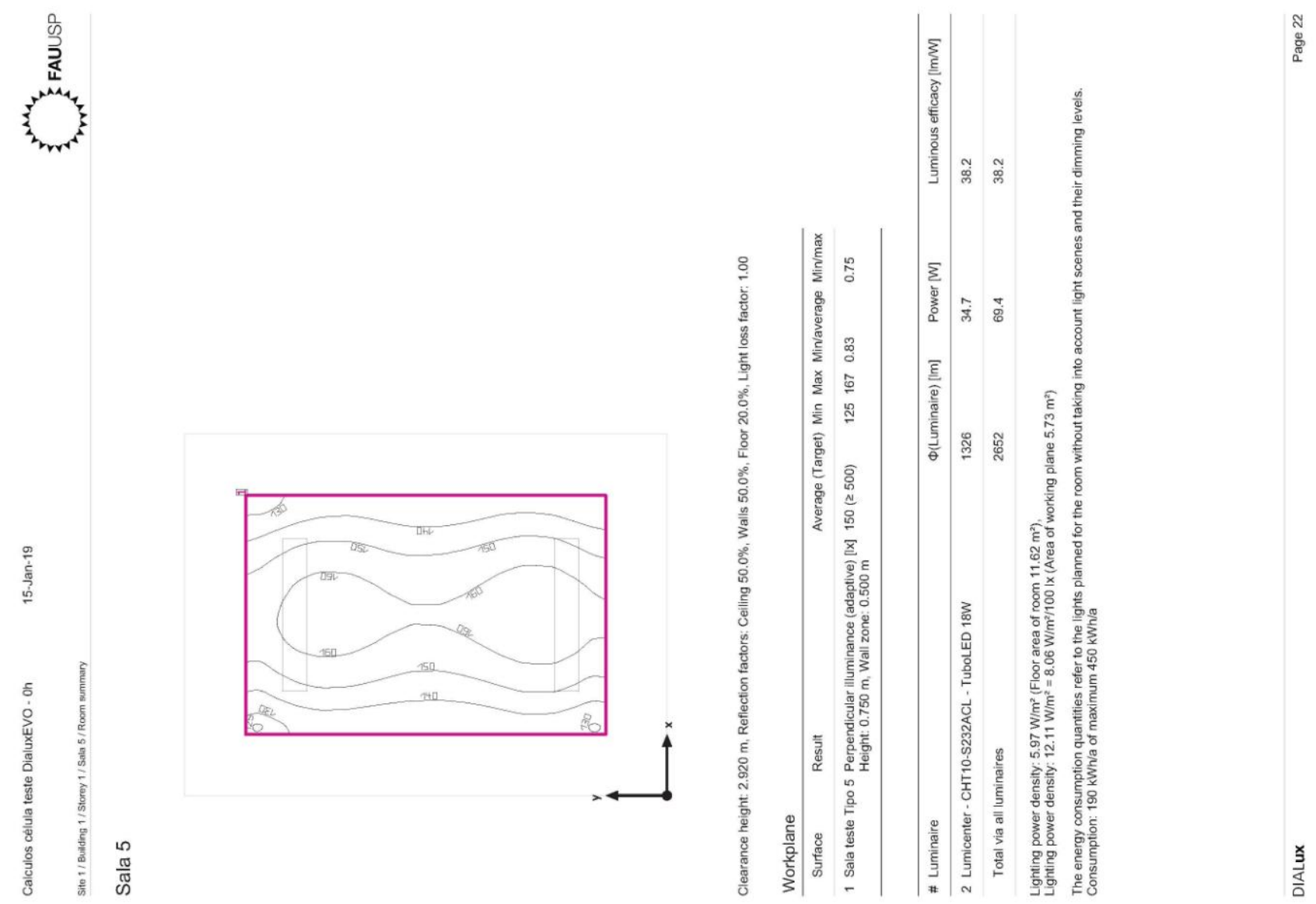

每

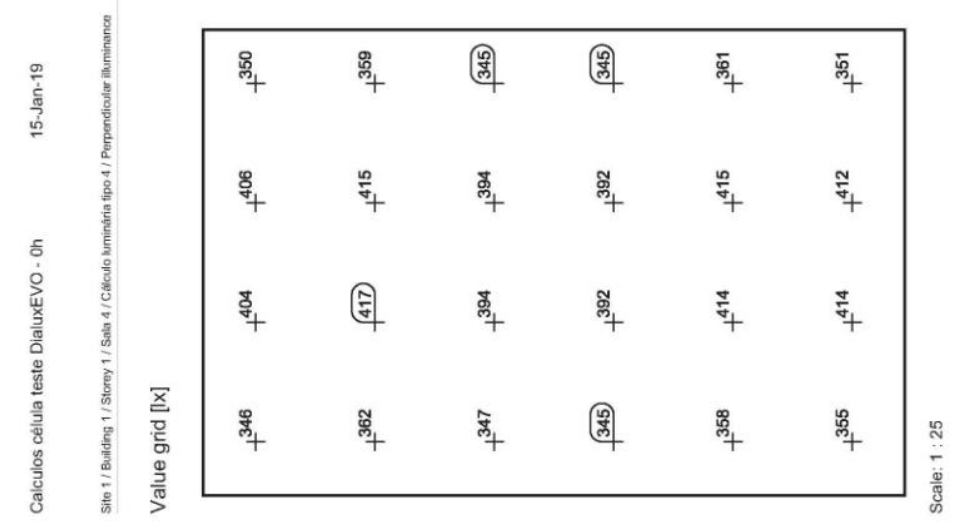




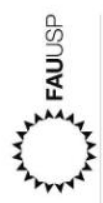
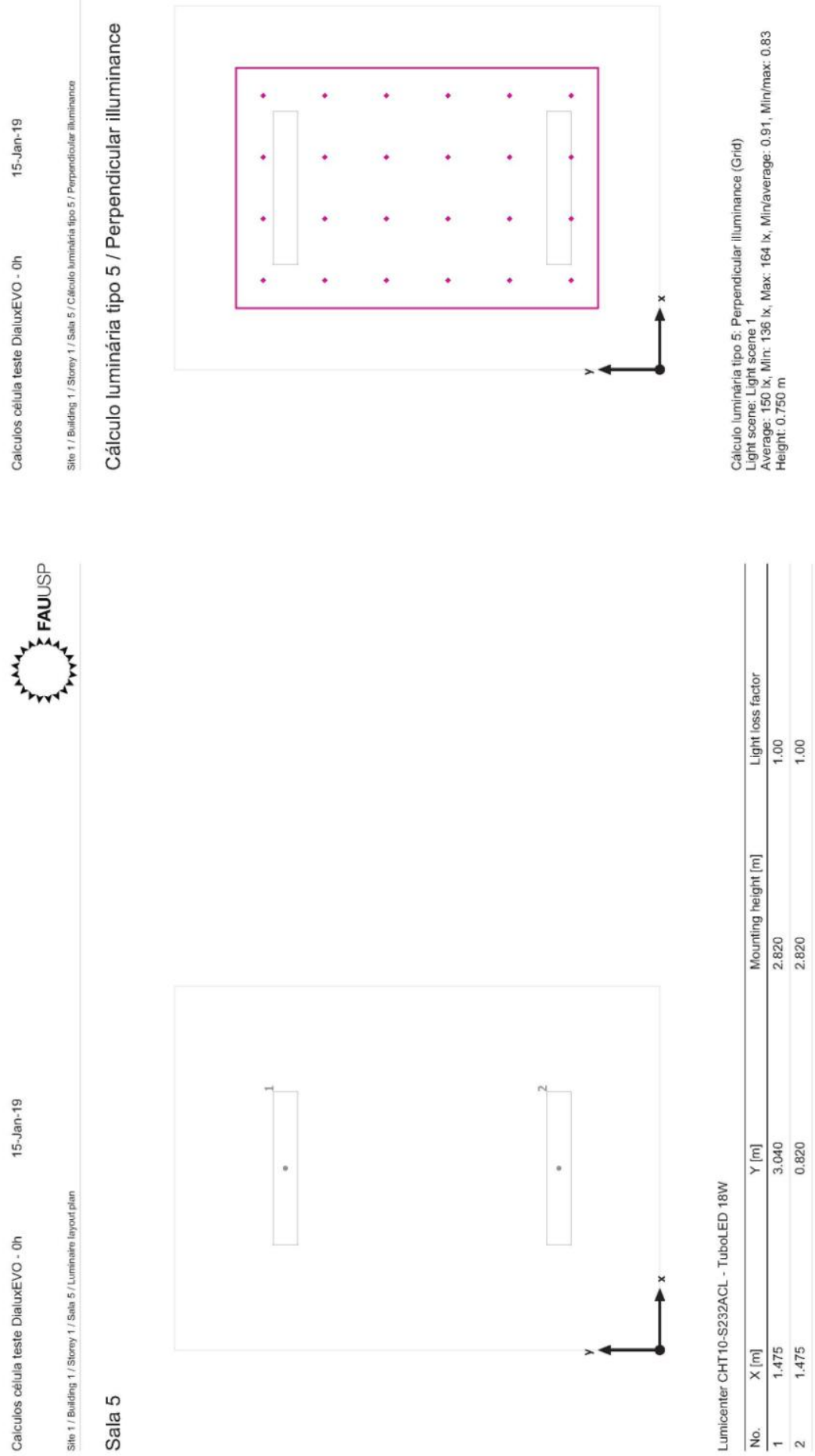

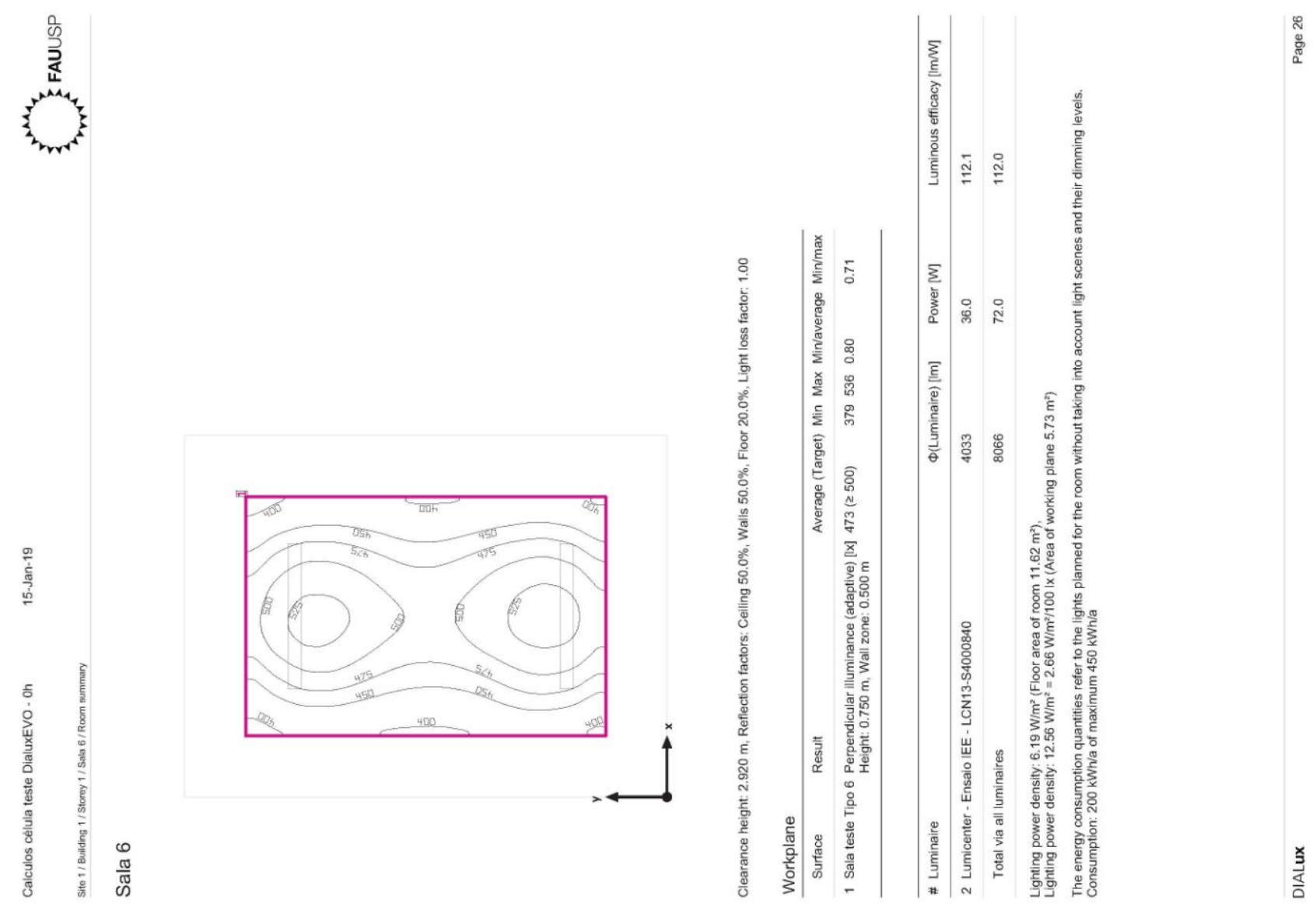

每

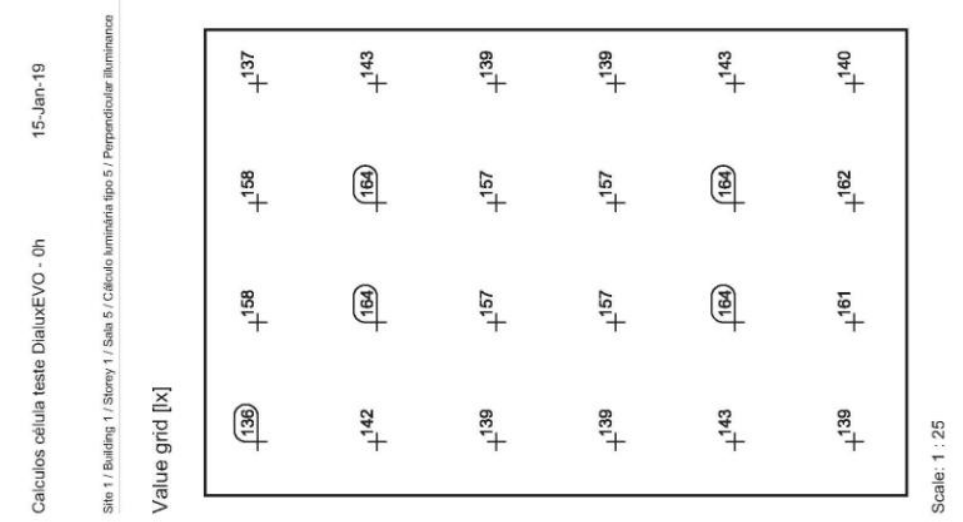




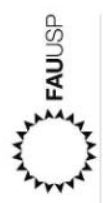
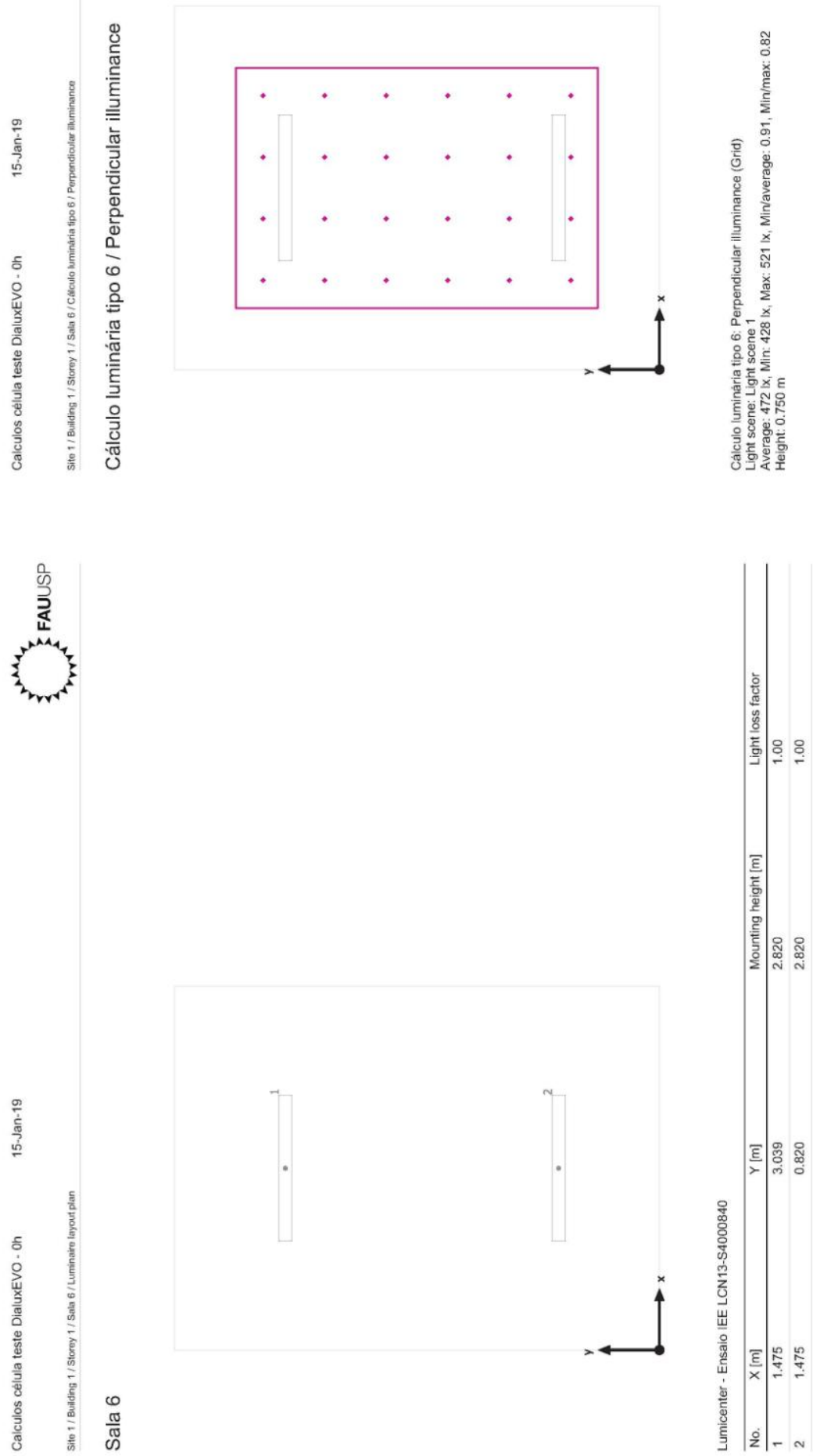

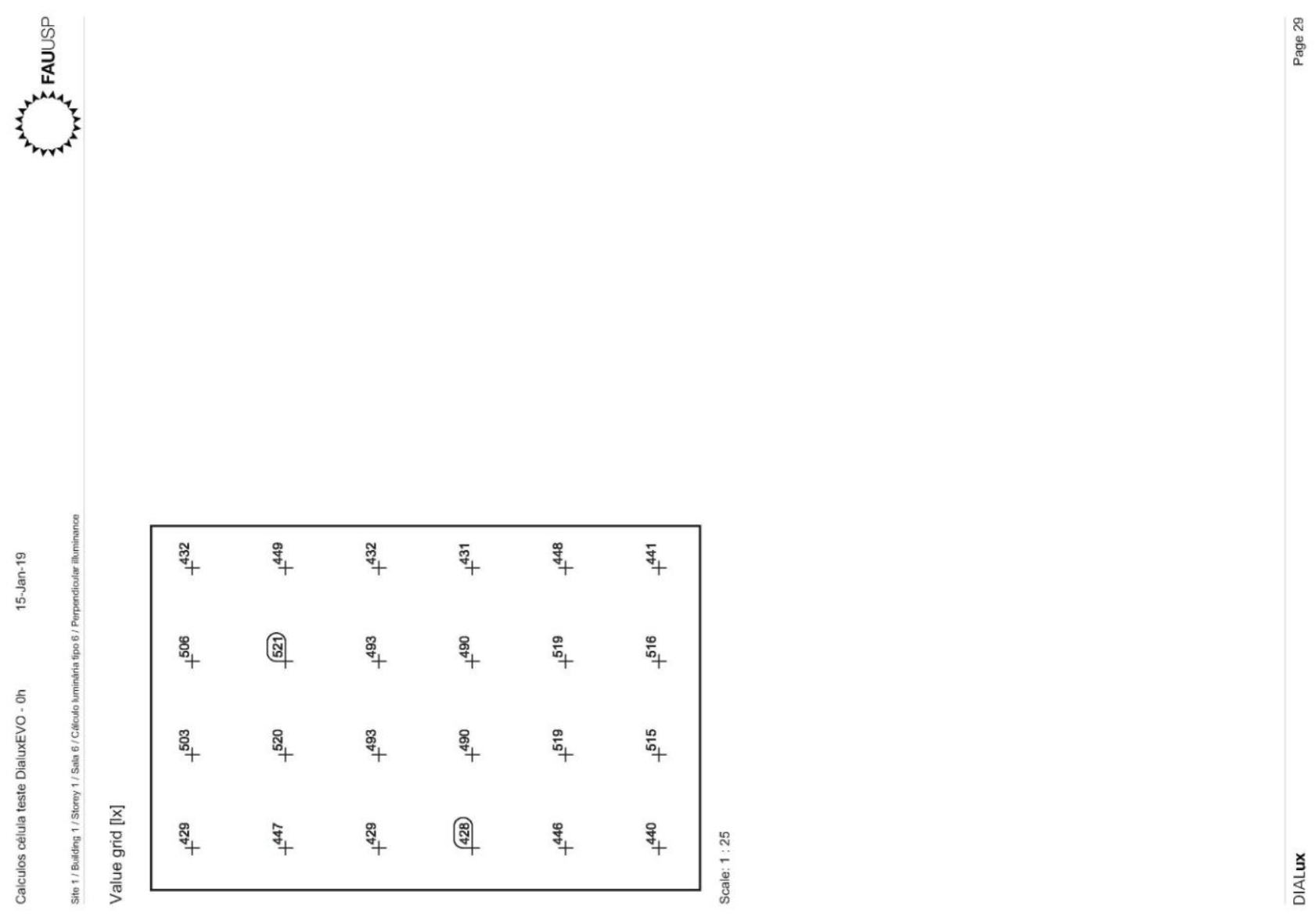

172 

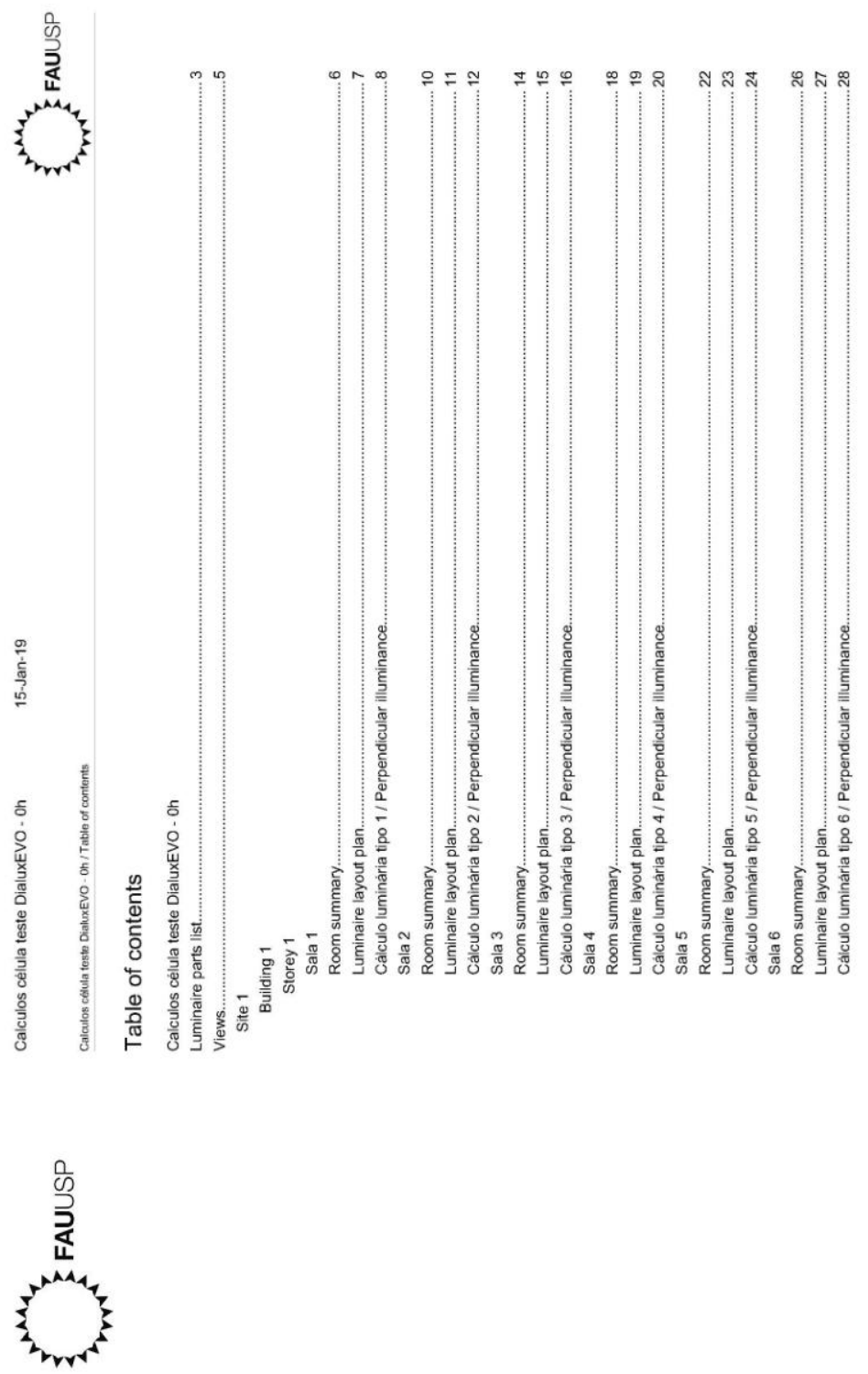

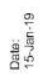

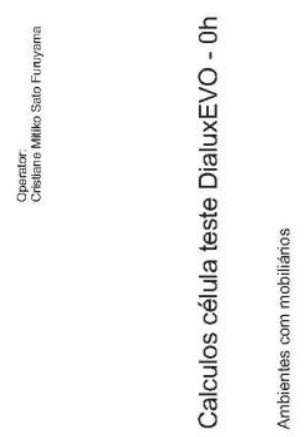



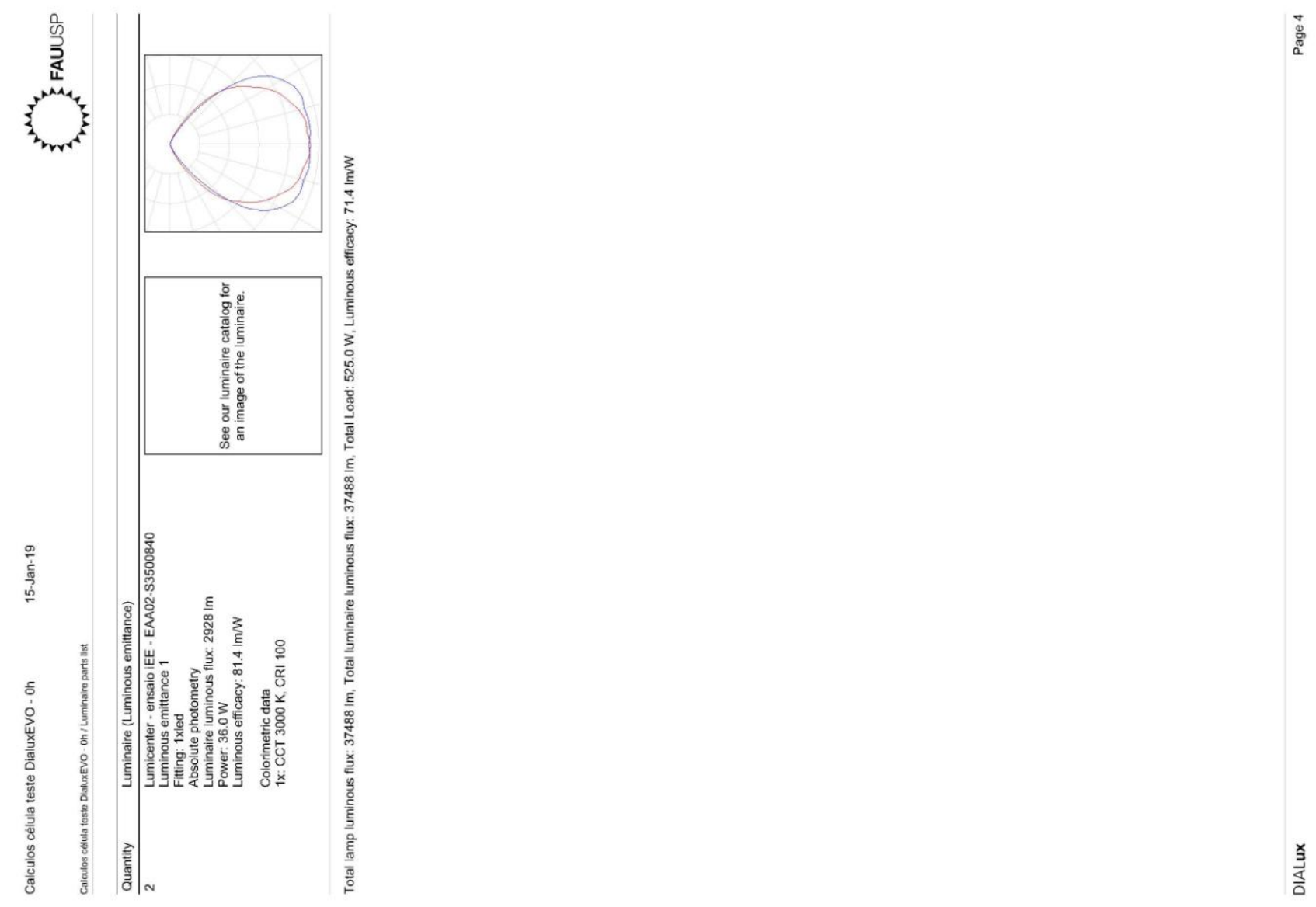

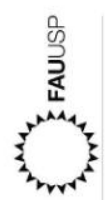
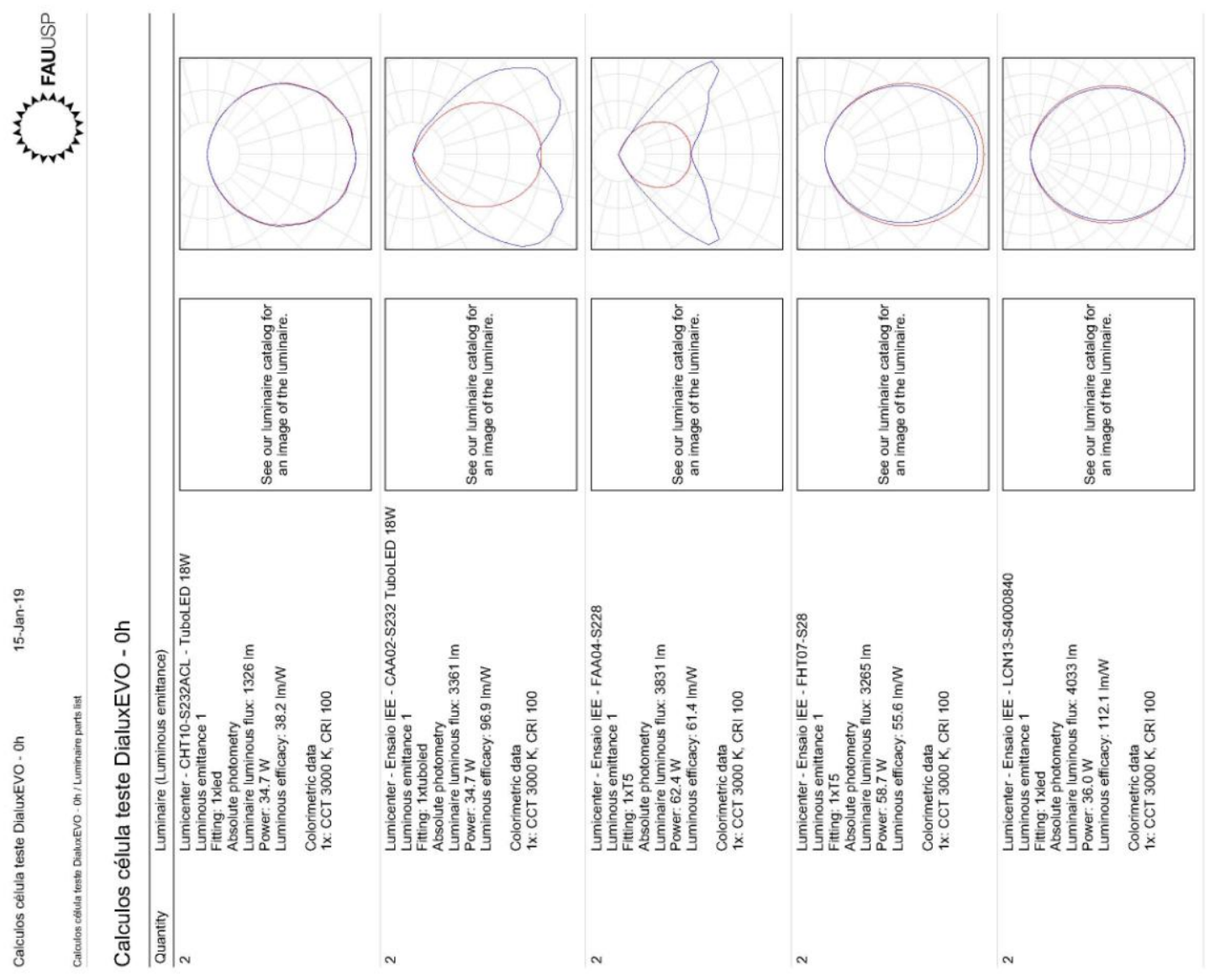

ฐू

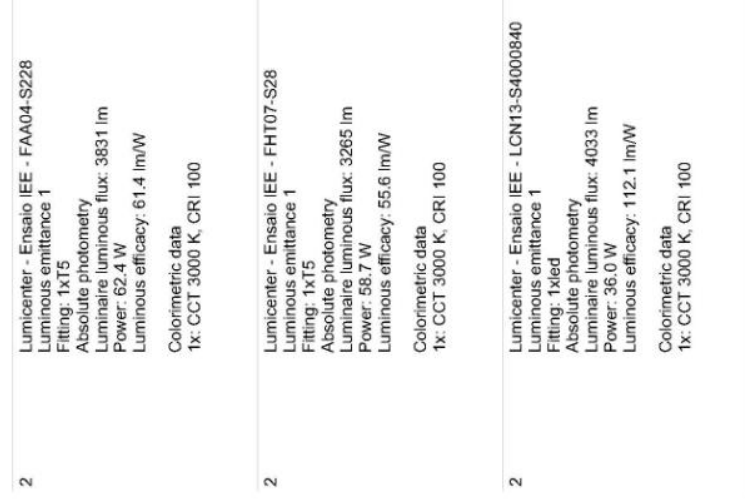



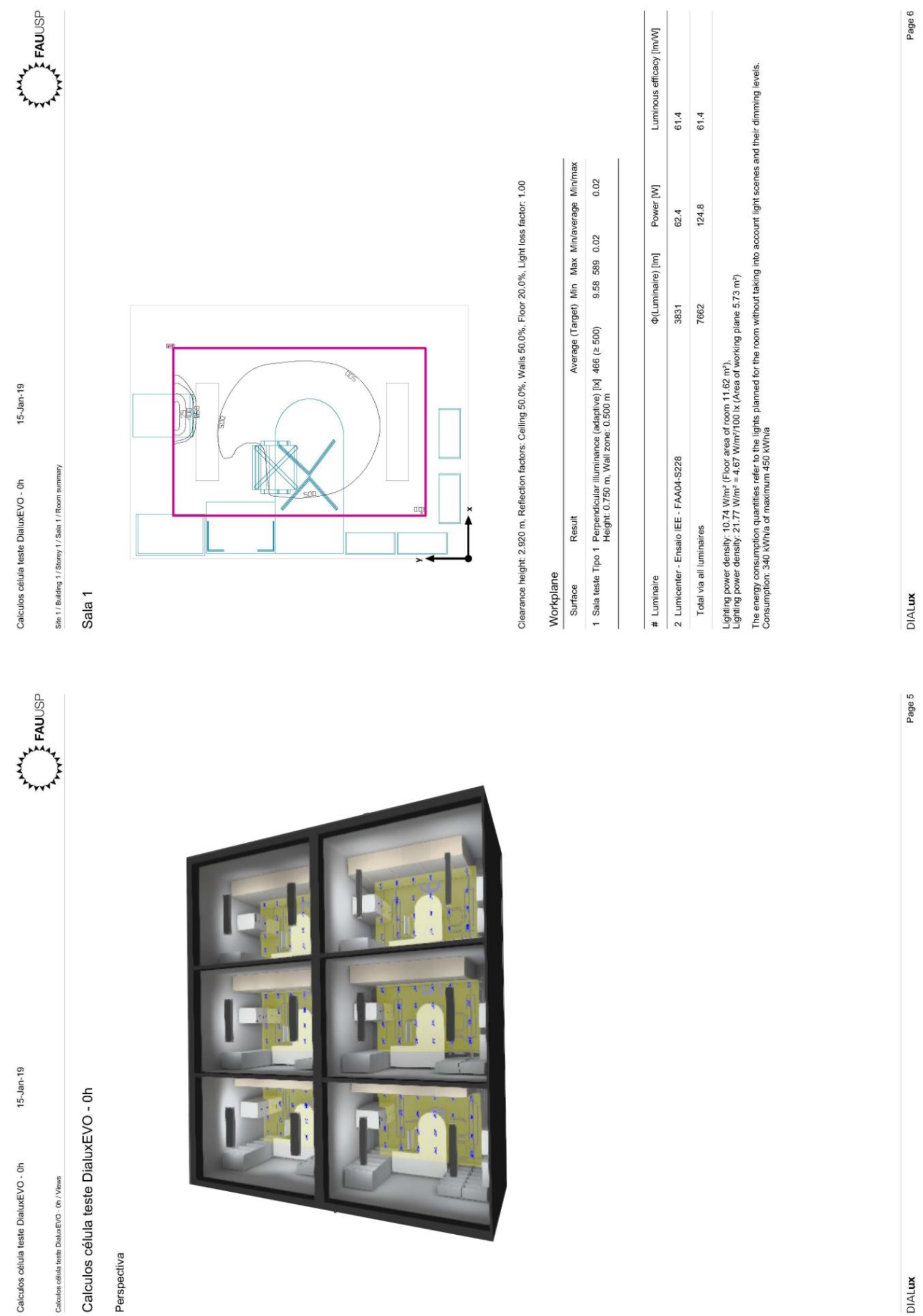


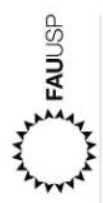
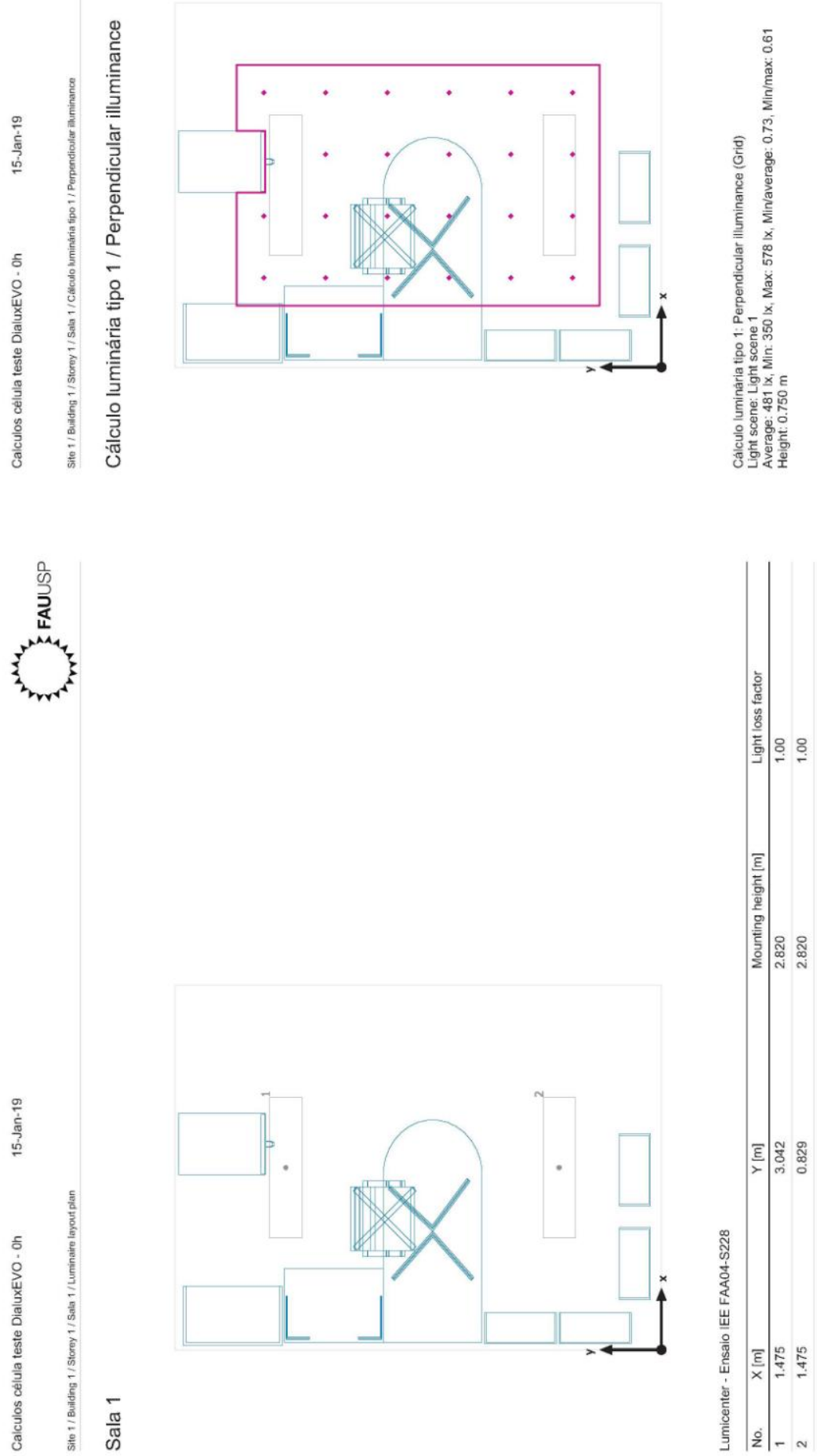

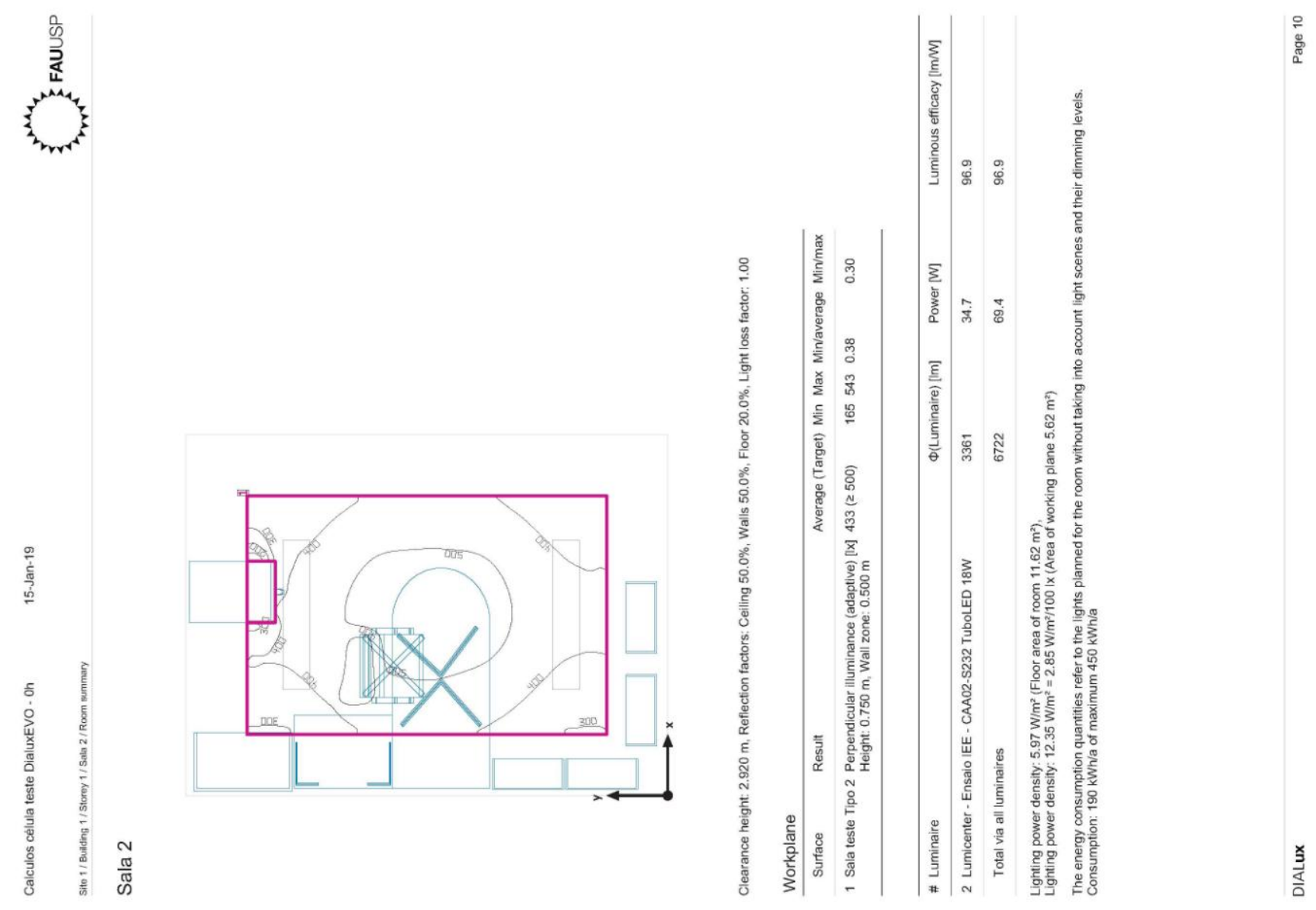

每

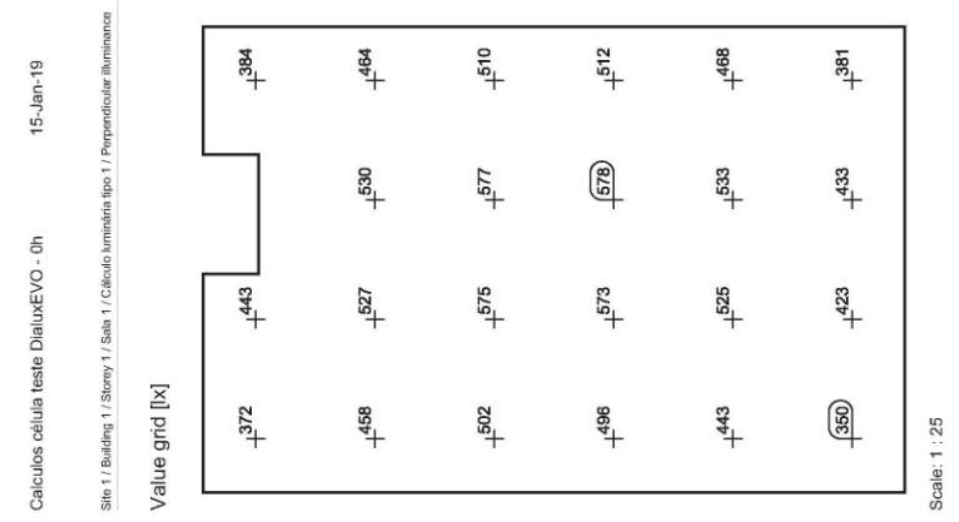




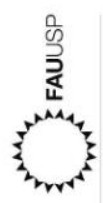
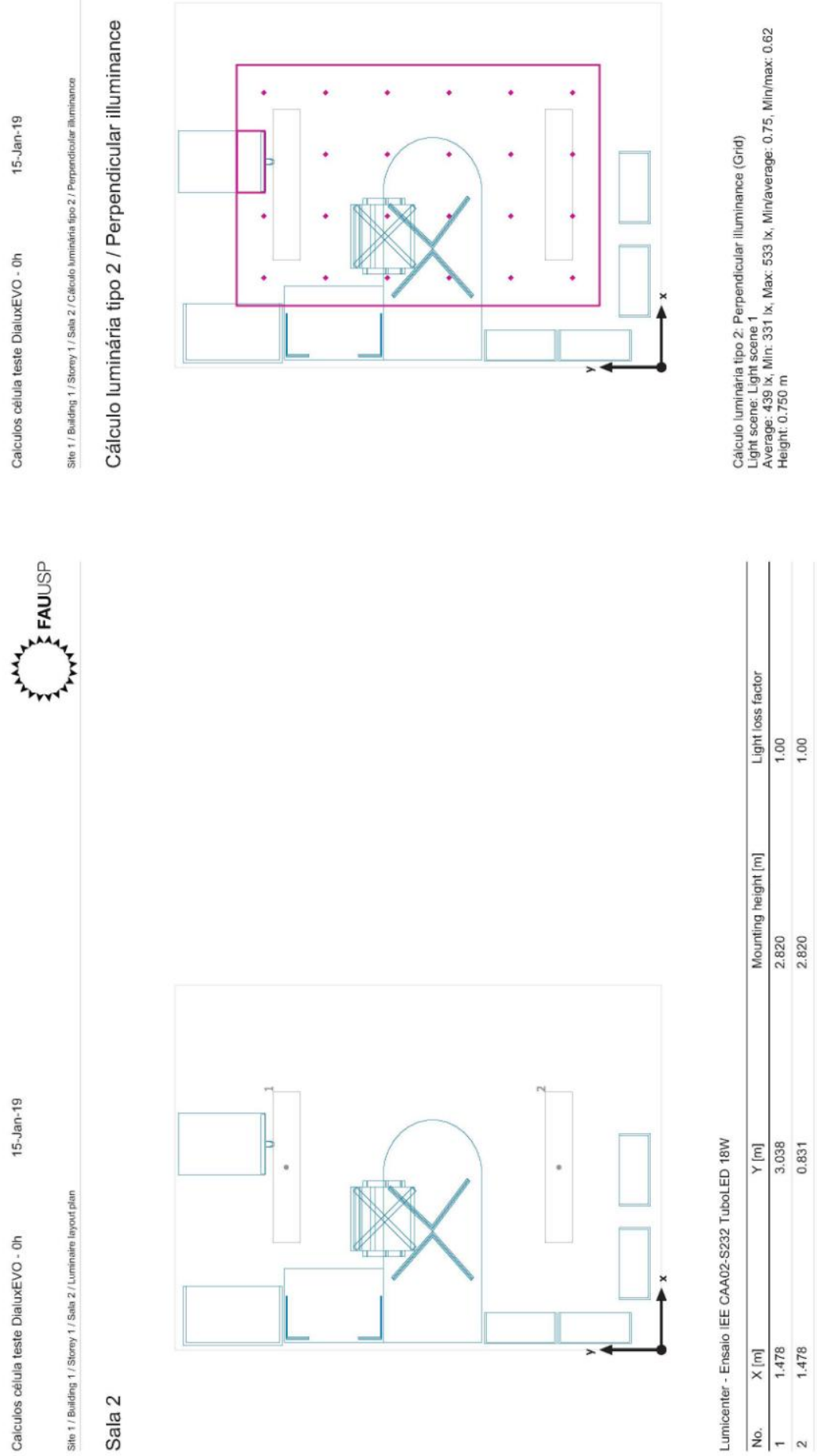

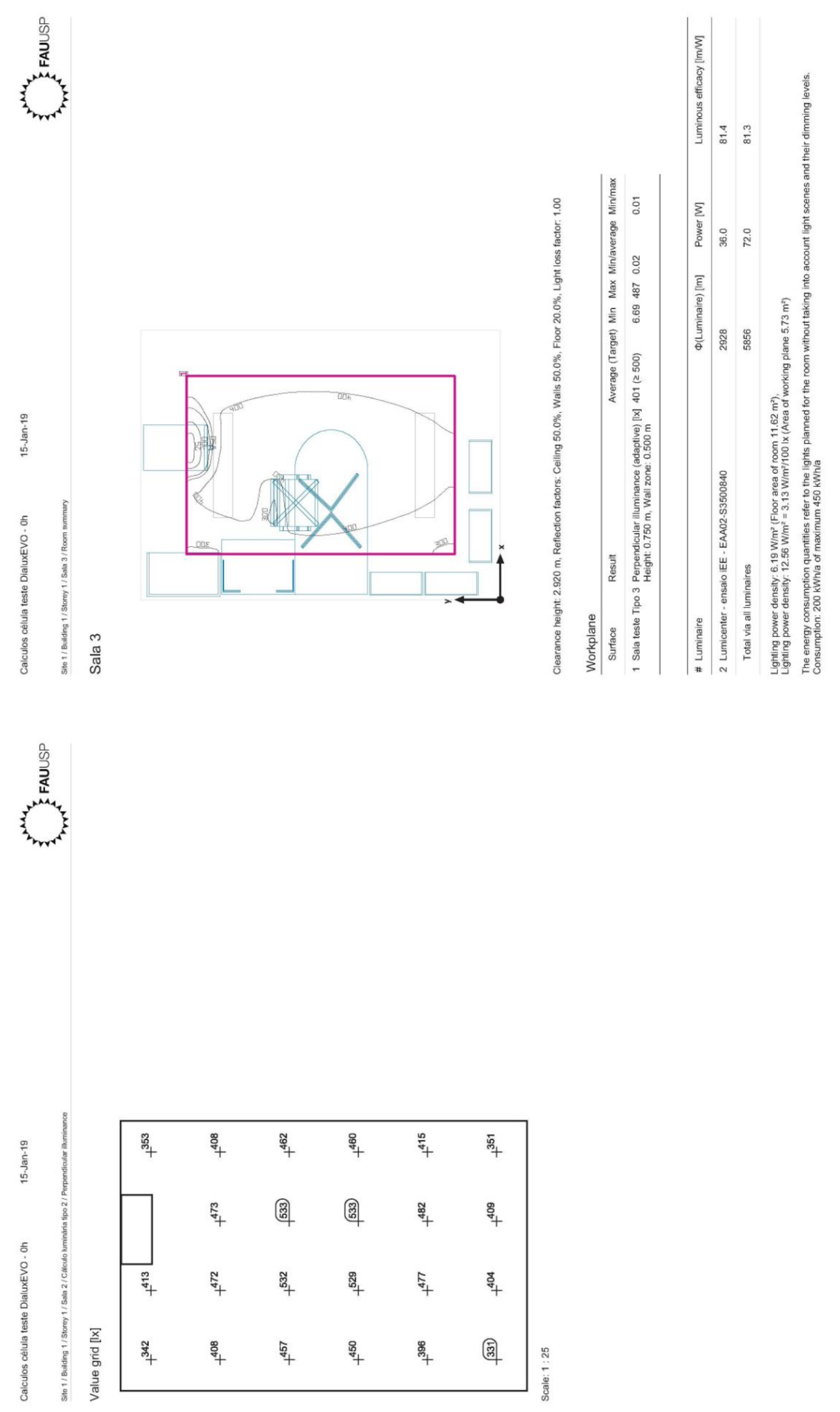

179 


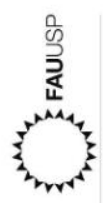
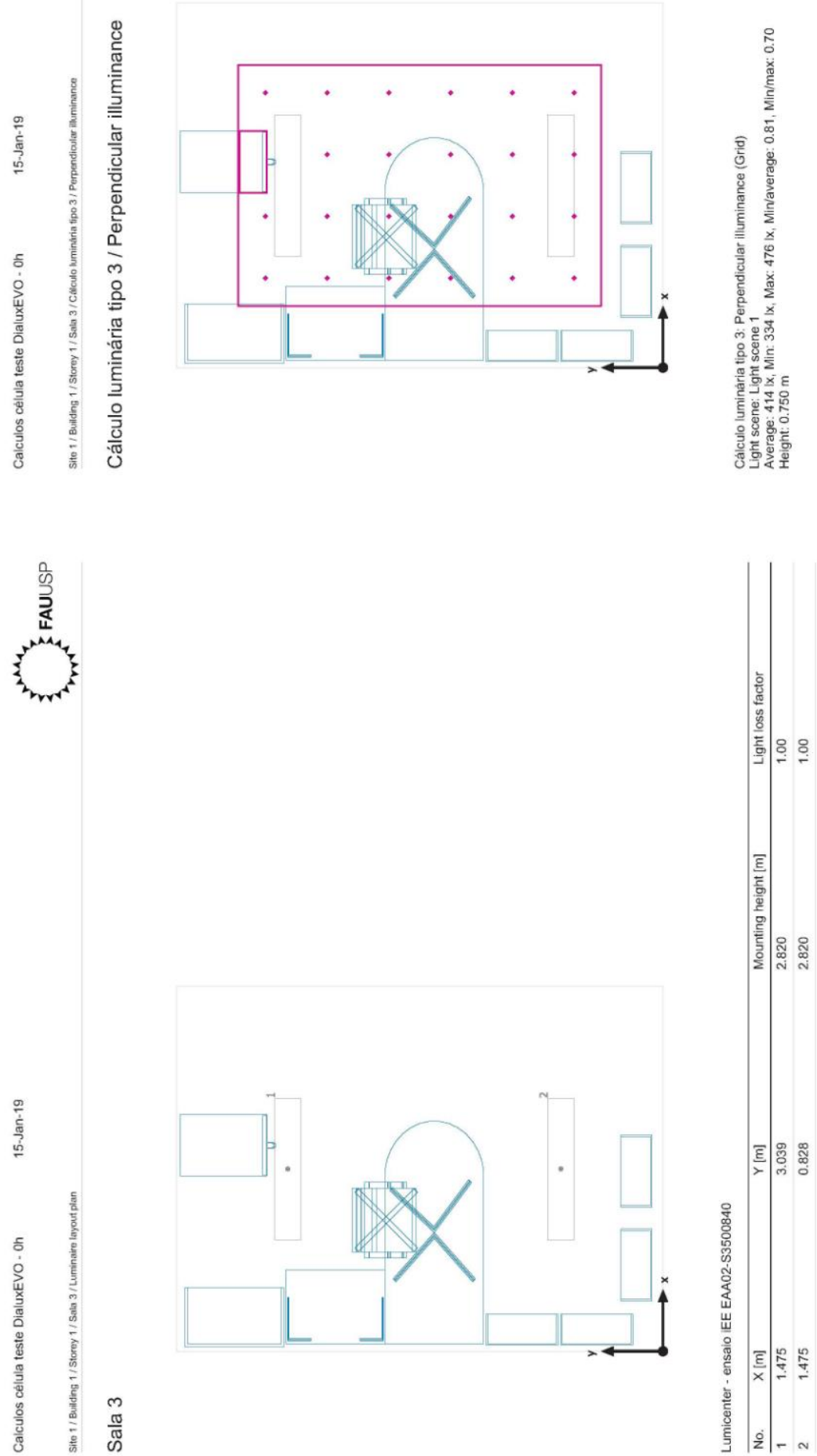
每)
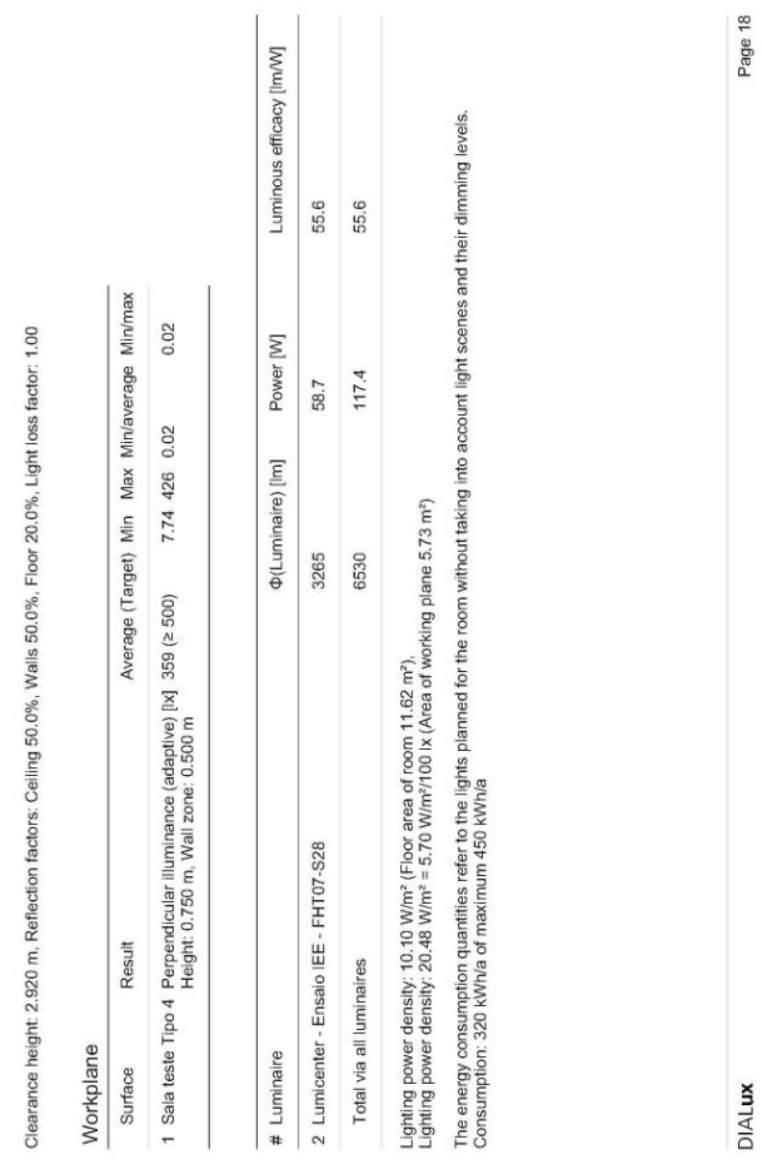

年

壹

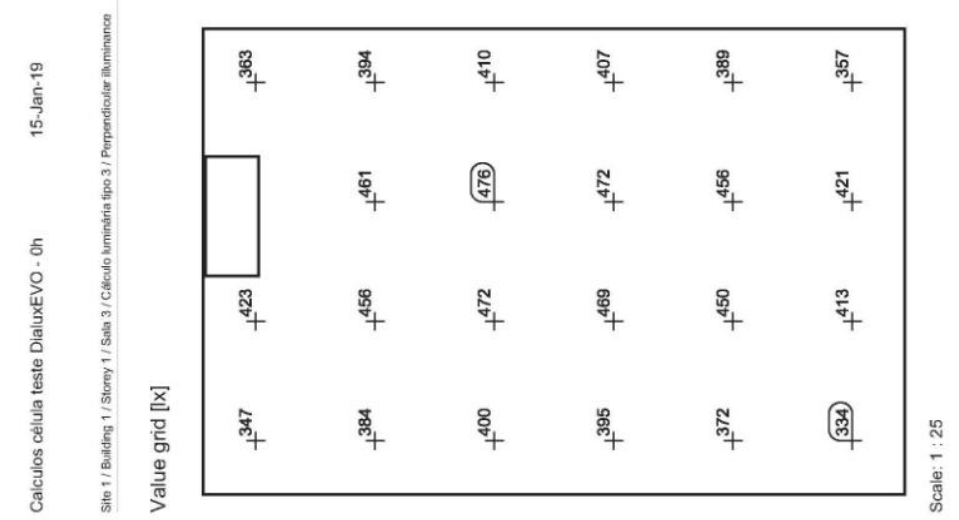




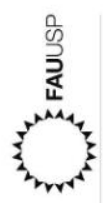
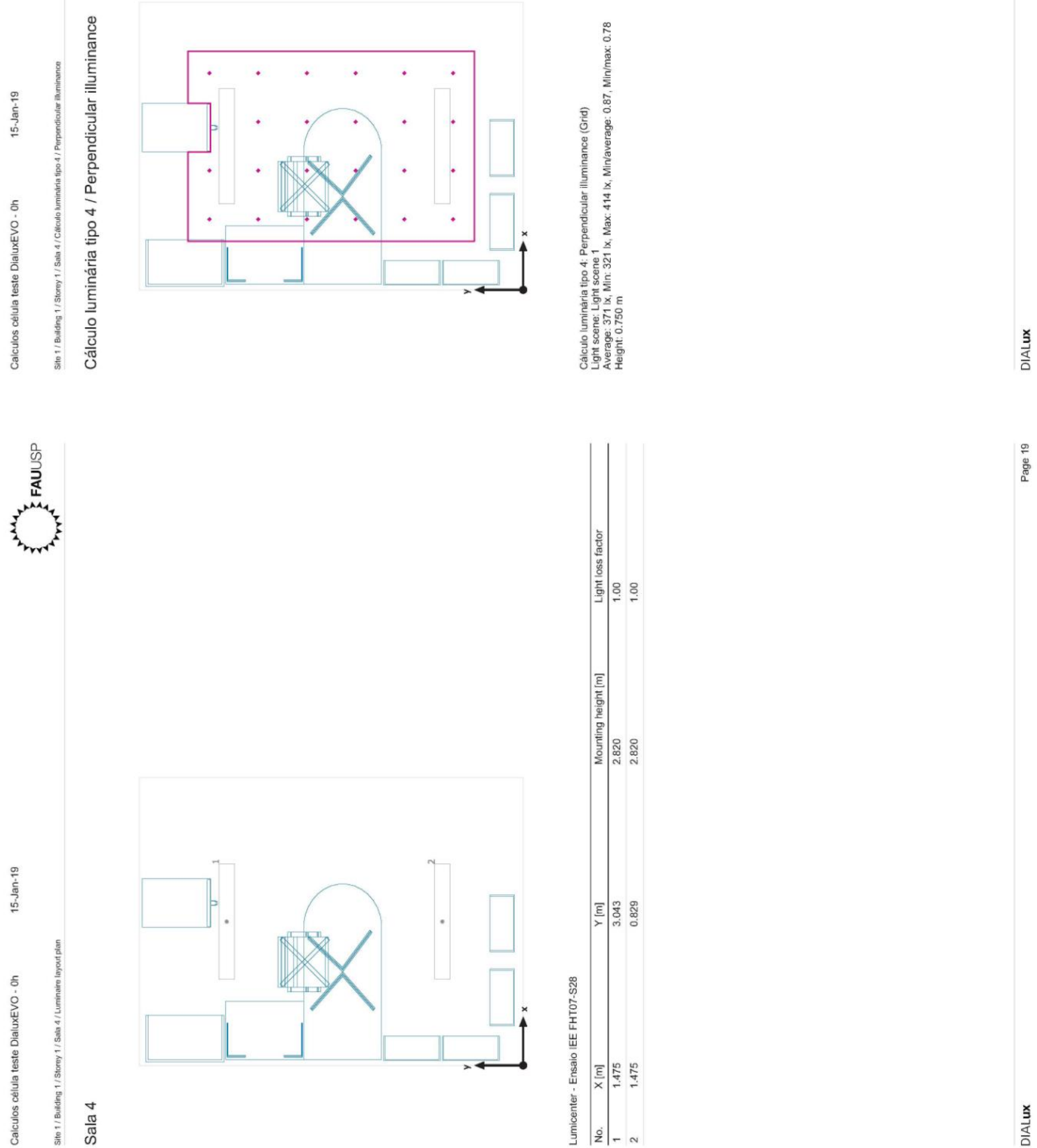

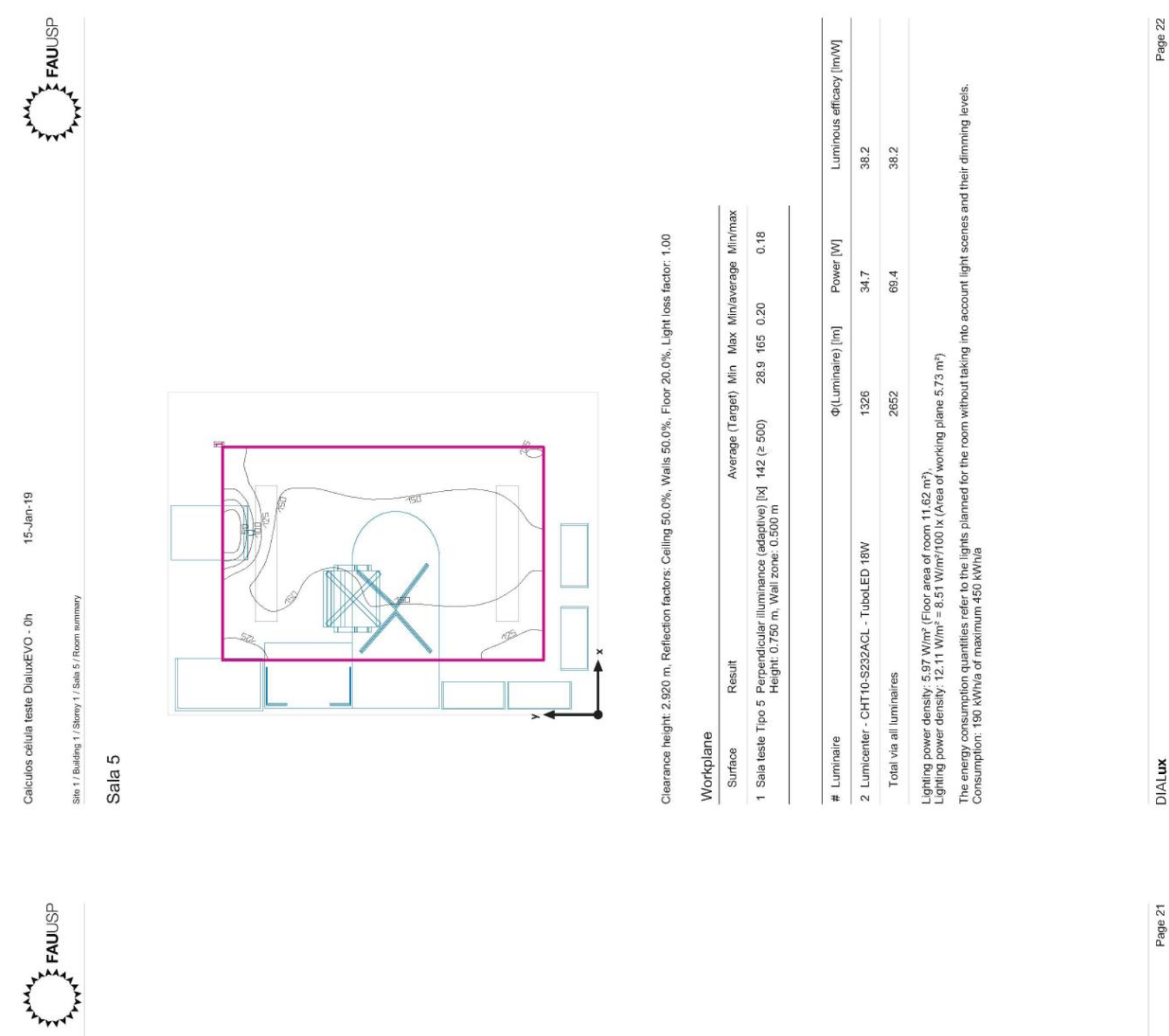

站

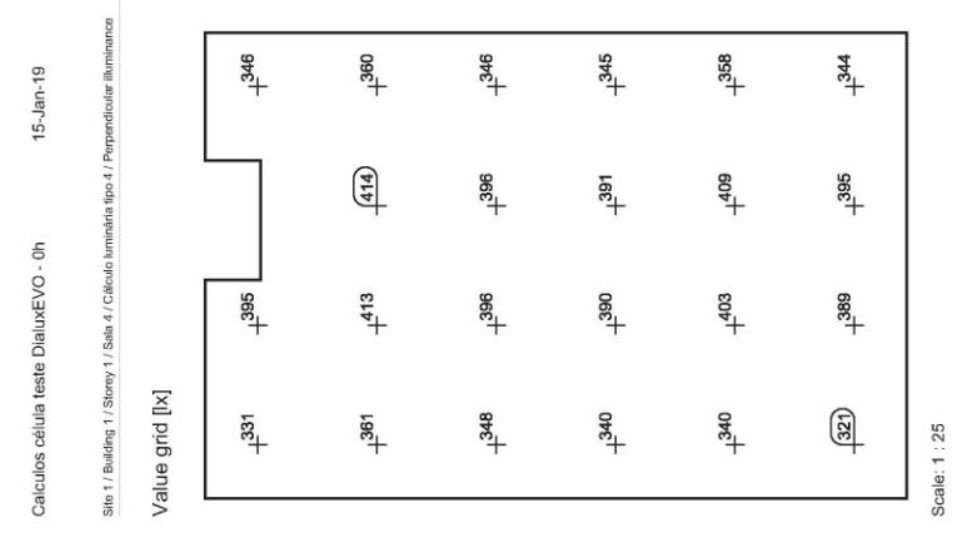

183 


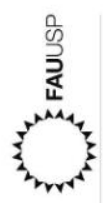
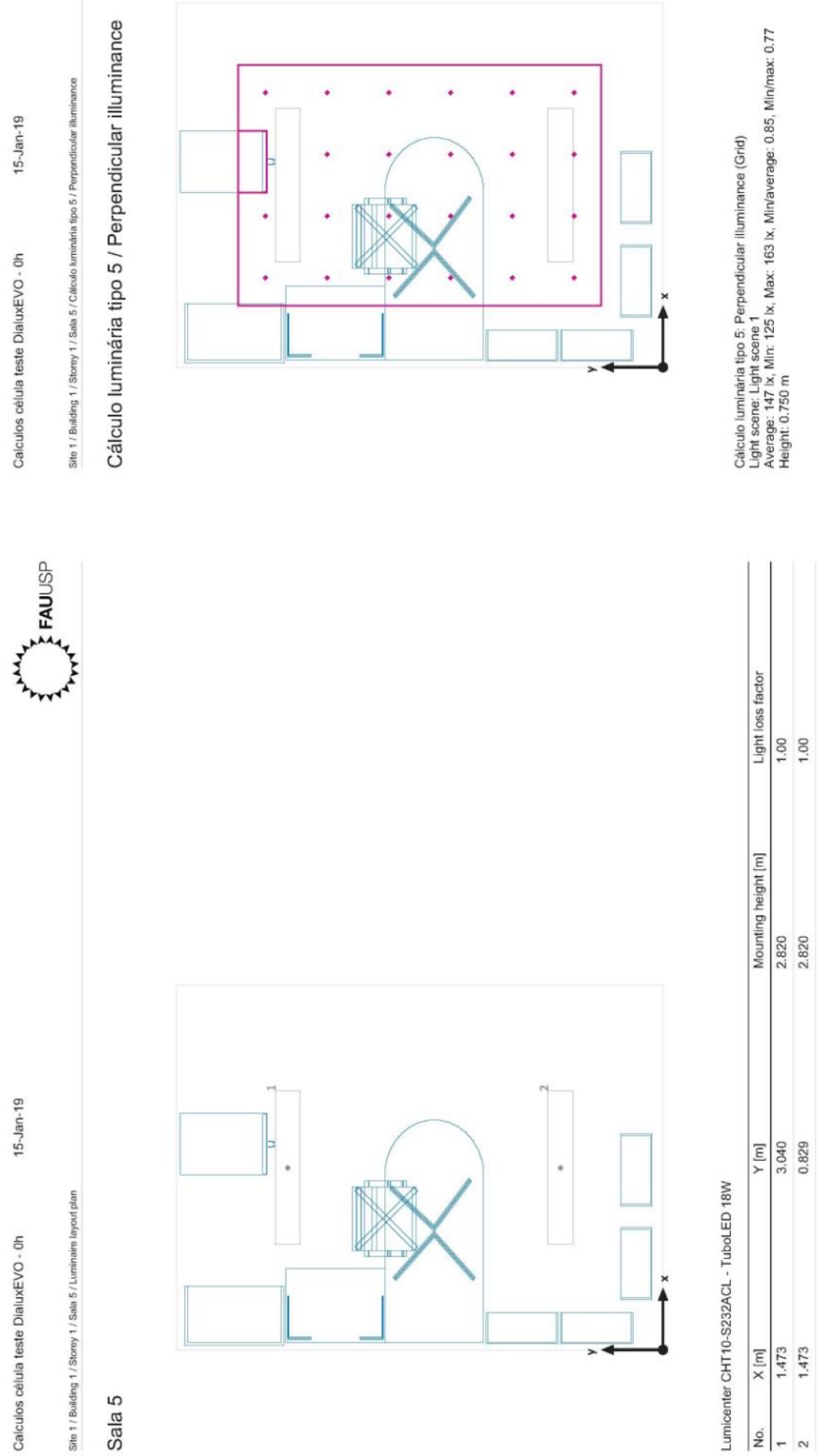

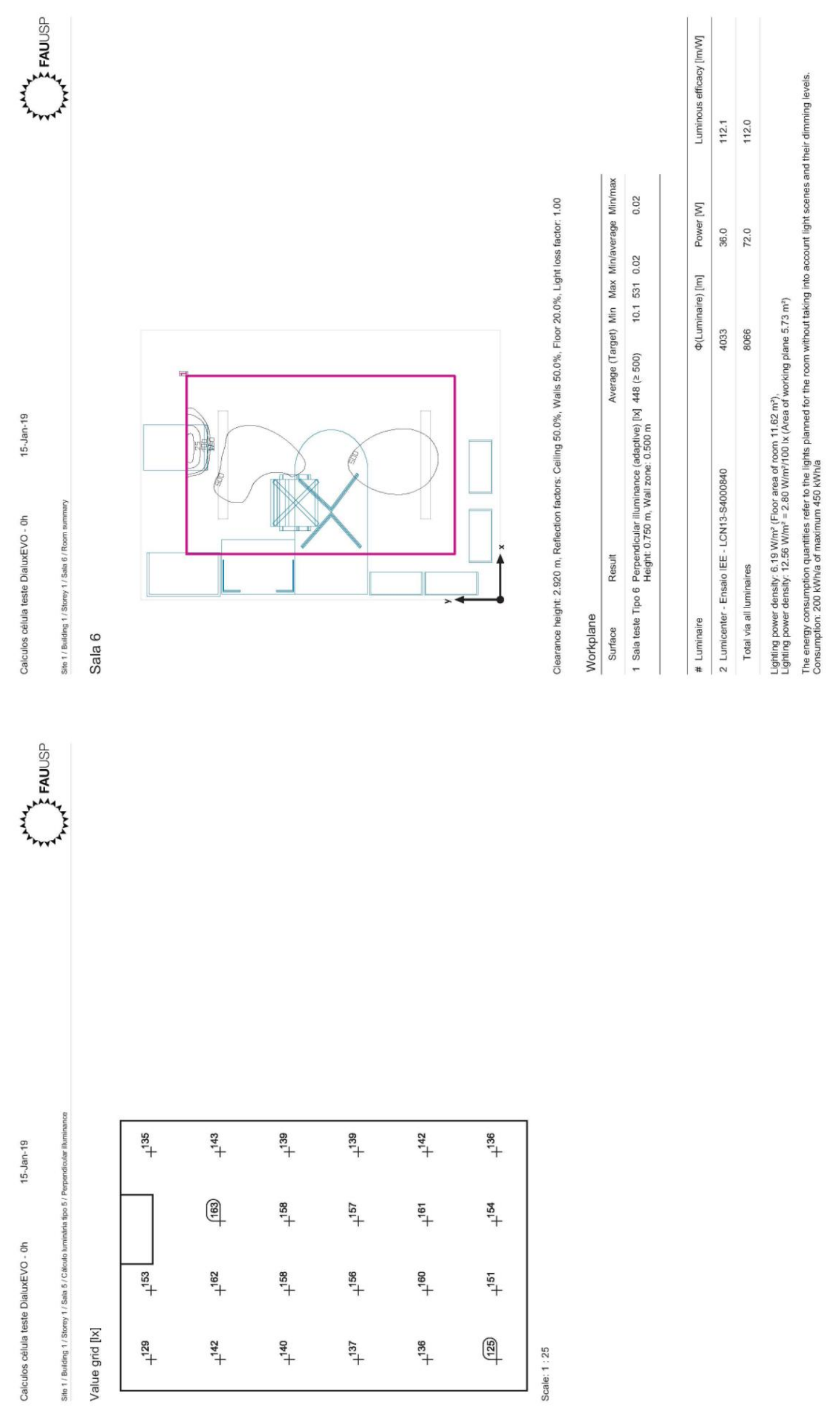

185 


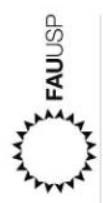
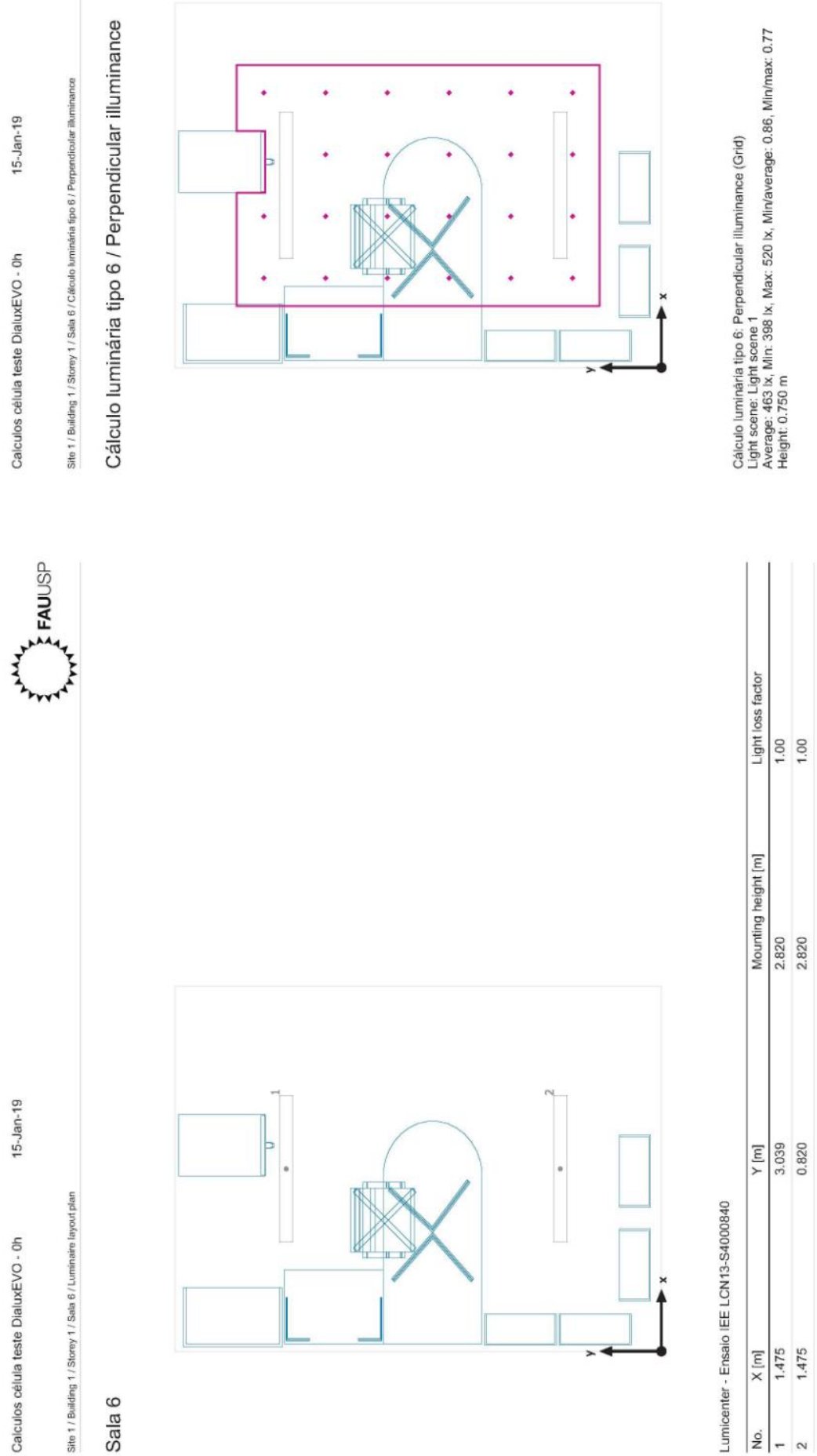

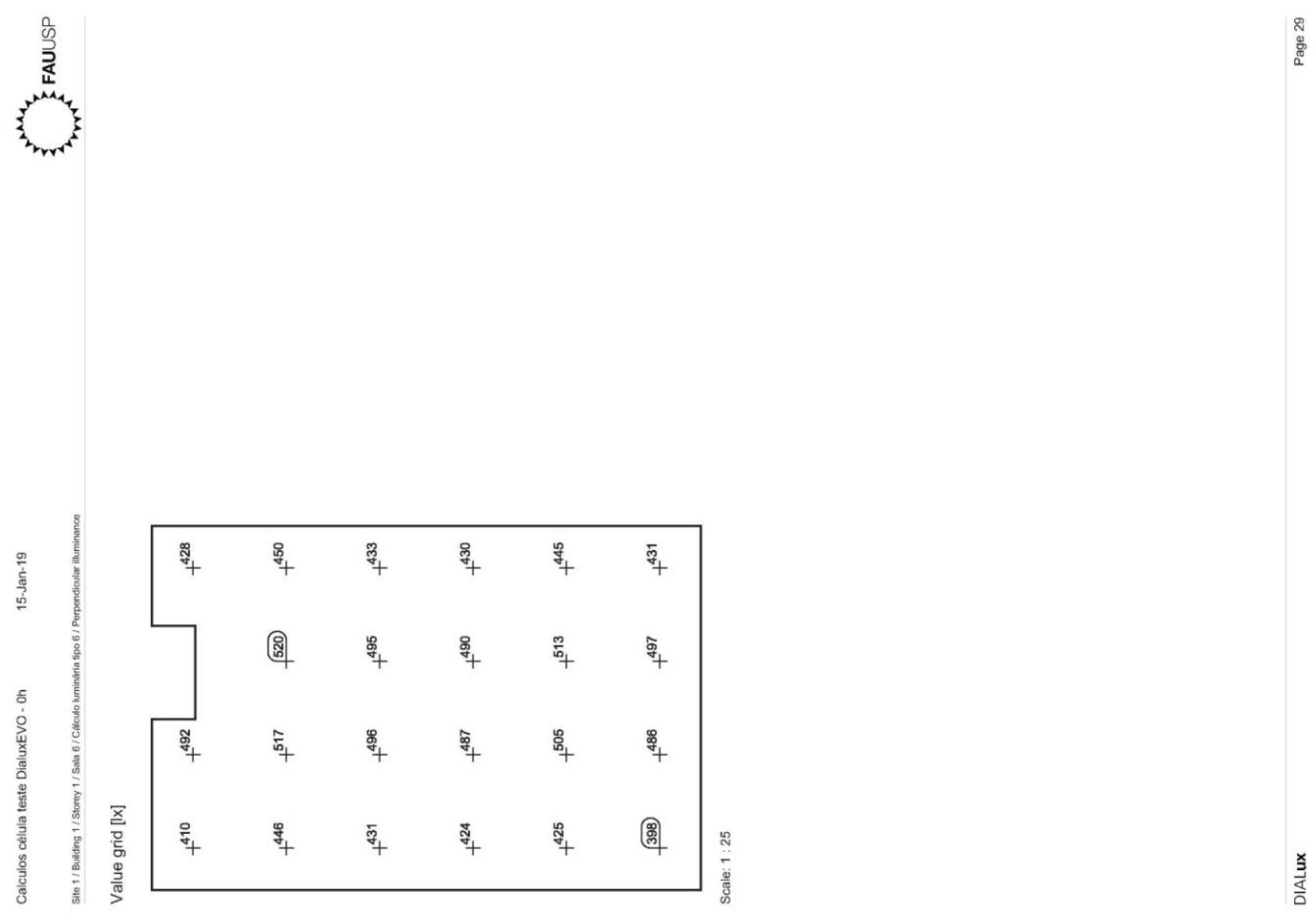

187 

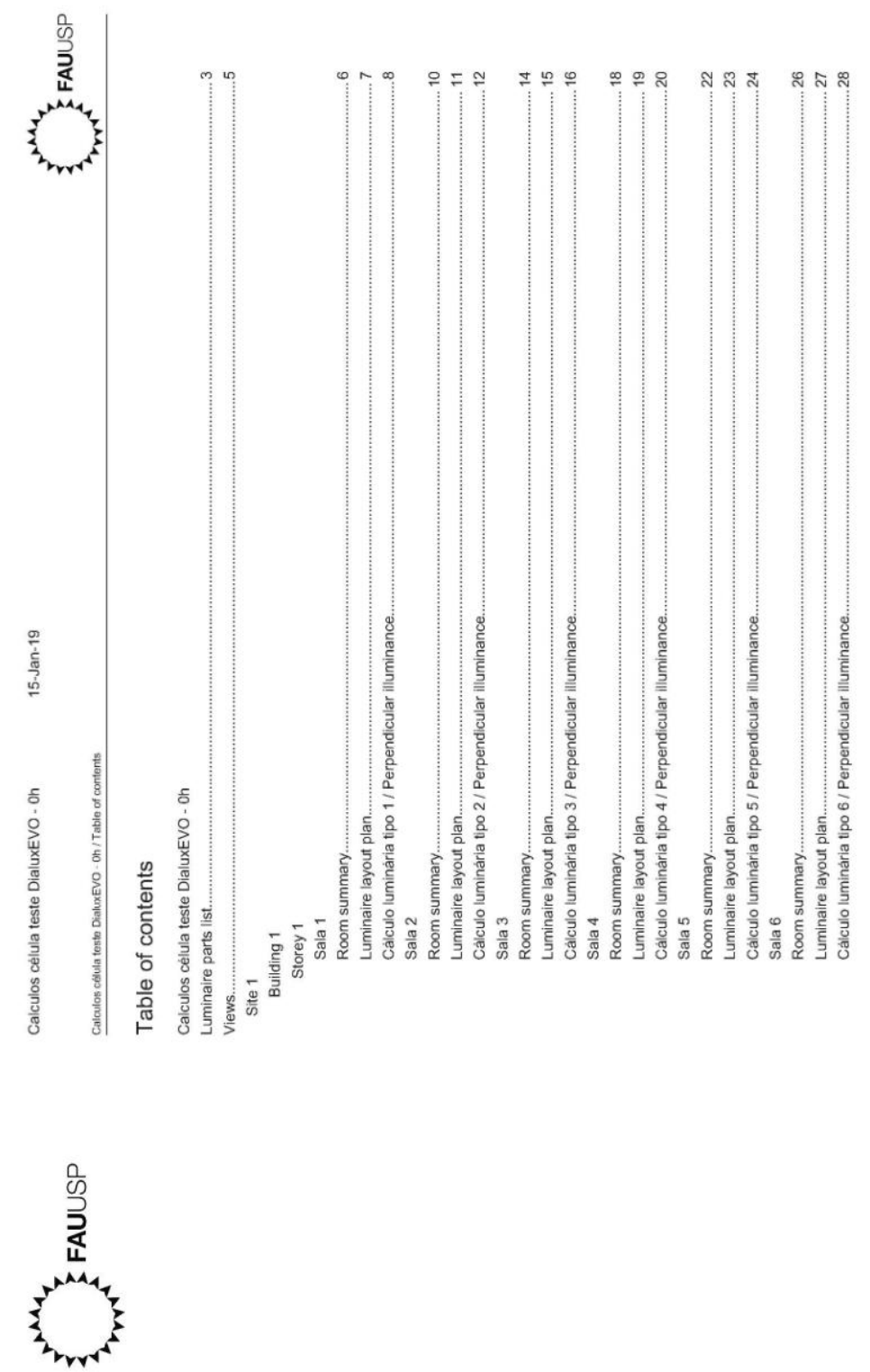

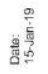

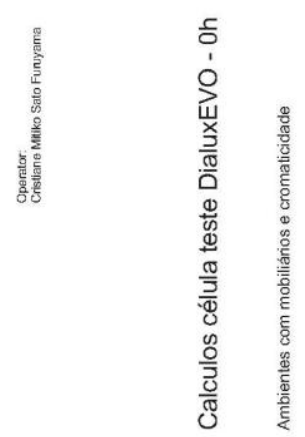



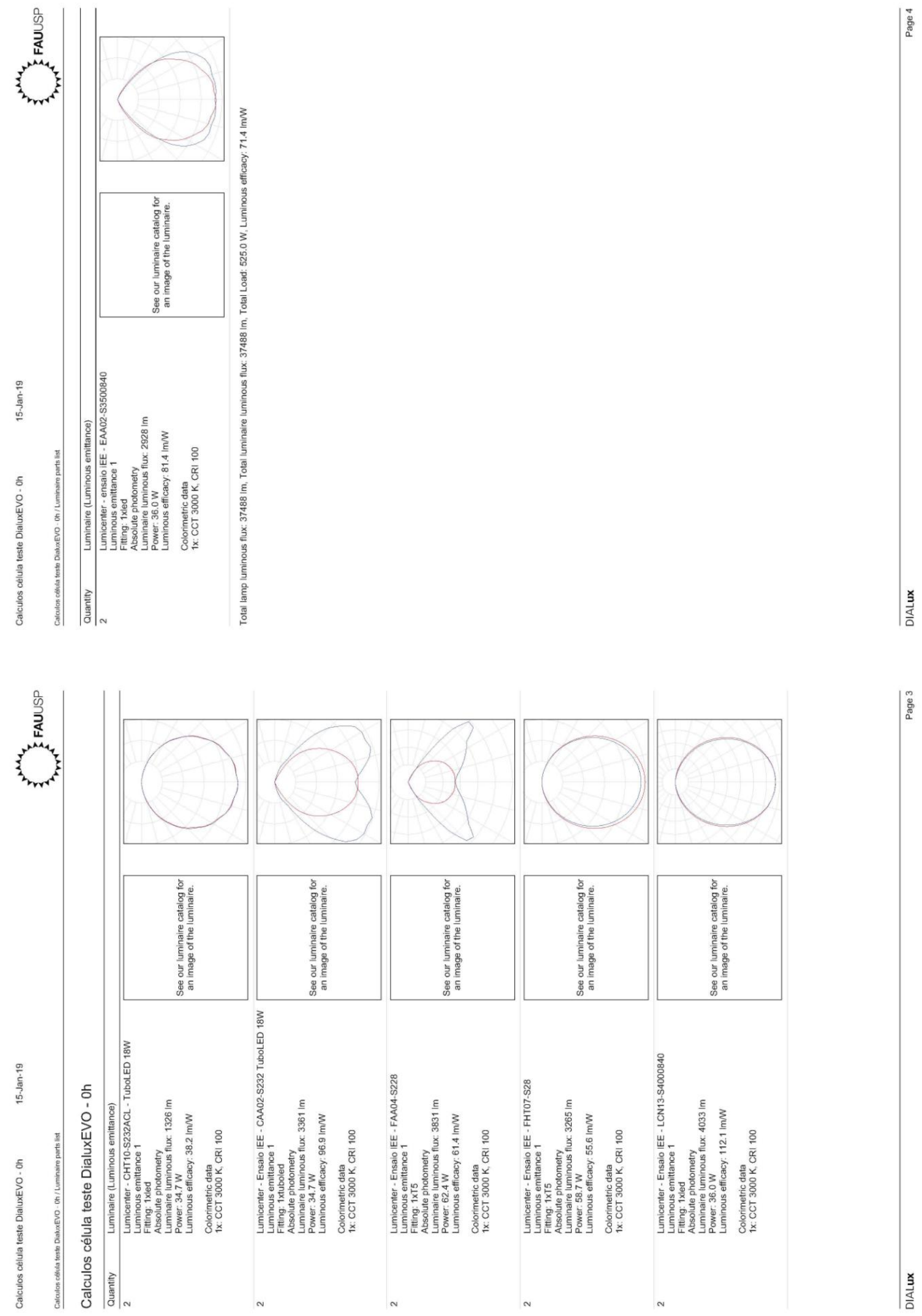

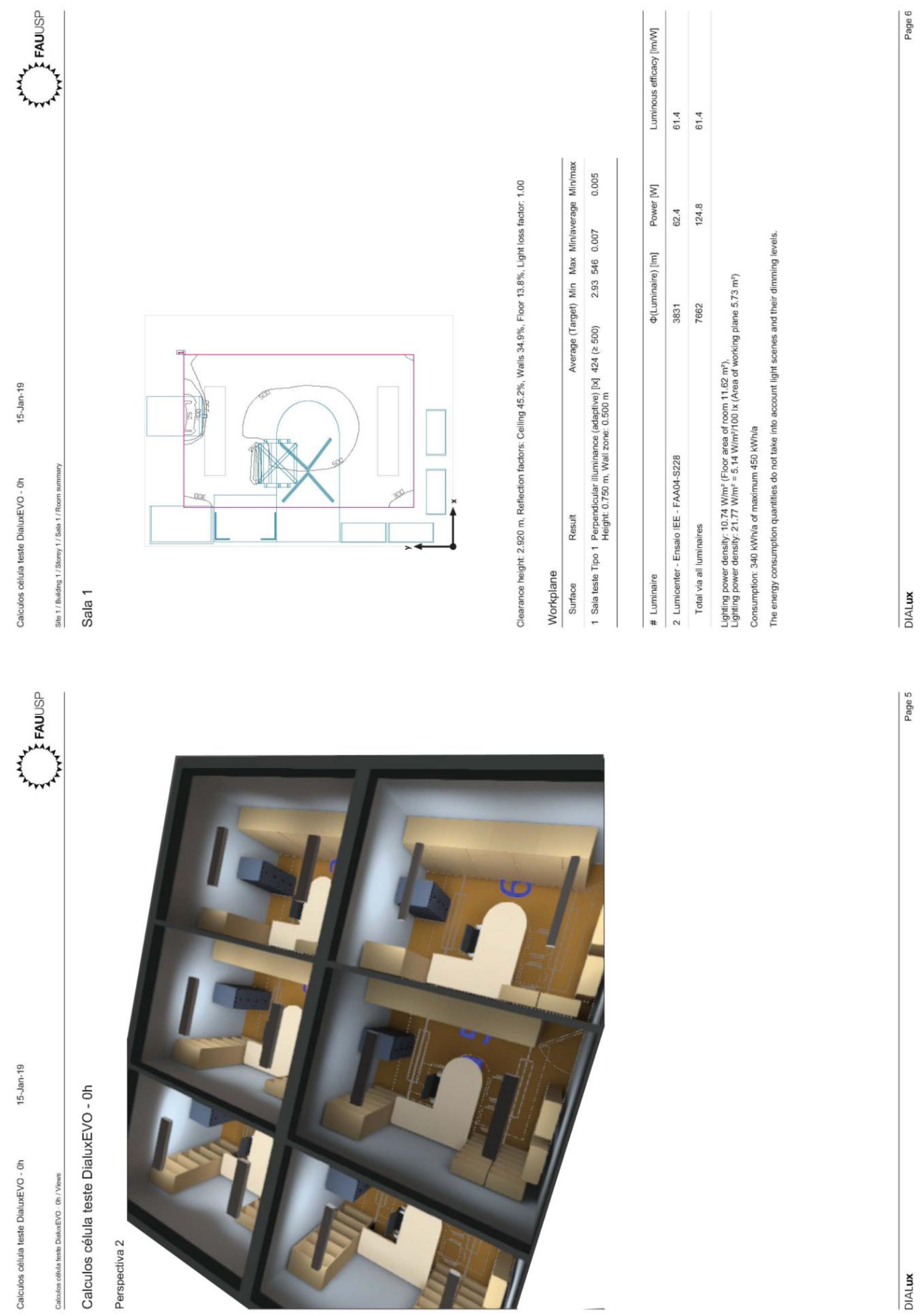

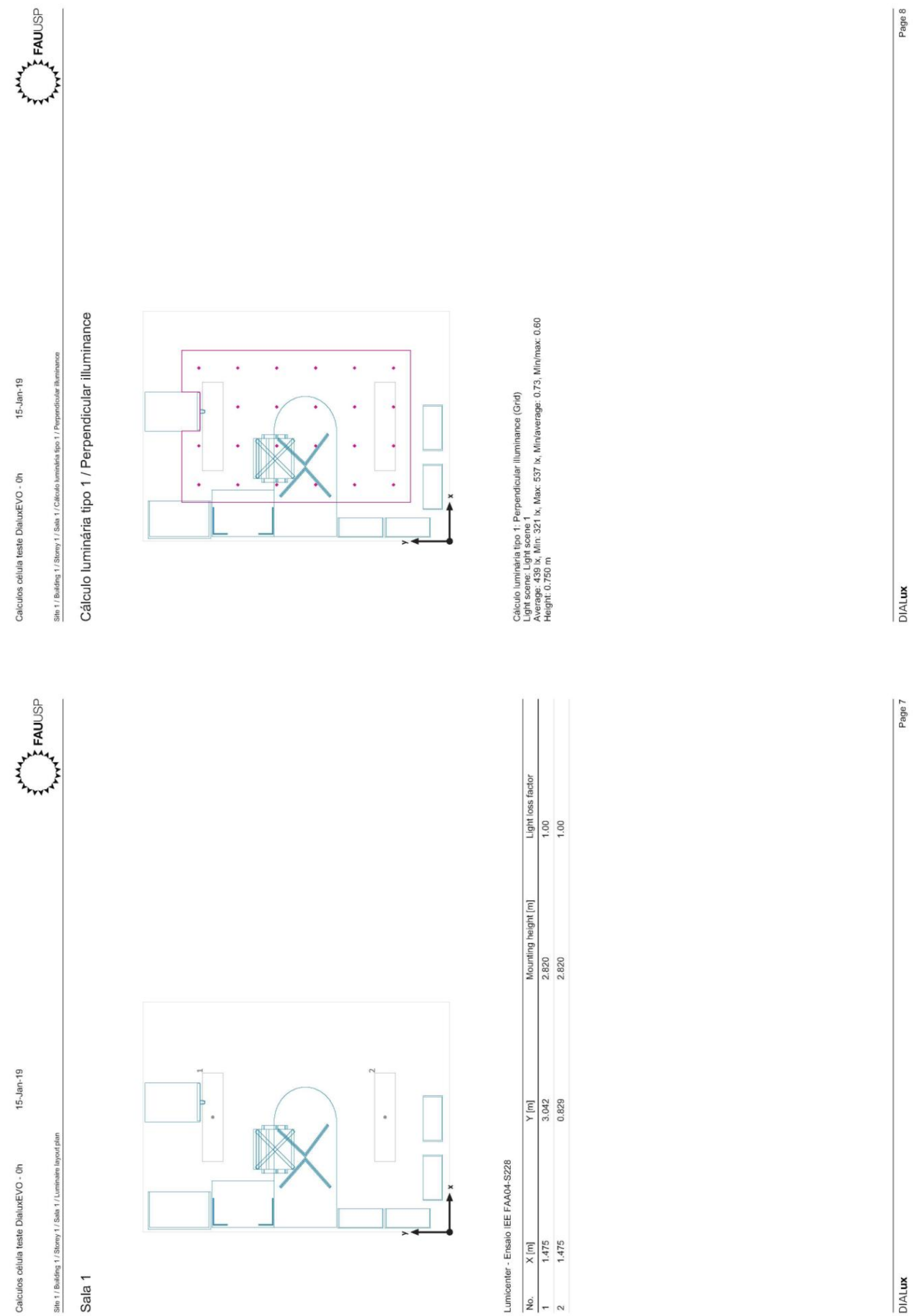

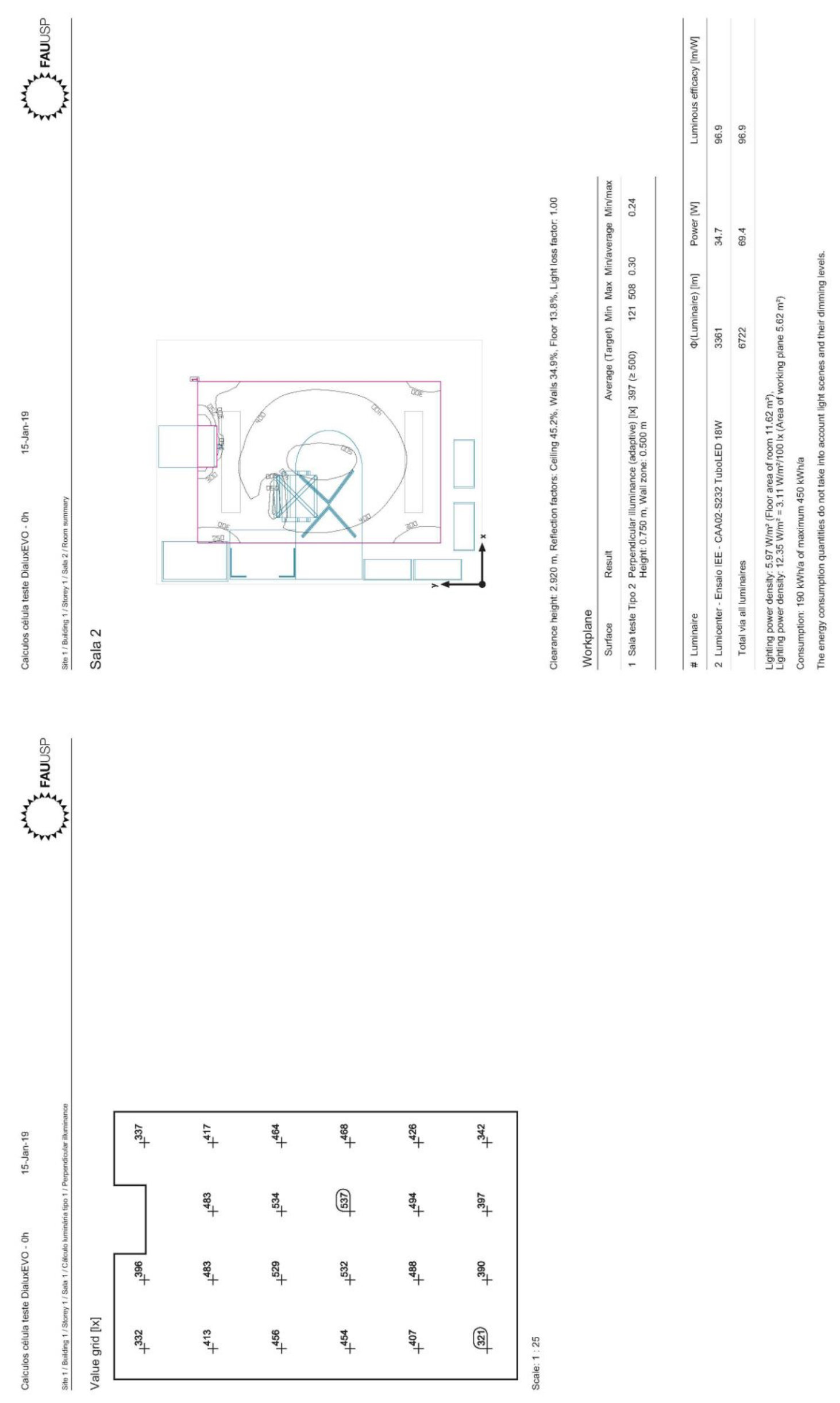

㩊

192 


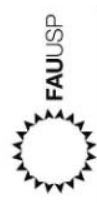

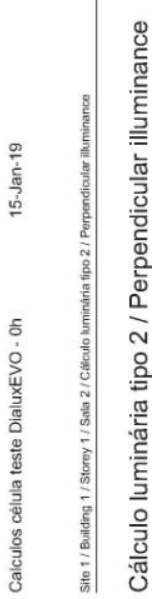
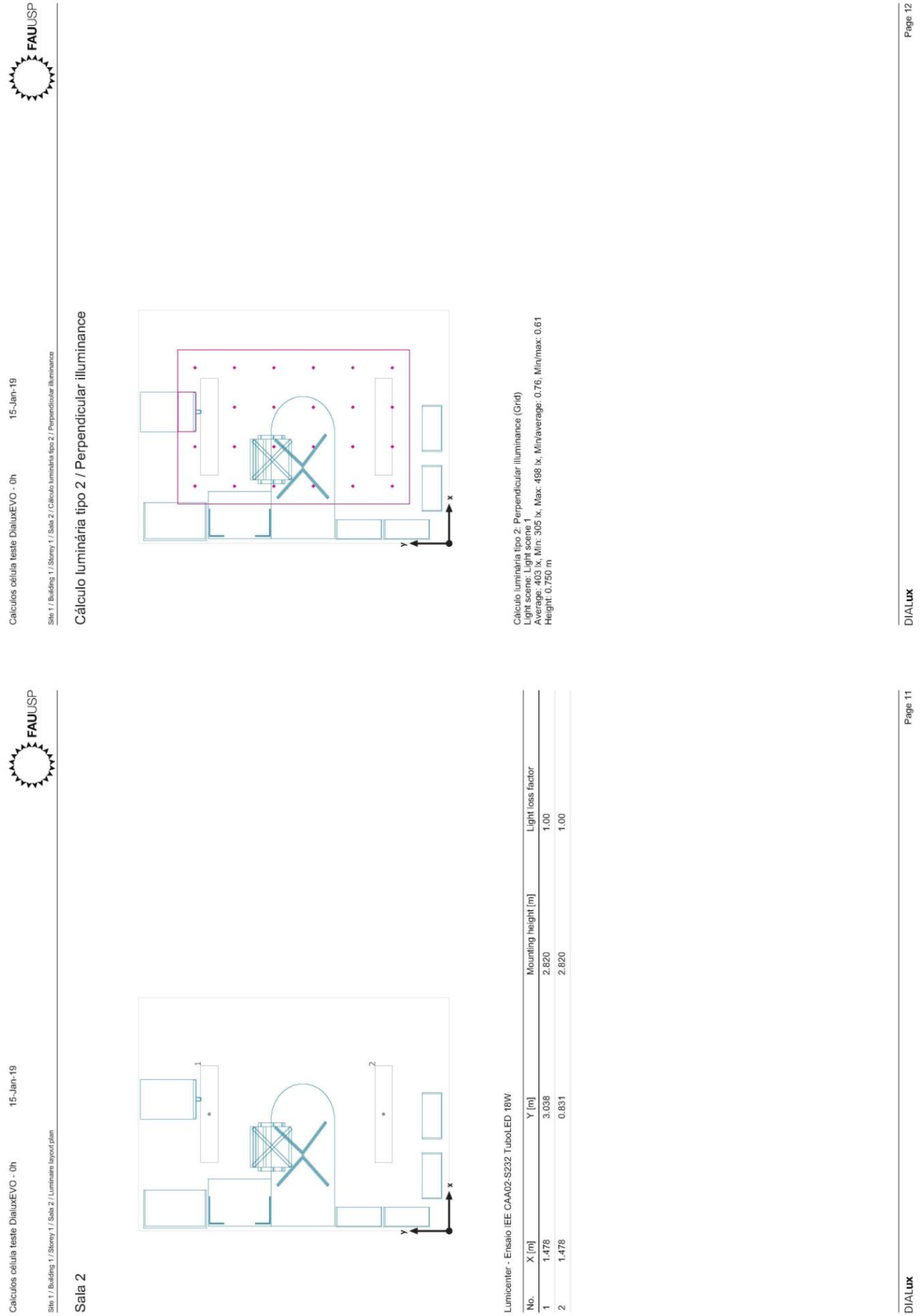

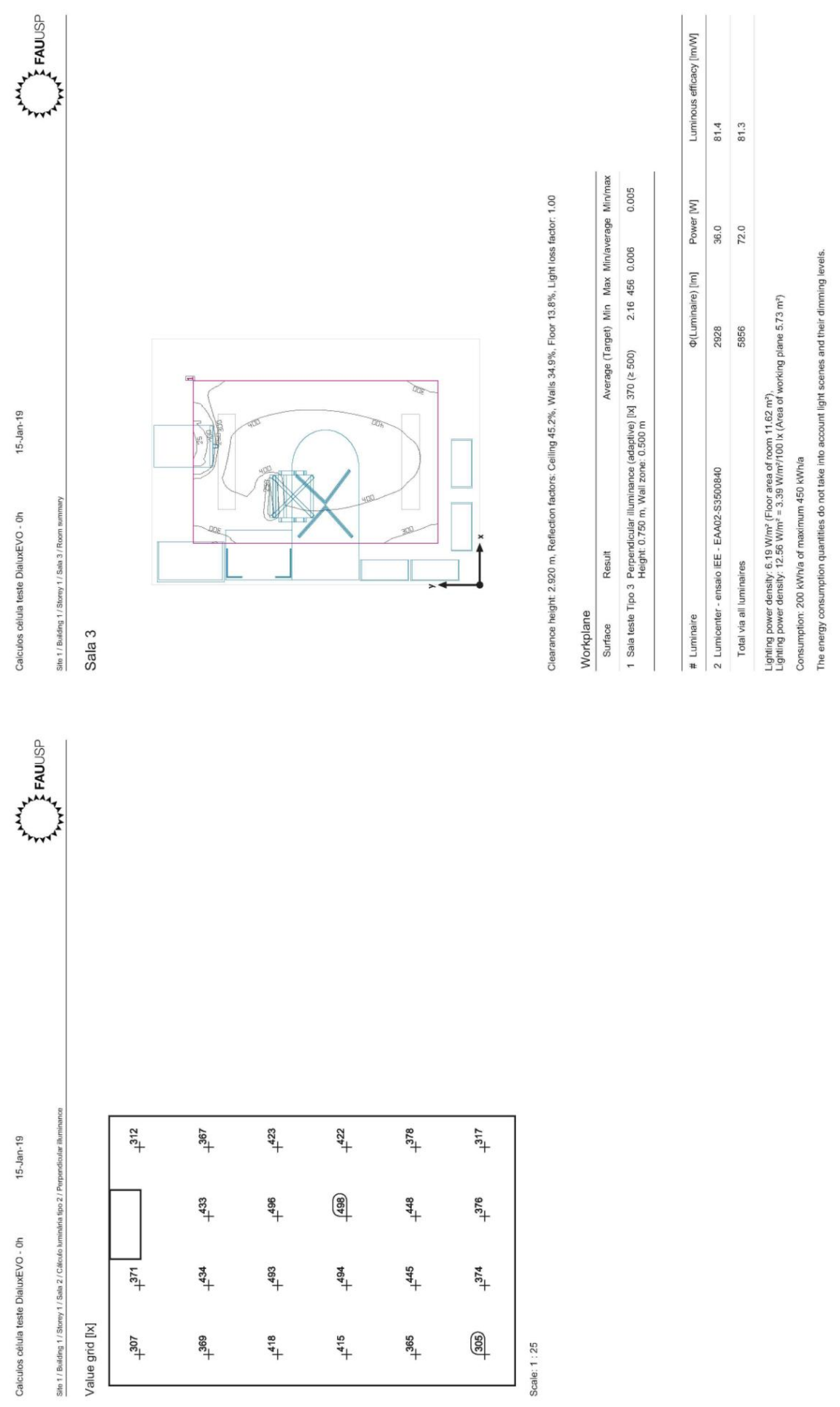

194 


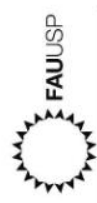

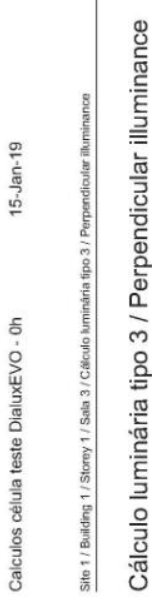
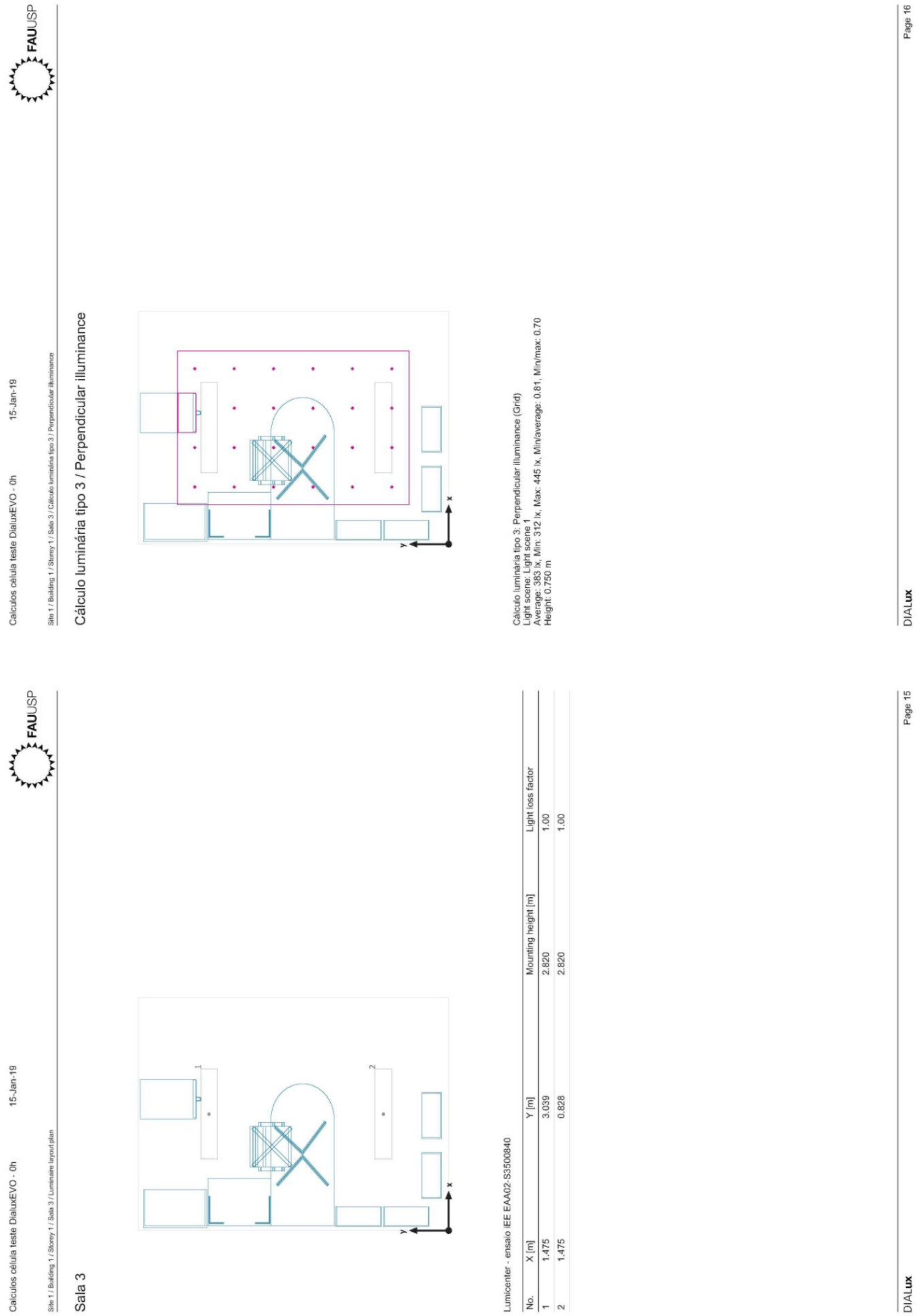

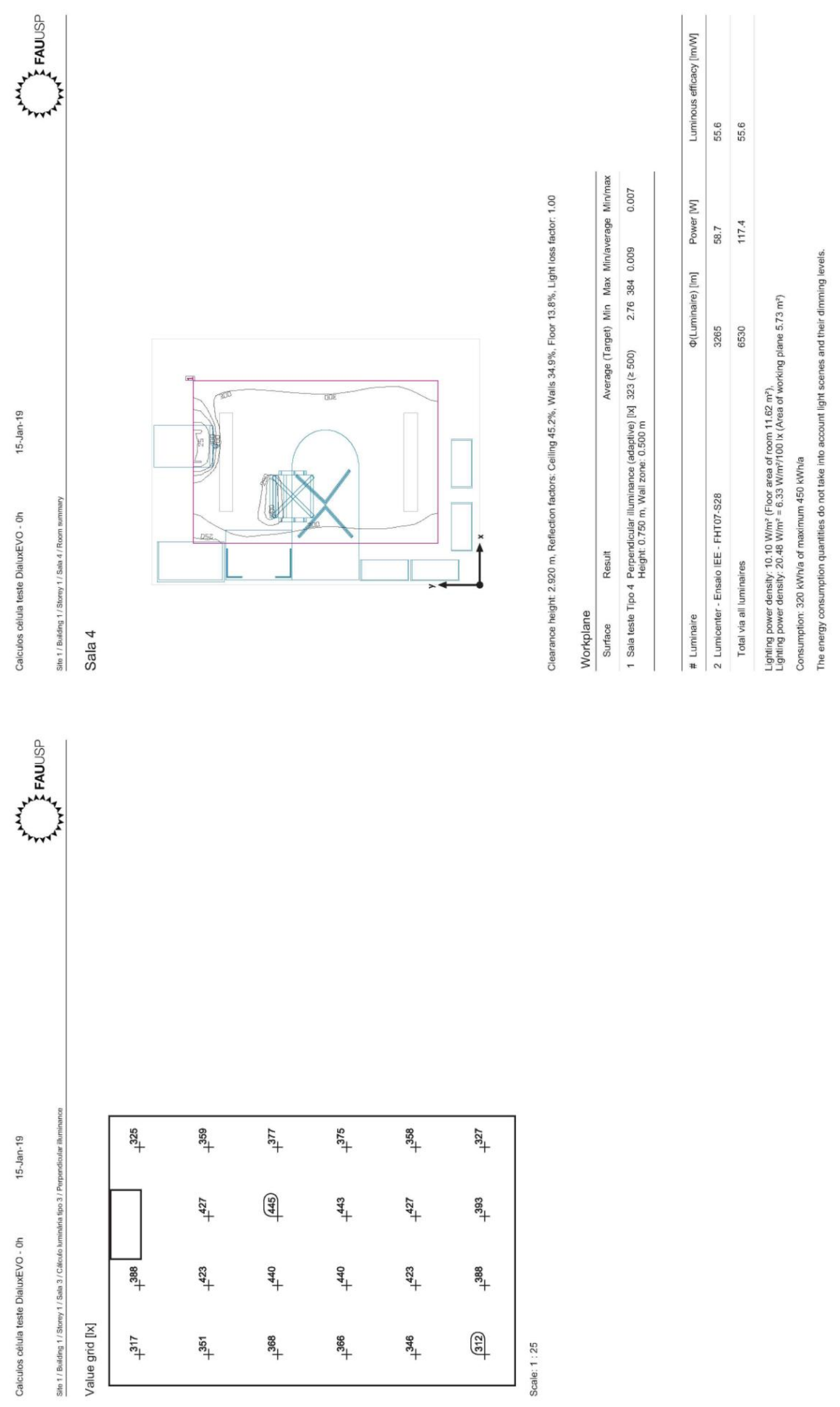

196 


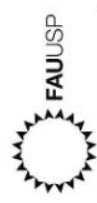

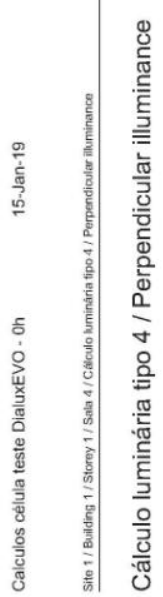
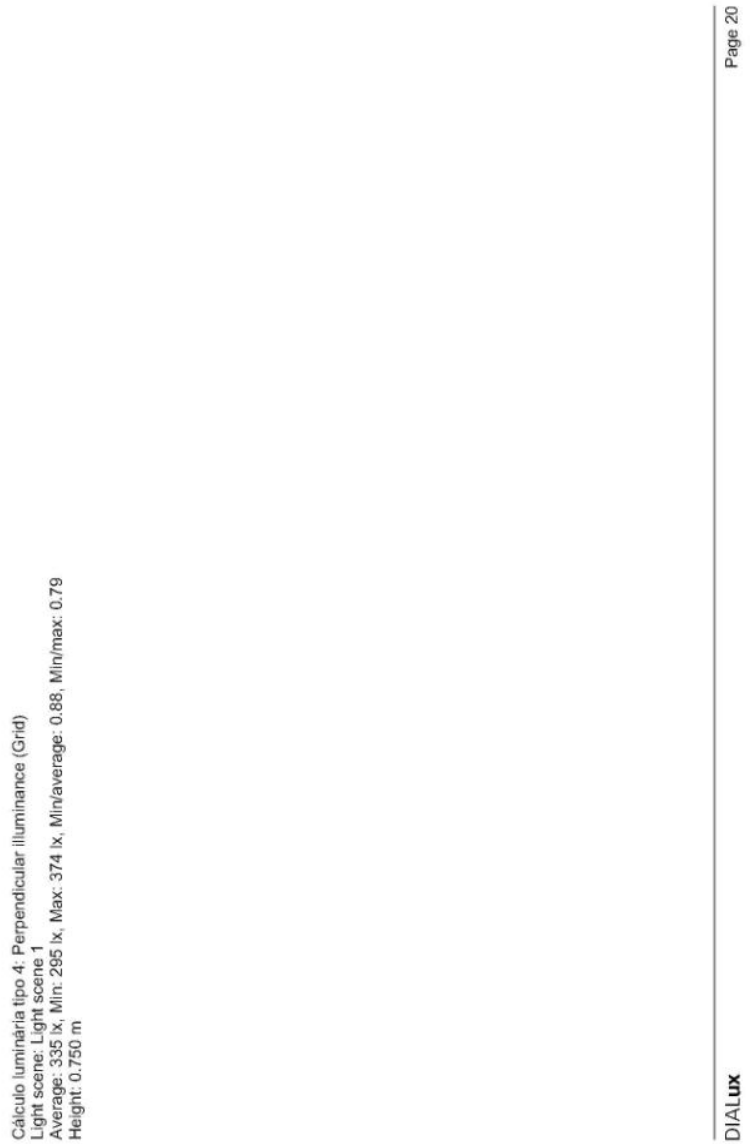

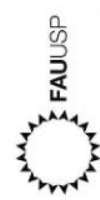
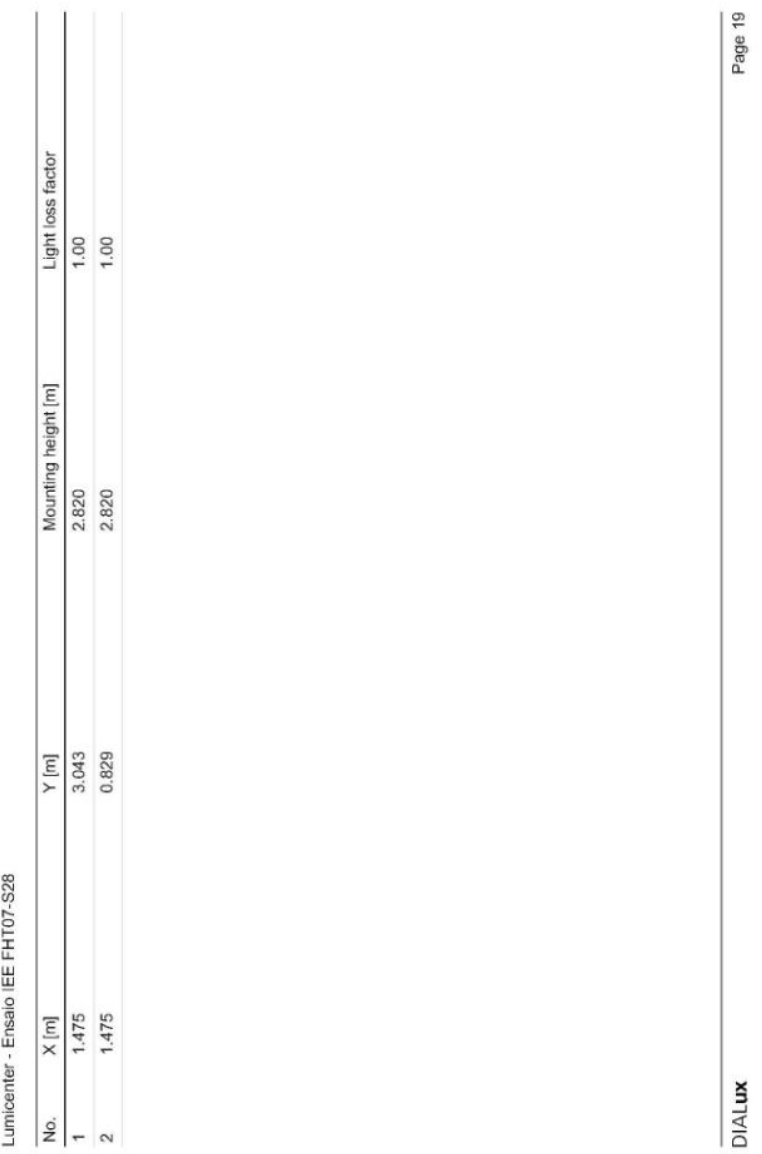

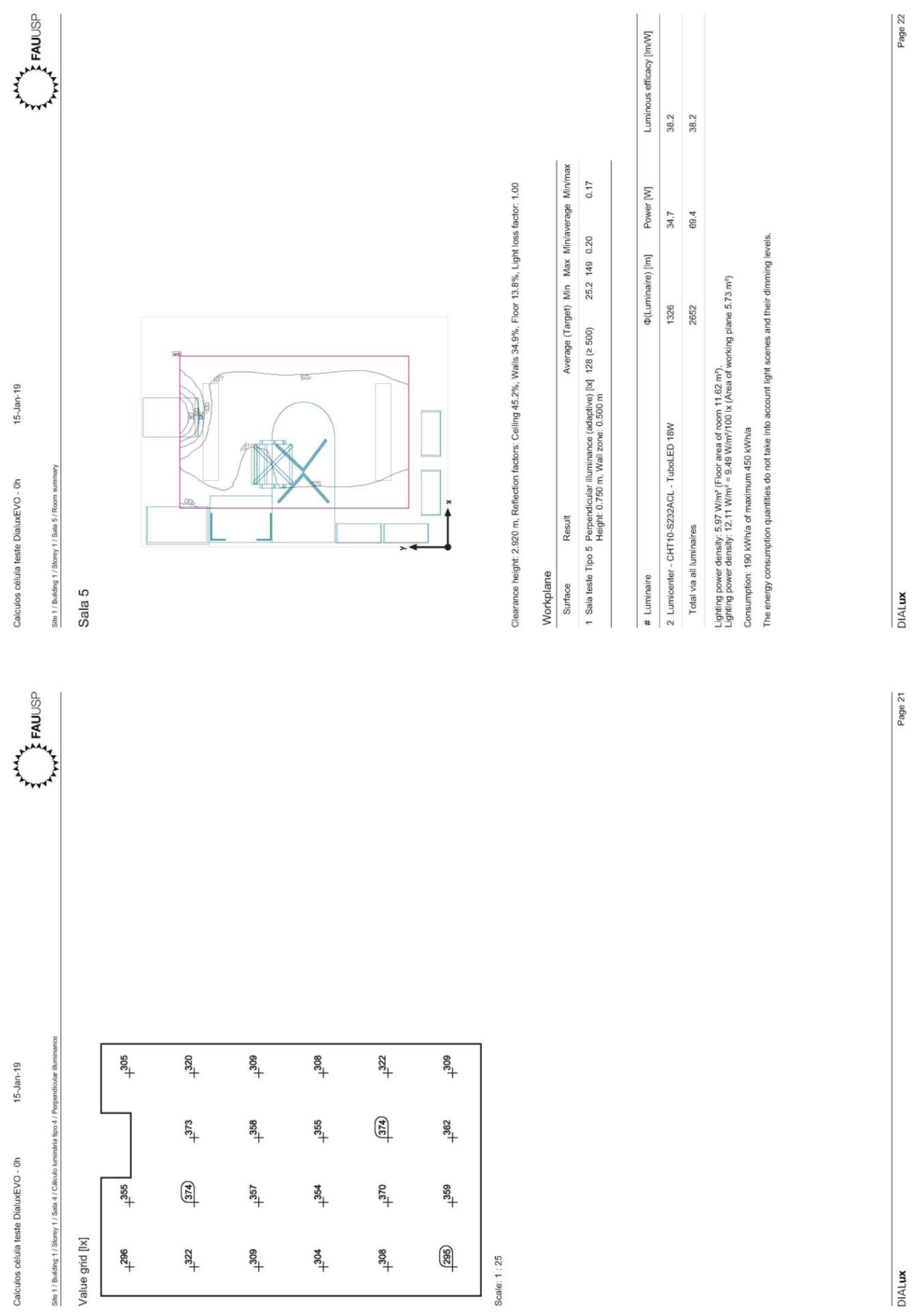

198 


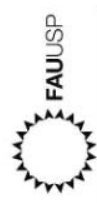

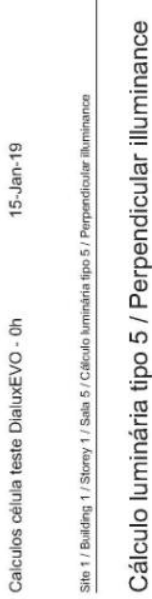
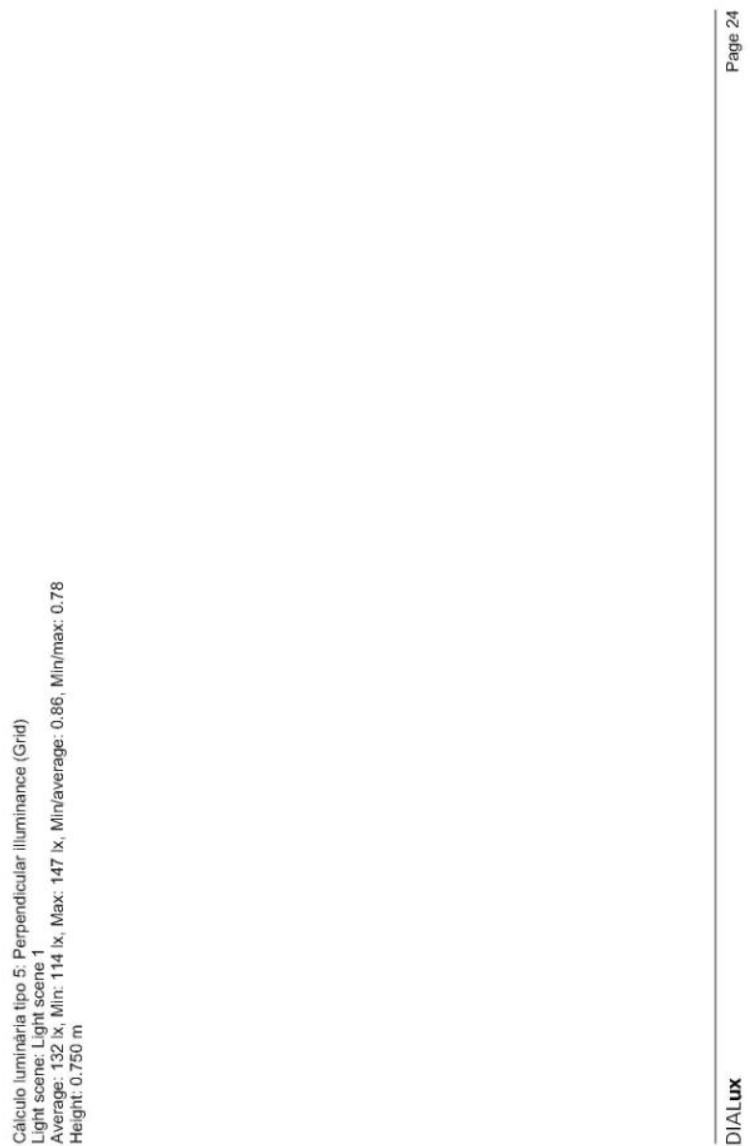

|
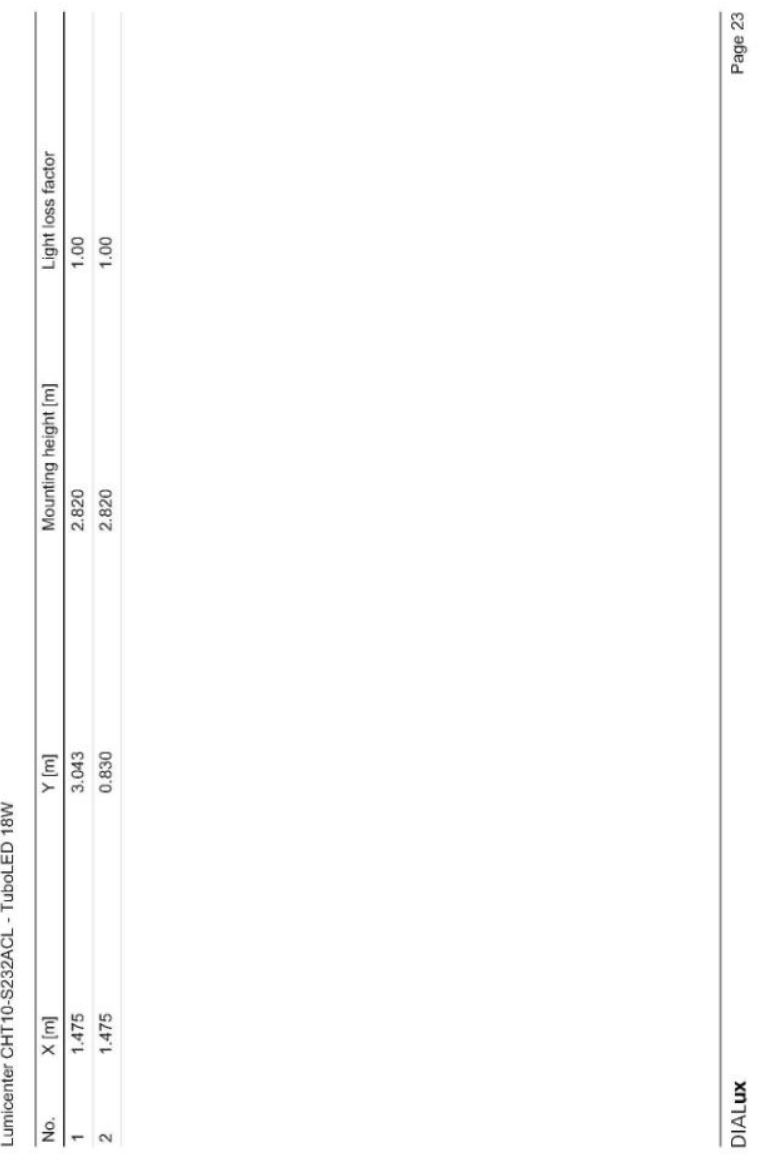

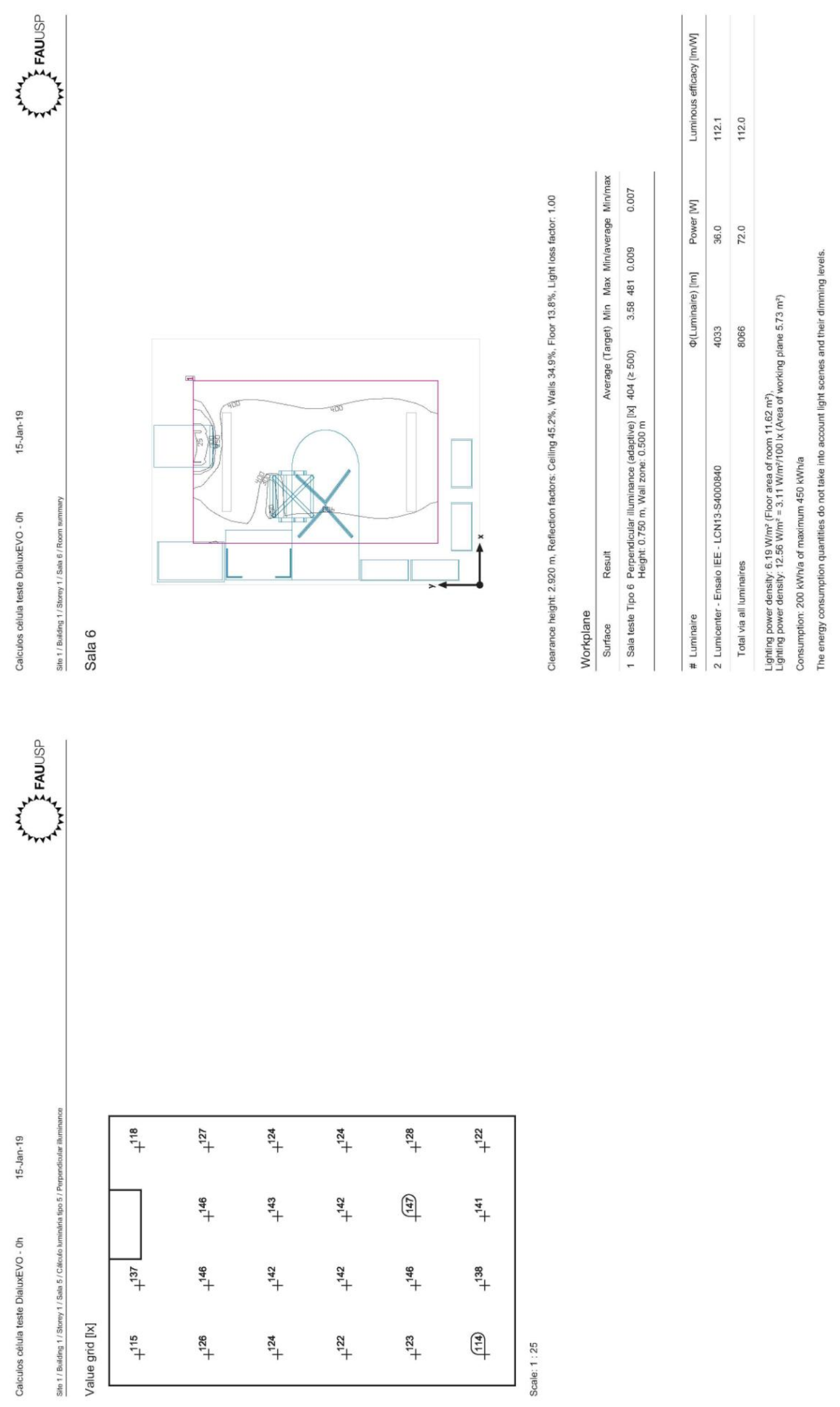

200 


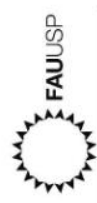

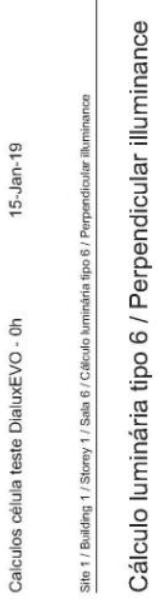
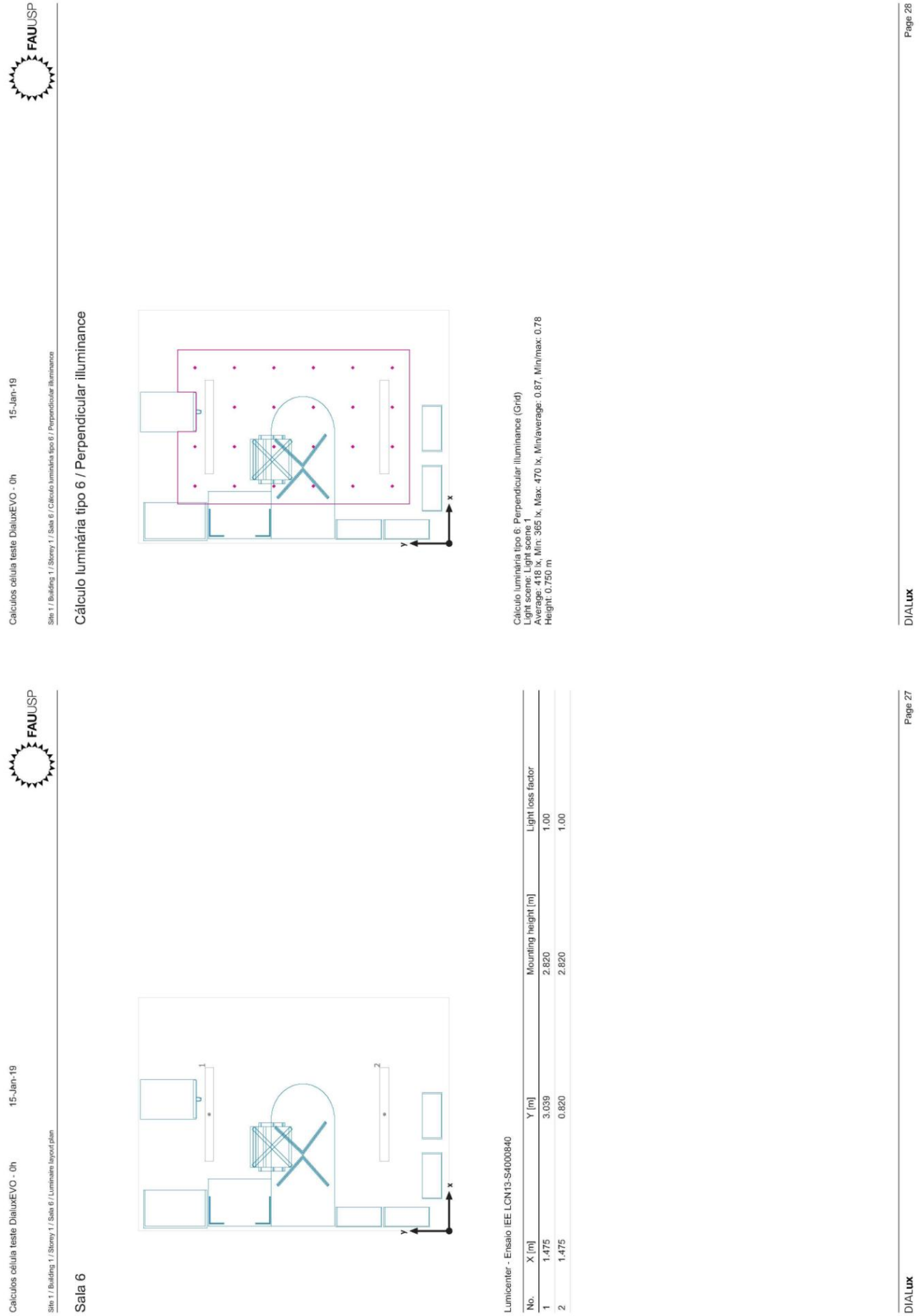

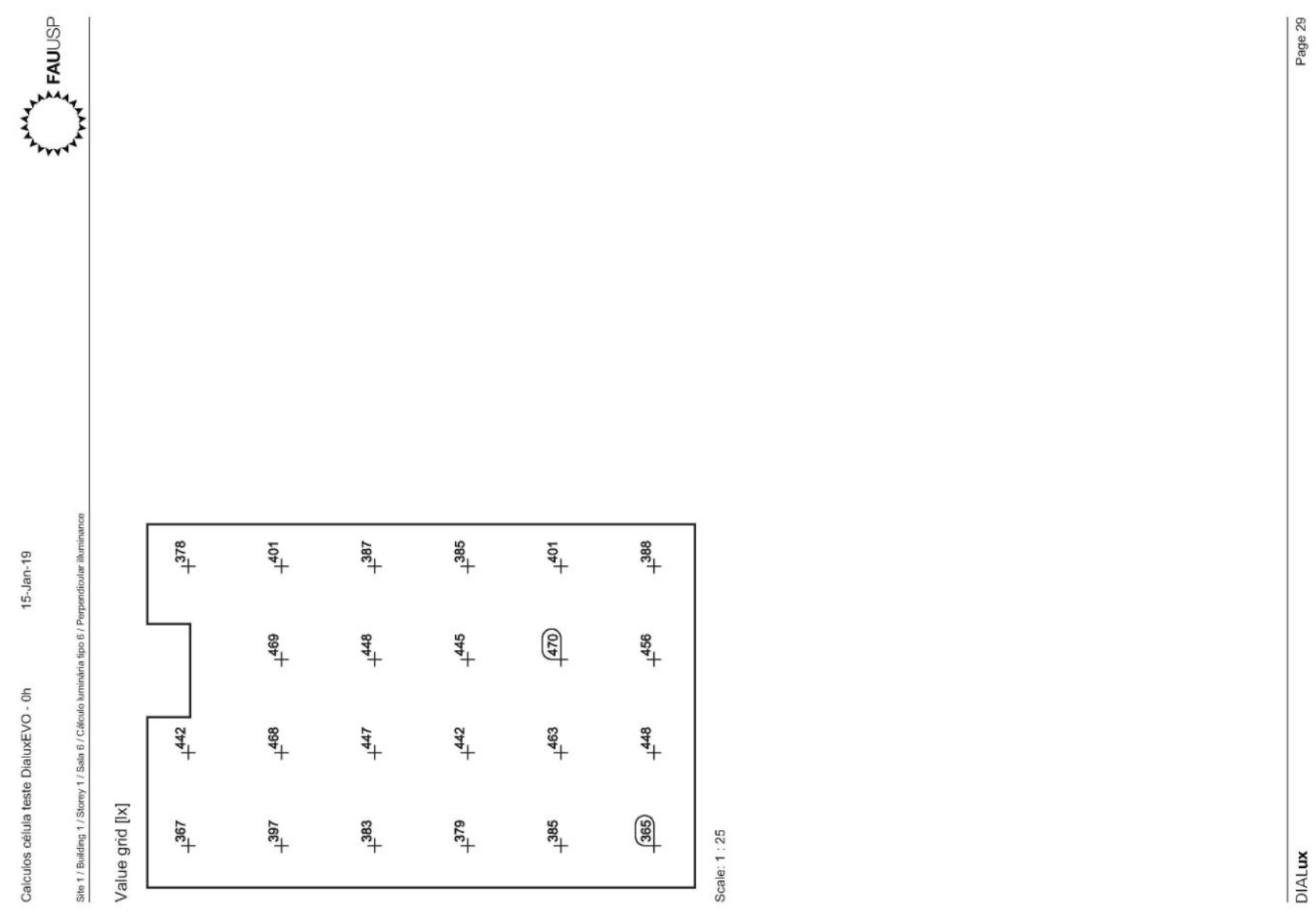

202 
ANEXO III

MEMORIAIS DE CÁLCULOS

PROGRAMA AGi32 

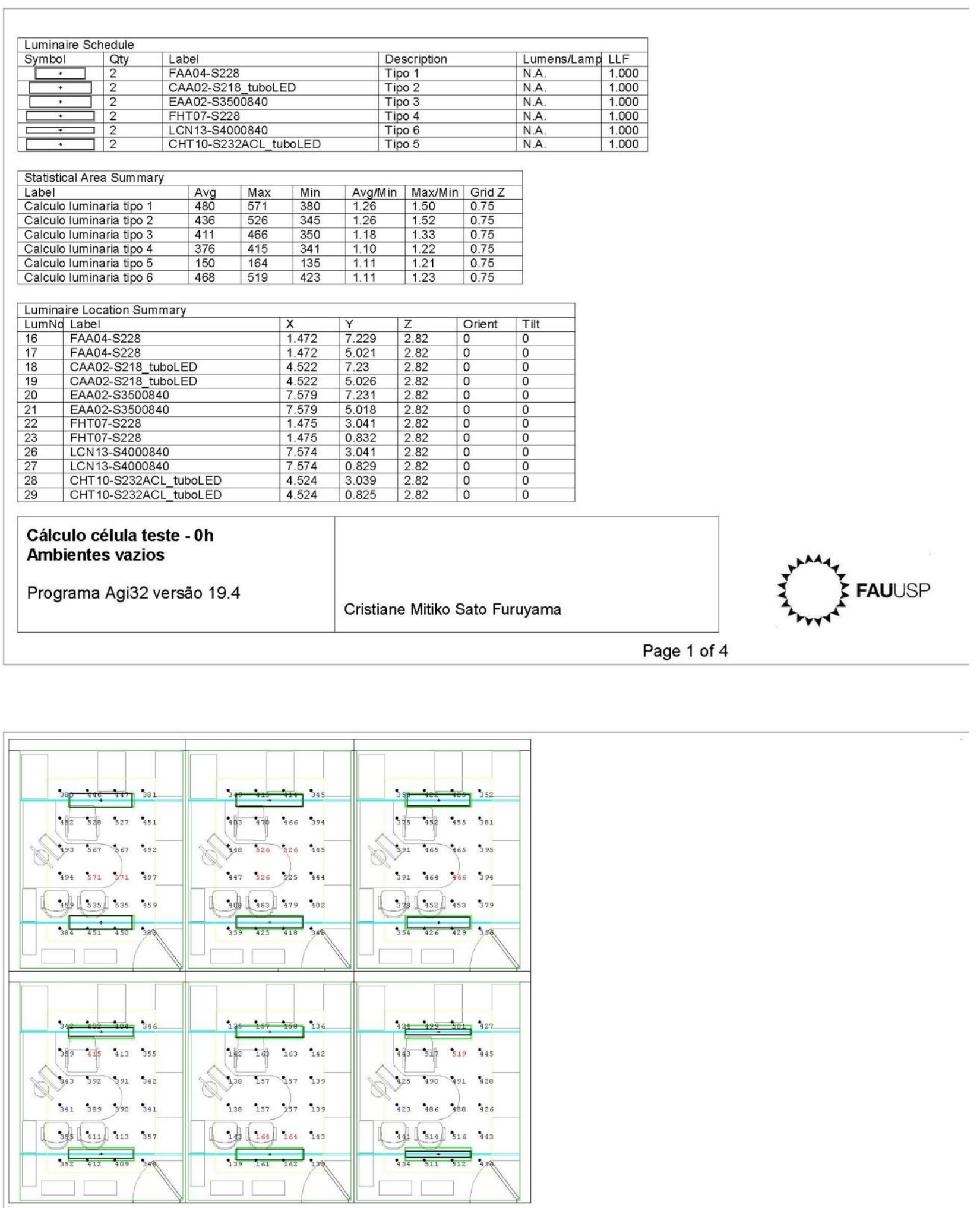

Cálculo célula teste - oh Ambientes vazios

Programa Agi32 versão 19.4 

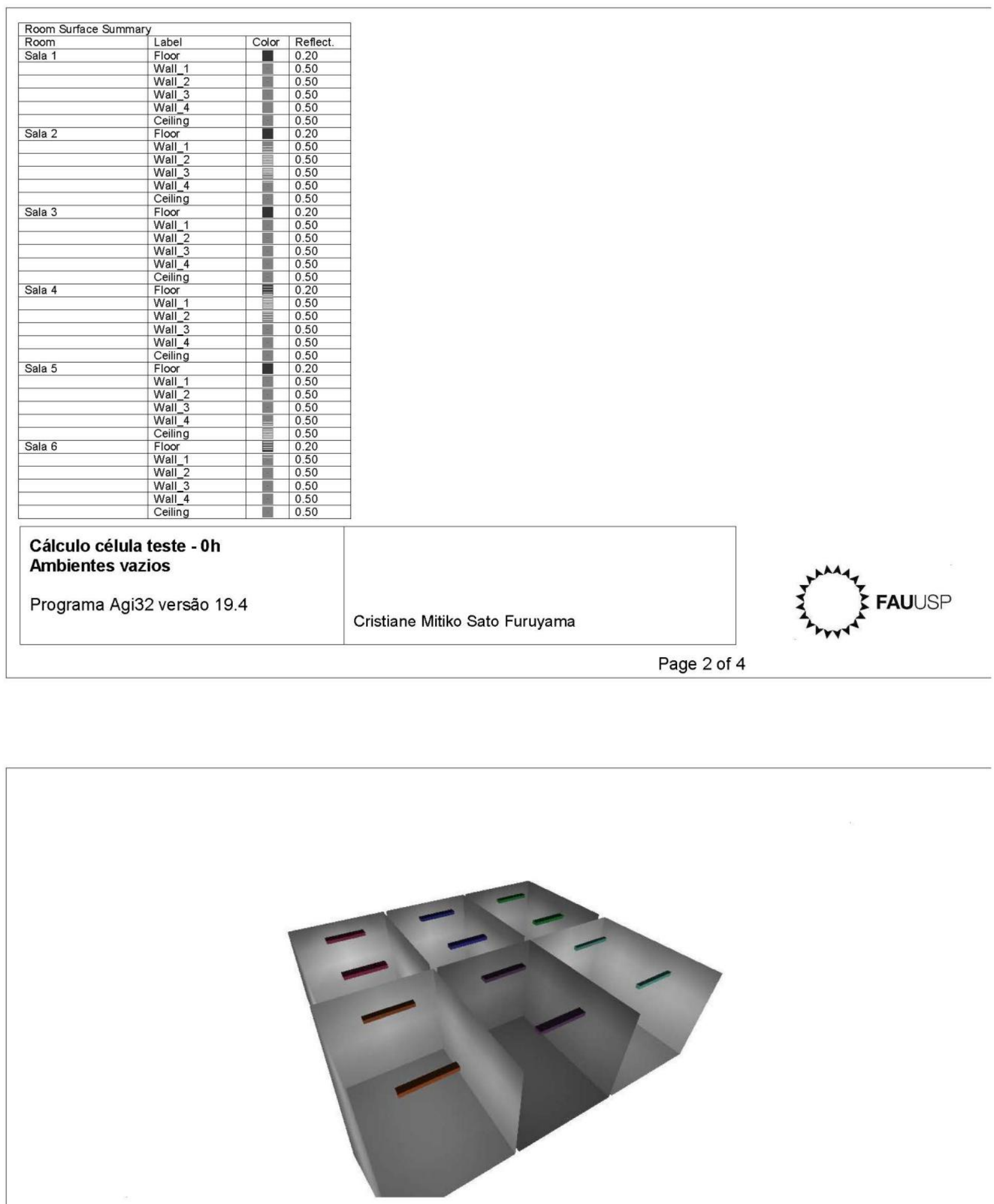

Cálculo célula teste - Oh

Ambientes vazios

Programa Agi32 versão 19.4

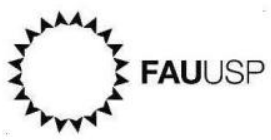



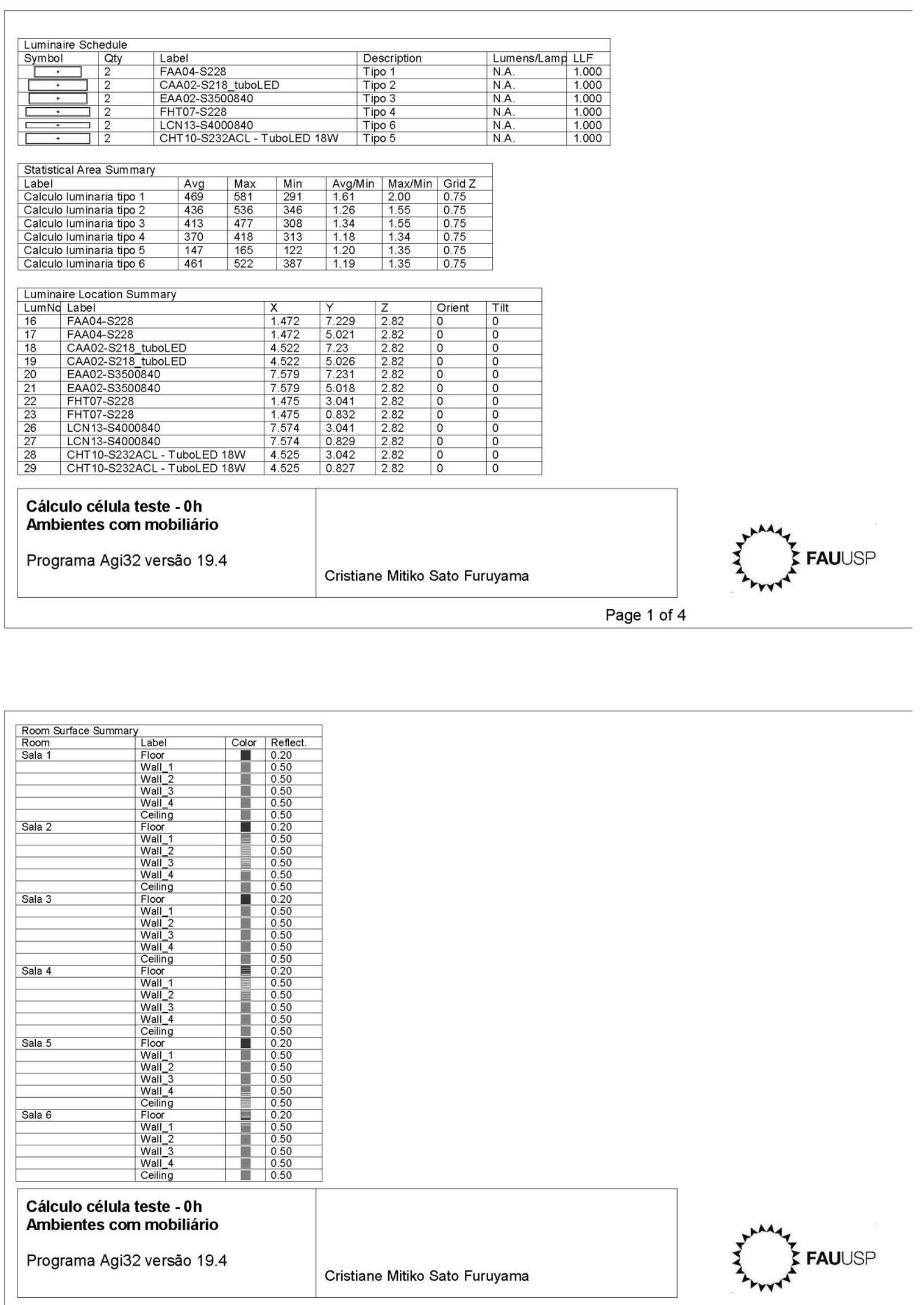

Page 2 of 4 


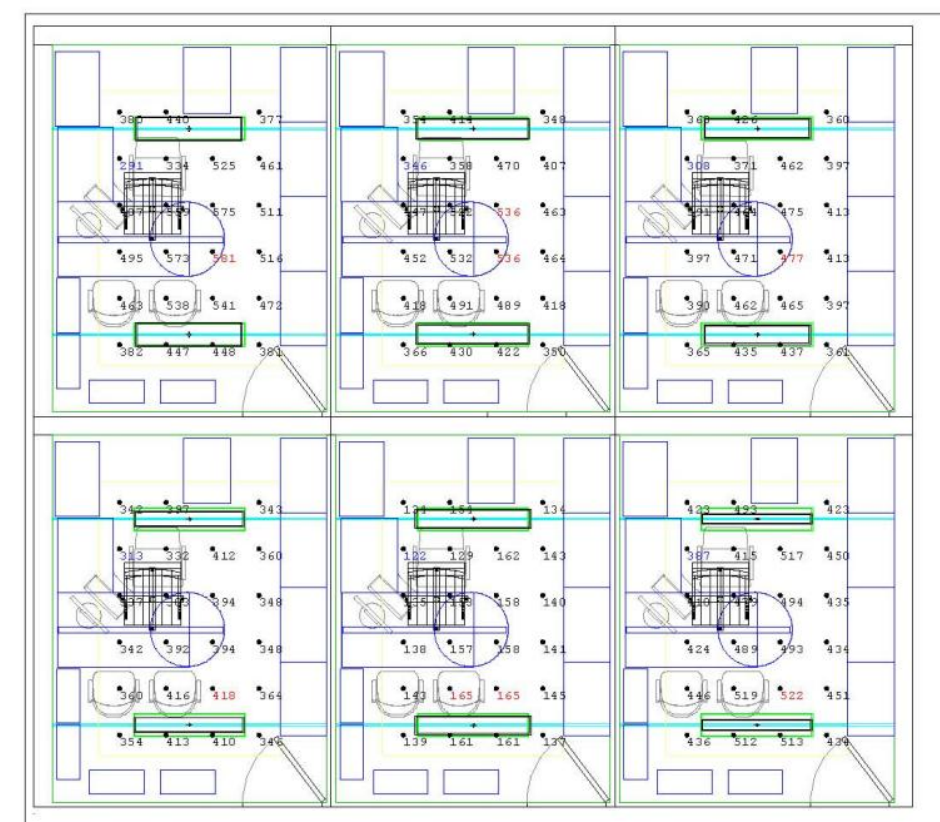

Cálculo célula teste - $0 \mathrm{~h}$

Ambientes com mobiliário

Programa Agi32 versão 19.4

Cálculo célula teste - $0 \mathrm{~h}$ Ambientes com mobiliário

Programa Agi32 versão 19.4

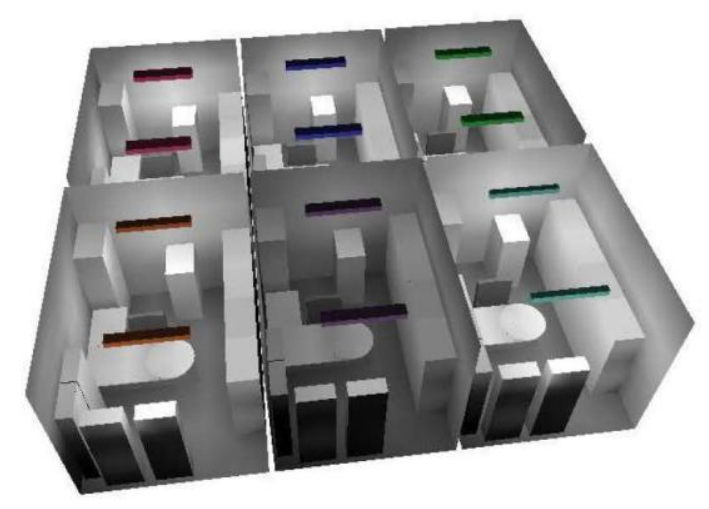

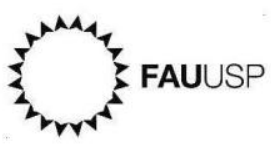





Cálculo célula teste - $0 \mathrm{~h}$

Ambientes mobiliados e cromatizados

Programa Agi32 versão 19.4

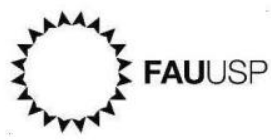




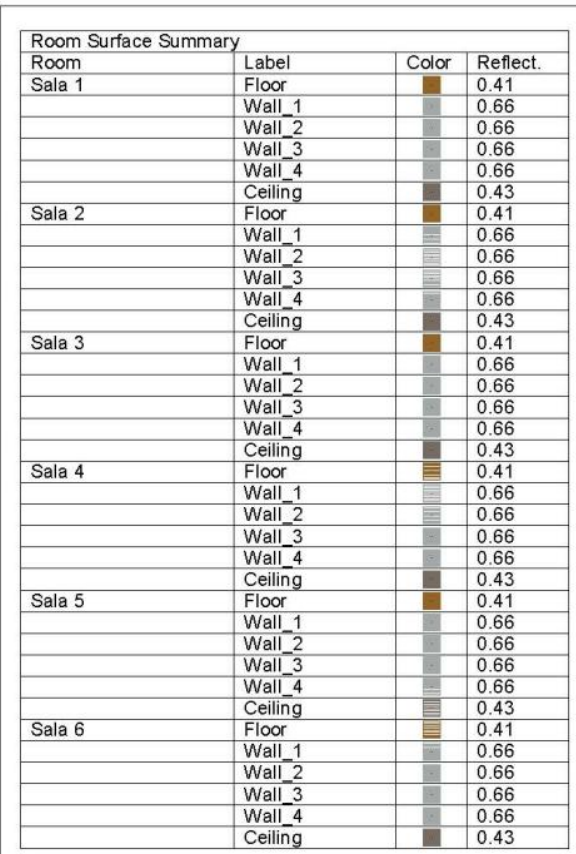

Cálculo célula teste - $0 \mathrm{~h}$

Ambientes mobiliados e cromatizados

Programa Agi32 versão 19.4

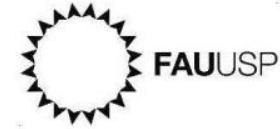

Cálculo célula teste - $0 \mathrm{~h}$

Ambientes mobiliados e cromatizados

Programa Agi32 versão 19.4 
ANEXO IV

MEMORIAIS DE CÁLCULOS

PROGRAMA RELUX 


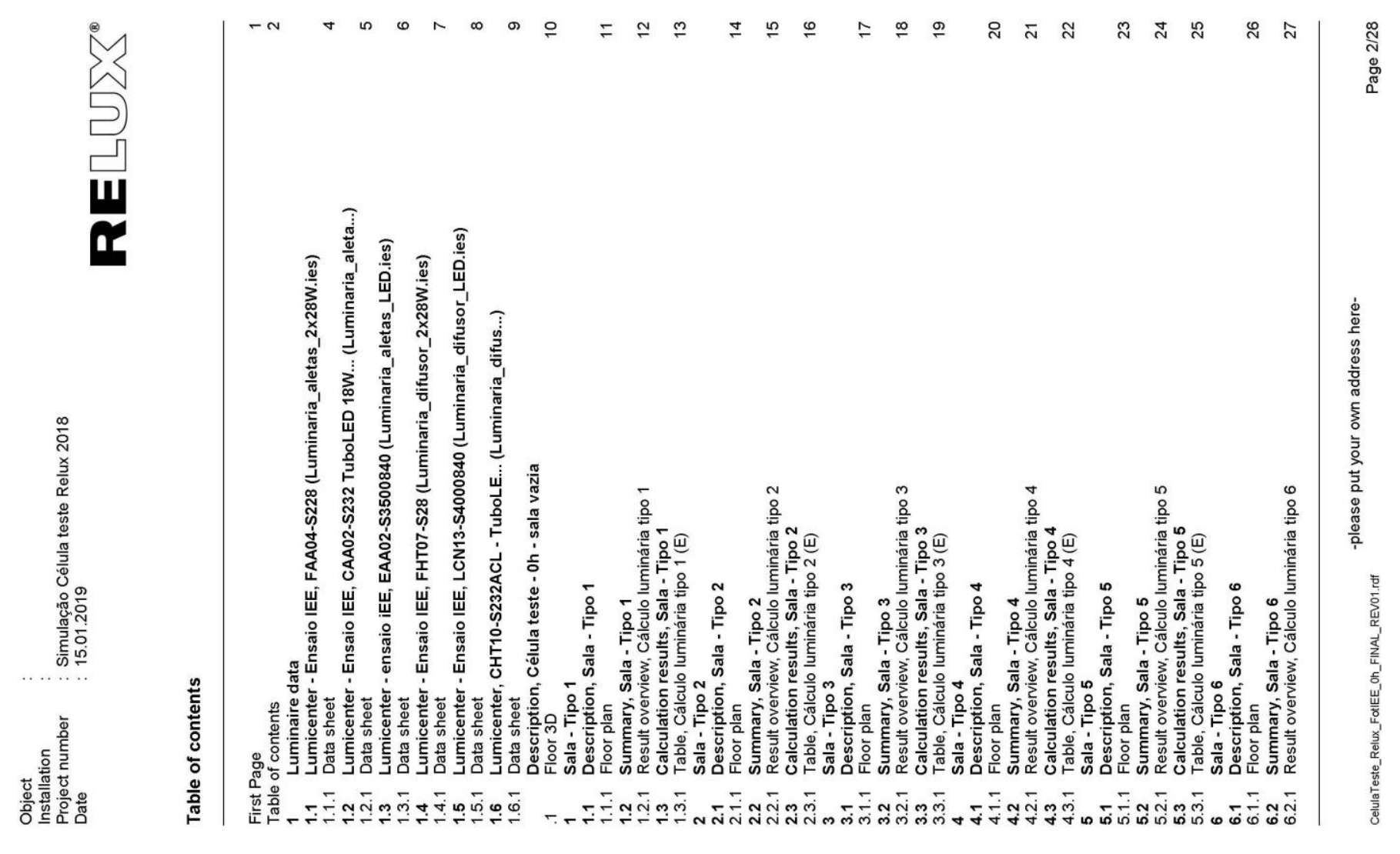

岕

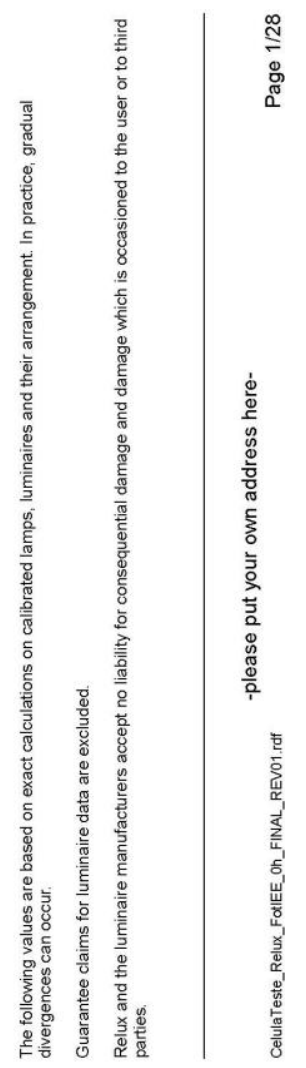



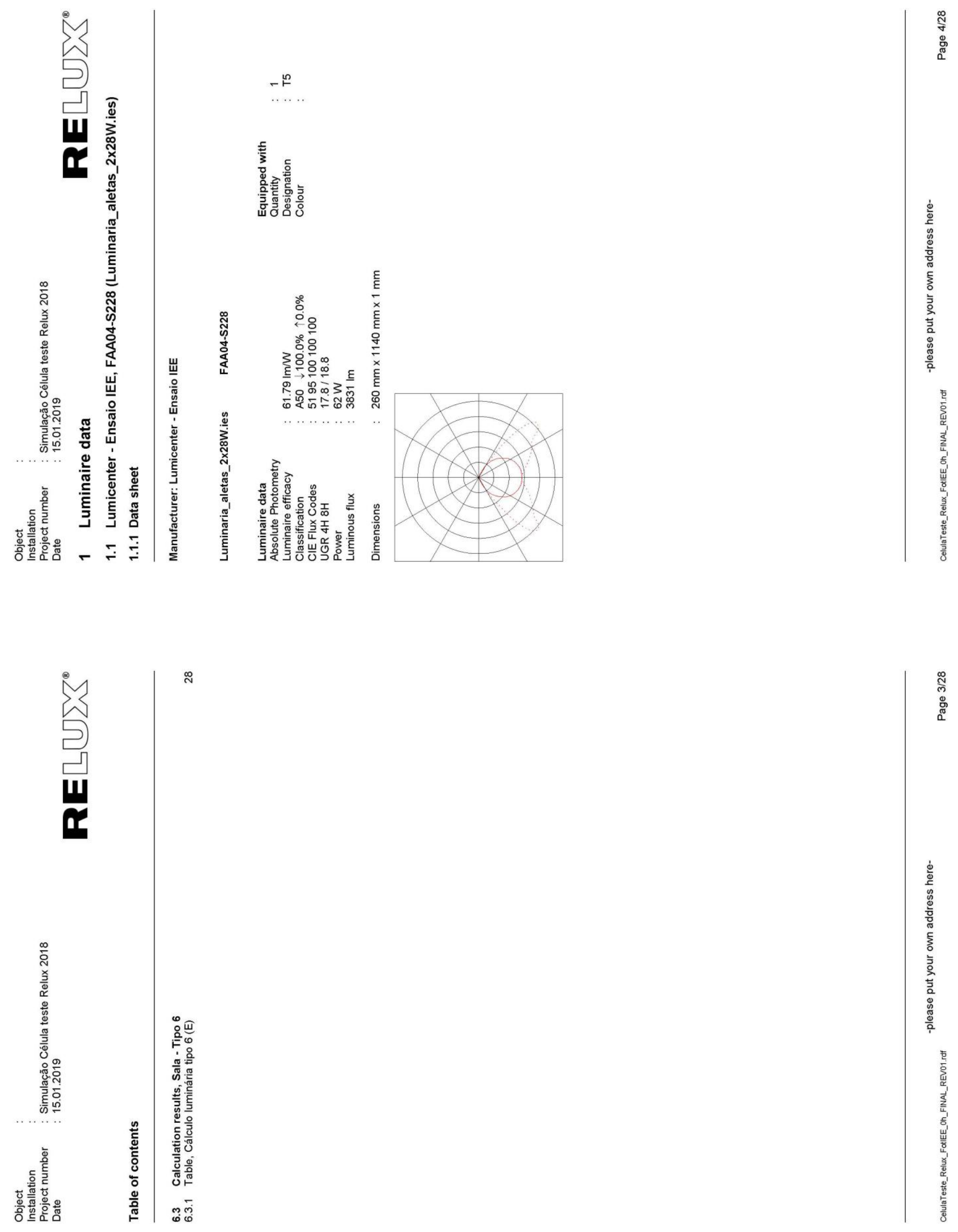

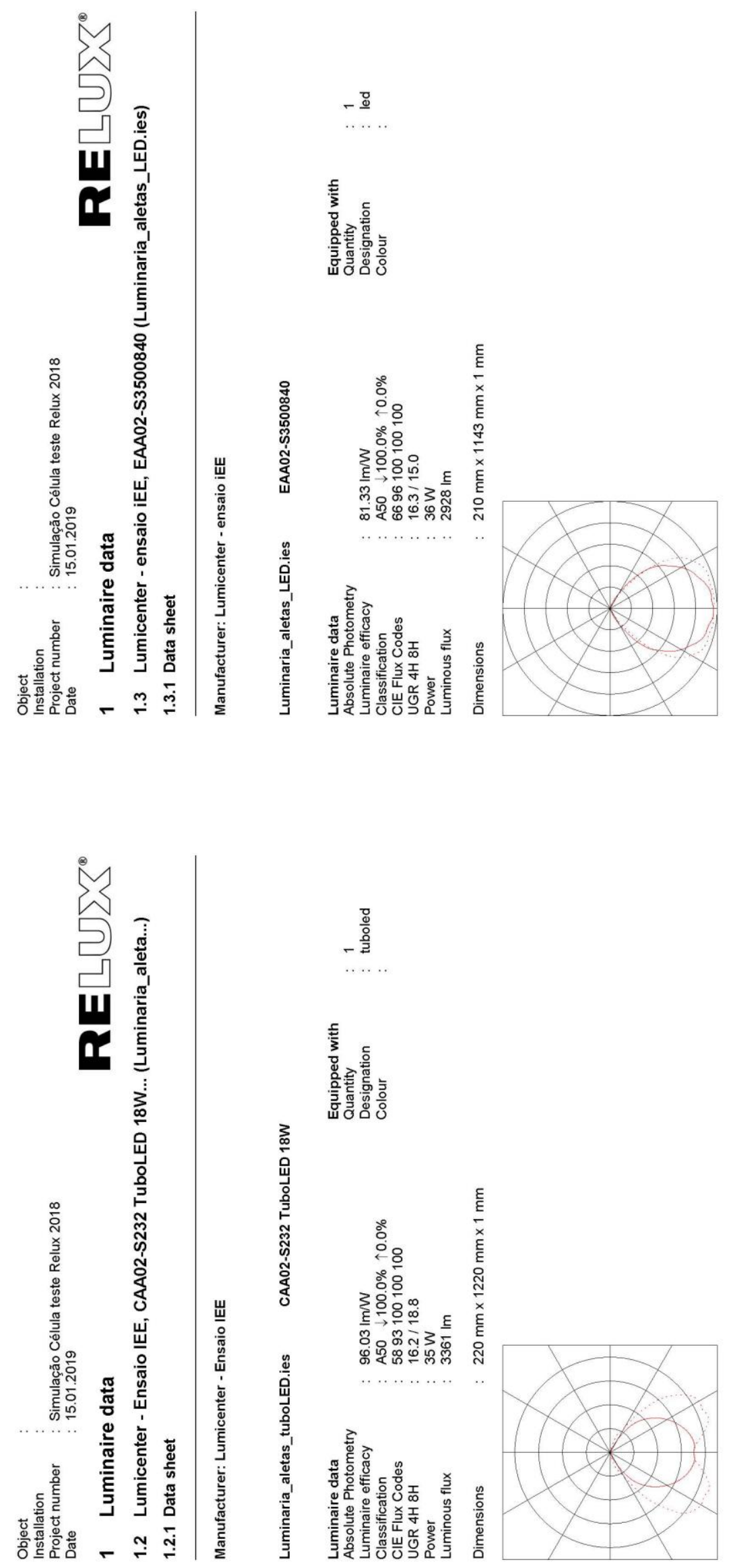

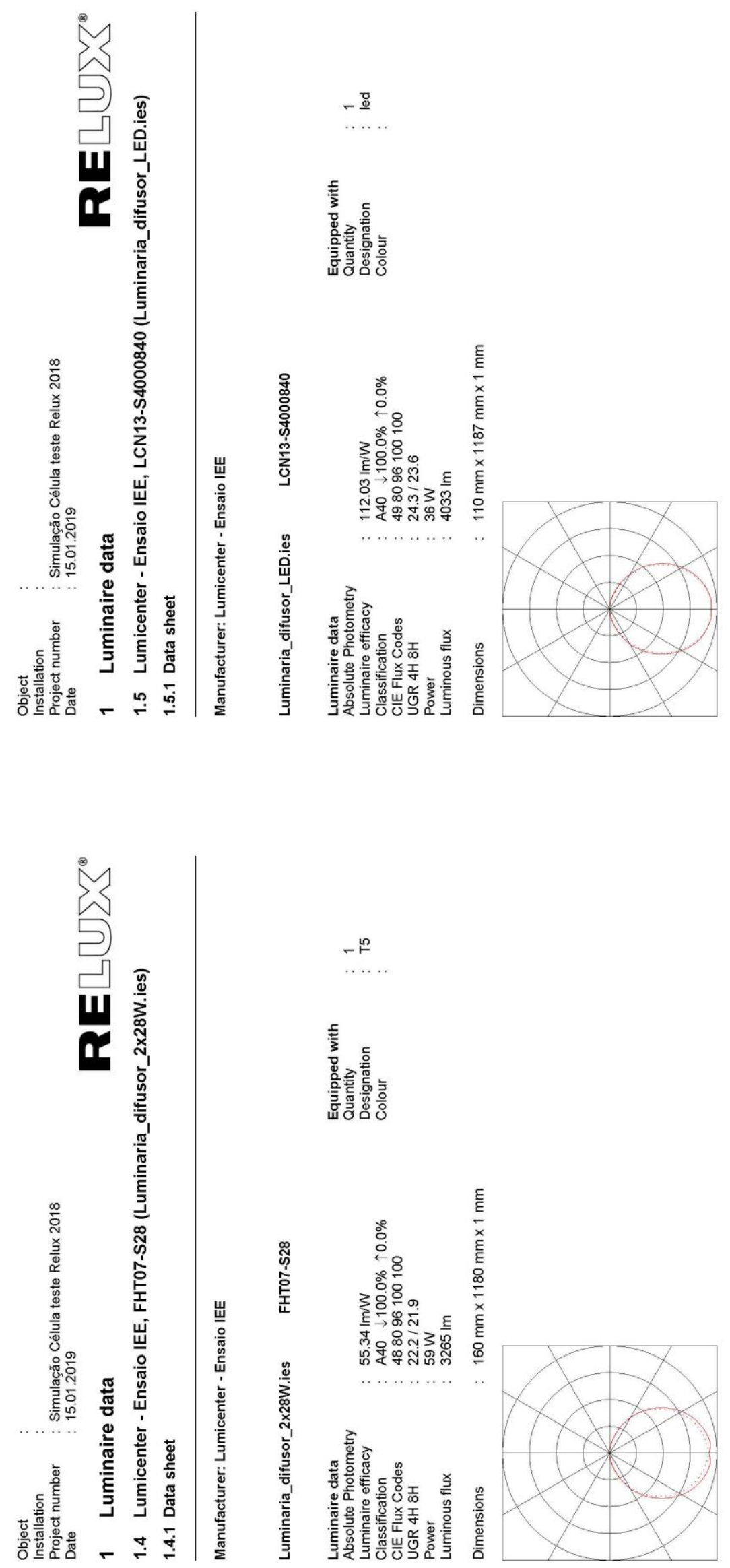

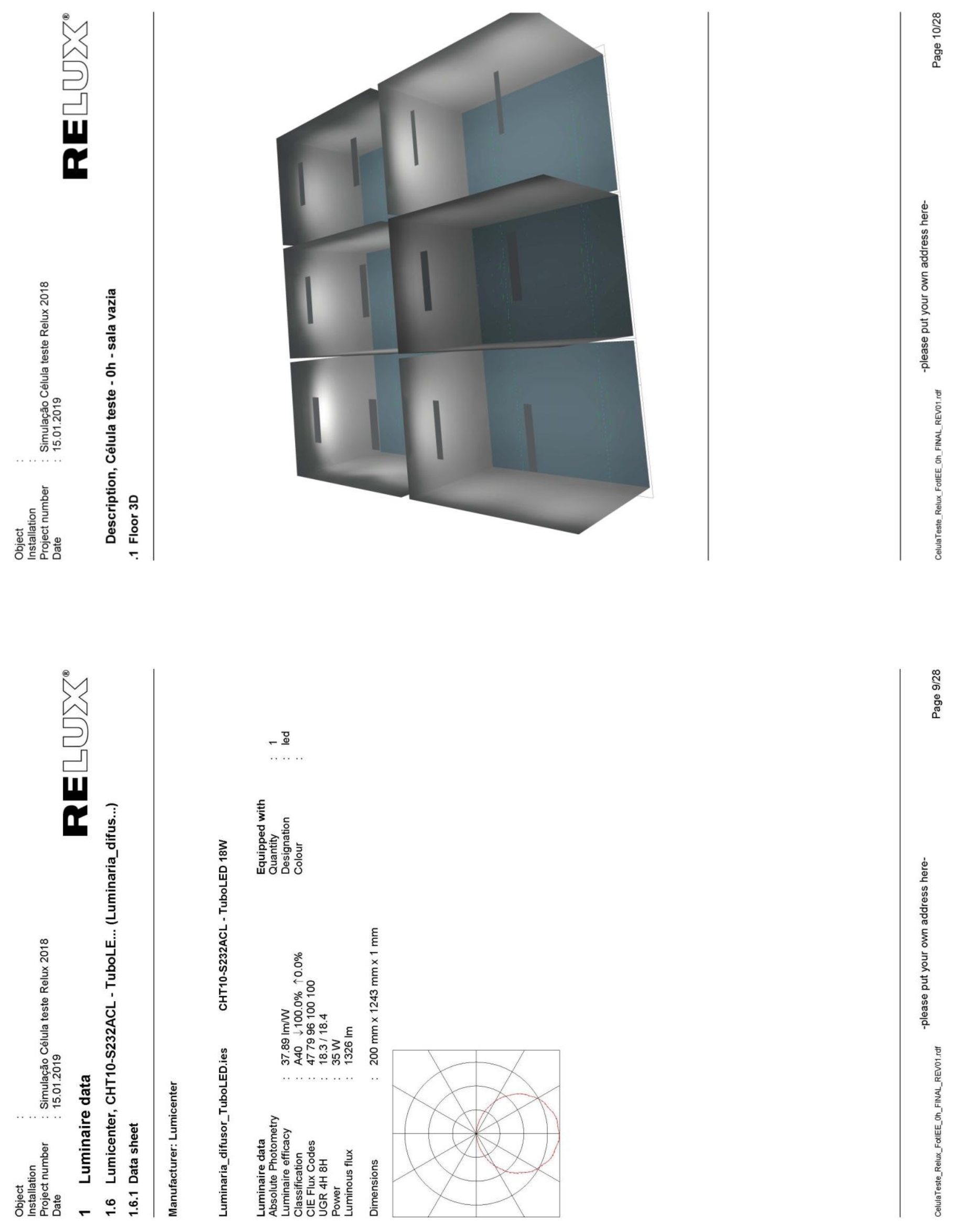

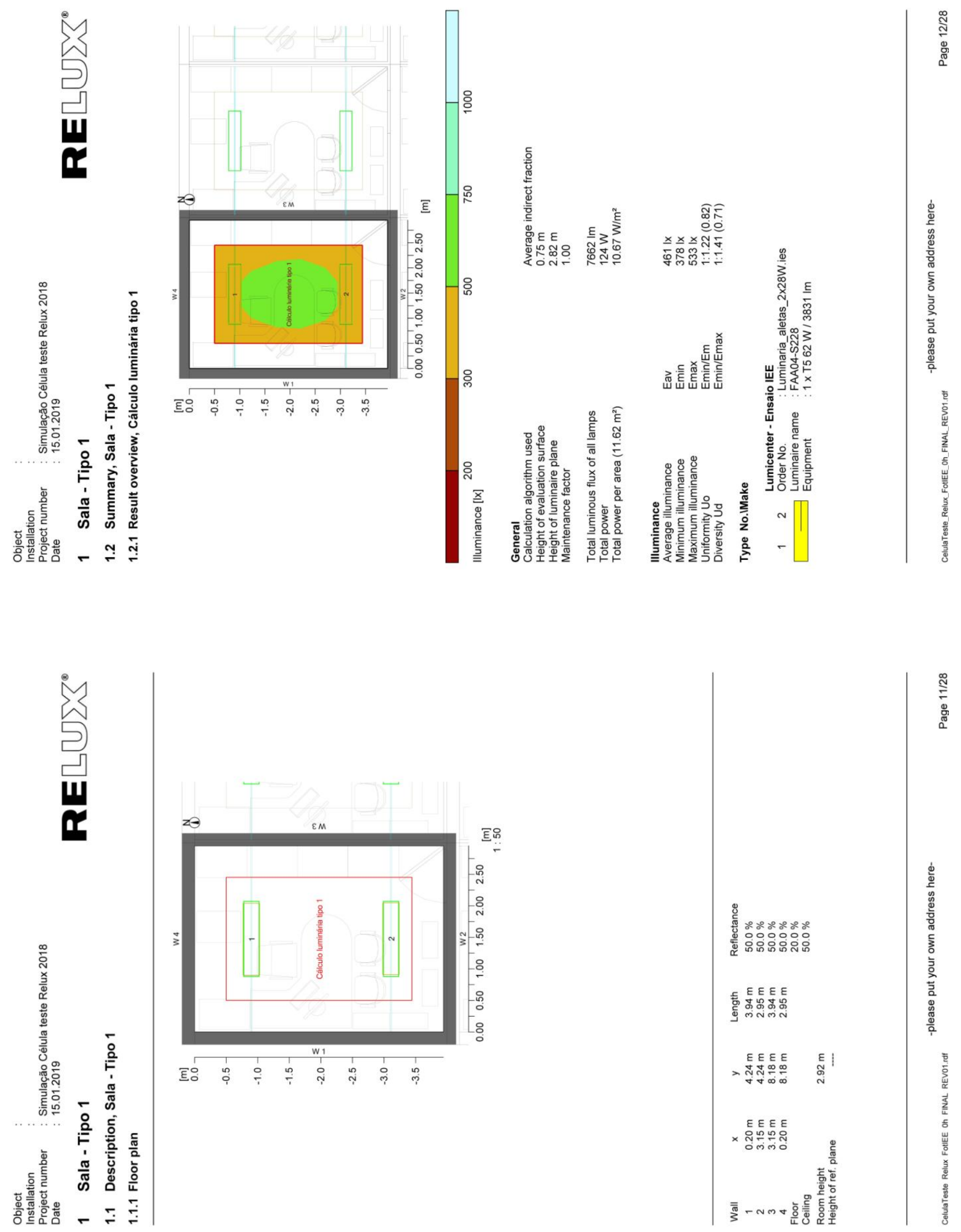

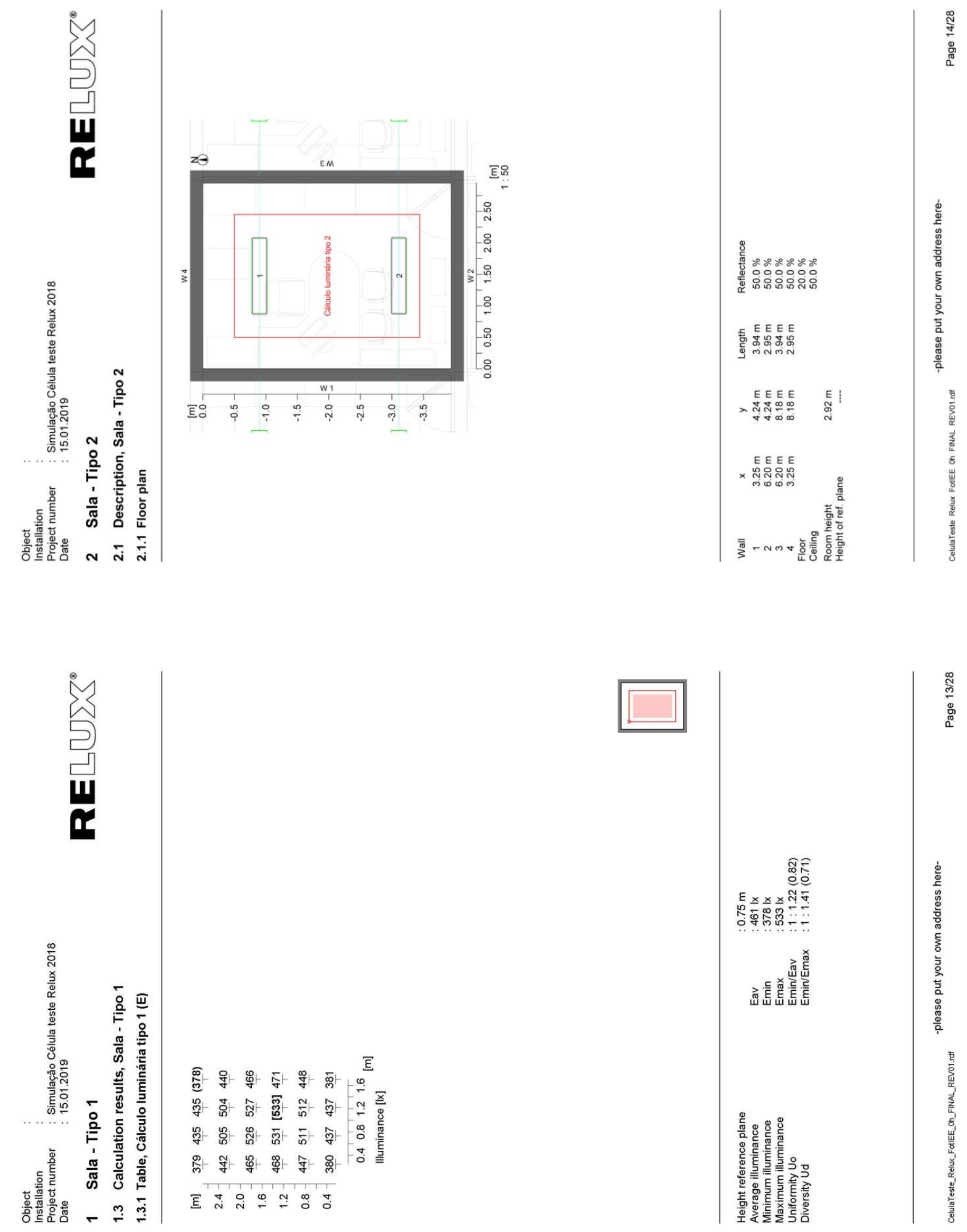

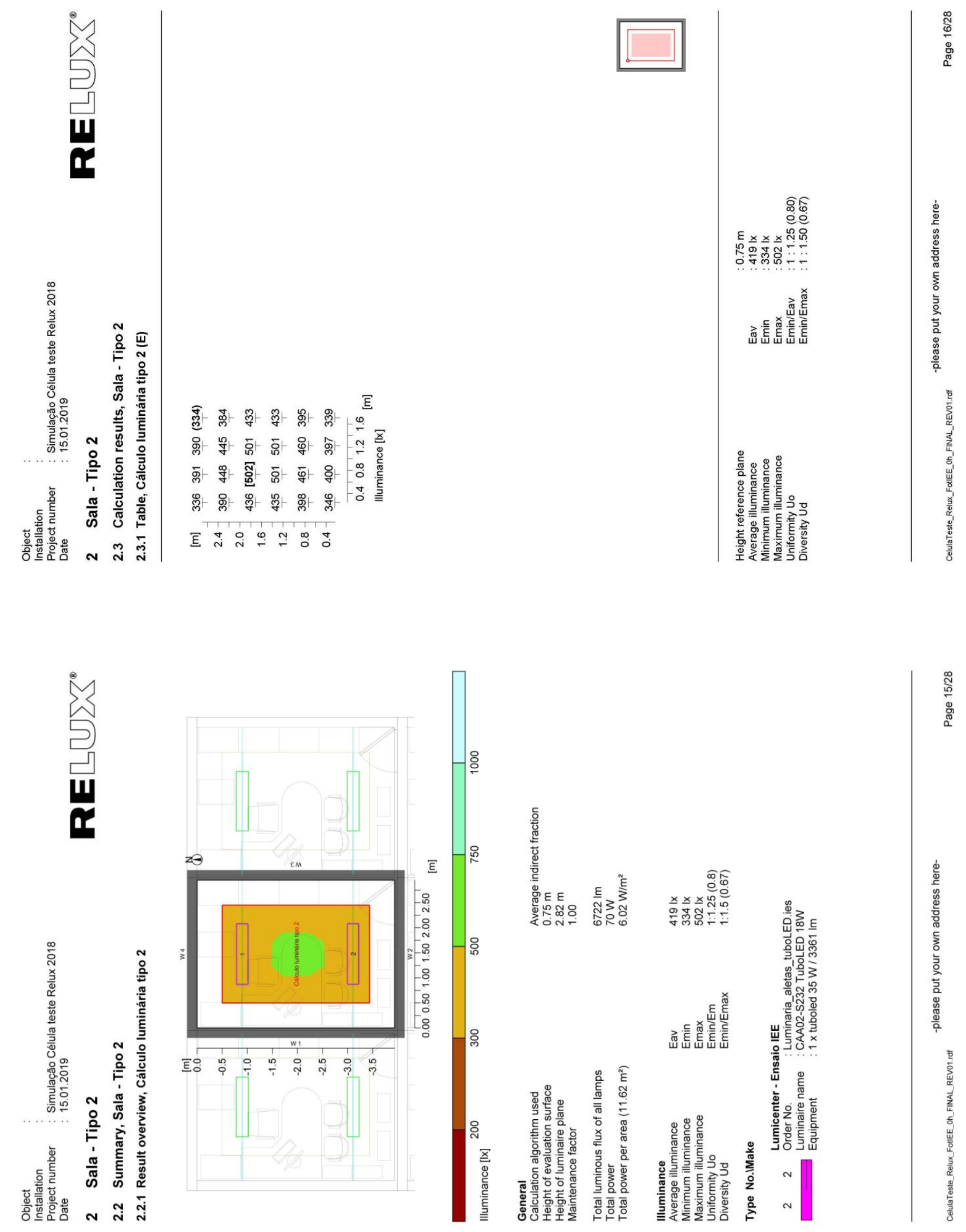

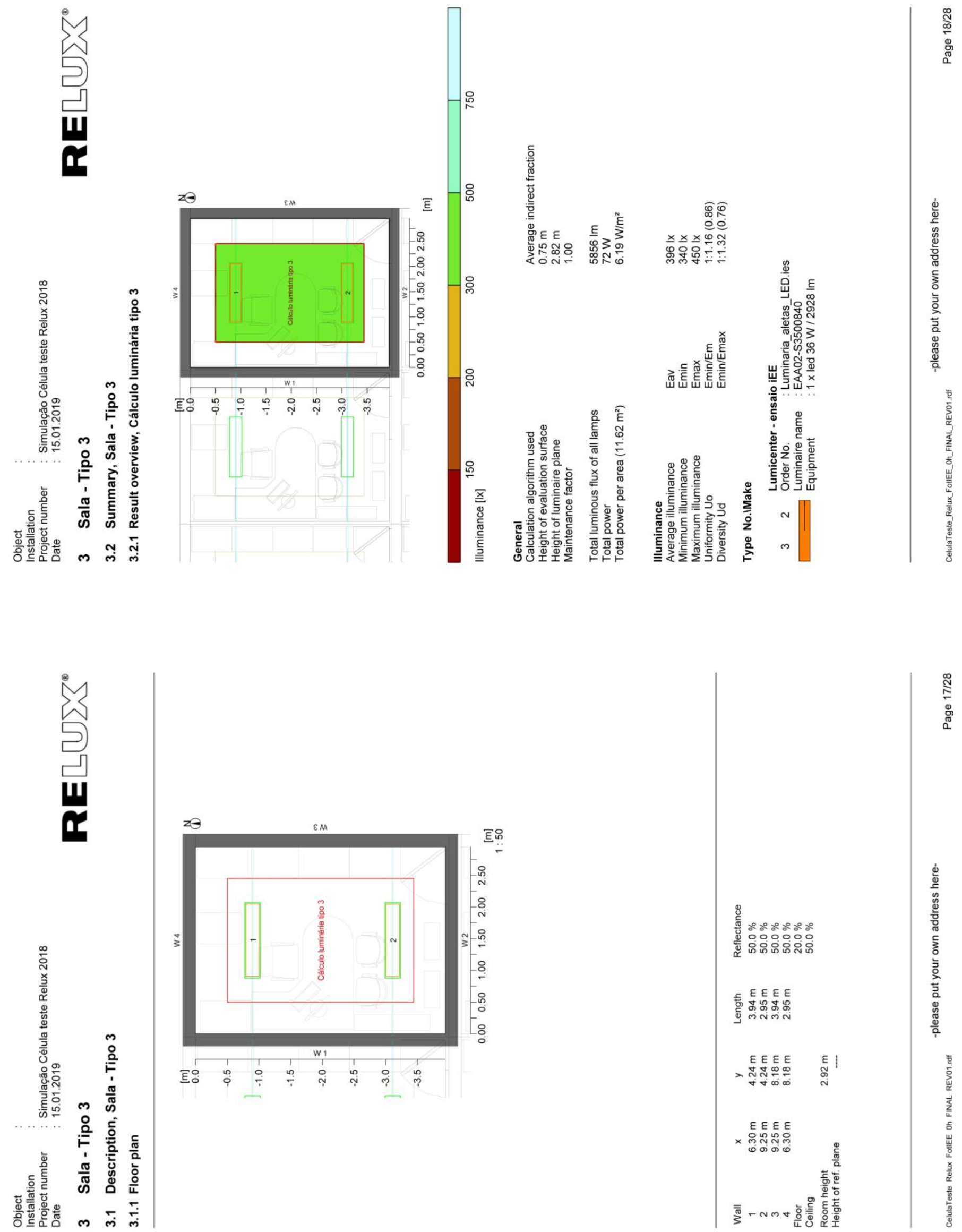

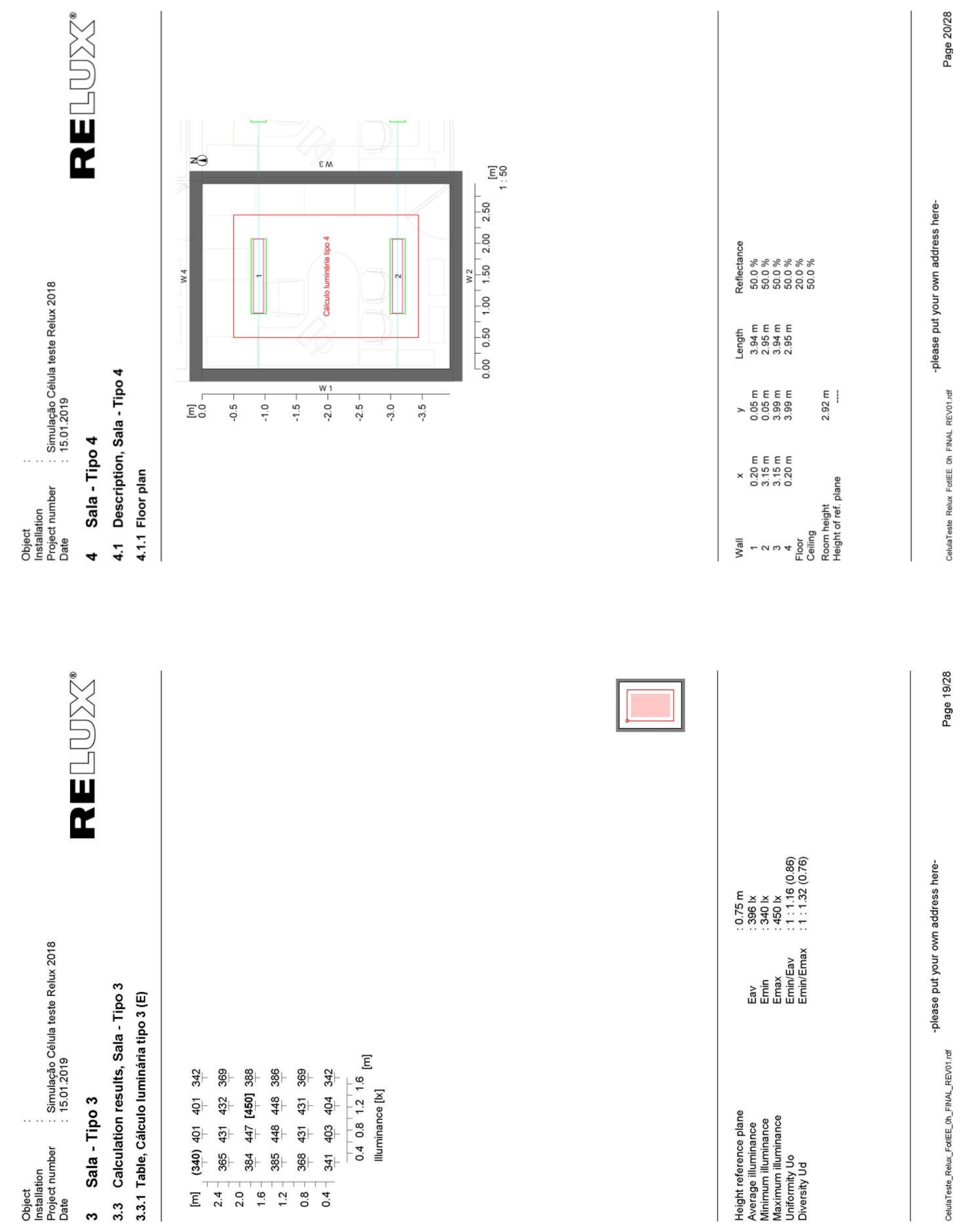

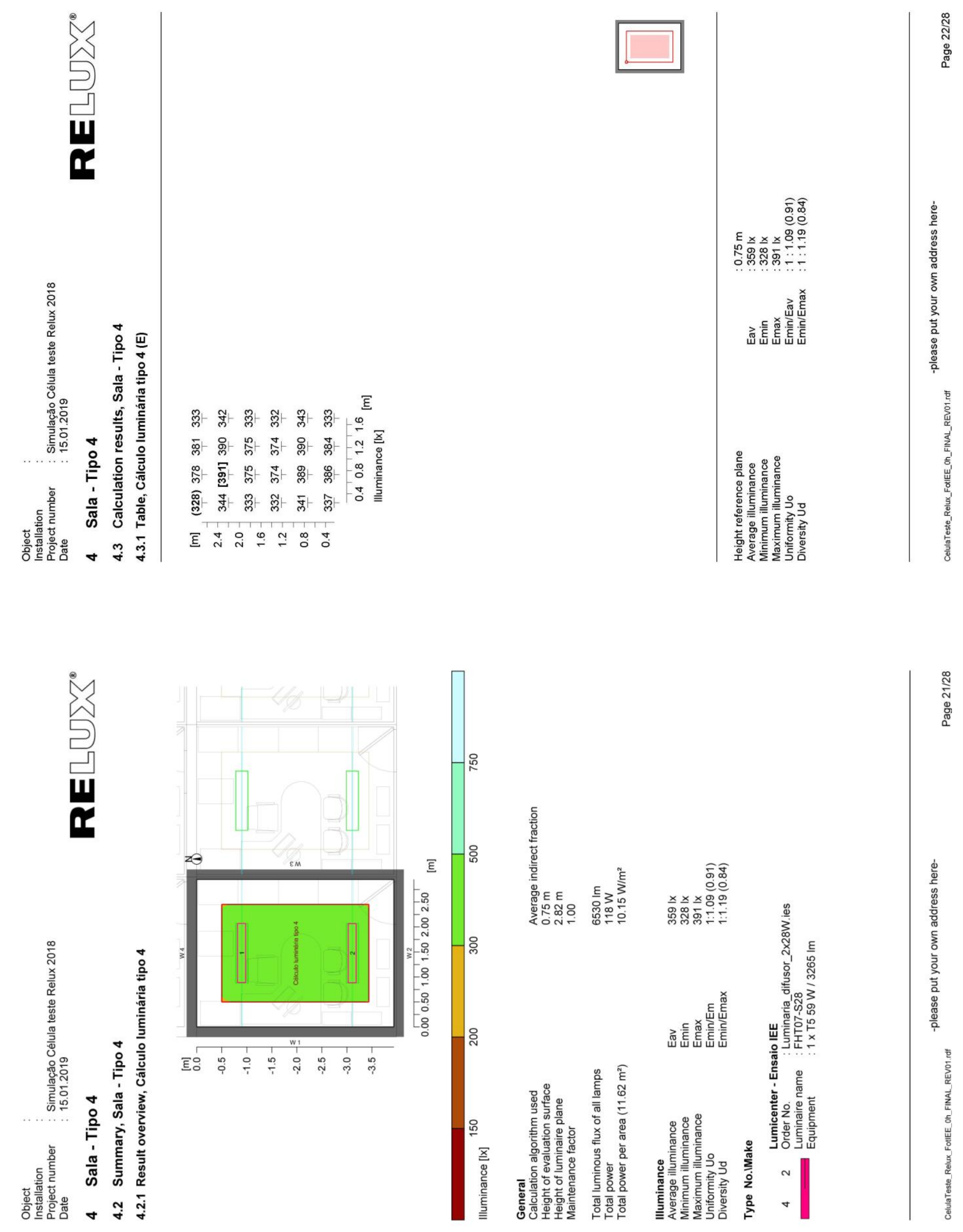

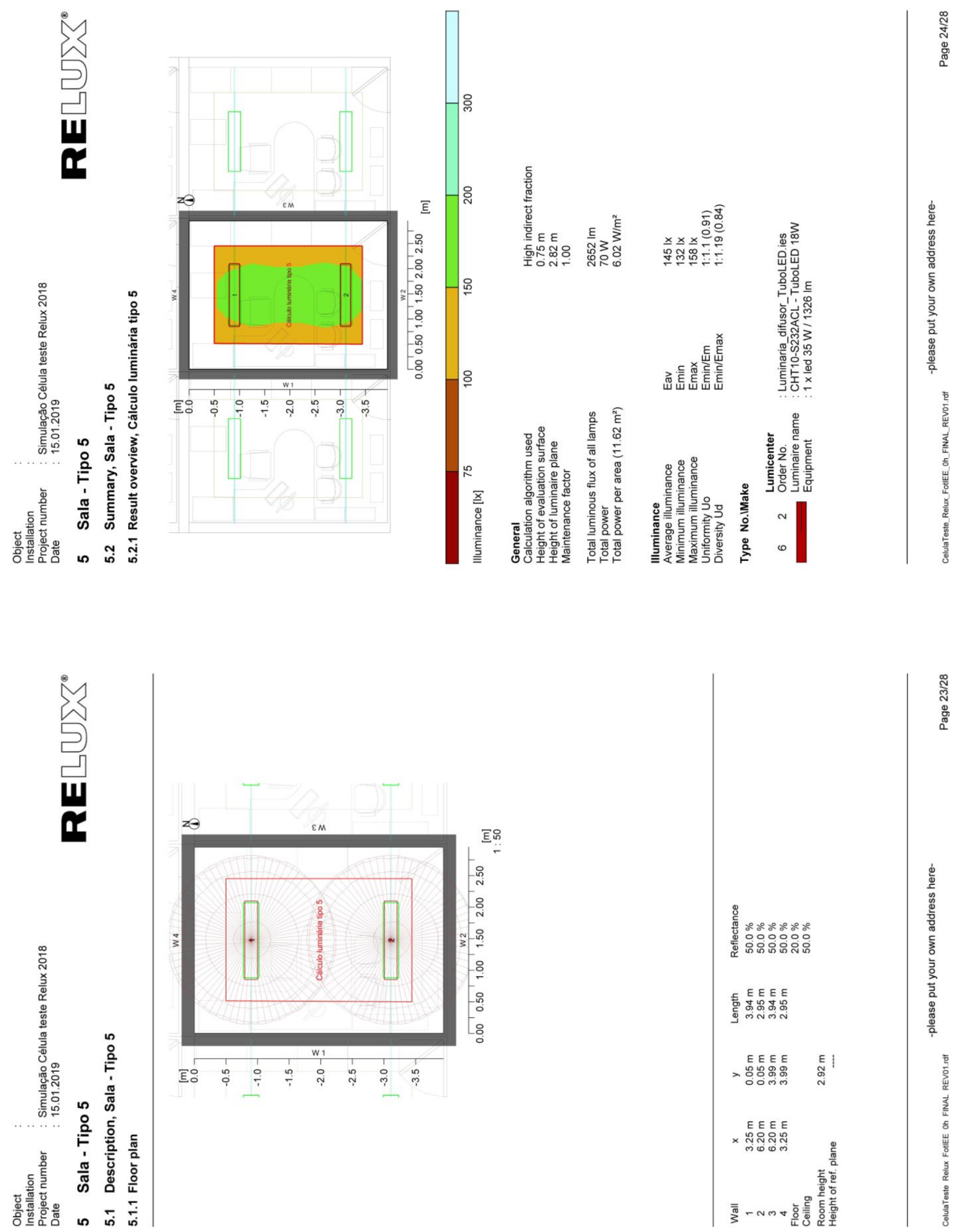

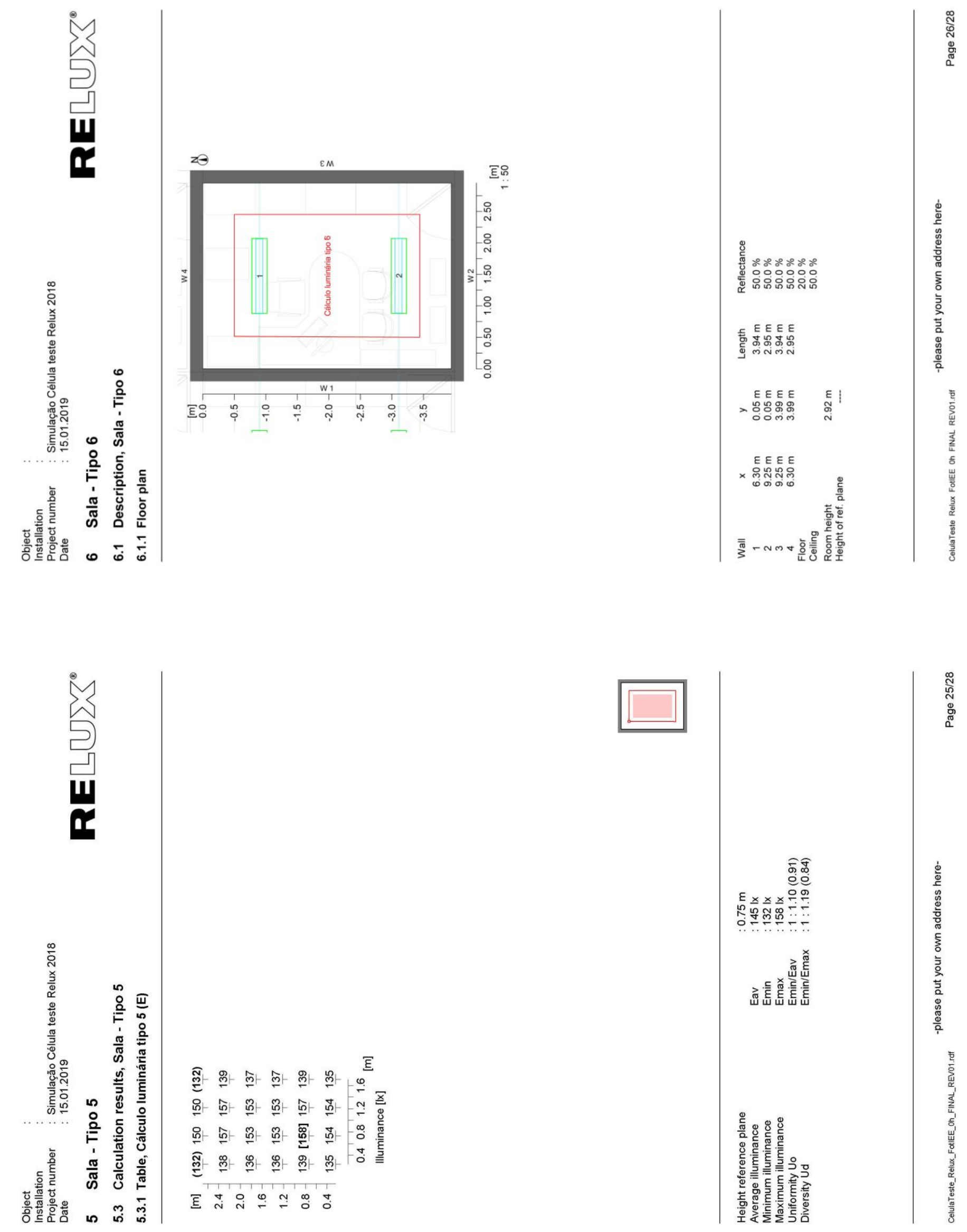

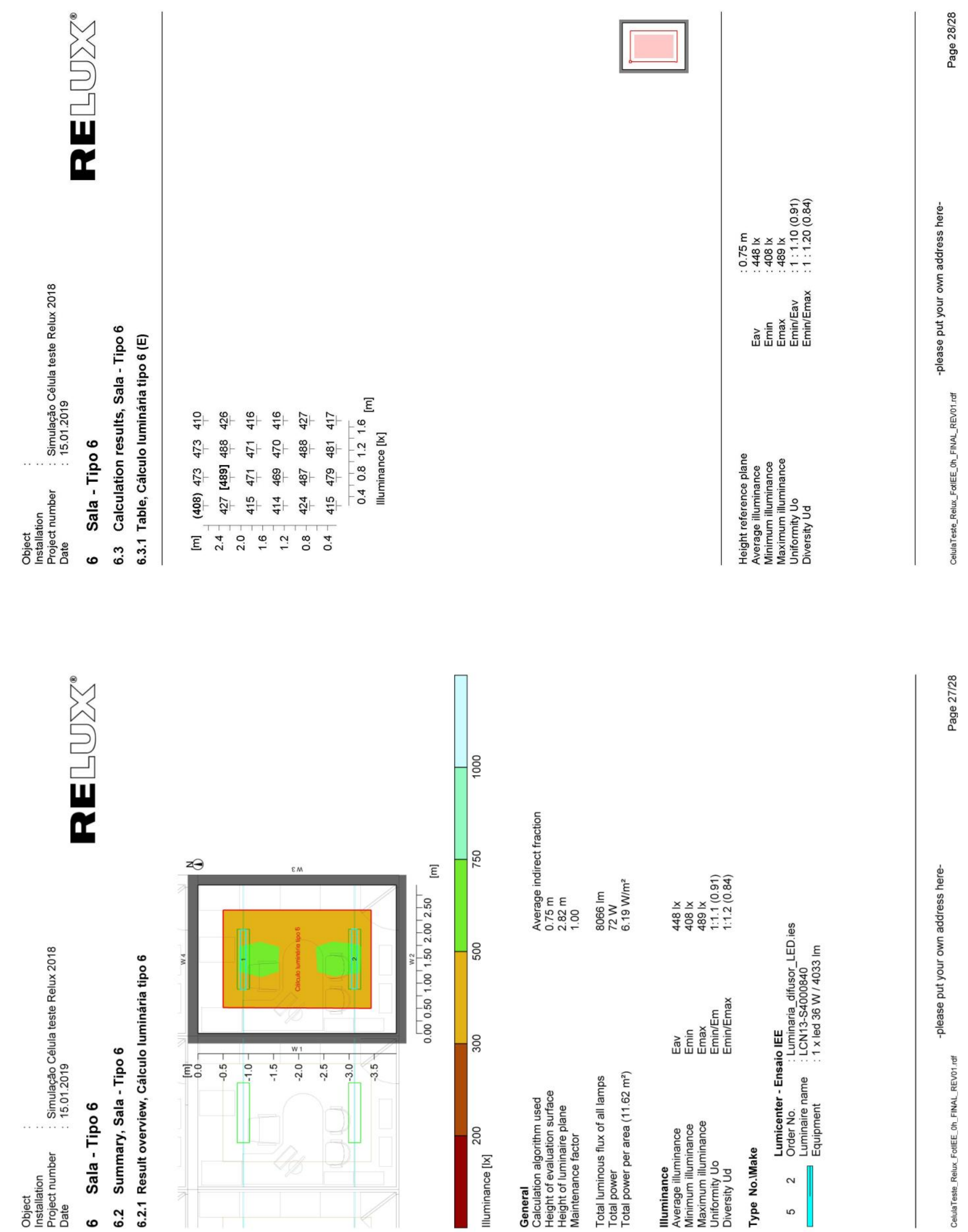

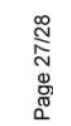

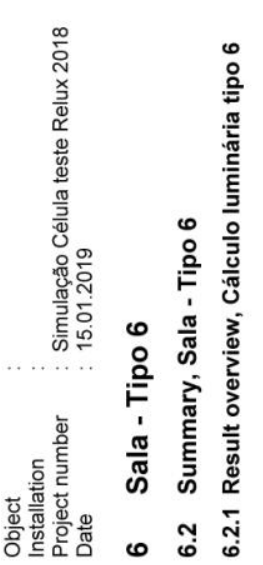




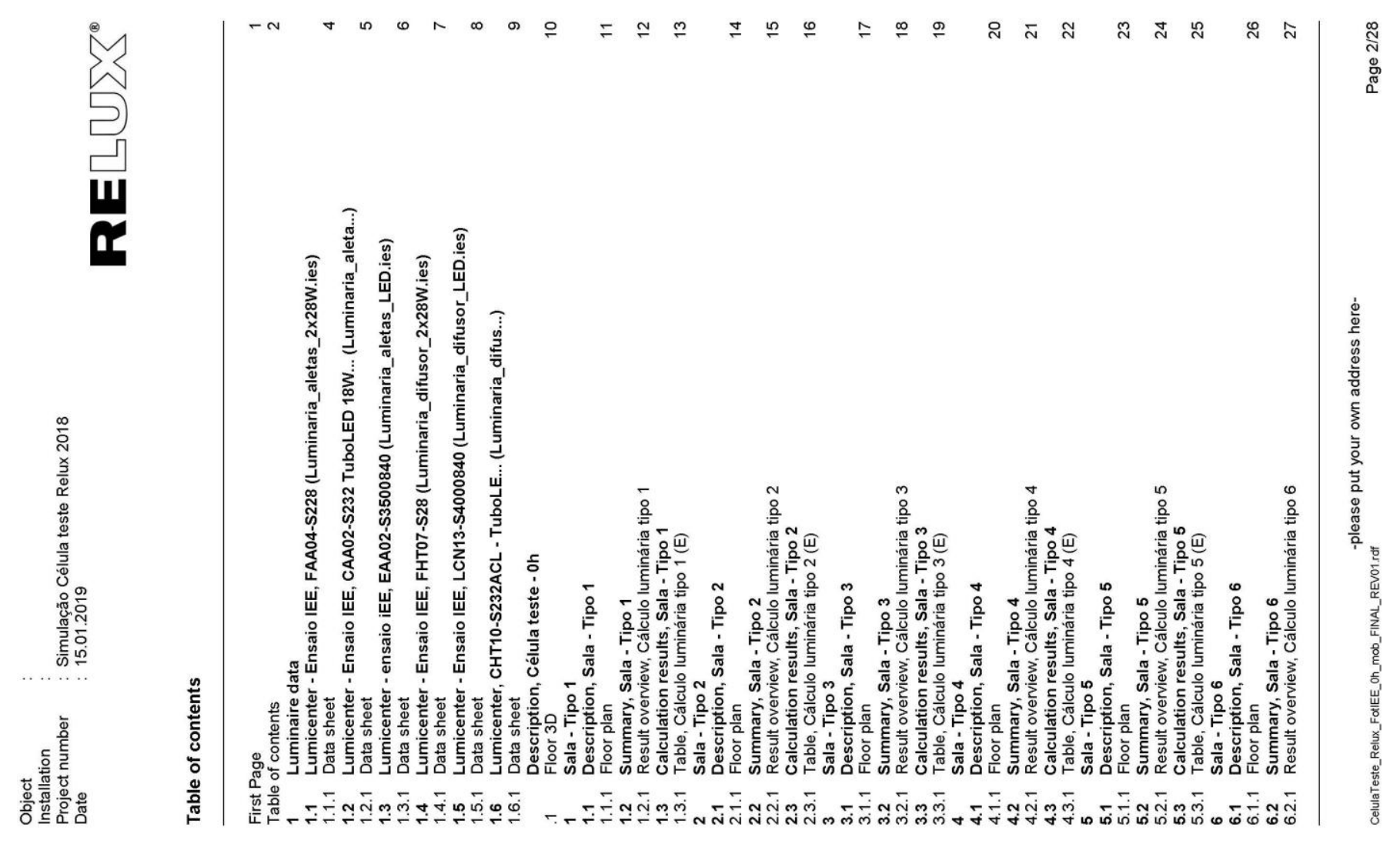

岕

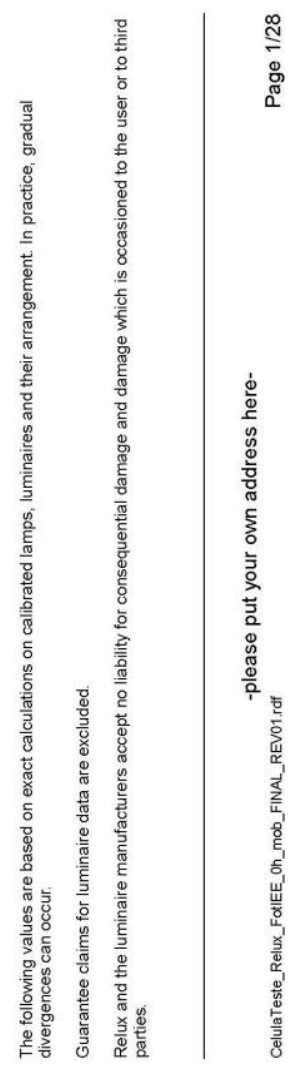



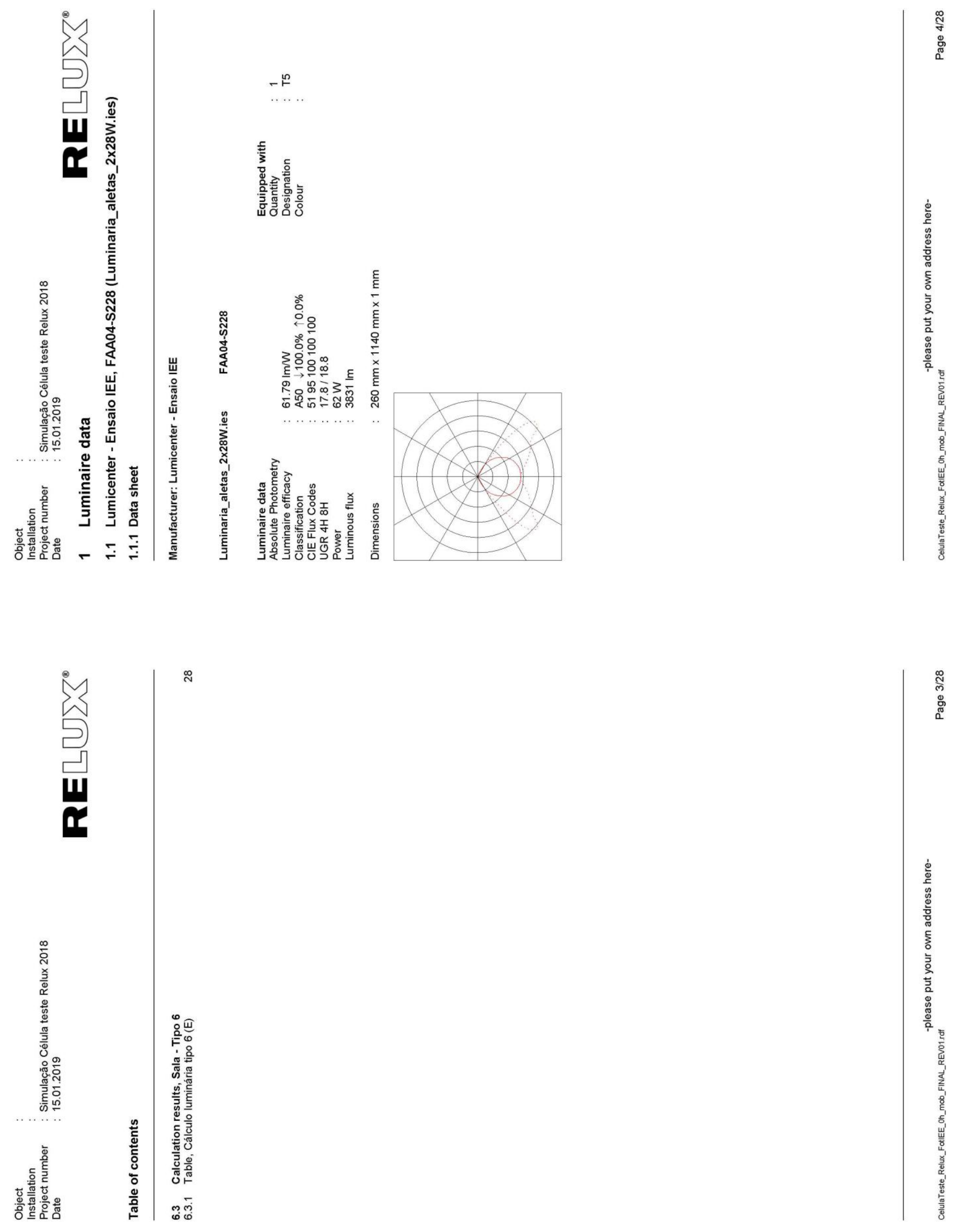

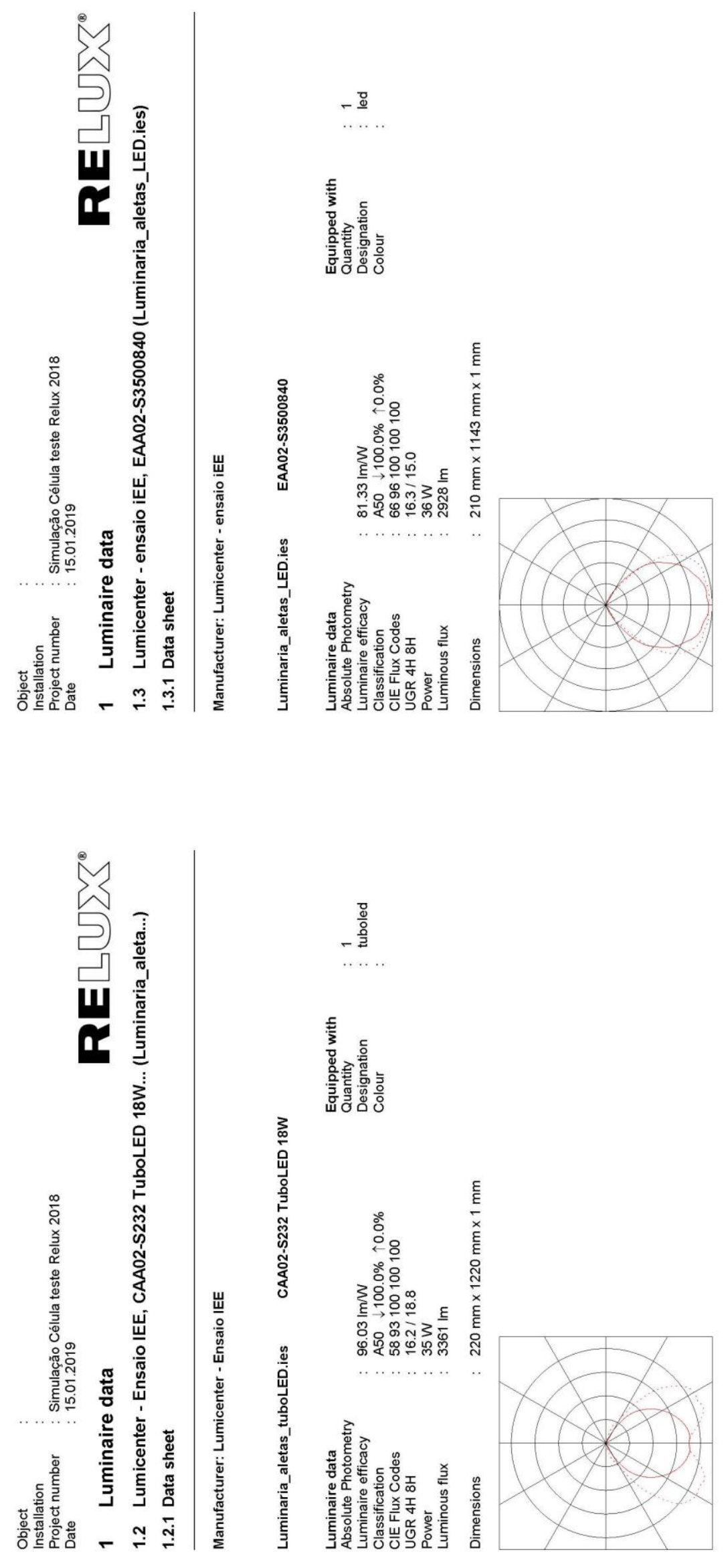

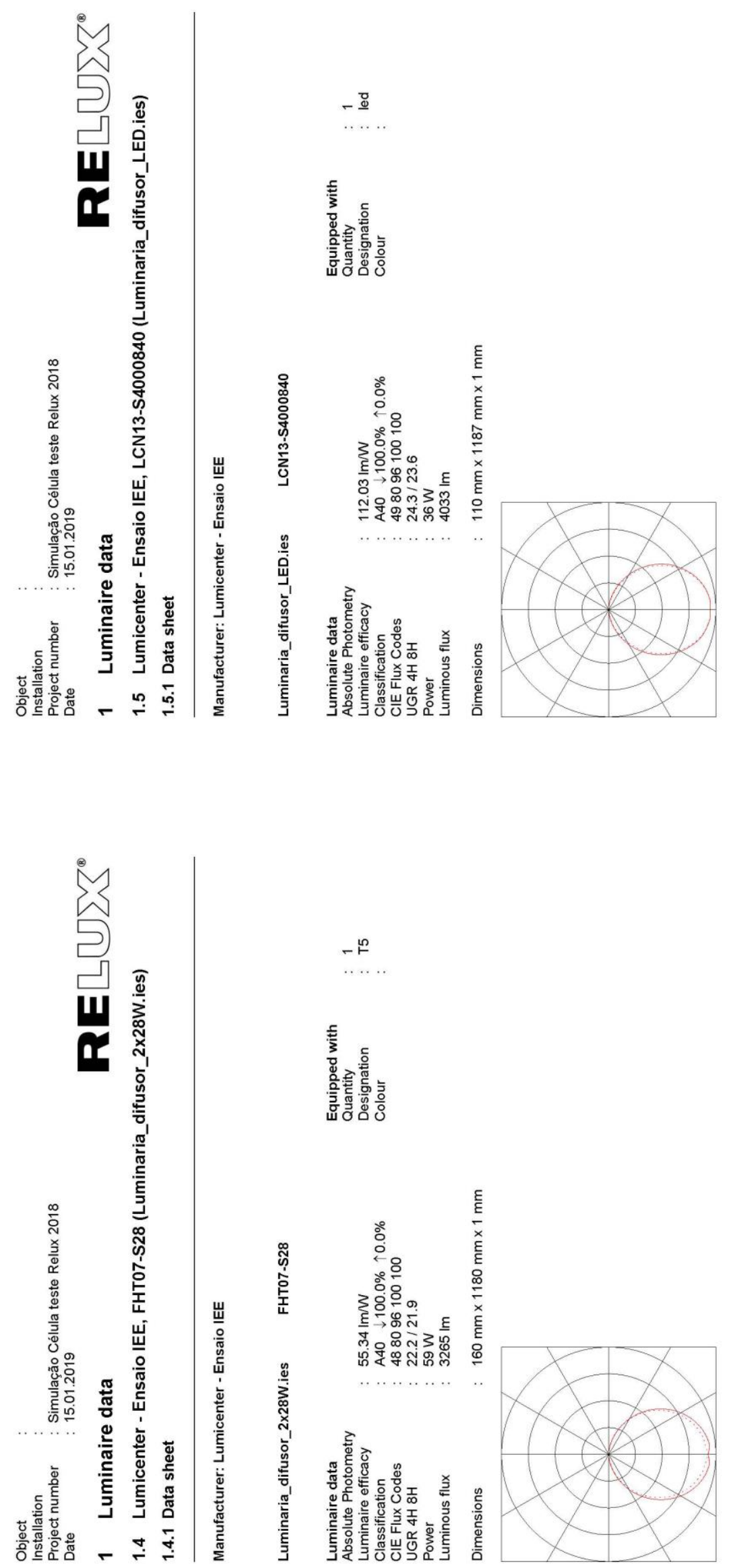

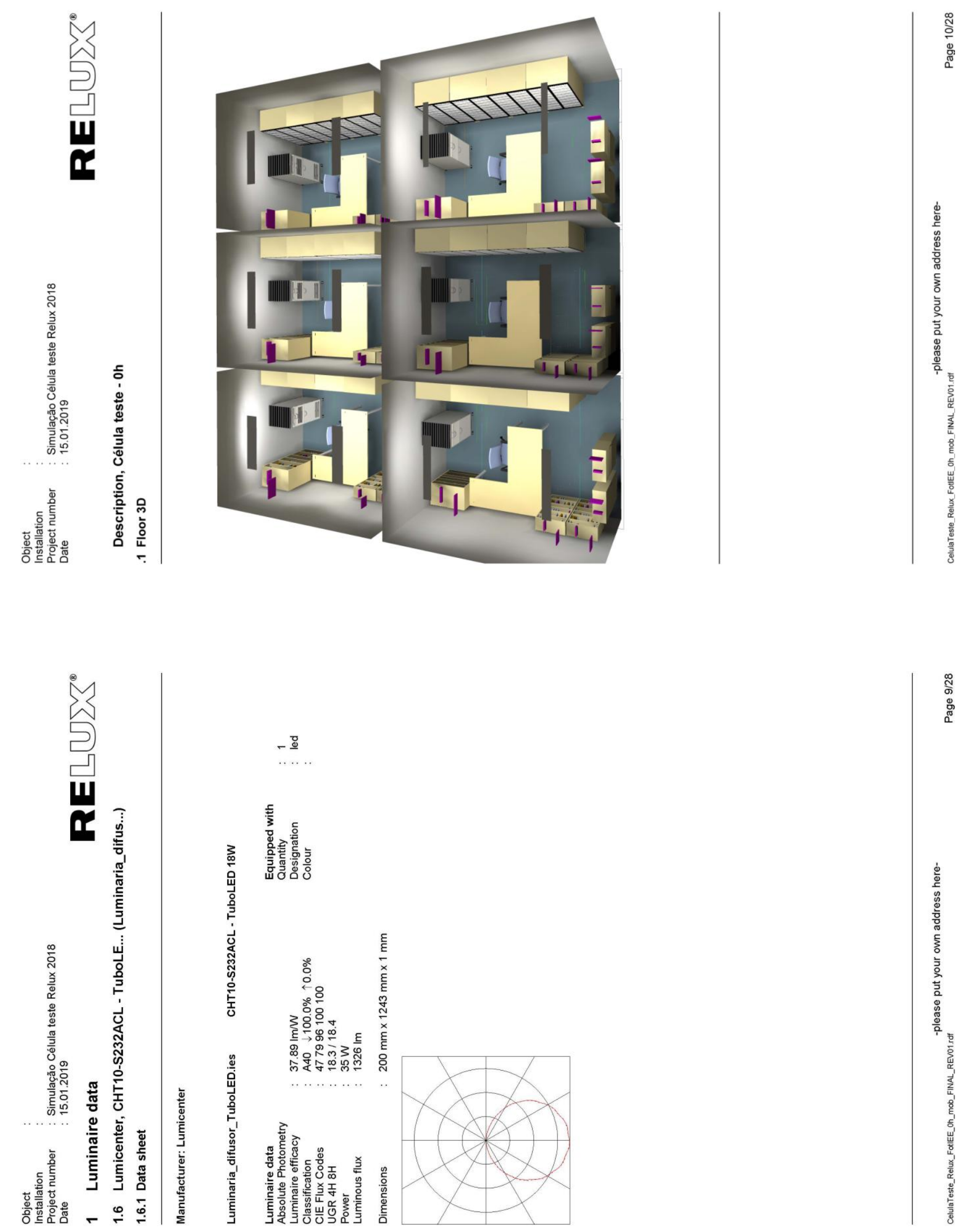

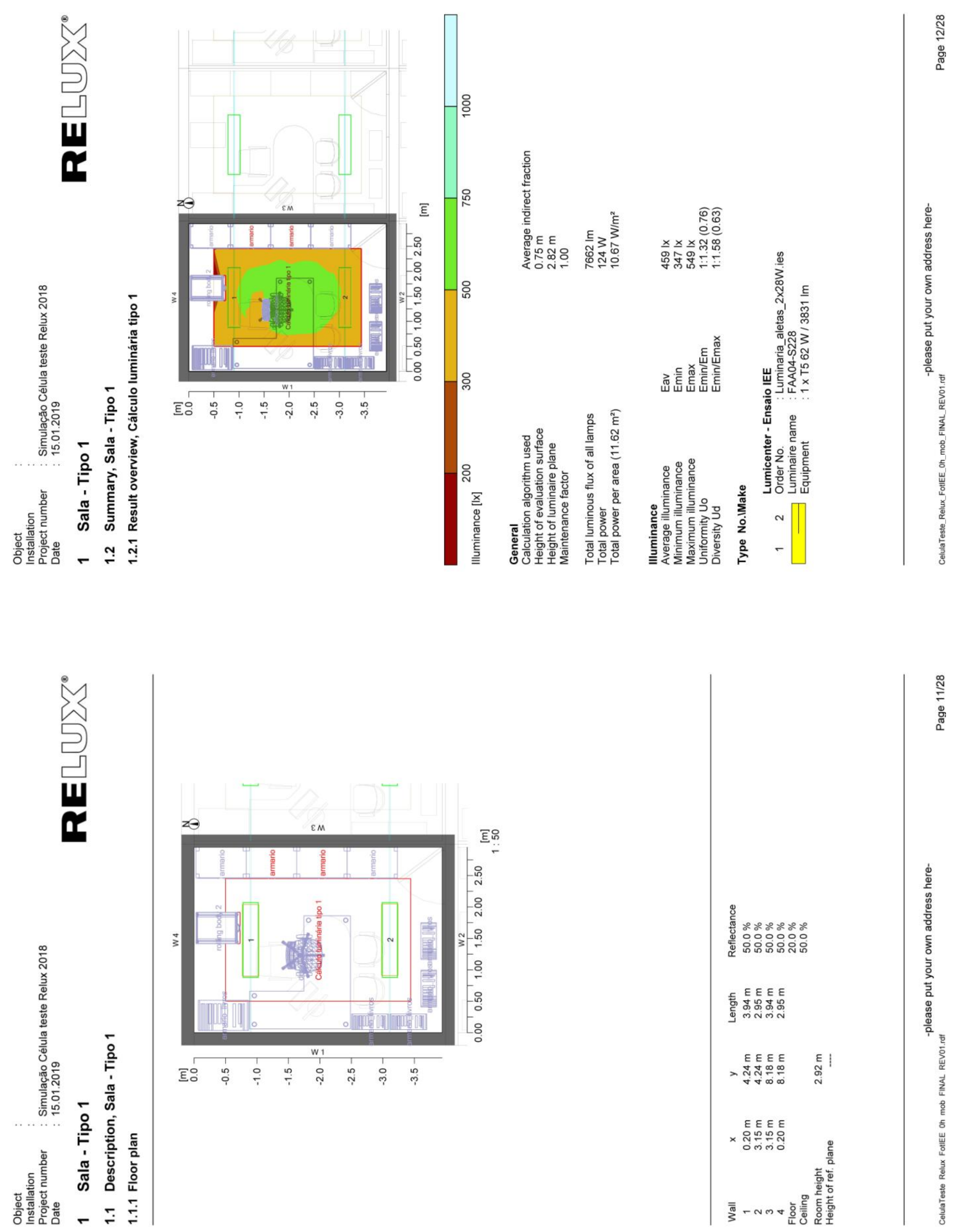

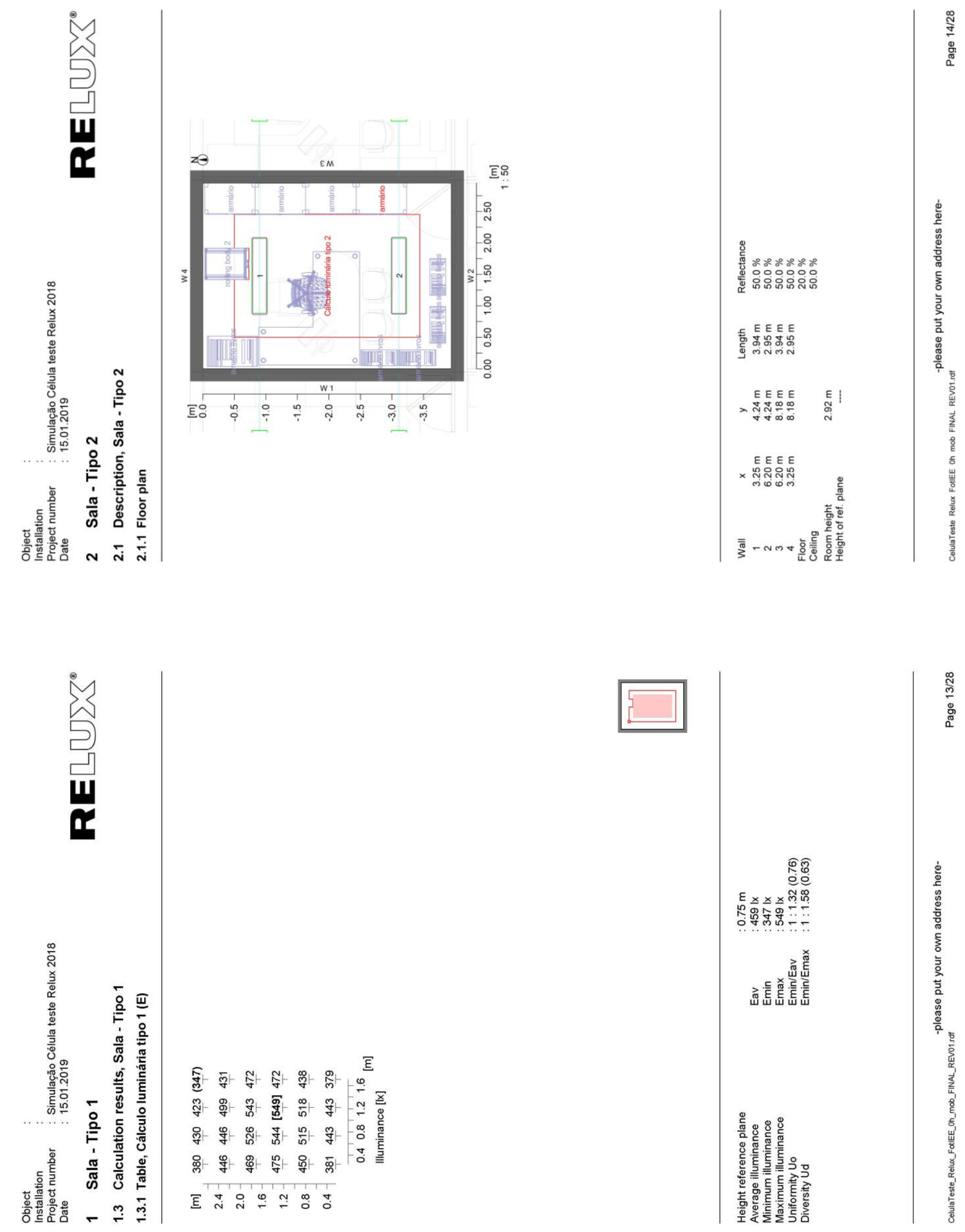

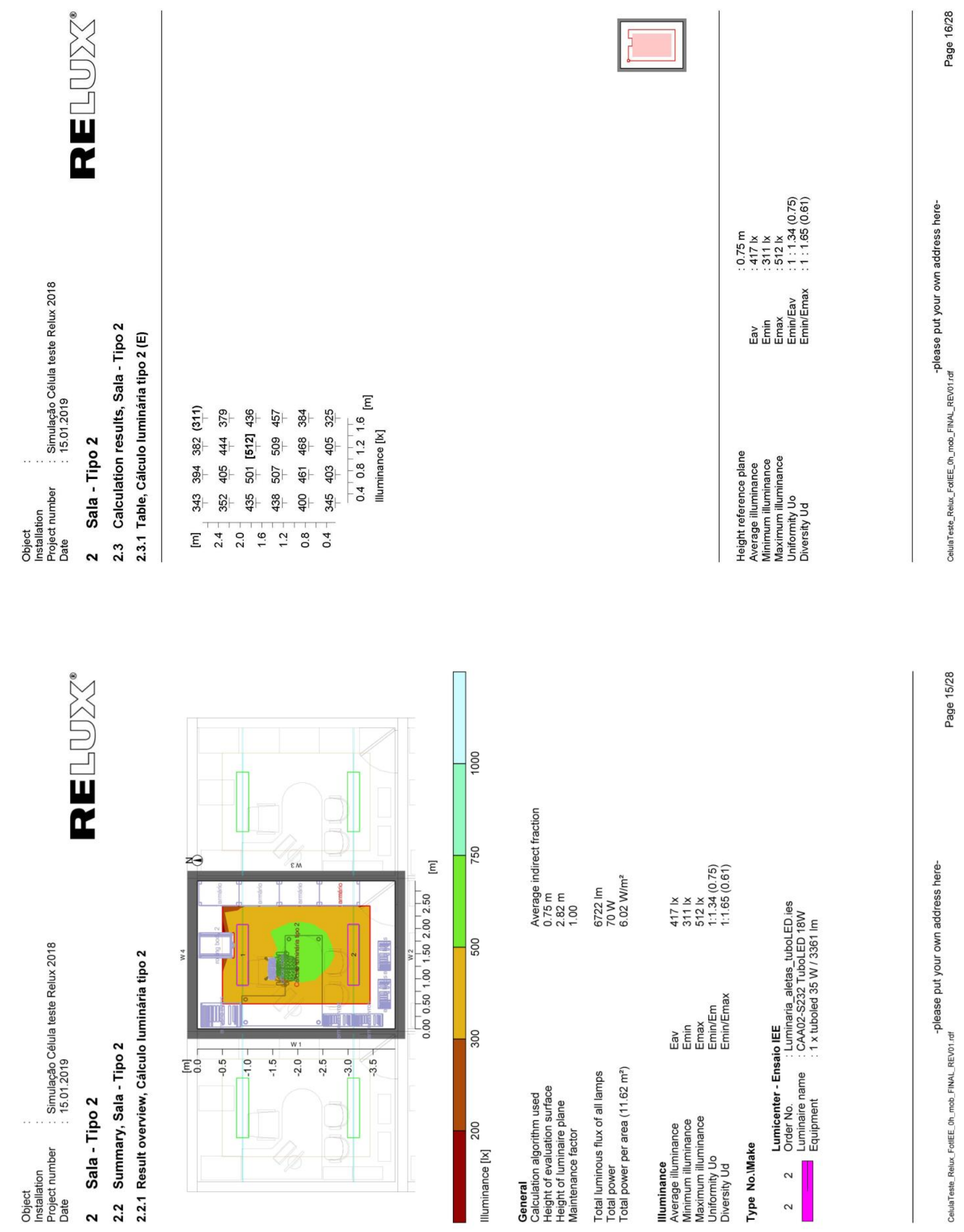

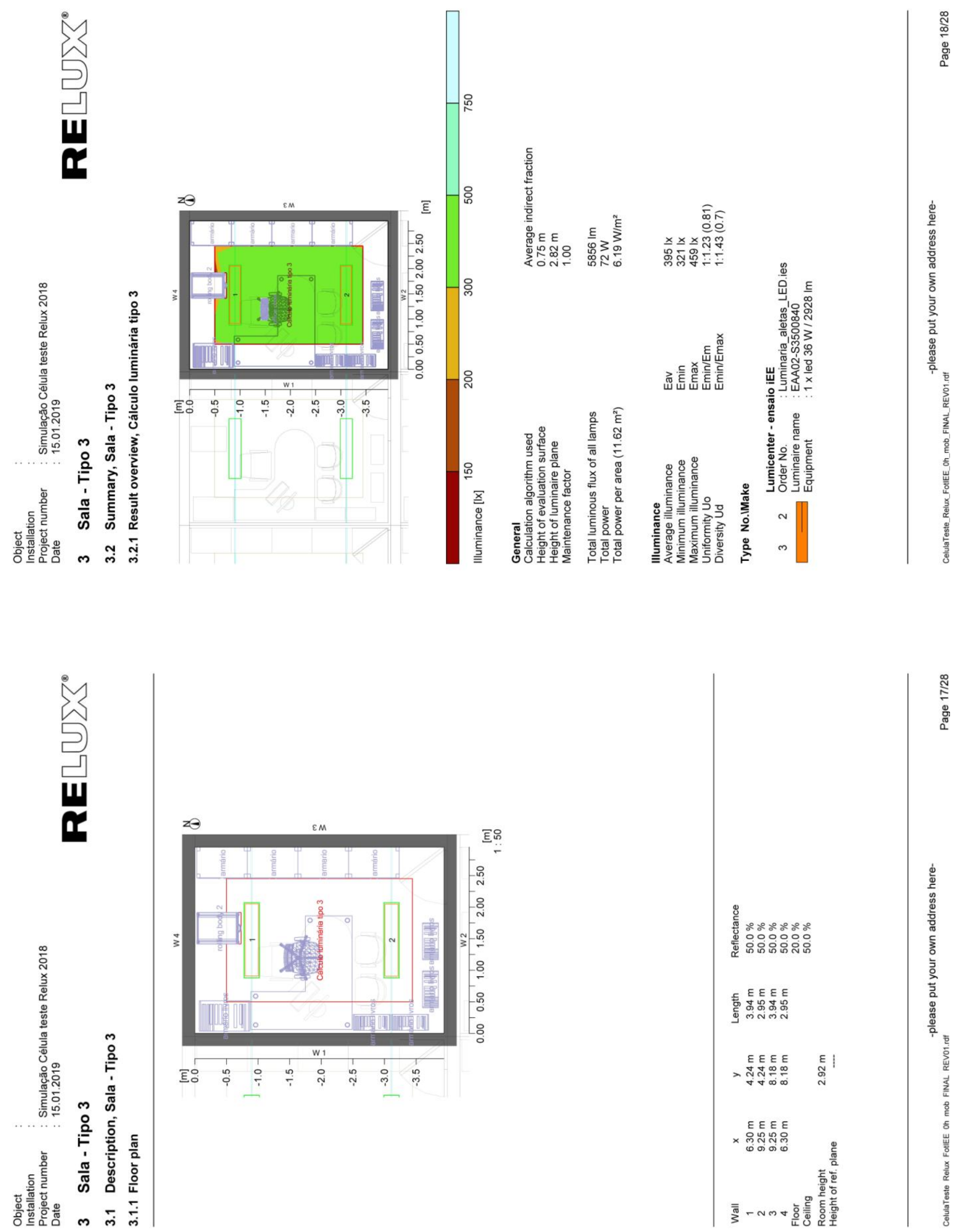

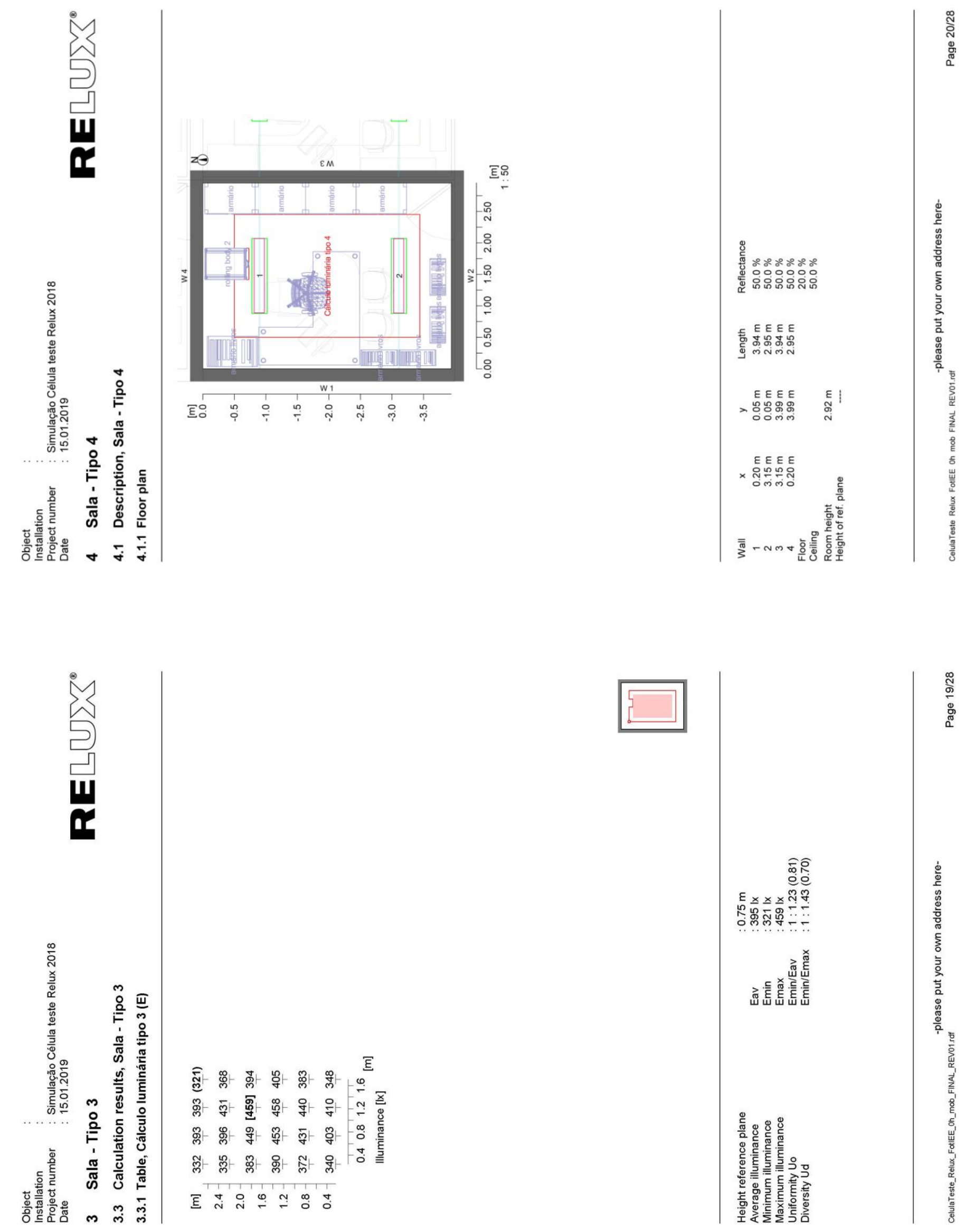

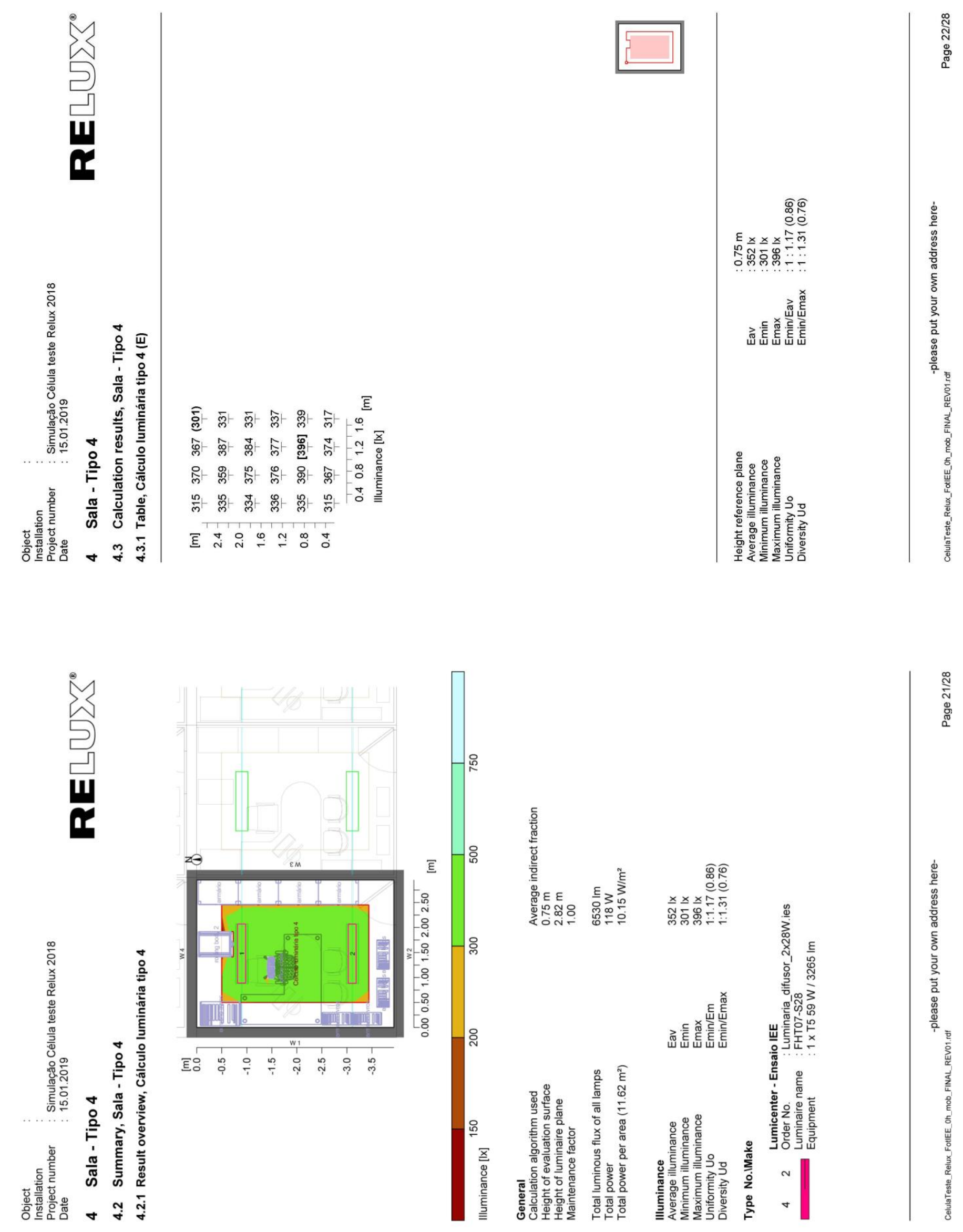

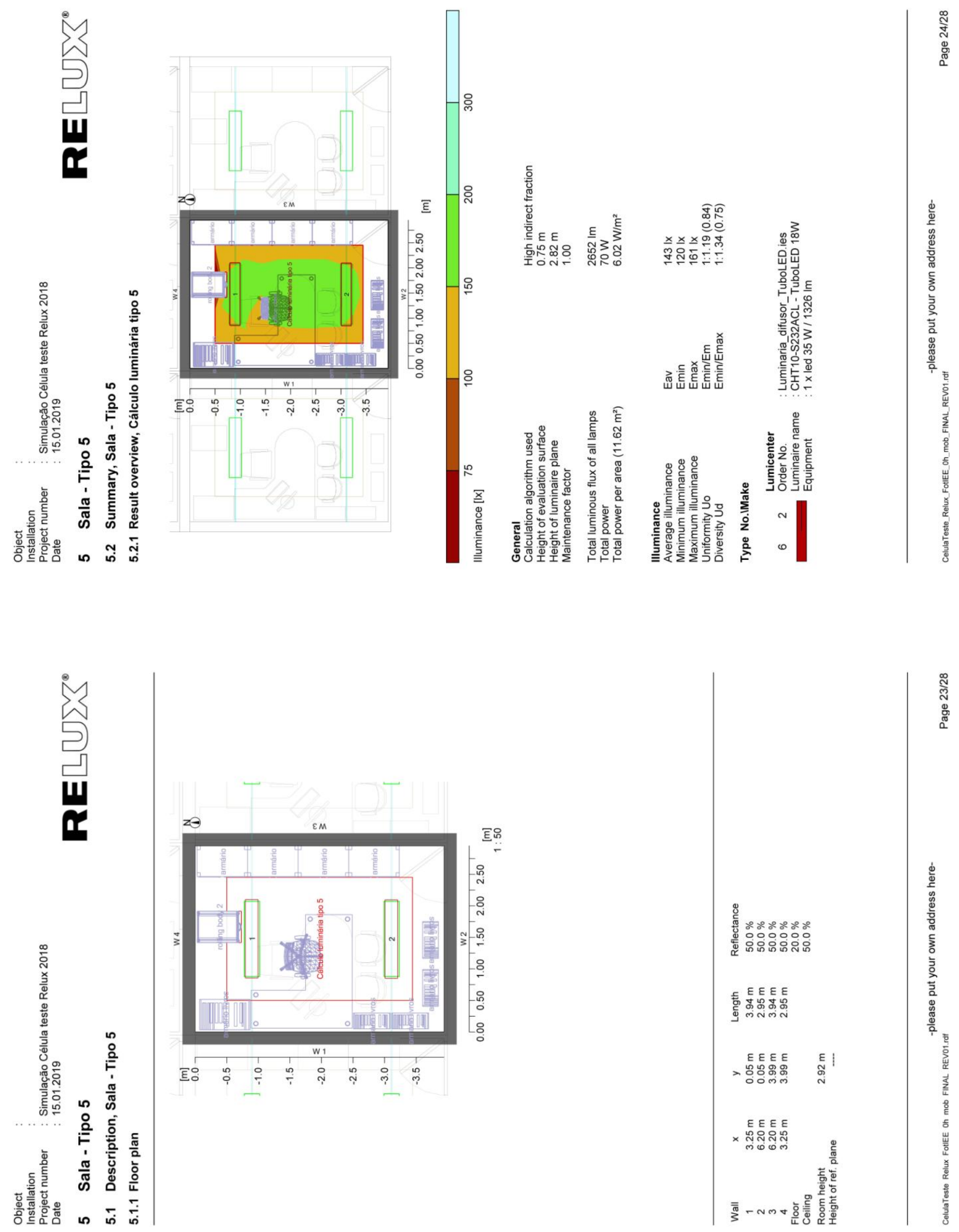

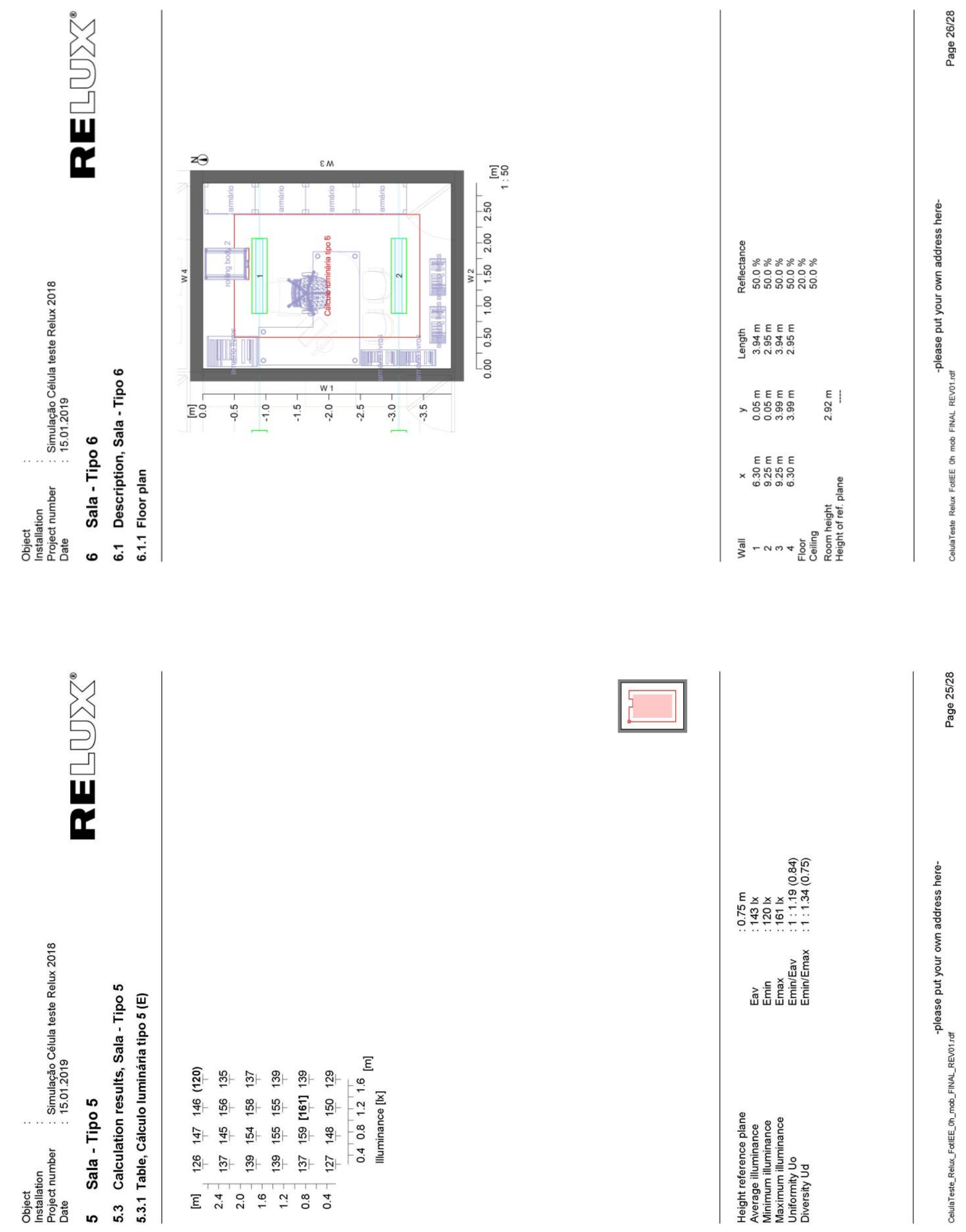

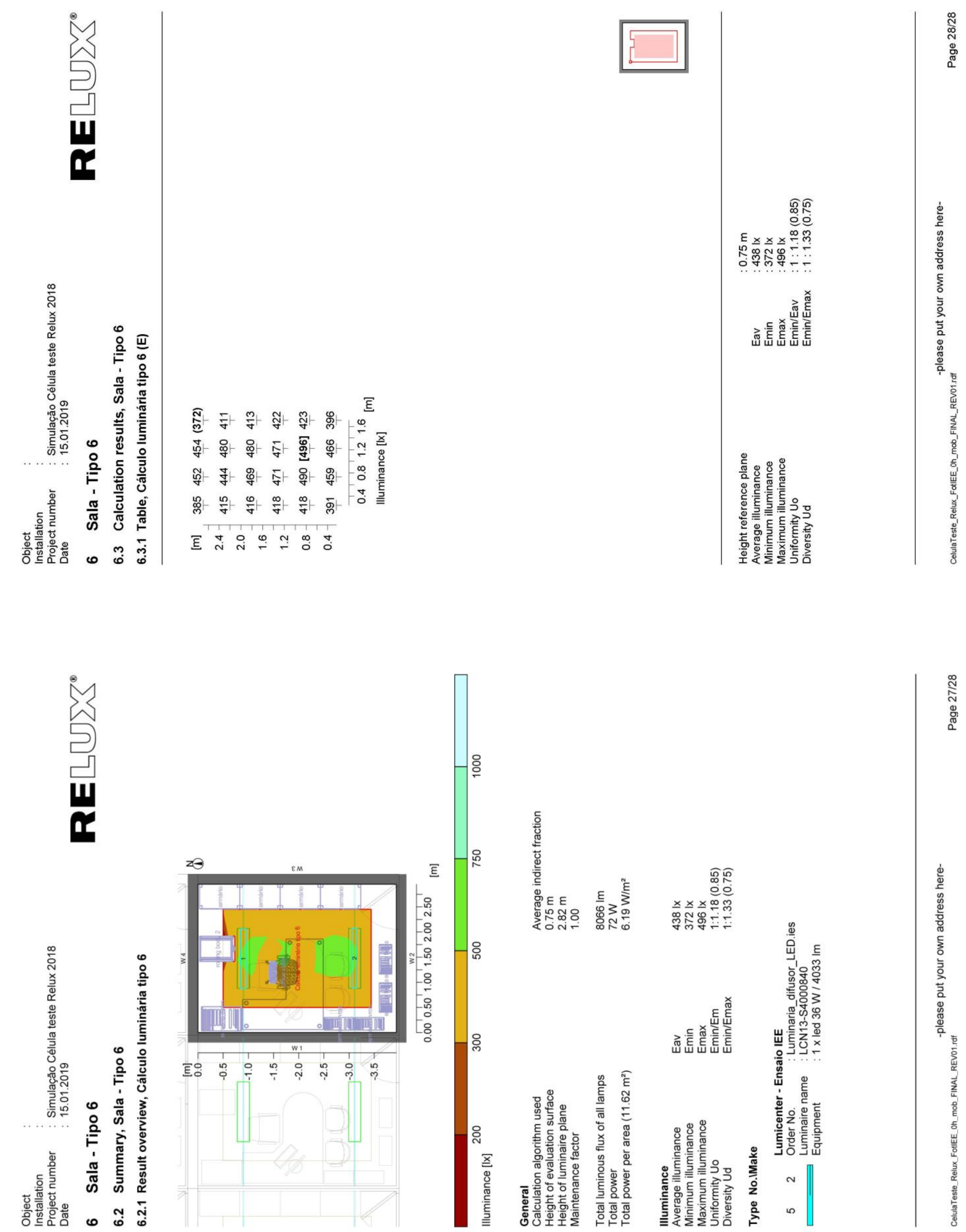

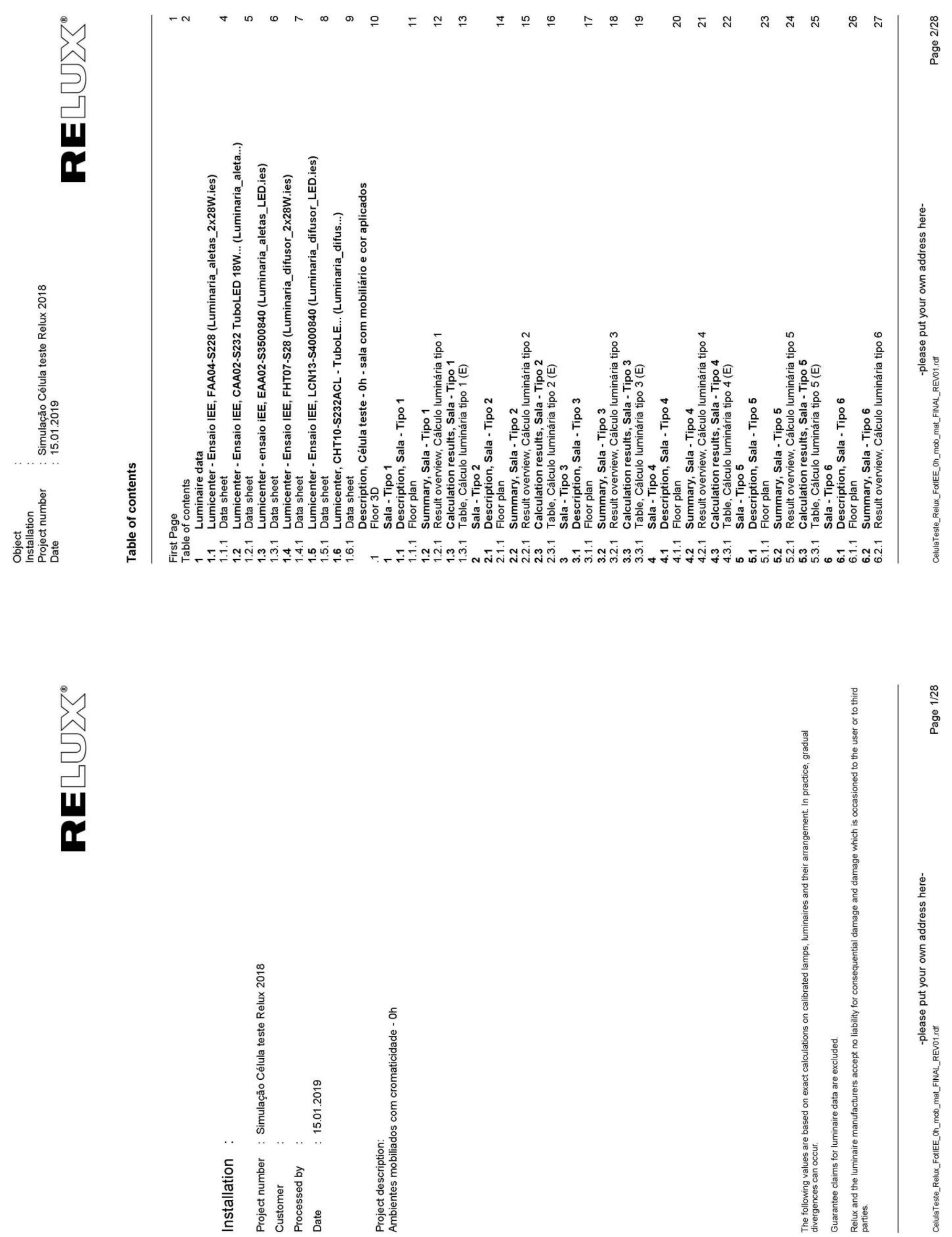

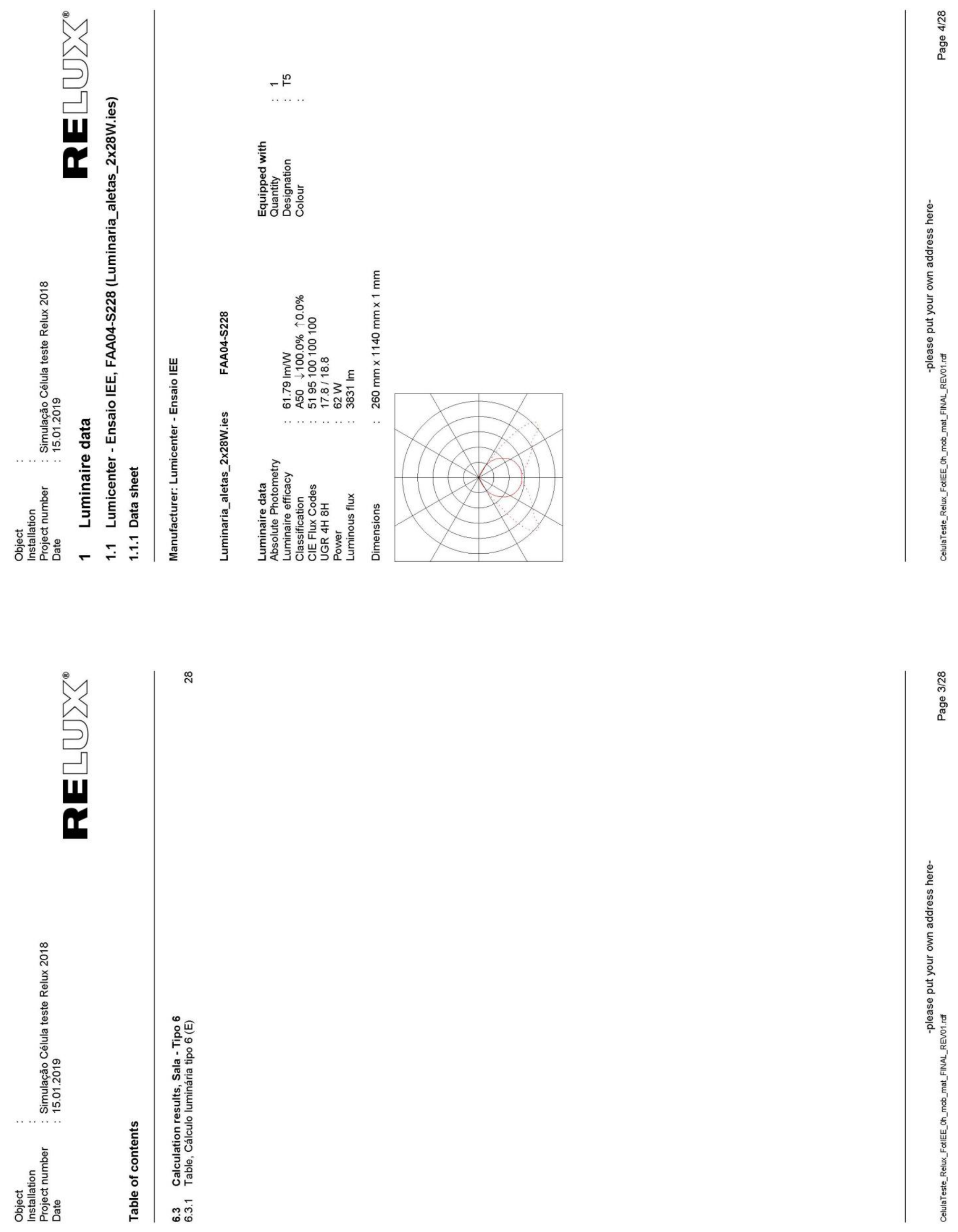

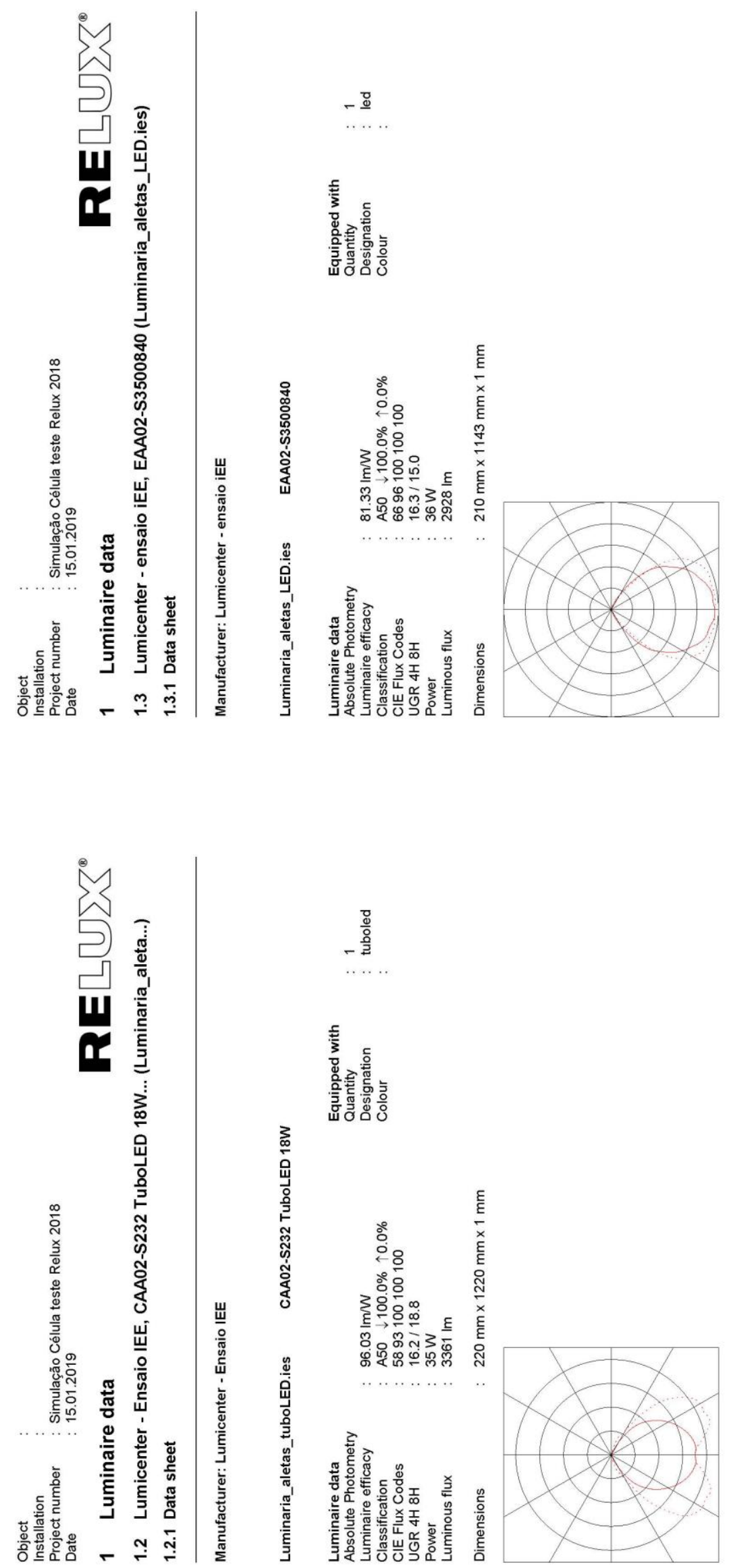

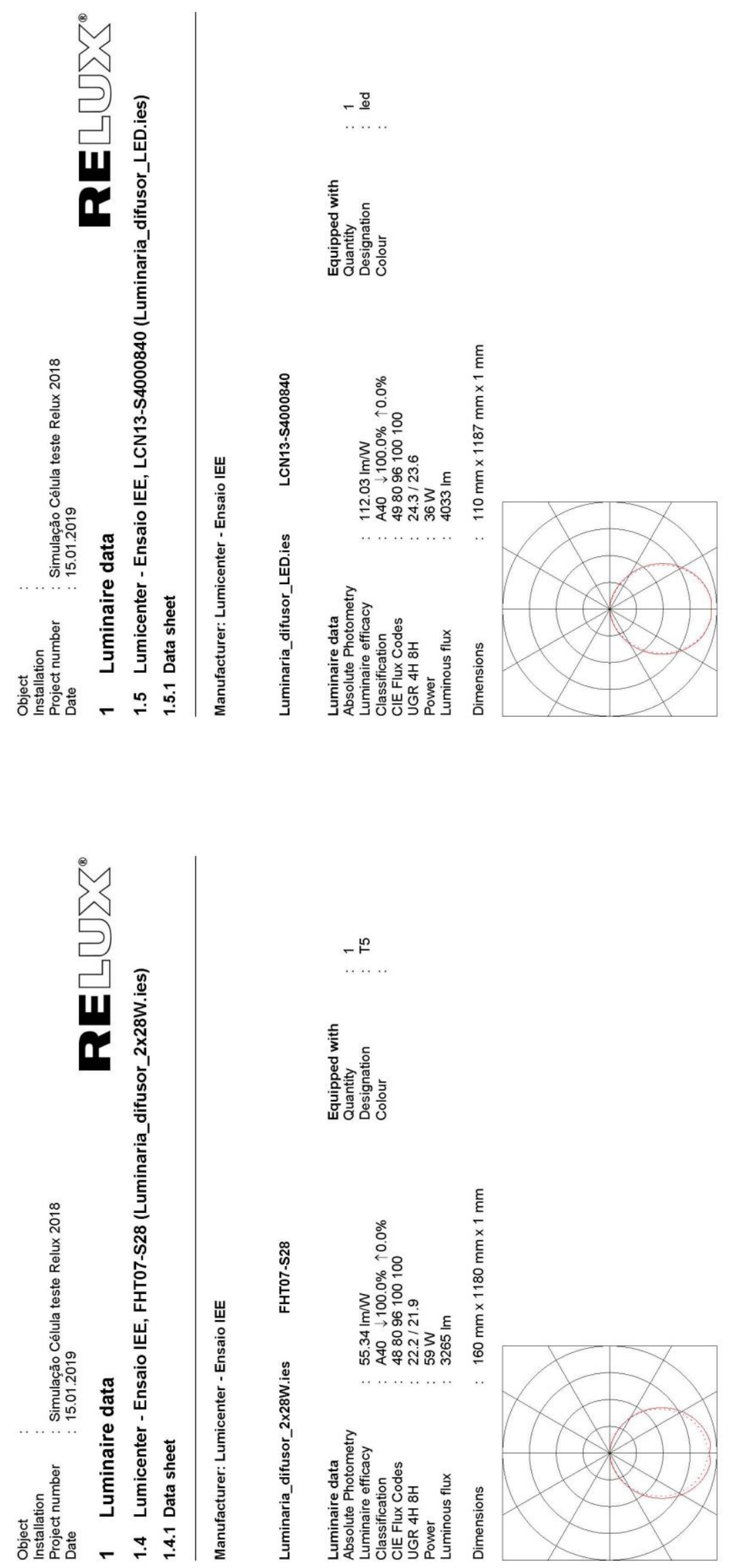

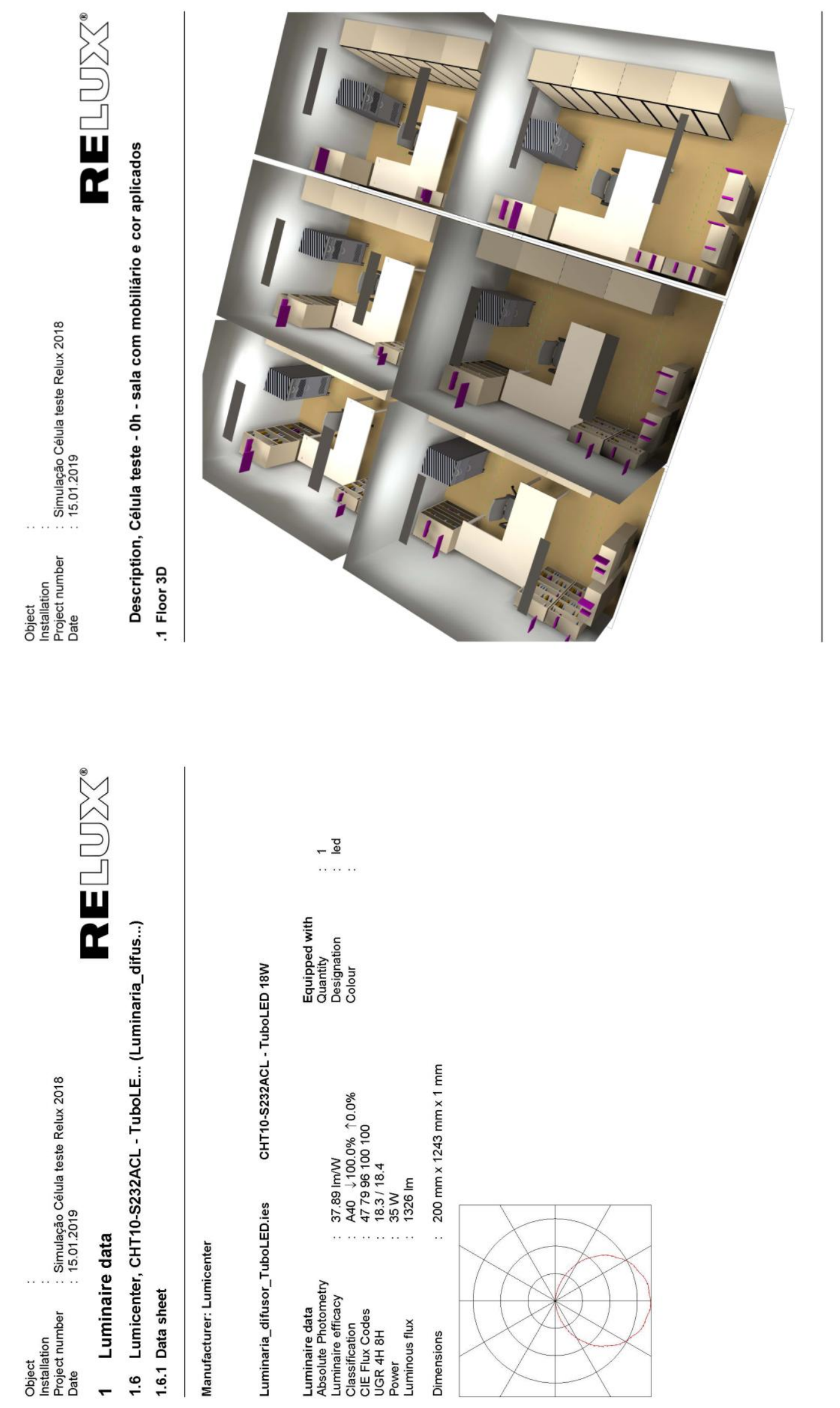

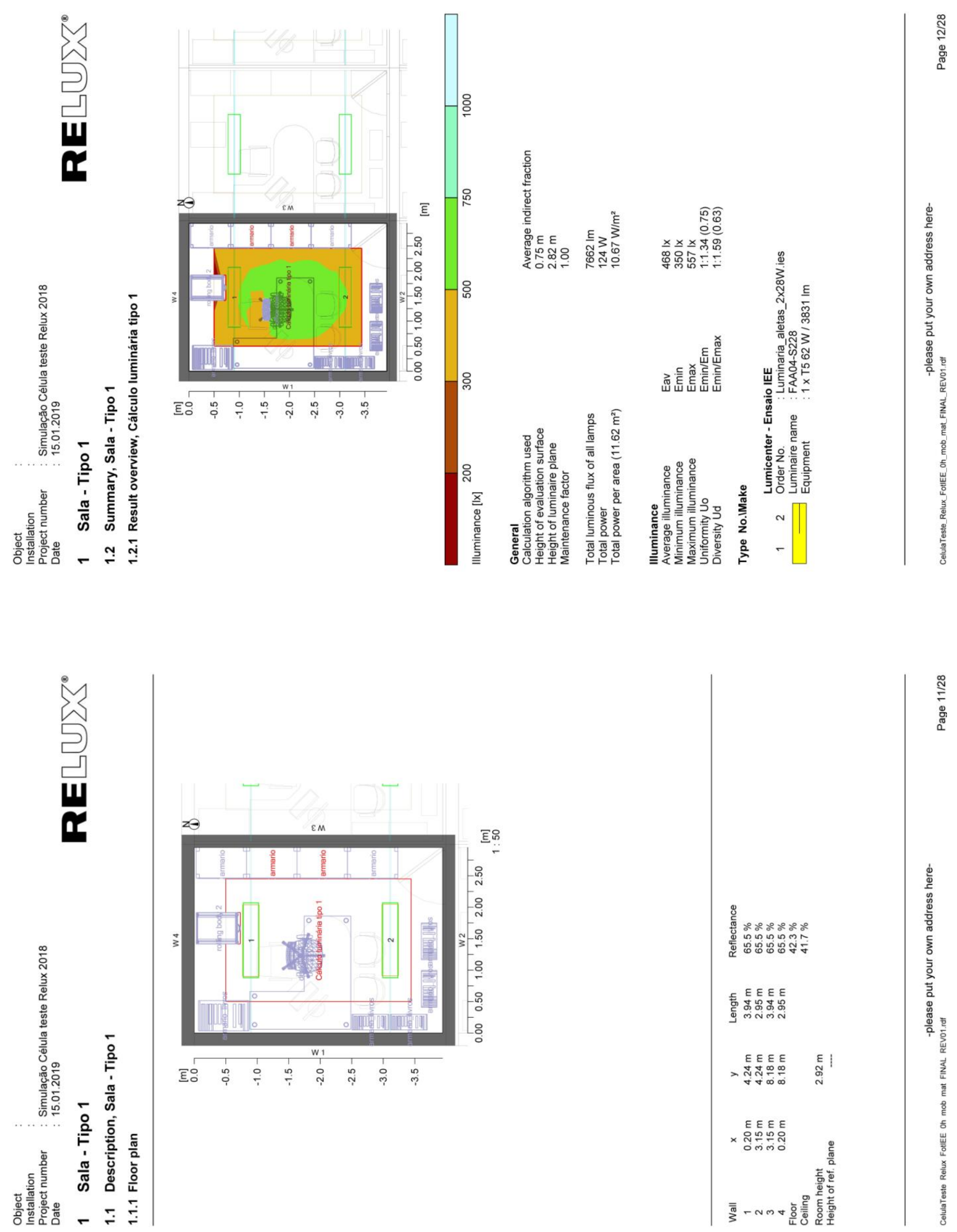

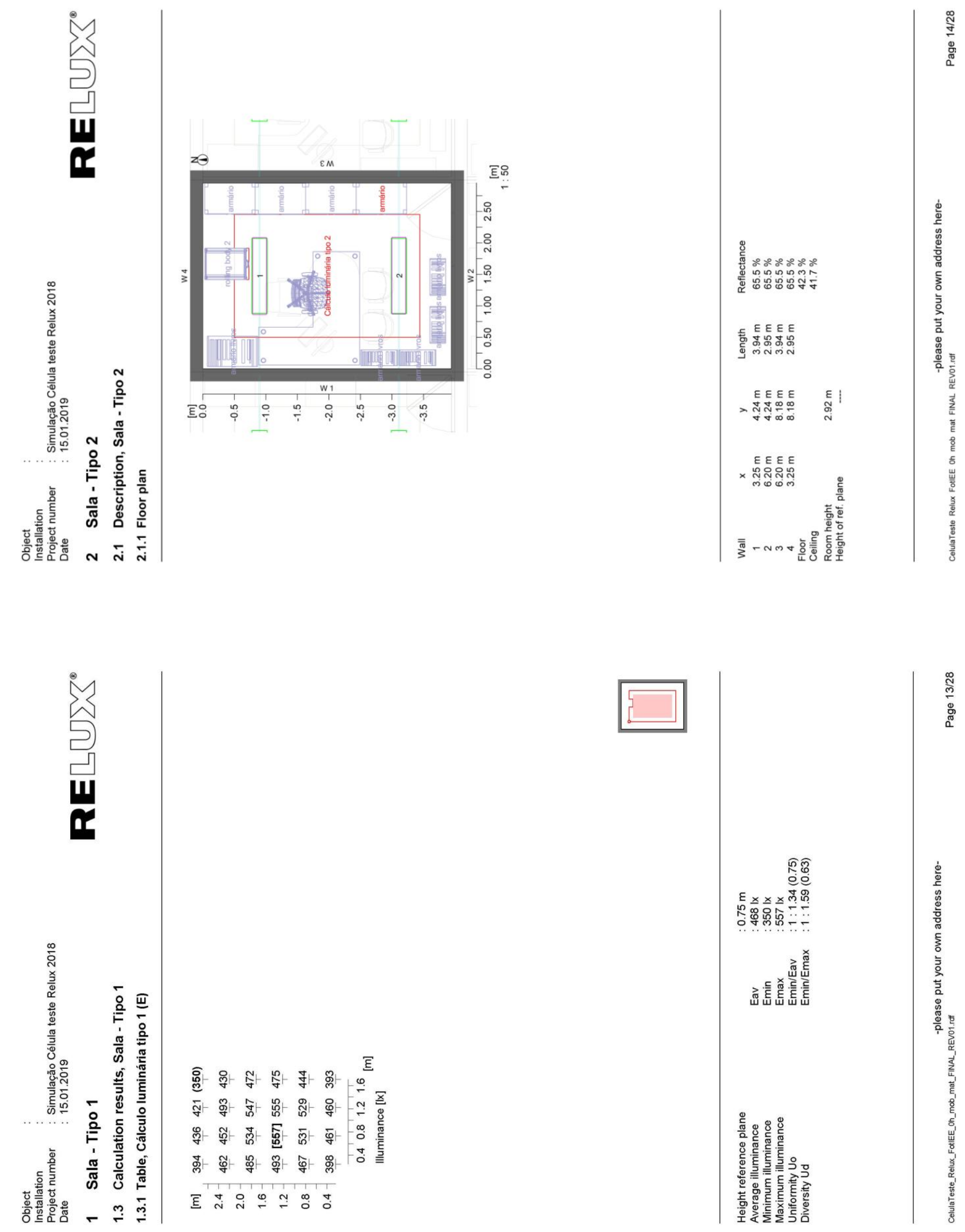

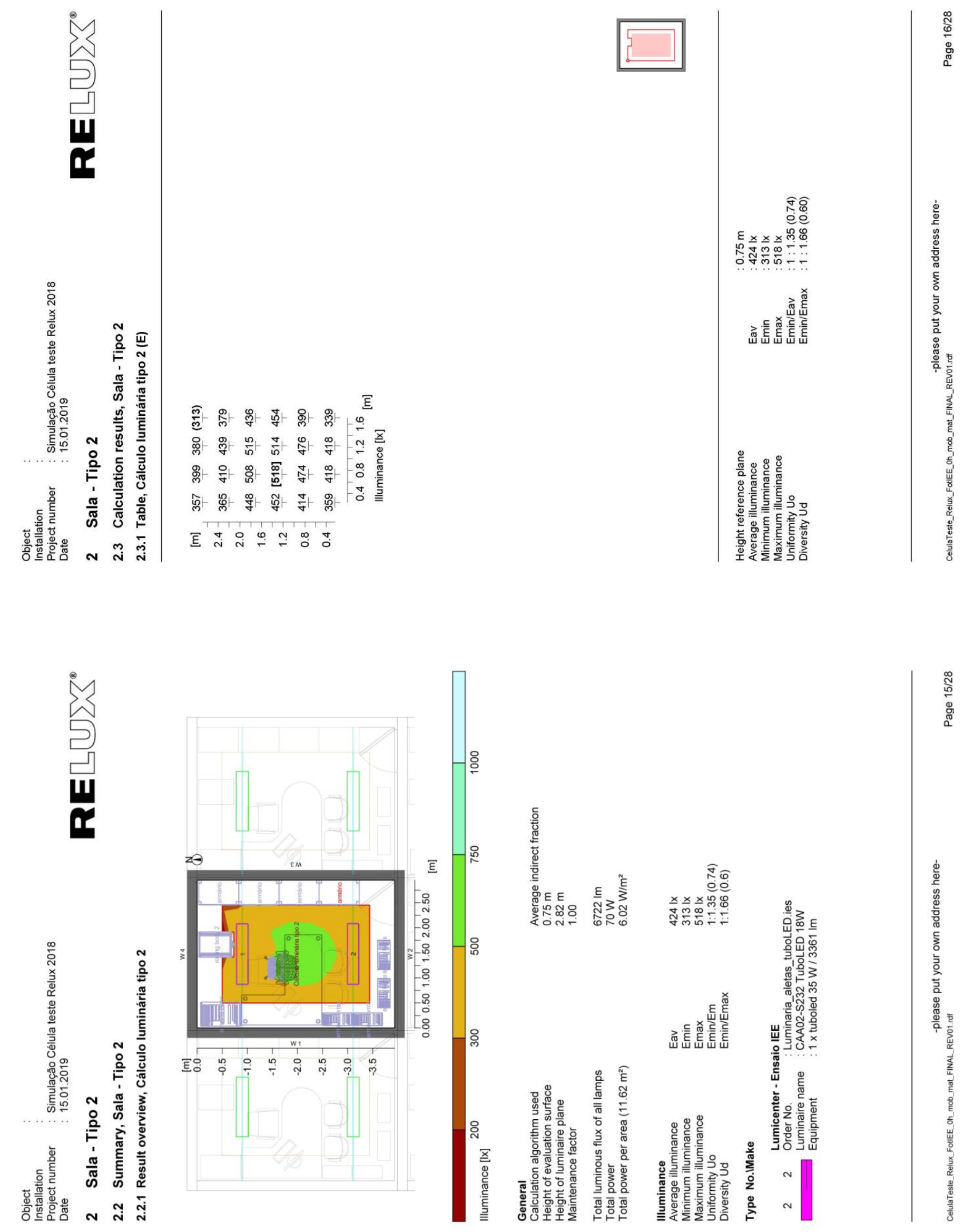

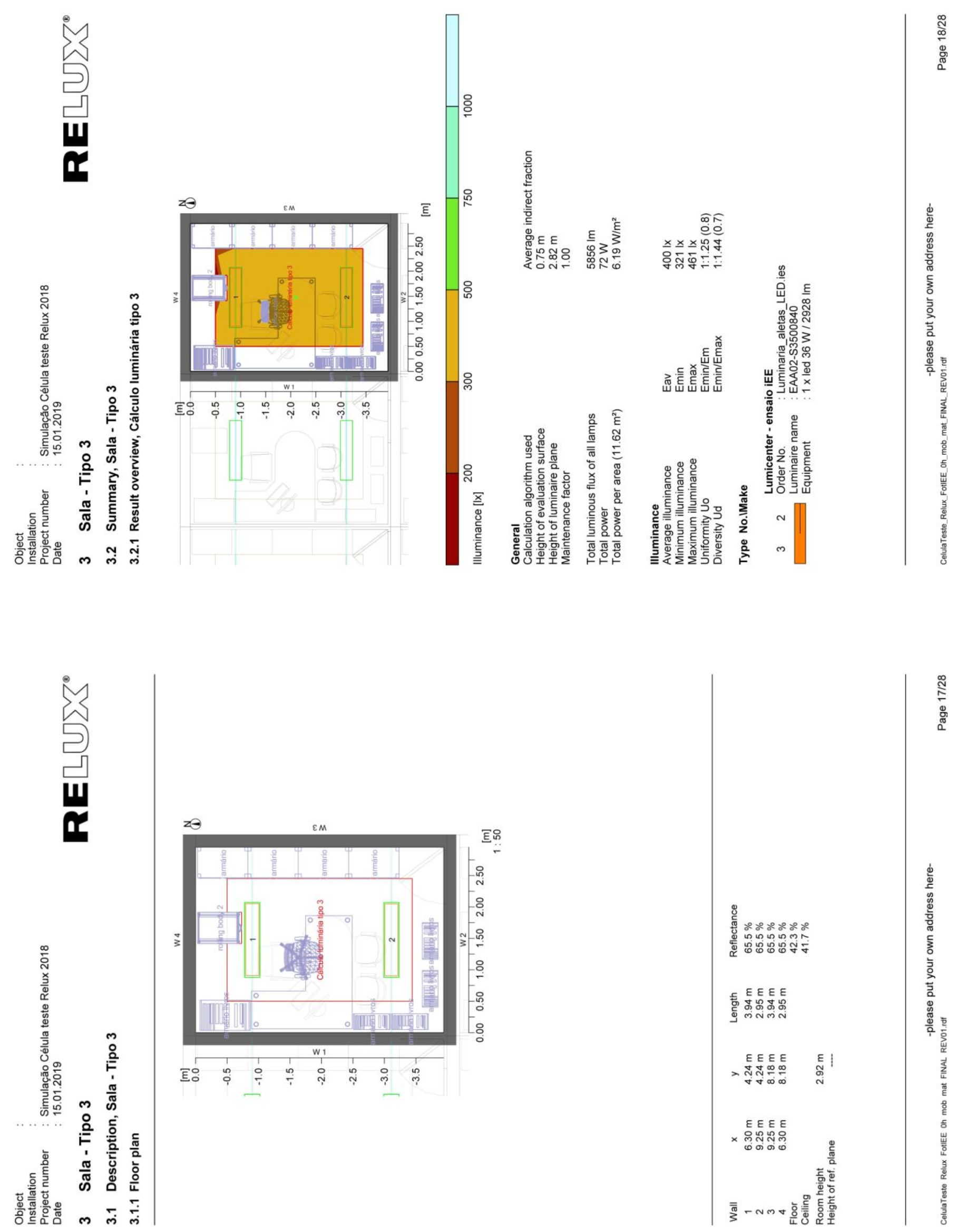

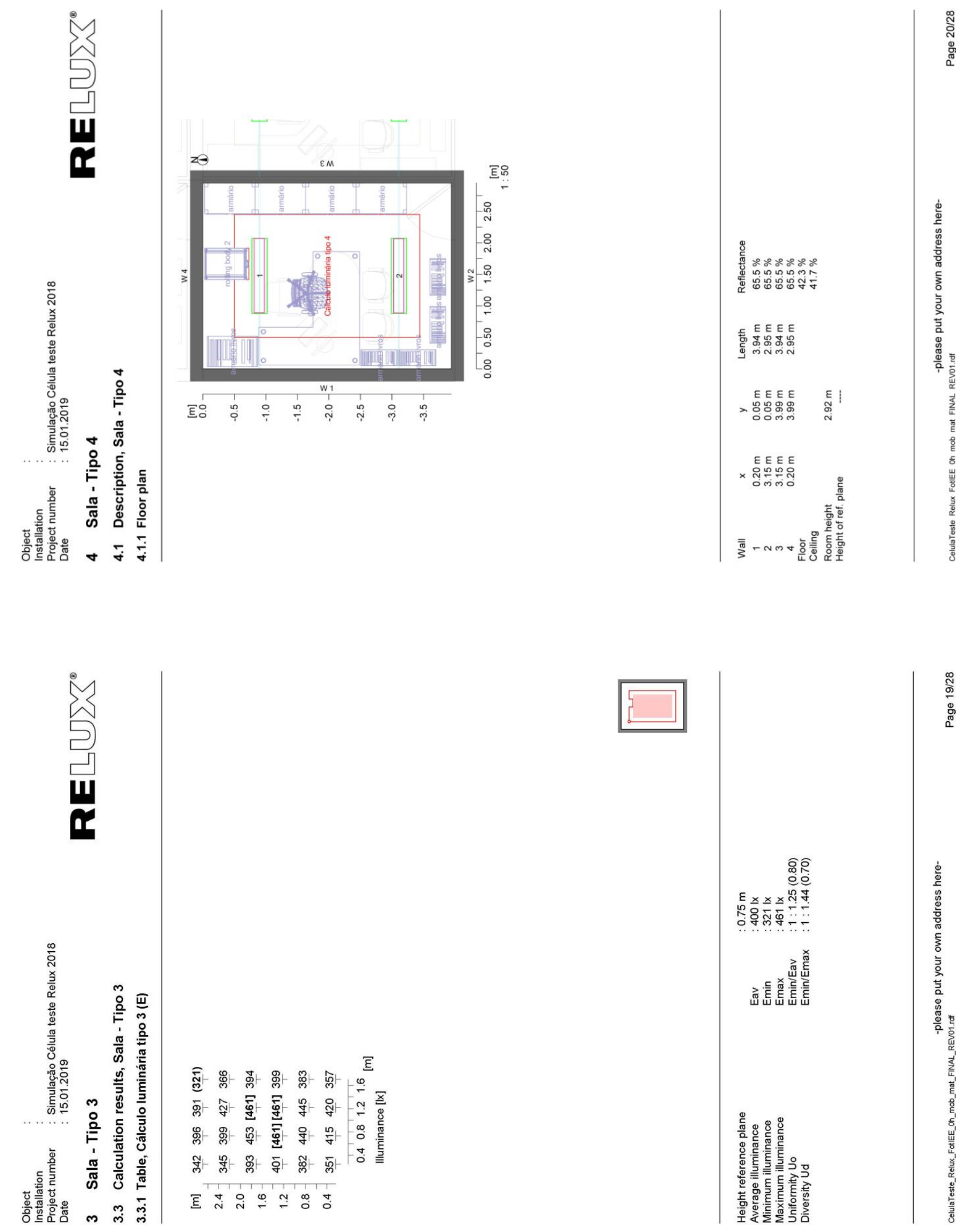

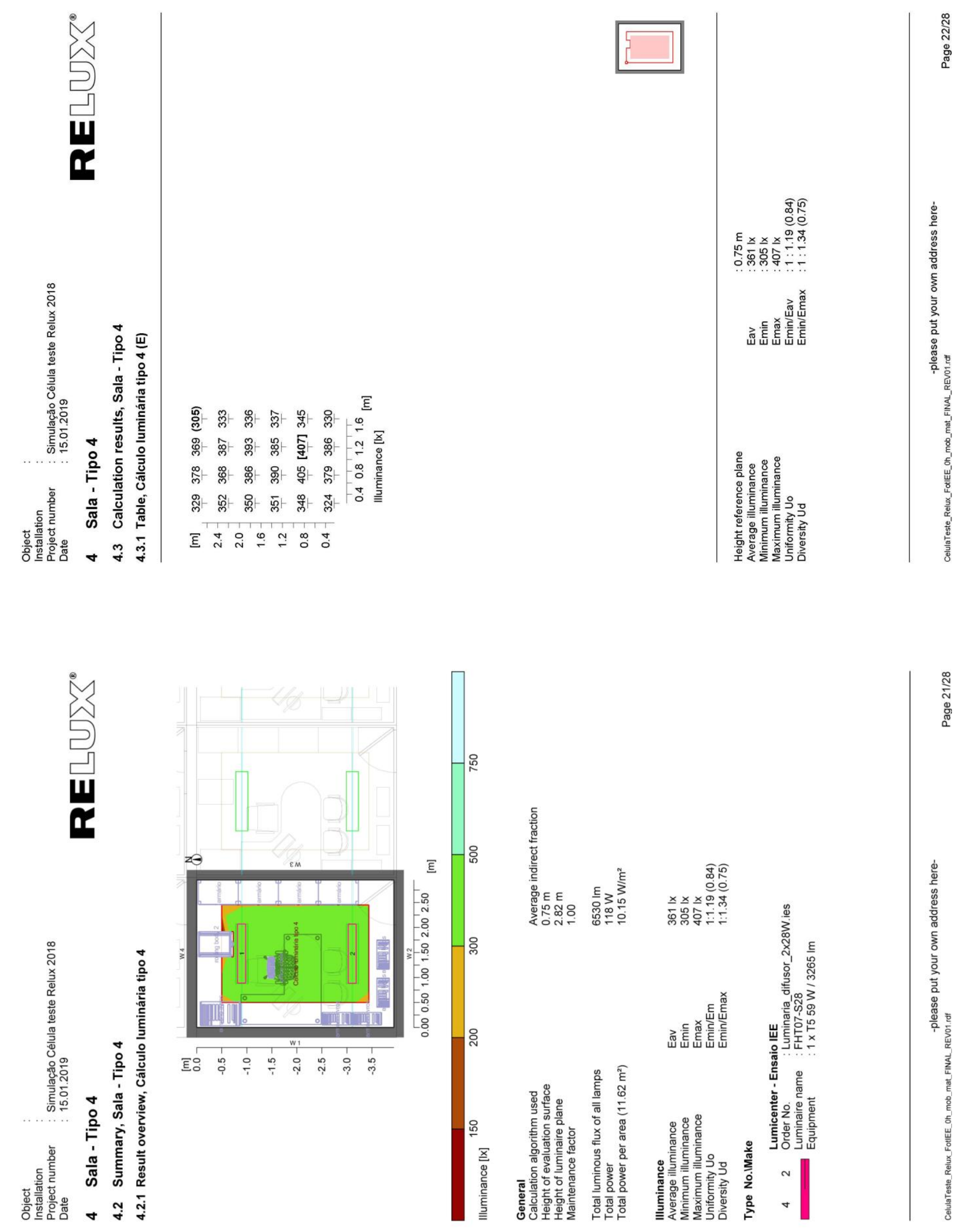

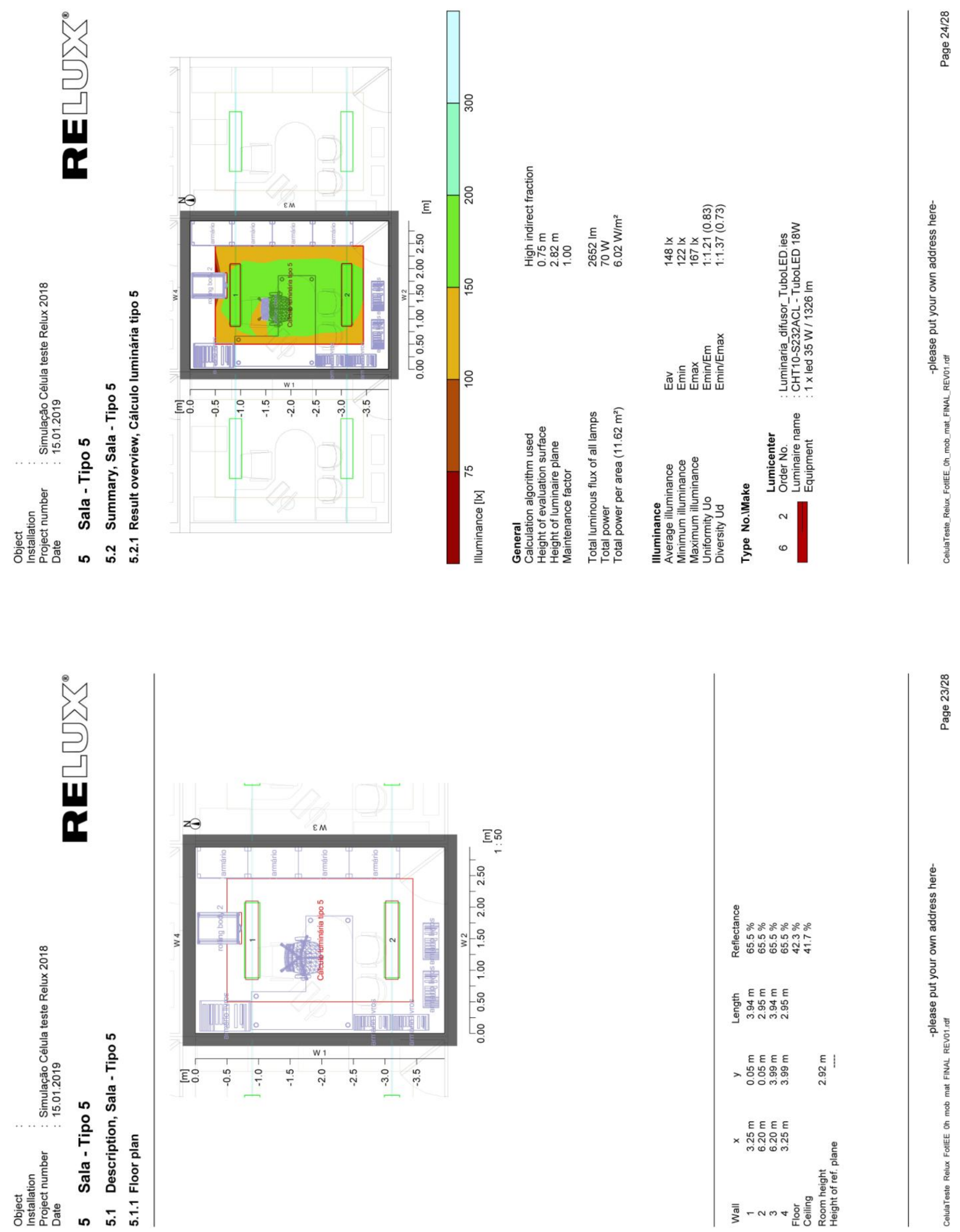

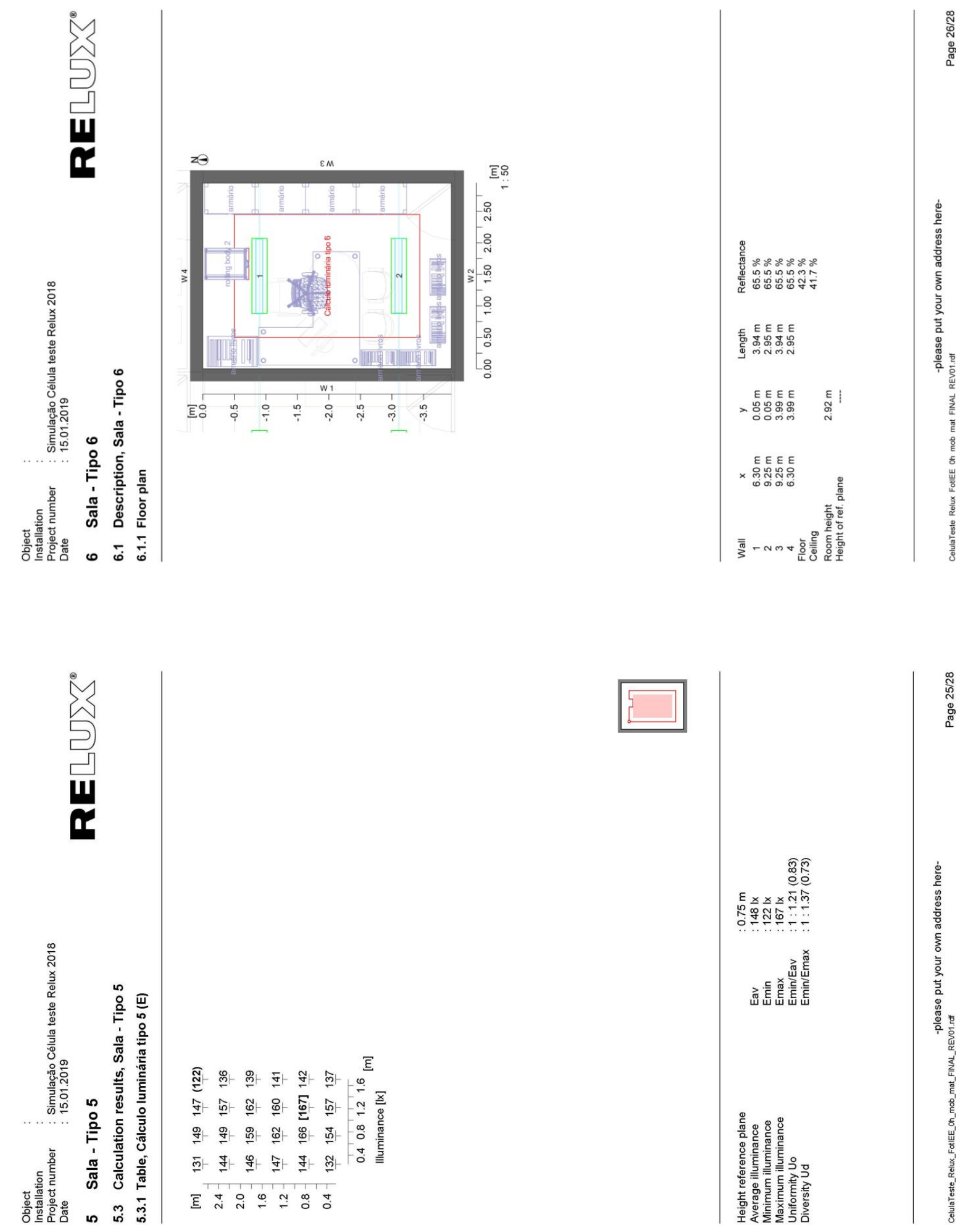

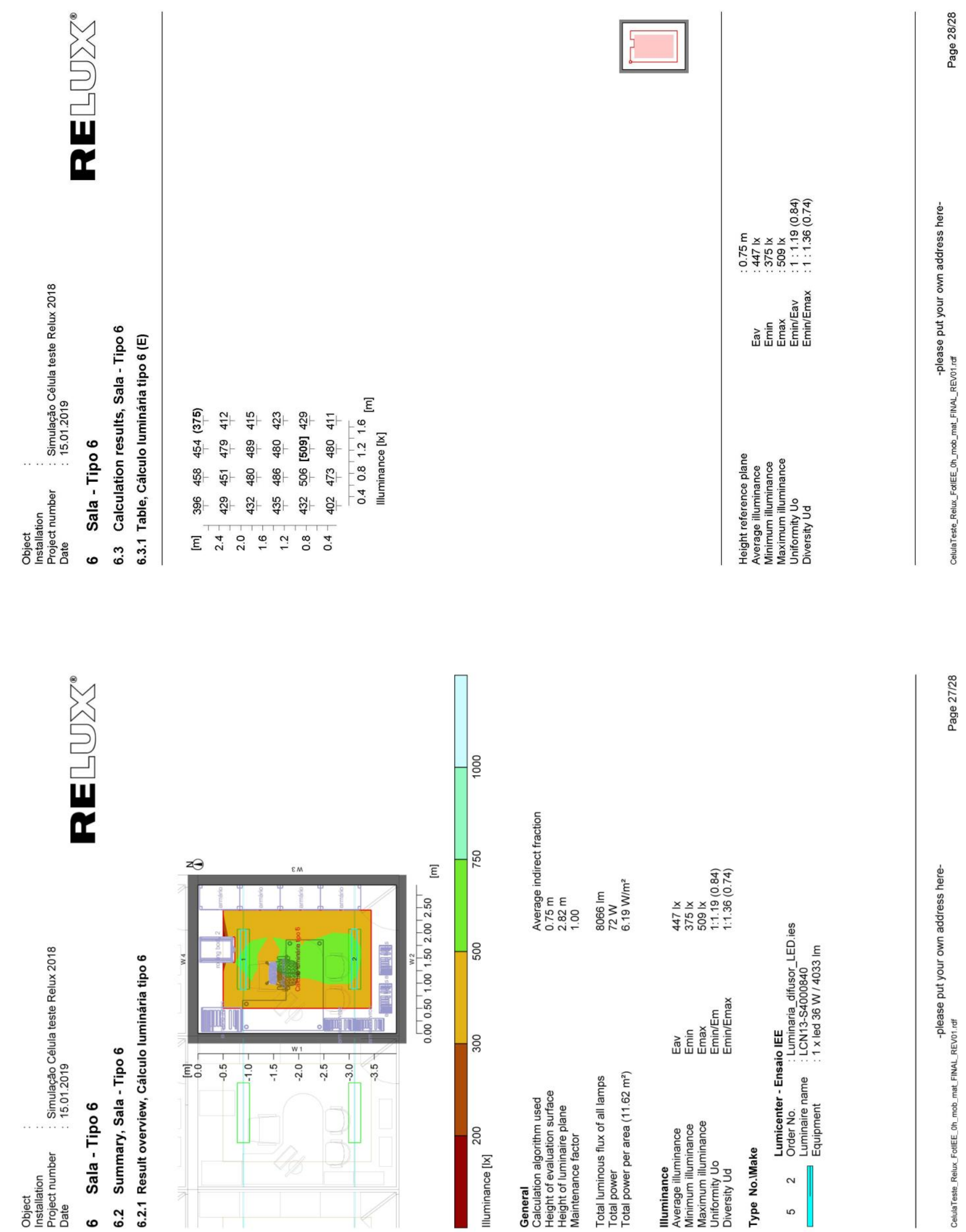